\title{
Connecting hemosysis and visceral injury during cardiovascular surgery : studies on the causes, effects, and treatment of hemolysis-induced organ injury
}

Citation for published version (APA):

Vermeulen Windsant, I. C. (2012). Connecting hemosysis and visceral injury during cardiovascular surgery : studies on the causes, effects, and treatment of hemolysis-induced organ injury. [Doctoral Thesis, Maastricht University]. Maastricht University. https://doi.org/10.26481/dis.20120928iv

Document status and date:

Published: 01/01/2012

DOI:

10.26481/dis.20120928iv

Document Version:

Publisher's PDF, also known as Version of record

\section{Please check the document version of this publication:}

- A submitted manuscript is the version of the article upon submission and before peer-review. There can be important differences between the submitted version and the official published version of record. People interested in the research are advised to contact the author for the final version of the publication, or visit the DOI to the publisher's website.

- The final author version and the galley proof are versions of the publication after peer review.

- The final published version features the final layout of the paper including the volume, issue and page numbers.

Link to publication

\footnotetext{
General rights rights.

- You may freely distribute the URL identifying the publication in the public portal. please follow below link for the End User Agreement:

www.umlib.nl/taverne-license

Take down policy

If you believe that this document breaches copyright please contact us at:

repository@maastrichtuniversity.nl

providing details and we will investigate your claim.
}

Copyright and moral rights for the publications made accessible in the public portal are retained by the authors and/or other copyright owners and it is a condition of accessing publications that users recognise and abide by the legal requirements associated with these

- Users may download and print one copy of any publication from the public portal for the purpose of private study or research.

- You may not further distribute the material or use it for any profit-making activity or commercial gain

If the publication is distributed under the terms of Article 25fa of the Dutch Copyright Act, indicated by the "Taverne" license above, 


\section{Connecting hemolysis and visceral injury during cardiovascular surgery}

Studies on the causes, effects, and treatment of hemolysis-induced organ injury 
(C) 2012 Iris Vermeulen Windsant, Maastricht

ISBN: 978-90-9026809-5

Layout: Tiny Wouters

Cover: Xander Vermeulen Windsant XVW Architectuur

Production: Datawyse Maastricht

Printing of this thesis was financially supported by

Stichting Hartsvrienden RESCAR Maastricht HaemoScan BV Groningen

The studies presented in this thesis were performed at the Nutrition and Toxicology Research Institute Maastricht (NUTRIM), which participates in the Graduate School VLAG (Food Technology, Agro-biotechnology, Nutrition and Health Sciences), accredited by the Royal Netherlands Academy of Arts and Sciences (KNAW). Furthermore, the studies presented in this manuscript were funded by Stichting Annadal and the Profileringsfonds of the MUMC+. 


\section{Connecting hemolysis and visceral injury during cardiovascular surgery}

Studies on the causes, effects and treatment of hemolysis-induced organ injury

PROEFSCHRIFT

Ter verkrijging van de graad van doctor aan de Universiteit Maastricht, op gezag van de Rector Magnificus, Prof. dr. L.L.G. Soete, volgens het besluit van het College van Decanen,

in het openbaar te verdedigen op vrijdag 28 september 2012 om 14.00 uur

door

Iris Catharina Vermeulen Windsant 


\section{PROMOTORES}

Prof. dr. W.A. Buurman

Prof. dr. M.J.H.M. Jacobs

\section{BEOORDELINGSCOMMISSIE}

Prof. dr. H. ten Cate (voorzitter)

Prof. dr. P.J.E.H.M. Kitslaar

Prof. dr. K.L.M. Leunissen

Prof. dr. G. Marx (Universitäts Klinikum Aachen)

Prof. dr. C.D.A. Stehouwer 


\section{CONTENTS}

$\begin{array}{lll}\text { Chapter } 1 & \text { General Introduction } & 7\end{array}$

Chapter 2 Circulating intestinal fatty acid binding protein as an early marker of intestinal necrosis after aortic surgery; a prospective observational cohort study

Chapter 3 Visceral injury and systemic inflammation in patients undergoing extracorporeal circulation during aortic surgery

Chapter 4 Cardiovascular surgery and organ damage; time to reconsider the role of hemolysis

Chapter 5 Hemolysis compromises nitric oxide-dependent vasodilatory responses in patients undergoing major cardiovascular surgery

Chapter 6 Hemolysis is associated with acute kidney injury during major aortic surgery

Chapter 7 Hemolysis increases nitric oxide consumption and visceral tissue damage after cardiac surgery

Chapter 8 Blood transfusions increase circulating plasma free hemoglobin levels and plasma nitric oxide consumption: a prospective observational pilot study

Chapter 9 Hemolysis-induced organ damage is reduced by nutritional 161 activation of the vagal anti-inflammatory reflex

Chapter 10 Summary and discussion

Nederlandse samenvatting

Dankwoord

Curriculum vitae

Publicatielijst

Abbreviations 


General introduction 


\section{INTRODUCTION}

Cardiovascular disease is the major cause of death worldwide, claiming over 7.2 million lives in 2004 due to coronary heart disease alone. ${ }^{1}$ In the Netherlands, the total number of patients diagnosed with coronary heart disease was 730.400 in 2007 (RIVM). In 2008, 16.877 patients required open heart surgery to sufficiently treat coronary and/or cardiac valve disease. ${ }^{2}$

The introduction of the cardiopulmonary bypass (CPB) in the early nineteen sixties as a more routine technique during cardiovascular surgery led to a significant increase in treatment options for patients with serious cardiovascular disease, such as patients with multifocal coronary artery disease, cardiac valve disorders or patients with major vascular disease such as (thoracoabdominal) aortic aneurysms. CPB, also called extracorporeal circulation, enabled ongoing organ perfusion and oxygenation during extensive and time-consuming operations of the heart and/or aorta. Nevertheless, despite major technical and medical refinements since its first introduction, CPBassisted surgery is still associated with (relatively) high morbidity and mortality. Principally, major postoperative complications such as renal dysfunction (requiring dialysis), and pulmonary complications such as prolonged mechanical ventilation, ventilation assisted pneumonia or the adult respiratory distress syndrome, are relatively common. ${ }^{3-6}$ Several CPB-related factors, such as ischemia-reperfusion injury, hemodilution, and initiation of a pro-inflammatory response, have been extensively studied for their role in the development of these postoperative complications. ${ }^{7}$ Furthermore the impact of intravascular hemolysis caused by mechanical stress within the CPB system, among other factors, has been mentioned in the literature but not related to organ injury or patient outcome.

This thesis aimed to elucidate the causes of acute hemolysis and its effects on the development of postoperative complications after (major) cardiovascular surgery.

\section{POSTOPERATIVE COMPLICATIONS OF CARDIOVASCULAR SURGERY WITH CARDIOPULMONARY BYPASS}

\section{Open (thoraco)abdominal aortic aneurysm repair}

The term aneurysm denotes an abnormal dilatation of a blood vessel. Although theoretically any blood vessel may become aneurysmal, the infrarenal abdominal aorta (AAA) is most commonly affected. In contrast, the most extensive type of aneurysmal disease of the large arteries; the thoracoabdominal aortic aneurysm (TAAA) is a less commonly diagnosed phenomenon representing only $0.25 \%$ of all aortic aneurysms. ${ }^{8}$ Outward rupture of the weakened vessel wall represents the major risk of any aneurysmal blood vessel. Rupture of an aortic aneurysm is usually fatal due to severe 
hemorrhage and, if possible, requires emergency repair with concomitant high surgical morbidity and mortality. ${ }^{9}$ Depending on the type of TAAA, 2-year survival rates of $24-52 \%$ have been reported. The overall 5 -year survival rate is $17-19 \%{ }^{10}$ Aneurysms can be surgically treated either through classical open reconstruction or by endovascular exclusion, depending on aneurysm anatomy, patient characteristics and preference and/or experience of the surgeon and hospital facilities. Despite the fact that elective surgical treatment is often imperative to improve survival, mortality rates remain high after open TAAA surgery; up to $15 \% .{ }^{11}$ The primary causes of in-hospital death are cardiac complications (46\%), respiratory failure (15\%), sepsis (12\%) and coagulopathy (12\%). ${ }^{12}$ The incidence of nonfatal complications after TAAA repair is accordingly high. Significant post-operative complications occur in $77 \%$ of cases; $41 \%$ of patients have pulmonary complications, $28 \%$ renal complications, $21 \%$ liver dysfunction, or gastro-intestinal complications in $7 \%$ (such as bowel ischemia, ileus, or peptic ulceration). ${ }^{13}$ Finally, spinal cord-injury is seen in $12 \%$ of cases. A combination of these complications is often seen (31\%) and, at worst, can progress into multiple organ failure (MOF). Nevertheless, successful open TAAA repair causes the 5-year survival rate to triple or even quadruple to $66-80 \% .^{11,12}$

\section{Cardiac surgery}

The incidence of complications after cardiac surgery is largely dependent on the type of surgery performed, with higher incidence rates reported after complex cardiac surgery such as combined bypass and valve surgery, and ascending aortic aneurysm repair. $^{14}$ The following incidence rates apply to patients undergoing cardiac surgery with CPB.

Acute kidney injury (AKI) is among the most common and serious postoperative complications with reported incidence rates varying between $5 \%-30 \%{ }^{4,6,15-17}$, depending on the definition used. AKI-associated morbidity and mortality is high, especially when patients require (transient) dialysis. ${ }^{18}$ Considering other visceral complications, a recent report of Rodriguez et al. indicated that gastro-intestinal complications occur in approximately $1.2 \%$ of patients, with an associated mortality rate of $32 \% .{ }^{14}$ Of these complications, gastrointestinal bleeding is the most common (33\%), followed by mesenteric ischemia (13.1\%), pancreatitis $(12.8 \%)$, cholecystitis (9.3\%), peptic ulceration (6\%), and diverticulitis (3\%). Fulminant liver failure had the lowest incidence (2\%) but carried highest mortality $(55 \%) .^{14}$ Next to visceral complications, patients undergoing cardiac surgery frequently suffer from pulmonary dysfunction which include a spectrum of clinical symptoms ranging from mild postoperative dyspnea, the need for prolonged mechanical ventilation ( $>48 \mathrm{~h}$ ), to the adult respiratory distress syndrome (ARDS) in $2 \%$ of cases with a $50 \%$ mortality rate. ${ }^{19}$ Lastly, patients often suffer from the development of the systemic inflammatory 
response syndrome (SIRS), as cardiac surgery is associated with a strong systemic inflammatory response. ${ }^{20}$ At worst, although less frequently reported, SIRS may progress into sepsis and septicemia $(3.4 \%)^{6}$, and MOF $(0.5 \%) .{ }^{6,21}$

The pathophysiology of complications after cardiovascular surgery with CPB is complex and has been extensively studied before. Therefore, a complete discussion of every aspect of the pathophysiological mechanisms underlying postoperative complications would be beyond the scope of this thesis. Nevertheless, the next paragraph highlights some important factors which play a role in the development of complications after CPB-assisted surgery.

\section{PATHOPHYSIOLOGY OF COMPLICATIONS AFTER CARDIOVASCULAR SURGERY WITH CARDIOPULMONARY BYPASS: TRADITIONAL CONTRIBUTING FACTORS}

The complication rate after cardiac surgery is dependent on many patient-related factors, such as increased age, chronic renal dysfunction, and decreased cardiac output. Furthermore, a number of surgery-related factors such as emergency surgery, use of intra-aortic balloon pump, increased number of blood transfusions, and length of CPB time and aortic cross clamp time have been frequently reported. In general, the CPB is considered to play an important role in the pathophysiology of complications after CPB-assisted surgery by induction of hypoperfusion and ischemia-reperfusion injury, coagulation, inflammation, and hemodilution. ${ }^{22-28}$ In line, lower morbidity and mortality rates after off-pump coronary artery bypass grafting (OPCAB surgery) have generally been explained by the absence of the CPB. ${ }^{29}$ Surprisingly however, the largest randomized controlled trial to date on this subject (the ROOBY trial), covering 2203 CABG patients, actually reported on worse composite outcome and poorer graft patency 1 year postoperatively in patients subjected to OPCAB surgery compared with patients in the on-pump group. ${ }^{21}$

\section{Ischemia-reperfusion injury}

Ischemia-reperfusion injury describes the seemingly paradoxical injury caused by reperfusion of ischemic tissue. ${ }^{30}$ Ischemia, either due to insufficient or absent blood flow, deprives downstream tissue cells from oxygen and nutrients, and allows enhanced expression of proinflammatory gene products (cytokines), while more protective gene products such as nitric oxide synthase (which enables nitric oxide formation) are repressed. Furthermore, ischemia stimulates leucocyte attraction. Paradoxically, re-introduction of oxygen enables formation of toxic reactive oxygen species, and triggers an intense inflammatory response, contributing to severe cellular damage in not only the ischemic tissue itself, but also in remote organs. ${ }^{30,31}$ Ischemiareperfusion injury is now appreciated as a crucial pathophysiological mechanism in the 
development of tissue damage in the gut ${ }^{32}$, kidney $^{33}$, liver $^{34}$, heart $^{35}$, lungs $^{23}$, brain $^{36}$, and skeletal muscle tissue ${ }^{37}$. The extent and duration of ischemia-reperfusion injury differs between cardiac and aortic aneurysm surgery. During TAAA surgery, connection of the selective perfusion catheters require clamping and opening of the aorta, causing a short period of absolute ischemia distally of the proximal aortic cross clamp. In AAA patients, in whom a CPB is not used, the extent of ischemia-reperfusion depends on the location of the aortic cross clamp. In general, a moderate degree of ischemiareperfusion injury affects the lower extremities, although this extent of ischemiareperfusion injury is generally well tolerated..$^{38}$ In patients undergoing cardiac surgery, the myocardium suffers absolute ischemia (during coronary reconstruction). ${ }^{39}$ In contrast, the rest of the body is "only" subjected to relative ischemia-reperfusion injury due to the transition from physiologic to non-physiologic, and back to physiologic tissue perfusion before, during, and after CPB, respectively. ${ }^{40}$

\section{Increased coagulation}

The extensive non-physiological surface of the CPB causes profound hemostatic derangements during surgery. Exposure of blood to the circuit immediately causes contact activation (intrinsic pathway) of the clotting system through kallikrein, prekallikrein, high-molecular-kininogen, and factor XII. ${ }^{41}$ Subsequently, stimulated by complement activation, activation of the extrinsic pathway results in thrombin and fibrin generation, cross-linking of fibrin, and platelet activation. The extrinsic pathway is also directly activated by cellular debris and release of tissue factor from the surgical field and vessel injury. The consequences of extrinsic pathway activation are counteracted by administration of heparin before initiation of CPB. Next to activation of coagulation, consumption and dilution of coagulation proteins occurs as well, provoking a heightened state of fibrinolysis during CPB, imposing increased risk of hemorrhage. ${ }^{42}$ Finally, activation of coagulation also contributes to the inflammatory response by inducing cytokine/chemokine expression and leukocyte migration. The pro-inflammatory role of thrombin, a central player in coagulation, is particularly well described in this setting. ${ }^{43}$

\section{Inflammation}

Activation of inflammation during cardiovascular surgery with CPB is a complex process and occurs at different sites and different times throughout surgery. Contributing factors include surgical trauma ${ }^{44}$, blood contact with the nonphysiological surfaces of the CPB, and ischemia-reperfusion injury. ${ }^{45}$ Also, loss of intestinal barrier function due to increased gut permeability may promote translocation of bacteria-derived endotoxins from the intestinal lumen to the circulation. ${ }^{46}$ The ensuing endotoxemia plays an important role in the induction of the 
SIRS, sepsis, and multiple organ failure after surgery. ${ }^{47}$ Together, all these factors trigger the complement system with formation of the highly pro-inflammatory C3a and C5a, promote production of several pro-inflammatory cytokines such as IL-6 and IL-8, oxygen free radicals, and increase the expression of adhesion molecules including $\mathrm{E}$ selectin, P-selectin, integrins, and the intracellular adhesion molecule and vascular cell adhesion molecule. This further stimulates infiltration and activation of polymorphonuclear neutrophils. ${ }^{24,45}$

\section{Hemodilution}

After initiation of $\mathrm{CPB}$, the blood of the patient is immediately diluted with the crystalloid priming volume of the CPB-circuit. Hemodilution facilitates a decrease in blood viscosity so that the blood supply to the organs can be maintained without increasing the arterial pressure. Nevertheless, (excessive) hemodilution causes a significant drop in hematocrit (hemodilutional anemia) which adversely affects the oxygen carrying capacity of blood, compromising tissue oxygenation. ${ }^{27}$ In line, an inverse dose-dependent relation between hemodilution and postoperative renal injury has been reported. ${ }^{48}$ Also, hemocrit levels below $24 \%$ were related to enhanced plasma lactate levels (reflecting inadequate oxygen delivery to cells), renal tubular injury, intestinal mucosal damage, and increased blood transfusions requirements, which further promoted tissue injury. ${ }^{28}$

It becomes evident that the pathophysiology of tissue injury during cardiovascular surgery (with $\mathrm{CPB}$ ) is complex and multifactorial.

\section{HEMOLYSIS AND THE INTRAVASCULAR NITRIC OXIDE METABOLISM}

\section{Potential causes of hemolysis during cardiovascular surgery}

Intravascular rupture of red blood cells (RBCS), or hemolysis, is a well known phenomenon during cardiovascular surgery, and is generally attributed to CPB. ${ }^{41,49-56}$ Prolonged exposure of red blood cells to the mechanical forces within the circuit (especially shear stress), the non-physiological surfaces, roller pump, and blood-air interfaces substantially impairs RBC deformability, and promotes RBC aggregability. ${ }^{49}$ As normal RBC deformability is imperative for $\mathrm{RBCs}$ to pass through the microcirculation, loss of deformability causes entrapment of RBC in the microcirculatory bed. Also, decreased RBC deformability and increased RBC aggregability results in significantly enhanced blood viscosity, which further impairs passage of rigid RBCs through the microcirculation. ${ }^{57}$ When RBC damage finally becomes too extensive, rupture of the cell membrane follows, resulting in release of 
intracellular RBC components such as hemoglobin (then referred to as free hemoglobin, $\mathrm{fHb}$ ) and arginase-1. Beside $\mathrm{CPB}$, we consider the use of autotransfusion devices (cell savers) and transfusion of stored RBCs (packed cells) to also significantly contribute to (sub)lethal RBC damage in this setting. Cell savers expose RBCs to significant (centrifugal) forces, inflicting sublethal RBC damage. ${ }^{49}$ Prolonged storage of blood results in both hemolysis and sublethal damage of red cells. ${ }^{58}$ Subsequent transfusion of stored red blood cell products may cause a direct (transfusion of the $\mathrm{fHb}$-containing storage medium), and delayed (rupture of less viable RBCs) increase of $\mathrm{fHb}$ in the patient. ${ }^{59}$

\section{Pathophysiology of hemolysis-induced organ injury}

Although the development of red blood cell damage is a well-known phenomenon during cardiac surgery, its role in the development of postoperative complications has not been equally studied. In the last decade however, the number of studies reporting on the adverse effect of hemolysis in patients with chronic hemolytic diseases has increased substantially. Furthermore, a (new) pathophysiological mechanism by which hemolysis induces tissue injury and organ compromise has been proposed. ${ }^{60}$

Hemolysis is a hallmark characteristic of several conditions such as malaria, sickle cell disease, paroxysmal nocturnal hemolysis, thalassemia, pyruvate kinase deficiency, and autoimmune hemolytic anemia. ${ }^{61}$ Although these various chronic hemolytic diseases each have unique symptoms, all patients suffering from hemolysis experience symptoms ranging from mild muscle and chest pains, dysphagia, fatigue, muscle spasms, erectile dysfunction to severe thrombosis and vaso-occlusion, renal and hepatic failure, stroke, severe anemia, and multiple organ failure. ${ }^{62-64}$ The relation between hemolysis and these complications was not evident until the association between increased plasma $\mathrm{fHb}$ levels, released from ruptured erythrocytes, and a decreased bioavailability of intravascular nitric oxide (NO) in sickle cell disease was described in $2002 .^{60}$ In their landmark paper, the group of Gladwin demonstrated that intravascular scavenging of endothelial-derived $\mathrm{NO}$ by oxygenated $\mathrm{fHb}$ was related to decreased NO-bioavailability in plasma, and attenuated forearm blood flow. ${ }^{60}$ Furthermore, the vascular response to intra-arterial infusion of nitric oxide donors was abrogated, indicating NO-scavenging. ${ }^{60}$ Before 2002, the NO-scavenging property of oxygenated hemoglobin molecules was already described (Reaction 1), but this phenomenon was not linked to the pathophysiology of symptoms complicating diseases associated with increased levels of oxygenated $\mathrm{fHb}^{65,66}$

Reaction 1. $\mathrm{HbFe}^{2+} \mathrm{O}_{2}$ (oxyfHb) $+\mathrm{NO} \rightarrow \mathrm{HbFe}^{3+}$ (metHb) $+\mathrm{NO}_{3}{ }^{-}$(nitrate) 
The reaction between oxygenated $\mathrm{fHb}$ (oxy $\mathrm{fHb}$ ) is fast $\left(6-8 \cdot 10^{7} \mathrm{M} / \mathrm{L} / \mathrm{sec}\right.$ ), irreversible and yields methemoglobin (metHb) and nitrate. Beside oxy $\mathrm{fHb}$, also deoxygenated $\mathrm{fHb}$ is able to react with NO, generating iron-nitrosyl-Hb (reaction 2).

Reaction 2. $\mathrm{HbFe}^{2+}$ (deoxyfHb) $+\mathrm{NO} \longleftrightarrow \longrightarrow \mathrm{HbFe}^{2+} \mathrm{NO}$ (iron-nitrosyl-Hb)

The reaction speed of reaction 2 is lower compared to that of reaction 1 $\left(1 \cdot 10^{7} \mathrm{M} / \mathrm{L} / \mathrm{sec}\right)$. Furthermore, reaction 2 is not irreversible in contrast to the reaction between oxyHb and $\mathrm{NO}^{60,61}$ Therefore, the contribution of oxyfHb to the decrease of intravascular NO during hemolysis is greater than that of deoxyfHb.

NO, a gaseous molecule, is synthesized by nitric oxide synthases (NOS) during the conversion of L-Arginine to L-Citrulline (Figure 1.1). NO is the principal endogenous vasodilator and is a central regulator of vascular homeostasis. In vivo, constitutive production of NO by endothelial NO synthase (eNOS), accounts for $25-30 \%$ of basal human blood flow. ${ }^{67}$ Next to inducing vasodilation, endothelial-derived NO also attenuates platelet activation and aggregation, intravascular thrombosis, and inflammation (leukocyte migration and adhesion) (Table 1.1). ${ }^{68,69}$ A reduction of NO bioavailability by $\mathrm{fHb}$ therefore explained (or at least further clarified) a variety of complications seen in patients with chronic hemolytic disease.

Table 1.1 Stimulatory and inhibitory effects of NO in the vasculature

\begin{tabular}{ll}
\hline Stimulation & Inhibition \\
\hline + Vascular smooth muscle cell relaxation & - Platelet aggregation \\
+ Vasodilation & - Neutrophil adhesion \\
+ Vascular smooth muscle cell apoptosis & - Vascular smooth muscle cell proliferation \\
+ Endothelial cell proliferation & - Vascular smooth muscle cell migration \\
+ Re-endothelialization & - Endothelial cell apoptosis \\
& - Matrix formation \\
\hline
\end{tabular}

The human body harbors an intrinsic defense mechanism to increased levels of $\mathrm{fHb}$. Binding of $\mathrm{fHb}$ to the plasma (acute phase) protein haptoglobin ( $\mathrm{Hp}$ ) generates $\mathrm{fHb}-\mathrm{Hp}$ complexes, which reduces, albeit not abolishes, the NO-scavenging potential of $\mathrm{fHb}{ }^{70,71} \mathrm{CD} 163$, a membrane receptor expressed by circulating monocytes and tissue macrophages in the liver and spleen, facilitates endocytosis and clearance of the $\mathrm{fHb}$ $\mathrm{Hp}$ complexes. ${ }^{72}$ Clearance of $\mathrm{fHb}$ through $\mathrm{Hp}$ (although beneficial) thus results in concomitant clearance of $\mathrm{Hp}$ during excessive hemolysis, increasing the hosts susceptibility to the adverse effects of $\mathrm{fHb}$. Hemopexin forms a second line of defense by scavenging $\mathrm{fHb}$-derived ferric heme, enabling degradation of ferric heme in the liver. This way, hemopexin attenuates both heme-catalyzed oxidative damage and heme-bound iron loss after hemolysis. ${ }^{73,74}$ 




Figure 1.1 Simplified scheme of the pathological effects of hemolysis on the intravascular nitric oxide metabolism. Intravascular hemolysis results in release of arginase-1 and free hemoglobin (striped boxes) into the vascular lumen. Free hemoglobin is principally present in its oxygenated form (oxyfHb), and to a lesser extent as deoxygenated $\mathrm{fHb}$ (deoxyfHb). Under physiological circumstances, nitric oxide (NO) is generated during the conversion of L-arginine into citrulline by endothelial nitric oxide synthase (eNOS) in the vascular endothelial cells. Enhanced arginase-1 levels can indirectly result in decreased NO bioavailability through conversion of the substrate Larginine into ornithine, which does not yield $\mathrm{NO}$. OxyfHb and deoxyfHb directly contribute to a reduction of NO-bioavailability through NO-scavenging. The reaction between oxyfHb and NO is stronger and irreversible compared to the reaction between deoxyfHb and $\mathrm{NO}$, resulting in the formation of methemoglobin and nitrate, and iron-nitrosyl $\mathrm{Hb}$, respectively. A significant reduction in intravascular NO-bioavailability impairs activation of guanylate cyclase in the vascular smooth muscle cells, an enzyme required for the generation of cyclic guanine monophosphate (cGMP) from guanosine $5^{\prime}$-triphosphate (GTP). A reduction in cGMP concentrations results in reduced smooth muscle cell relaxation, limiting vasodilation. This way, hemolysis contributes to impaired tissue perfusion through a reduction of NO-bioavailability.

Beside $\mathrm{fHb}$, also arginase-1 is released (Figure 1.1) from ruptured erythrocytes. This enzyme converts L-arginine, the substrate for NO formation, to ornithine and urea. $^{75} \mathrm{~A}$ reduction in L-Arginine availability might therefore further reduce NO-bioavailability. Consistent with this concept, a significant decrease of the arginase-ornithine ratio, indicating higher arginase activity, was significantly associated with greater severity of pulmonary hypertension, and increased mortality in sickle cell disease. ${ }^{76}$ In contrast, in a report on liver surgery patients in whom significantly increased arginase-1 levels were found, L-arginine concentrations were not altered. ${ }^{77}$ Also, enhanced arginase-1 levels in patients undergoing open TAAA surgery were not related to changes in the arginine-ornithine ratio, suggesting that the impact of arginase release on the arginine metabolism is not (highly) clinically relevant in this setting (Hanssen SJ; Thesis "Hemolysis, microcirculatory changes and organ injury induced by cardiovascular surgery", 2011). Finally, the availability of intracellular L-arginine is in far excess of the 
enzymatic requirements (or capacity) of the NOS enzymes. Therefore, a reduction of L-arginine due to increased arginase might not have a major influence on NObioavailability. Despite this surplus of arginine availability however, supplementation of arginine has been shown to increase NO concentrations and promote tissue perfusion in vivo. ${ }^{78}$ This phenomenon is commonly referred to as the arginine paradox. In conclusion, the NO-scavenging effect of $\mathrm{fHb}$ significantly reduces NO-bioavailability during hemolysis. The contributing effect of arginase- 1 , through a reduction of Larginine, on NO-bioavailability during hemolysis remains to be determined.

\section{CLINICAL CONSEQUENCES OF INTRAVASCULAR HEMOLYSIS IN THE ACUTE SETTING}

As described in the previous section, the adverse effect of hemolysis on the intravascular NO-metabolism is more and more appreciated in the setting of chronic hemolysis. In several patient and animal studies, increased $\mathrm{fHb}$ has now been directly linked to decreased NO-bioavailability by increased plasma NO-consumption, impaired NO-mediated fore-arm vasodilation, increased systemic, pulmonary, and renal blood pressure (through vasoconstriction), vaso-occlusive pain, increased platelet activation, hemoglobinuria, and impaired renal function. ${ }^{60,79-83}$ The adverse effects of $\mathrm{fHb}$ on the NO-metabolism were already observed at $\mathrm{fHb}$ concentrations of $6 \mu \mathrm{mol} / \mathrm{l}^{60}$

In contrast to the chronic setting, the clinical consequences of acute hemolysis are less extensively studied. Notwithstanding, several studies previously reported on the adverse effects of hemolysis on renal function in patients undergoing cardiovascular surgery. As $\mathrm{fHb}$ was believed to merely be toxic after glomerular filtration, these study focused on (or explained the adverse relation by) the direct nephrotoxicity of $\mathrm{fHb}$. In line, increased $\mathrm{fHb}$ levels have been associated with renal injury and increased mortality in children and adults after cardiac surgery. ${ }^{52,56}$ Furthermore, patients displaying serum ferritin levels below the median of the study group (ferritin is the principal heme-derived free iron-sequestering protein) were at increased risk of renal injury compared to patients with ferritin concentrations above the median. ${ }^{51}$ In a recent (2007) review by Haasse et al. on CPB-associated acute kidney injury, the focus again lay on iron-mediated formation of reactive oxygen species within the renal tubuli, and precipitation of $\mathrm{fHb}$ molecules causing tubular obstruction. ${ }^{84}$ In this thesis, we propose that the intravascular NO-scavenging property of $\mathrm{fHb}$ is as important, or potentially even more important, to the nephrotoxic effect of $\mathrm{fHb}$ (and hemoglobinderived free heme and free iron) for the development of renal injury during cardiovascular surgery. Furthermore, we also evaluated the role of hemolysis in the induction of intestinal injury in this setting, which has, to our knowledge, not been studied before. 
In conclusion, $\mathrm{fHb}$ has been identified as an important mediator of microcirculatory dysfunction and tissue injury development in different patients populations. The link between increased plasma $\mathrm{fHb}$ concentrations and adverse outcome has been particularly well studied in the setting of chronic hemolysis, and to a lesser extent in patients with acute hemolysis. Although this thesis principally focuses on the potential causes and consequences of acutely increased $\mathrm{fHb}$ levels during cardiovascular surgery (with cardiopulmonary bypass), fHb may also play an important mechanistic role in other settings (Table 1.2).

Table 1.2 Overview of examples of (clinical) settings in which $\mathrm{fHb}$-induced NO-scavenging has been related to adverse outcome (A), or may underlie increased morbidity and mortality (B).

\begin{tabular}{llll}
\hline A Established adverse effect & B Potential adverse effect & \\
\hline - SC-disease & $60,61,64,76,85-92$ & - Cardiovascular surgery + CPB & T \\
- Malaria & $93-95$ & - (Massive) blood transfusions & ${ }^{2}, \mathrm{~T}$ \\
- Thalassemia & 96 & - Transfusions with artificial blood substitutes & $\mathrm{S}$ \\
- PNH & 97 & - Acute hemolytic transfusion reactions & $\mathrm{S}$ \\
- Pre-eclampsia & 98 & - Mechanical heart valve-induced hemolysis & $\mathrm{S}$ \\
& & - Hereditary spherocytosis & $\mathrm{S}$ \\
& & - Hereditary stomatocytosis & $\mathrm{S}$ \\
& & - Chemical/infection-induced anemia & $\mathrm{S}$ \\
& & - Sports-related hemolysis & $\mathrm{S}$ \\
\hline
\end{tabular}

Abbreviations: $\mathrm{PNH}$, paroxysmal nocturnal hemoglobinuria; SC, sickle-cell; T, discussed in this thesis; $\mathrm{S}$, suggested, but not studied.

This thesis largely focuses on the adverse effects of $\mathrm{fHb}$ in the development of (visceral) organ injury. Notwithstanding, cell free myoglobin shares several features with $\mathrm{fHb}$, including its NO-scavenging property. ${ }^{99-101}$ It may thus be hypothesized that release of free myoglobin during cardiovascular surgery, as a consequence of myocardial damage and/or skeletal muscle injury, also contributes to intravascular NOscavenging in this setting. Although of particular interest, an overview on the effects of free myoglobin on the NO-metabolism is beyond the scope of this thesis.

\section{POTENTIAL THERAPEUTIC OPTIONS TO REDUCE THE ADVERSE EFFECTS OF INTRAVASCULAR HEMOLYSIS}

The identification of the NO-scavenging property of $\mathrm{fHb}$, and the subsequent adverse effect on plasma NO-bioavailability, microcirculatory perfusion, and tissue integrity, has provided a new therapeutic target to improve patient outcome after (chronic) hemolytic episodes. Attenuation of the unwanted consequences of increased plasma $\mathrm{fHb}$ can be achieved through inactivation of $\mathrm{fHb}$ or supplementation of NO. A full overview of the (potential) therapeutic options lies outside the scope of this introduction as they are discussed in more detail in Chapter 4 of this thesis. However, 
another way to counteract fHb-induced impaired vasodilation (or even vasoconstriction) may be to stimulate NO-independent vasodilation. In fact, an increased vasodilatory response (i.e. increased fore-arm blood flow) to acetylcholine (Ach), a partly NO-independent and endothelium-dependent vasodilator, was observed in patients with sickle-cell disease as compared with normal subjects. This observation may indicate (a compensatory) upregulation of non-NO vasodilators in the hemolysis-induced decreased bioavailability of NO. Ach is the principal neurotransmitter of the autonomic/parasympatic nervous system. It has been recently found that the release of Ach can be stimulated by dietary fat. ${ }^{102}$ Enteral high fat feeding stimulates cholecystokinin 1 (CCK-1) receptors in the small intestine and subsequently activates afferent and efferent vagal nerve fibers, ultimately leading to enhanced release of Ach. ${ }^{103}$ Stimulation of Ach-bioavailability not only promotes Achinduced vasodilation (mediated by NO, prostaglandins and prostacyclins), but was also found to significantly preserve intestinal integrity after intestinal hypoperfusion/ischemia-reperfusion (in a rodent model of hemorrhagic shock), and significantly attenuate the ensuing systemic inflammatory response. ${ }^{102,103}$ Considering the fact that cardiovascular surgery (with $\mathrm{CPB}$ ) is associated with the development of (intestinal) tissue injury, the induction of (systemic) inflammation, and, as we propose in this thesis, impaired vasodilation through $\mathrm{fHb}$-induced NO-consumption, administration of high fat enteral nutrition may prove to be an interesting therapeutic intervention in this setting, as we investigated in chapter 9. 


\section{AIMS OF THIS THESIS}

As outlined in this chapter, we consider acute hemolysis and scavenging of intravascular $\mathrm{NO}$ by the release of $\mathrm{fHb}$, to be an important contributing factor in the development of postoperative complications after (major) vascular surgery and complex cardiac surgery.

The aims of this thesis were to subsequently:

1. investigate the development and extent of intestinal mucosal injury and renal tubular damage in patients undergoing aortic or cardiac surgery, with and without CPB (Chapter 2, 3, 6, and 7),

2. study the extent of acute hemolysis during aortic surgery and cardiac surgery with and without CPB, and its effects on the NO-metabolism (Chapter 4, 6, and 7),

3 . investigate the relation between acute hemolysis and organ injury in aortic and cardiac surgery (Chapter 4, 6, and 7),

4. investigate the potential contribution of transfusion of stored blood to circulating $\mathrm{fHb}$ levels in patients (Chapter 8),

5. study the effect of a potential therapeutic role of enteral high fat feeding in a rodent model of acute hemolysis (Chapter 9). 


\section{REFERENCES}

1. WHO factsheet 317, September 2009.

2. Hartstichting, Hart Bulletin edition 40, nr.6, December 2009.

3. Thakar CV, Worley S, Arrigain S, Yared JP, Paganini EP. Influence of renal dysfunction on mortality after cardiac surgery: modifying effect of preoperative renal function. Kidney Int 2005; 67:1112-9.

4. Lassnigg A, Schmidlin D, Mouhieddine M, Bachmann LM, Druml W, Bauer P, Hiesmayr M. Minimal changes of serum creatinine predict prognosis in patients after cardiothoracic surgery: a prospective cohort study. J Am Soc Nephrol 2004; 15:1597-605.

5. Hammermeister KE, Burchfiel C, Johnson R, Grover FL. Identification of patients at greatest risk for developing major complications at cardiac surgery. Circulation 1990; 82:IV380-9.

6. Koch CG, Li L, Sessler DI, Figueroa P, Hoeltge GA, Mihaljevic T, Blackstone EH. Duration of red-cell storage and complications after cardiac surgery. N Engl J Med 2008; 358:1229-39.

7. Elahi MM, Khan JS, Matata BM. Deleterious effects of cardiopulmonary bypass in coronary artery surgery and scientific interpretation of off-pump's logic. Acute Card Care 2006; 8:196-209.

8. Svensjo S, Bengtsson H, Bergqvist D. Thoracic and thoracoabdominal aortic aneurysm and dissection: an investigation based on autopsy. Br J Surg 1996; 83:68-71.

9. Bown MJ, Cooper NJ, Sutton AJ, Prytherch D, Nicholson ML, Bell PR, Sayers RD. The post-operative mortality of ruptured abdominal aortic aneurysm repair. Eur J Vasc Endovasc Surg 2004; 27:65-74.

10. Cambria RA, Gloviczki P, Stanson AW, Cherry KJ, Jr., Bower TC, Hallett JW, Jr., Pairolero PC. Outcome and expansion rate of 57 thoracoabdominal aortic aneurysms managed nonoperatively. Am J Surg 1995; 170:213-7.

11. Gloviczki P. Surgical repair of thoracoabdominal aneurysms: patient selection, techniques and results. Cardiovasc Surg 2002; 10:434-41.

12. Cina CS, Lagana A, Bruin G, Ricci C, Doobay B, Tittley J, Clase CM. Thoracoabdominal aortic aneurysm repair: a prospective cohort study of 121 cases. Ann Vasc Surg 2002; 16:631-8.

13. Achouh PE, Madsen K, Miller CC, 3rd, Estrera AL, Azizzadeh A, Dhareshwar J, Porat E, Safi HJ. Gastrointestinal complications after descending thoracic and thoracoabdominal aortic repairs: a 14year experience. J Vasc Surg 2006; 44:442-6.

14. Rodriguez R, Robich MP, Plate JF, Trooskin SZ, Sellke FW. Gastrointestinal complications following cardiac surgery: a comprehensive review. J Card Surg 2010; 25:188-97.

15. Conlon PJ, Stafford-Smith M, White WD, Newman MF, King S, Winn MP, Landolfo K. Acute renal failure following cardiac surgery. Nephrol Dial Transplant 1999; 14:1158-62.

16. Mangano CM, Diamondstone LS, Ramsay JG, Aggarwal A, Herskowitz A, Mangano DT. Renal dysfunction after myocardial revascularization: risk factors, adverse outcomes, and hospital resource utilization. The Multicenter Study of Perioperative Ischemia Research Group. Ann Intern Med 1998; 128:194-203.

17. Wijeysundera DN, Rao V, Beattie WS, Ivanov J, Karkouti K. Evaluating surrogate measures of renal dysfunction after cardiac surgery. Anesth Analg 2003; 96:1265-73.

18. Rosner MH, Okusa MD. Acute kidney injury associated with cardiac surgery. Clin J Am Soc Nephrol 2006; 1:19-32.

19. Clark SC. Lung injury after cardiopulmonary bypass. Perfusion 2006; 21:225-8.

20. Ortolano GA, Aldea GS, Lilly K, O'Gara P, Alkon JD, Mader F, Murad T, Altenbern CP, Tritt CS, Capetandes A, Gikakis NS, Wenz B, Shemin RJ, Downey FX, 3rd. A review of leukofiltration in cardiac surgery: the time course of reperfusion injury may facilitate study design of anti-inflammatory effects. Perfusion 2002; 17 Suppl:53-62.

21. Shroyer AL, Grover FL, Hattler B, Collins JF, McDonald GO, Kozora E, Lucke JC, Baltz JH, Novitzky D. Onpump versus off-pump coronary-artery bypass surgery. N Engl J Med 2009; 361:1827-37.

22. Ohri SK, Becket J, Brannan J, Keogh BE, Taylor KM. Effects of cardiopulmonary bypass on gut blood flow, oxygen utilization, and intramucosal pH. Ann Thorac Surg 1994; 57:1193-9.

23. den Hengst WA, Gielis JF, Lin JY, Van Schil PE, De Windt LJ, Moens AL. Lung ischemia-reperfusion injury: a molecular and clinical view on a complex pathophysiological process. Am J Physiol Heart Circ Physiol; 299:H1283-99. 
24. Moat NE, Shore DF, Evans TW. Organ dysfunction and cardiopulmonary bypass: the role of complement and complement regulatory proteins. Eur J Cardiothorac Surg 1993; 7:563-73.

25. Gillinov AM, Redmond JM, Winkelstein JA, Zehr KJ, Herskowitz A, Baumgartner WA, Cameron DE. Complement and neutrophil activation during cardiopulmonary bypass: a study in the complementdeficient dog. Ann Thorac Surg 1994; 57:345-52.

26. Juneja R, Mehta Y. Inflammation and cardiopulmonary bypass. Ann Card Anaesth 1998; 1:1-4.

27. Vermeer H, Teerenstra S, de Sevaux RG, van Swieten HA, Weerwind PW. The effect of hemodilution during normothermic cardiac surgery on renal physiology and function: a review. Perfusion 2008; 23:329-38.

28. Huybregts RA, de Vroege R, Jansen EK, van Schijndel AW, Christiaans HM, van Oeveren W. The association of hemodilution and transfusion of red blood cells with biochemical markers of splanchnic and renal injury during cardiopulmonary bypass. Anesth Analg 2009; 109:331-9.

29. Massoudy P, Wagner S, Thielmann M, Herold U, Kottenberg-Assenmacher E, Marggraf G, Kribben A, Philipp T, Jakob H, Herget-Rosenthal $\mathrm{S}$. Coronary artery bypass surgery and acute kidney injury--impact of the off-pump technique. Nephrol Dial Transplant 2008; 23:2853-60.

30. Carden DL, Granger DN. Pathophysiology of ischaemia-reperfusion injury. J Pathol 2000; 190:255-66.

31. Collard CD, Gelman S. Pathophysiology, clinical manifestations, and prevention of ischemiareperfusion injury. Anesthesiology 2001; 94:1133-8.

32. Kong SE, Blennerhassett LR, Heel KA, McCauley RD, Hall JC. Ischaemia-reperfusion injury to the intestine. Aust N Z J Surg 1998; 68:554-61.

33. Weight SC, Bell PR, Nicholson ML. Renal ischaemia--reperfusion injury. Br J Surg 1996; 83:162-70.

34. Bahde R, Spiegel HU. Hepatic ischaemia-reperfusion injury from bench to bedside. Br J Surg 2010; 97:1461-75.

35. Turer AT, Hill JA. Pathogenesis of myocardial ischemia-reperfusion injury and rationale for therapy. Am J Cardiol 2010; 106:360-8.

36. Pan J, Konstas AA, Bateman B, Ortolano GA, Pile-Spellman J. Reperfusion injury following cerebral ischemia: pathophysiology, MR imaging, and potential therapies. Neuroradiology 2007; 49:93-102.

37. Crinnion JN, Homer-Vanniasinkam S, Gough MJ. Skeletal muscle reperfusion injury: pathophysiology and clinical considerations. Cardiovasc Surg 1993; 1:317-24.

38. Westman B, Johansson G, Soderlund K, Wernerman J, Hammarqvist F. Muscle glutathione metabolism during ischemia and reperfusion in patients undergoing aorto-bifemoral bypass surgery. Acta Anaesthesiol Scand 2006; 50:699-705.

39. Anselmi A, Abbate A, Girola F, Nasso G, Biondi-Zoccai GG, Possati G, Gaudino M. Myocardial ischemia, stunning, inflammation, and apoptosis during cardiac surgery: a review of evidence. Eur J Cardiothorac Surg 2004; 25:304-11.

40. Undar A, Masai T, Yang SQ, Goddard-Finegold J, Frazier OH, Fraser CD, Jr. Effects of perfusion mode on regional and global organ blood flow in a neonatal piglet model. Ann Thorac Surg 1999; 68:1336-43.

41. Besser MW, Klein AA. The coagulopathy of cardiopulmonary bypass. Crit Rev Clin Lab Sci 2011; 47:197212.

42. Yavari M, Becker RC. Coagulation and fibrinolytic protein kinetics in cardiopulmonary bypass. J Thromb Thrombolysis 2009; 27:95-104.

43. Jennewein $C$, Paulus $P$, Zacharowski K. Linking inflammation and coagulation: novel drug targets to treat organ ischemia. Curr Opin Anaesthesiol $2011 ; 24: 375-80$.

44. Gu YJ, Mariani MA, Boonstra PW, Grandjean JG, van Oeveren W. Complement activation in coronary artery bypass grafting patients without cardiopulmonary bypass: the role of tissue injury by surgical incision. Chest 1999; 116:892-8.

45. Paparella D, Yau TM, Young E. Cardiopulmonary bypass induced inflammation: pathophysiology and treatment. An update. Eur J Cardiothorac Surg 2002; 21:232-44.

46. Ohri SK, Bjarnason I, Pathi V, Somasundaram S, Bowles CT, Keogh BE, Khaghani A, Menzies I, Yacoub $\mathrm{MH}$, Taylor KM. Cardiopulmonary bypass impairs small intestinal transport and increases gut permeability. Ann Thorac Surg 1993; 55:1080-6.

47. Fink MP, Delude RL. Epithelial barrier dysfunction: a unifying theme to explain the pathogenesis of multiple organ dysfunction at the cellular level. Crit Care Clin 2005; 21:177-96. 
48. Habib RH, Zacharias A, Schwann TA, Riordan CJ, Engoren M, Durham SJ, Shah A. Role of hemodilutional anemia and transfusion during cardiopulmonary bypass in renal injury after coronary revascularization: implications on operative outcome. Crit Care Med 2005; 33:1749-56.

49. Vercaemst L. Hemolysis in cardiac surgery patients undergoing cardiopulmonary bypass: a review in search of a treatment algorithm. J Extra Corpor Technol 2008; 40:257-67.

50. Cheung AT, Cruz-Shiavone GE, Meng QC, Pochettino A, Augoustides JA, Bavaria JE, Ochroch EA. Cardiopulmonary bypass, hemolysis, and nitroprusside-induced cyanide production. Anesth Analg 2007; 105:29-33.

51. Davis CL, Kausz AT, Zager RA, Kharasch ED, Cochran RP. Acute renal failure after cardiopulmonary bypass in related to decreased serum ferritin levels. J Am Soc Nephrol 1999; 10:2396-402.

52. Gbadegesin R, Zhao S, Charpie J, Brophy PD, Smoyer WE, Lin JJ. Significance of hemolysis on extracorporeal life support after cardiac surgery in children. Pediatr Nephrol 2009; 24:589-95.

53. Hei F, Irou S, Ma J, Long C. Plasma exchange during cardiopulmonary bypass in patients with severe hemolysis in cardiac surgery. Asaio J 2009; 55:78-82.

54. Leijdekkers VJ, Wirds JW, Vahl AC, van Genderingen HR, Siebenga J, Westerhof N, Tangelder GJ, Bulder ER, Rauwerda JA. The visceral perfusion system and distal bypass during thoracoabdominal aneurysm surgery: an alternative for physiological blood flow? Cardiovasc Surg 1999; 7:219-24.

55. Sakota D, Sakamoto R, Sobajima H, Yokoyama N, Waguri S, Ohuchi K, Takatani S. Mechanical damage of red blood cells by rotary blood pumps: selective destruction of aged red blood cells and subhemolytic trauma. Artif Organs 2008; 32:785-91.

56. Tanaka K, Kanamori Y, Sato T, Kondo C, Katayama Y, Yada I, Yuasa H, Kusagawa M. Administration of haptoglobin during cardiopulmonary bypass surgery. ASAIO Trans 1991; 37:M482-3.

57. Cabrales P. Effects of erythrocyte flexibility on microvascular perfusion and oxygenation during acute anemia. Am J Physiol Heart Circ Physiol 2007; 293:H1206-15.

58. Kim-Shapiro DB, Lee J, Gladwin MT. Storage lesion: role of red blood cell breakdown. Transfusion 2011; 51:844-51.

59. Donadee C, Raat NJ, Kanias T, Tejero J, Lee JS, Kelley EE, Zhao X, Liu C, Reynolds H, Azarov I, Frizzell S, Meyer EM, Donnenberg AD, Qu L, Triulzi D, Kim-Shapiro DB, Gladwin MT. Nitric Oxide Scavenging by Red Blood Cell Microparticles and Cell-Free Hemoglobin as a Mechanism for the Red Cell Storage Lesion. Circulation 2011; 26:465-476.

60. Reiter CD, Wang X, Tanus-Santos JE, Hogg N, Cannon RO, 3rd, Schechter AN, Gladwin MT. Cell-free hemoglobin limits nitric oxide bioavailability in sickle-cell disease. Nat Med 2002; 8:1383-9.

61. Rother RP, Bell L, Hillmen P, Gladwin MT. The clinical sequelae of intravascular hemolysis and extracellular plasma hemoglobin: a novel mechanism of human disease. Jama 2005; 293:1653-62.

62. Moyo VM, Mukhina GL, Garrett ES, Brodsky RA. Natural history of paroxysmal nocturnal haemoglobinuria using modern diagnostic assays. Br J Haematol 2004; 126:133-8.

63. White NJ. The treatment of malaria. N Engl J Med 1996; 335:800-6.

64. Rees DC, Williams TN, Gladwin MT. Sickle-cell disease. Lancet 2010; 376:2018-31.

65. Eich RF, Li T, Lemon DD, Doherty DH, Curry SR, Aitken JF, Mathews AJ, Johnson KA, Smith RD, Phillips GN, Jr., Olson JS. Mechanism of NO-induced oxidation of myoglobin and hemoglobin. Biochemistry 1996; 35:6976-83.

66. Doyle MP, Hoekstra JW. Oxidation of nitrogen oxides by bound dioxygen in hemoproteins. J Inorg Biochem 1981; 14:351-8.

67. Chu A, Chambers DE, Lin CC, KuehI WD, Palmer RM, Moncada S, Cobb FR. Effects of inhibition of nitric oxide formation on basal vasomotion and endothelium-dependent responses of the coronary arteries in awake dogs. J Clin Invest 1991; 87:1964-8.

68. Radomski MW, Moncada S. Regulation of vascular homeostasis by nitric oxide. Thromb Haemost 1993; 70:36-41.

69. Davenpeck KL, Gauthier TW, Lefer AM. Inhibition of endothelial-derived nitric oxide promotes Pselectin expression and actions in the rat microcirculation. Gastroenterology 1994; 107:1050-8.

70. Edwards DH, Griffith TM, Ryley HC, Henderson AH. Haptoglobin-haemoglobin complex in human plasma inhibits endothelium dependent relaxation: evidence that endothelium derived relaxing factor acts as a local autocoid. Cardiovasc Res 1986; 20:549-56.

71. Azarov I, He X, Jeffers A, Basu S, Ucer B, Hantgan RR, Levy A, Kim-Shapiro DB. Rate of nitric oxide scavenging by hemoglobin bound to haptoglobin. Nitric Oxide 2008; 18:296-302. 
72. Kristiansen M, Graversen JH, Jacobsen C, Sonne O, Hoffman HJ, Law SK, Moestrup SK. Identification of the haemoglobin scavenger receptor. Nature 2001; 409:198-201.

73. Tolosano E, Hirsch E, Patrucco E, Camaschella C, Navone R, Silengo L, Altruda F. Defective recovery and severe renal damage after acute hemolysis in hemopexin-deficient mice. Blood 1999; 94:3906-14.

74. Delanghe JR, Langlois MR. Hemopexin: a review of biological aspects and the role in laboratory medicine. Clin Chim Acta 2001; 312:13-23.

75. Morris CR, Morris SM, Jr., Hagar W, Van Warmerdam J, Claster S, Kepka-Lenhart D, Machado L, Kuypers FA, Vichinsky EP. Arginine therapy: a new treatment for pulmonary hypertension in sickle cell disease? Am J Respir Crit Care Med 2003; 168:63-9.

76. Morris CR, Kato GJ, Poljakovic M, Wang X, Blackwelder WC, Sachdev V, Hazen SL, Vichinsky EP, Morris SM, Jr., Gladwin MT. Dysregulated arginine metabolism, hemolysis-associated pulmonary hypertension, and mortality in sickle cell disease. Jama 2005; 294:81-90.

77. van de Poll MC, Hanssen SJ, Berbee M, Deutz NE, Monbaliu D, Buurman WA, Dejong CH. Elevated plasma arginase-1 does not affect plasma arginine in patients undergoing liver resection. Clin Sci 2008; 114:231-41.

78. Vukosavljevic N, Jaron D, Barbee KA, Buerk DG. Quantifying the L-arginine paradox in vivo. Microvasc Res 2006; 71:48-54.

79. Minneci PC, Deans KJ, Shiva S, Zhi H, Banks SM, Kern S, Natanson C, Solomon SB, Gladwin MT. Nitrite reductase activity of hemoglobin as a systemic nitric oxide generator mechanism to detoxify plasma hemoglobin produced during hemolysis. Am J Physiol Heart Circ Physiol 2008; 295:H743-54.

80. Minneci PC, Deans KJ, Zhi H, Yuen PS, Star RA, Banks SM, Schechter AN, Natanson C, Gladwin MT, Solomon SB. Hemolysis-associated endothelial dysfunction mediated by accelerated NO inactivation by decompartmentalized oxyhemoglobin. J Clin Invest 2005; 115:3409-17.

81. Gladwin MT, Sachdev V, Jison ML, Shizukuda Y, Plehn JF, Minter K, Brown B, Coles WA, Nichols JS, Ernst I, Hunter LA, Blackwelder WC, Schechter AN, Rodgers GP, Castro O, Ognibene FP. Pulmonary hypertension as a risk factor for death in patients with sickle cell disease. N Engl J Med 2004; 350:88695.

82. Kato GJ, Hsieh M, Machado R, Taylor Jt, Little J, Butman JA, Lehky T, Tisdale J, Gladwin MT. Cerebrovascular disease associated with sickle cell pulmonary hypertension. Am J Hematol 2006; 81:503-10.

83. Villagra J, Shiva S, Hunter LA, Machado RF, Gladwin MT, Kato GJ. Platelet activation in patients with sickle disease, hemolysis-associated pulmonary hypertension, and nitric oxide scavenging by cell-free hemoglobin. Blood 2007; 110:2166-72.

84. Haase M, Haase-Fielitz A, Bagshaw SM, Ronco C, Bellomo R. Cardiopulmonary bypass-associated acute kidney injury: a pigment nephropathy? Contrib Nephrol 2007; 156:340-53.

85. Ballas SK, Marcolina MJ. Hyperhemolysis during the evolution of uncomplicated acute painful episodes in patients with sickle cell anemia. Transfusion 2006; 46:105-10.

86. Conran N, Franco-Penteado CF, Costa FF. Newer aspects of the pathophysiology of sickle cell disease vaso-occlusion. Hemoglobin 2009; 33:1-16.

87. Gladwin MT, Crawford JH, Patel RP. The biochemistry of nitric oxide, nitrite, and hemoglobin: role in blood flow regulation. Free Radic Biol Med 2004; 36:707-17.

88. Kato GJ, Gladwin MT. Evolution of novel small-molecule therapeutics targeting sickle cell vasculopathy. Jama 2008; 300:2638-46.

89. Kato GJ, Taylor JGt. Pleiotropic effects of intravascular haemolysis on vascular homeostasis. Br J Haematol 2010; 148:690-701.

90. Kaul DK, Liu XD, Chang HY, Nagel RL, Fabry ME. Effect of fetal hemoglobin on microvascular regulation in sickle transgenic-knockout mice. J Clin Invest 2004; 114:1136-45.

91. Machado RF, Gladwin MT. Chronic sickle cell lung disease: new insights into the diagnosis, pathogenesis and treatment of pulmonary hypertension. Br J Haematol 2005; 129:449-64.

92. Mack AK, Kato GJ. Sickle cell disease and nitric oxide: a paradigm shift? Int J Biochem Cell Biol 2006; 38:1237-43.

93. Yeo TW, Lampah DA, Gitawati R, Tjitra E, Kenangalem E, McNeil YR, Darcy CJ, Granger DL, Weinberg JB, Lopansri BK, Price RN, Duffull SB, Celermajer DS, Anstey NM. Impaired nitric oxide bioavailability and Larginine reversible endothelial dysfunction in adults with falciparum malaria. J Exp Med 2007; 204:2693-704 
94. Kumar S, Bandyopadhyay U. Free heme toxicity and its detoxification systems in human. Toxicol Lett 2005; 157:175-88.

95. Boretti FS, Buehler PW, D'Agnillo F, Kluge K, Glaus T, Butt OI, Jia Y, Goede J, Pereira CP, Maggiorini M, Schoedon G, Alayash Al, Schaer DJ. Sequestration of extracellular hemoglobin within a haptoglobin complex decreases its hypertensive and oxidative effects in dogs and guinea pigs. J Clin Invest 2009; 119:2271-80.

96. Morris CR, Kuypers FA, Kato GJ, Lavrisha L, Larkin S, Singer T, Vichinsky EP. Hemolysis-associated pulmonary hypertension in thalassemia. Ann N Y Acad Sci 2005; 1054:481-5.

97. Savage WJ, Brodsky RA. New insights into paroxysmal nocturnal hemoglobinuria. Hematology 2007; 12:371-6.

98. Sandrim VC, Montenegro MF, Palei AC, Metzger IF, Sertorio JT, Cavalli RC, Tanus-Santos JE. Increased circulating cell-free hemoglobin levels reduce nitric oxide bioavailability in preeclampsia. Free Radic Biol Med 2010; 49:493-500.

99. Gladwin MT, Kim-Shapiro DB. The functional nitrite reductase activity of the heme-globins. Blood 2008; 112:2636-47.

100. Paller MS. Hemoglobin- and myoglobin-induced acute renal failure in rats: role of iron in nephrotoxicity. Am J Physiol 1988; 255:F539-44.

101. Rassaf T, Flogel U, Drexhage C, Hendgen-Cotta U, Kelm M, Schrader J. Nitrite reductase function of deoxymyoglobin: oxygen sensor and regulator of cardiac energetics and function. Circ Res 2007; 100:1749-54.

102. Luyer MD, Greve JW, Hadfoune M, Jacobs JA, Dejong CH, Buurman WA. Nutritional stimulation of cholecystokinin receptors inhibits inflammation via the vagus nerve. J Exp Med 2005; 202:1023-9.

103. Lubbers T, de Haan JJ, Luyer MD, Verbaeys I, Hadfoune M, Dejong CH, Buurman WA, Greve JW. Cholecystokinin/Cholecystokinin-1 receptor-mediated peripheral activation of the afferent vagus by enteral nutrients attenuates inflammation in rats. Ann Surg 2010; 252:376-82. 

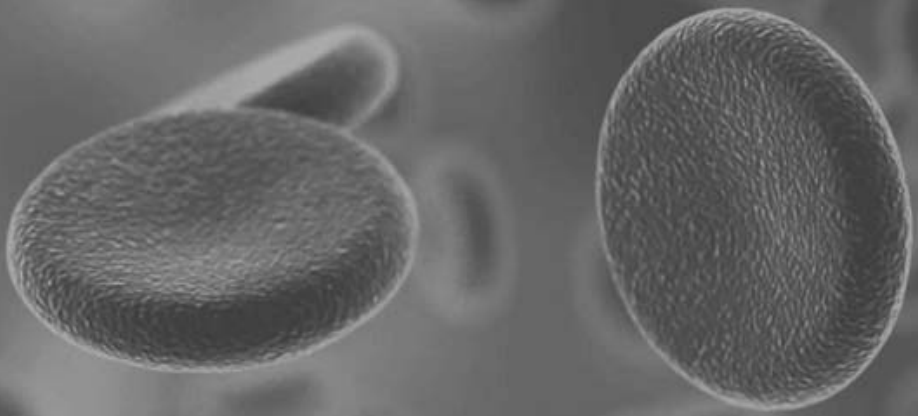
Circulating intestinal fatty acid binding protein as an early marker of intestinal necrosis after aortic surgery; a prospective observational cohort study

Iris C Vermeulen Windsant*, Femke A Hellenthal*, Joep PM Derikx, Martin H Prins, Wim A Buurman, Michael J Jacobs, Geert Willem H Schurink

* These authors contributed equally to this manuscript Annals of Surgery 2012;255:796-803 


\section{ABSTRACT}

\section{Objective}

To evaluate the usefulness of plasma IFABP levels in the early identification of intestinal necrosis (IN) in patients undergoing different types of aortic surgery.

\section{Summary background data}

Intestinal compromise greatly contributes to postoperative adverse outcome. IN is the most detrimental form of intestinal compromise and is notoriously difficult to diagnose. IFABP is a small protein exclusively expressed by mature enterocytes and a promising marker of intestinal damage.

\section{Methods}

Plasma IFABP concentrations were measured in blood samples taken perioperatively from 55 patients undergoing open thoracic or thoracoabdominal aneurysm repair (OR-TAA(A)), 25 patients undergoing conventional open abdominal aneurysm repair (OR-AAA) and 16 patients undergoing endovascular aneurysm repair (EVAR). Data were compared with perioperative changes in arterial $\mathrm{pH}$ and serum lactate.

\section{Results}

IFABP levels increased in all patients undergoing OR-TAA(A) and OR-AAA reaching peak levels shortly after surgery; $281 \pm 33 \mathrm{pg} / \mathrm{ml}$ to $2,298 \pm 490 \mathrm{pg} / \mathrm{ml}, \mathrm{p}<0.001$, and $187 \pm 31 \mathrm{pg} / \mathrm{ml}$ to $641 \pm 176 \mathrm{pg} / \mathrm{ml}, \mathrm{p}<0.05$ respectively. IFABP levels were significantly higher in patients undergoing OR-TAA(A) $(p<0.001)$. IFABP levels in EVAR-patients remained at baseline concentrations throughout the study. Four patients (2 OR-AAA, 2 OR-TAA(A)) developed fatal postoperative intestinal ischemia on day 2 or 3 postoperatively. High levels of plasma IFABP at the end of surgery had $100 \%$ sensitivity and $98.1 \%$ specificity for the identification of patients developing IN. In OR-AAA patients, arterial $\mathrm{pH}$ and lactate were of additional discriminating value. Complete discrimination between patients with and without IN using plasma IFABP could be made on the first postoperative day.

\section{Conclusions}

Analysis of plasma IFABP levels is of additional value to other current plasma markers in the diagnosis of IN, and enables early identification of patients with IN after aortic surgery days before clinical diagnosis. 


\section{INTRODUCTION}

Loss of intestinal wall integrity during various types of surgery greatly contributes to the development of the postoperative systemic inflammatory response syndrome, sepsis, and multiple organ failure. ${ }^{1-3}$ Patients undergoing aortic surgery are at increased risk for intraoperative mesenterial hypoperfusion and subsequent intestinal damage. This is mainly due to preexistent atherosclerotic disease of the mesenteric vasculature and several intraoperative factors such as aortic cross clamping, and use of extracorporeal circulation. In line, the incidence of postoperative intestinal necrosis (IN), the most deleterious consequence of intestinal hypoperfusion and ischemia/reperfusion, is relatively high in these patients, ranging 1-3\% after elective open aortic repair ${ }^{4-6}$, and up to $10 \%$ in case of emergency repair for ruptured aortic aneurysms. ${ }^{7}$ IN is significantly less frequent in patients undergoing endovascular repair. ${ }^{8}$ Nevertheless, improved perioperative patient care has not resulted in a decreased incidence and mortality $\left(70\right.$ to $90 \%{ }^{4}$ ) of IN following aortic surgery.

Diagnostic delay is considered to be the primary cause of the high mortality rate associated with $1 \mathrm{~N} .{ }^{9}$ Aspecific and inconsistent clinical symptoms often resemble normal or delayed postoperative course (especially after major aortic surgery), making the diagnosis notoriously challenging. Symptoms include abdominal pain, fever, abdominal distension and (bloody) diarrhea, presenting hours to days following surgery. Furthermore, laboratory parameters associated with histologically proven ischemic colitis, such as lactate, are not specific. ${ }^{10}$ Routine colonoscopy following open repair allows diagnosis of ischemic colitis on appearance, but fails to reliably differentiate between superficial and reversible mucosal injury and IN. Furthermore, it is not appropriate for the detection of ischemia of the small intestine. ${ }^{11}$

Intestinal fatty acid binding protein (IFABP) is a sensitive marker of intestinal mucosal damage and has been proposed as a potential tool for the diagnosis of clinically significant intestinal ischemia. ${ }^{12}$ IFABP is a small $(15 \mathrm{kDa})$ cytosolic protein exclusively expressed by mature enterocytes, and is rapidly released into the circulation upon enterocyte damage. ${ }^{13}$ In a recently published systematic review, Evenett et al. designated IFABP as having potential to improve diagnostic accuracy for the diagnosis of intestinal ischemia. ${ }^{14}$ In line, Thuijls et al. recently demonstrated that plasma and urine IFABP levels were significantly higher in 22 patients with abdominal complaints at the emergency department suspected of intestinal ischemia who finally developed this disease, compared to 24 patients with other final diagnoses. ${ }^{15}$ The current study aims to evaluate the incidence and extent of intestinal damage in patients undergoing open and endovascular repair of aortic aneurysms using plasma IFABP. More importantly, it was studied whether IFABP levels could improve early identification of clinically significant, i.e. transmural, postoperative IN in this high risk patient 
population, as this type of IN warrants direct medical and surgical intervention and is a direct cause of high morbidity and mortality.

\section{METHODS}

\section{Patients}

Three groups of patients undergoing aortic surgery with varying levels of surgical complexity were studied. Fifty five patients undergoing elective open repair of a thoracic or thoracoabdominal aortic aneurysm (OR-TAA(A)) were included. These patients were admitted to the Maastricht University Medical Center or the University Hospital of Aachen, between May 2006 and November 2008. Furthermore, we included twenty five patients undergoing elective open infrarenal or juxtarenal abdominal aortic aneurysm repair (OR-AAA), and sixteen patients undergoing endovascular repair of an abdominal aortic aneurysm (EVAR). The latter two patient groups were included at the Maastricht University Medical Center between January $1^{\text {st }}$ 2007 and January $1^{\text {st }}$ 2008. Patients undergoing emergency aortic aneurysm repair were not included. The study was approved by the Institutional Review Board of both institutes and written informed consent was obtained from every patient prior to surgery. All included patients were subjected to IFABP analysis. Patient characteristics and perioperative clinical data were prospectively collected from the patient's medical record. TAAA type was classified according to Crawford's classification. ${ }^{16}$ Preoperative renal function was estimated by calculating the estimated glomerular filtration rate according to the abbreviated Modification of Diet in Renal Disease (MDRD) as recommended by the National Kidney Foundation. Acute kidney injury (AKI) was defined according to the Acute Kidney Injury Network (AKIN) classification, based on perioperative creatinine changes. ${ }^{17}$

\section{Surgical procedures}

\section{Open thoracoabdominal and thoracic aortic aneurysm repair}

The surgical protocol was identical in both institutions and has been described in detail elsewhere. ${ }^{18}$ In short, a thoracolaparotomy was performed through the sixth intercostal space (or eighth intercostal space in type $V$ TAAA) to provide access to the aneurysm. After heparinization $(0.5 \mathrm{mg} / \mathrm{kg})$, extracorporeal circulation was established using a centrifugal pump with membrane oxygenation (Jostra Rotaflow with Jostra Quadrox, Maquet Cardiopulmonary AG, Hirrlingen, Germany). Depending on aneurysm extent, extracorporeal circulation (ECC) was expanded with a 4-branched tubing system enabling pressure-controlled perfusion of the celiac trunk, superior mesenteric artery, renal arteries, and if necessary intercostal arteries during aortic cross clamping 
(ACC) with oxygenated blood. Reimplantation of the inferior mesenteric artery was not performed. Postoperatively, all patients were transported to the Cardiothoracic Intensive Care Unit for postoperative monitoring, circulatory and ventilatory support.

\section{Open repair of an abdominal aortic aneurysm}

Open AAA repair was performed via a transperitoneal approach through a midline abdominal incision. Depending on the extent of the aneurysm, the aorta was cross clamped either at infra- or suprarenal level. After bilateral cross clamping of the iliac arteries, the aneurysm sac was opened in a longitudinal direction, intraluminal thrombus was removed and a Dacron tube or bifurcated graft (Gelsoft ${ }^{\mathrm{TM}}$ Plus, Vascutek LTD, Terumo, Renfrewshire, Scotland) was proximally and distally anastomosized by means of an in-lay technique. Reimplantation of the inferior mesenteric artery was not performed. Postoperatively, all patients were transported to the recovery room.

\section{Endovascular aortic reconstructive surgery}

All EVAR procedures were conducted under general anesthesia. Device selection was made on the basis of anatomic suitability and surgeon preference. Vascular access was achieved via a bilateral incision in the groin. Catheters were threaded through the femoral arteries into the aorta, and a self-expandable bifurcated aorto stent-graft (modular components, Zenith graft, Cook, Bjaerverskov, Denmark) was placed distally of the most distal renal artery. If overstenting of the internal ileac artery was unavoidable, the internal iliac artery was exluded by coiling in a separate procedure weeks prior to surgery. A control angiogram at the end of surgery showed patent mesenteric, renal and internal iliac arteries in all patients. Postoperatively, all patients were transported to the recovery room.

\section{Blood Sampling}

Peripheral arterial blood was drawn from the indwelling radial arterial line at preset time-points (Figure 2.1). For legibility reasons, time-point T4 (15 minutes after removal of ACC (OR-AAA) or cessation of ECC (OR-TAA(A))) will be indicated as "end of surgery" throughout the manuscript. In case the arterial line was removed prior to the second postoperative day, a venous blood sample was collected by venipuncture. Previous studies did not show a difference between plasma levels of IFABP in peripheral arterial and venous blood (unpublished data). Whole blood was collected in EDTA vacutainers (Becton Dickinson, Franklin Lakes, NJ), and immediately put on ice. All samples were centrifuged within 15 minutes after collection $\left(1,500 \mathrm{~g}\right.$ at $4^{\circ} \mathrm{C}$ for $\left.15 \mathrm{~min}\right)$, plasma was aliquoted and stored at $-80^{\circ} \mathrm{C}$ until further analysis. 


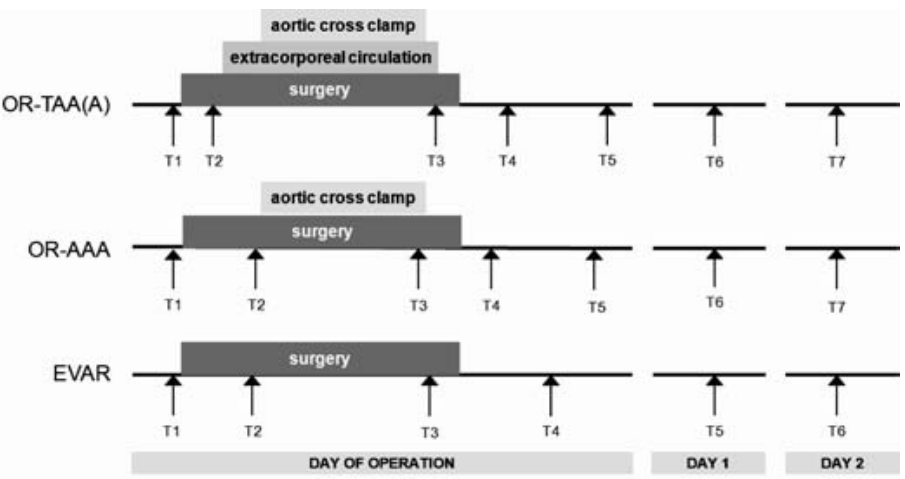

Figure 2.1 Timeline of blood sampling for all patient groups.

Overview of blood sample moments (indicated by the black arrows) in the three included patient populations during the study period. For all OR-TAAA and OR-AAA patients: T1, preoperatively: T7, first postoperative day; and T8, second postoperative day. For OR-TAAA patients specifically: T2, just before start of extracorporeal circulation; T3, just before cessation of extracorporeal circulation; T4, 15 minutes after cessation of extracorporeal circulation (reperfusion); T5, 2 hours after reperfusion; T6, 6 hours after reperfusion. For OR-AAA patients: T2, just before aortic cross clamping (ACC); T3, just before removal of the ACC; T4, 15 minutes after removal of ACC (reperfusion); T5, 2 hours after reperfusion; T6, 6 hours after reperfusion; For EVAR-patients: T1, preoperatively; T2, during insertion of guide wires; T3, deployment of stent; T4, 2 hours after stent deployment at recovery; T5, first postoperative day, T6, second postoperative day.

Abbreviations: OR-TAA(A), open repair of a thoracic or thoracoabdominal aortic aneurysm; ORAAA, open repair of an abdominal aortic aneurysm; EVAR, endovascular aortic aneurysm reconstruction.

\section{Assay for intestinal fatty acid binding protein}

After inclusion of all patients, plasma concentrations of IFABP were analyzed in all blood samples to assess intestinal epithelial mucosal injury. A commercially available enzyme linked immunosorbent assay [ELISA] for detection of human IFABP (Hycult Biotech, Uden, the Netherlands) was used according to manufacture guidelines. All samples were determined in duplicate $(<10 \%$ variation between duplicates was accepted) and averaged for statistical analysis. The detection limit of the ELISA was 41 $\mathrm{pg} / \mathrm{ml}$. The IFABP analysis was performed at the laboratory of the department of Surgery at the Maastricht University Medical Centre. A golden standard for the diagnosis of IN is currently lacking, and suspected IN is traditionally confirmed by emergency laparotomy. ${ }^{19}$ IFABP levels were quantified prior to retrospective comparison with postoperative clinical data.

\section{Conventional markers for intestinal ischemia: arterial $\mathrm{pH}$ and serum lactate}

Arterial $\mathrm{pH}$ and serum lactate were routinely analyzed by the department of Clinical 
Chemistry of the Maastricht University Medical Center or University Hospital of Aachen in the context of standard care. We collected these data to enable comparison to plasma IFABP levels on the following time-points; preoperatively, at the end of surgery, and on the first and second postoperative day. In EVAR patients arterial pH and lactate were not determined.

\section{Statistical analysis}

Continuous data in Tables are presented as median (interquartile range; IQR ranging the 25th-75th percentile), and as $\mathrm{N}$ (\%) for dichotomous data. Continuous data are presented as mean \pm S.E.M (Figure 2.2), or as Tukey box-whisker plots (Figure 2.3) indicating median, $1^{\text {st }}$ and $3^{\text {rd }}$ quartile (box), highest and lowest value within 1.5 interquartile range (IQR, whiskers), and values outside 1.5IQR (outliers). Differences in patient characteristics between study groups were compared using Pearson Chi-square test for dichotomous variables, with Fisher's correction when appropriate. Continuous data were analyzed using independent sample t-test or Mann-Whitney U-test depending on Gaussian distribution (checked using histograms and normal Q-Q plots). Continuous data with multiple time-points were analyzed using the repeated measures ANOVA with Bonferroni post-hoc correction, or the Friedman test with post-hoc Dunn's correction, depending on Gaussian distribution.

In Figure $\mathbf{2 . 2}$ and Figure $\mathbf{2 . 3}$ we did not analyze the statistical changes of plasma IFABP, arterial $\mathrm{pH}$, or serum lactate in patients with IN due to limited group size. Receiver Operating Characteristic (ROC) curves were drawn by plotting sensitivity against $100 \%$ specificity in order to find the optimal cut-off point of plasma IFABP, arterial $\mathrm{pH}$ or serum lactate which most accurately discriminated between patients with and without postoperative IN. The cut-off point was defined as the maximum sum of sensitivity and specificity. Lastly, positive and negative likelihood ratios were calculated. Statistical calculations were made using SPSS 15.0 for Windows (SPSS, Inc., Chicago, IL), and Prism 4.03 for Windows (GraphPad Software Inc. San Diego, CA). A p-value $<0.05$ was considered to indicate statistical significance. This study adheres to the STAndards for Reporting of Diagnostic Accuracy (STARD) criteria for studies reporting on diagnostic accuracy. ${ }^{20}$

\section{RESULTS}

\section{Patient characteristics and clinical outcome}

Ninety six patients undergoing surgical repair of an aortic aneurysm were studied; 55 patients undergoing open thoracoabdominal aortic aneurysm surgery (OR-TAA(A) group), and 41 patients diagnosed with an isolated abdominal aortic aneurysm, of 
whom 25 were treated using the conventional open procedure (OR-AAA group) and 16 by endovascular exclusion (EVAR group). Clinical baseline characteristics are presented in Table 2.1 and Supplemental Table 2.1S. OR-TAA(A) patients were significantly younger compared to both OR-AAA and EVAR patients (66 (55-71) vs. 70 (67-76), and $70(65-77)$ years, $p<0.001)$. Also, the male-female distribution was statistically significantly different in the OR-TAA $(A)$ group with $56 \%(N=31)$ male patients versus an almost completely male patient population in the other two groups $(p<0.001)$. As expected, intraoperative and postoperative factors associated with surgical complexity were significantly higher in TAAA patients (Table 2.1).

Table 2.1 Baseline characteristics, intraoperative variables, and outcome of OR-TAA(A), OR-AAA, and EVAR patients.

\begin{tabular}{|c|c|c|c|c|}
\hline Variable & $\begin{array}{c}\text { OR-TAA(A) } \\
(\mathrm{N}=55)\end{array}$ & $\begin{array}{l}\text { OR-AAA } \\
(\mathrm{N}=25)\end{array}$ & $\begin{array}{c}\text { EVAR } \\
(N=16)\end{array}$ & $\mathrm{p}$-value \\
\hline \multicolumn{5}{|l|}{ Preoperative } \\
\hline Age (years), median (IQR 25-75\%) & $66(55-71)$ & $70(67-76)$ & $70(65-77)$ & $<0.001$ \\
\hline Male, $\%(n)$ & $56(31)$ & $92(23)$ & $100(16)$ & $<0.001$ \\
\hline \multicolumn{5}{|l|}{ Intraoperative } \\
\hline Aortic cross clamp infrarenal, \% ( $n$ ) & n.a. & $80(20)$ & n.a. & - \\
\hline Aortic cross clamp time (min), median (IQR $25-75 \%)$ & $103(73-141)$ & $49(37-60)$ & n.a. & $<0.001$ \\
\hline Extracorporeal circulation time (min), median (IQR 25-75\%)) & $154(107-197)$ & n.a. & n.a. & - \\
\hline Blood loss (L), median (IQR 25-75\%) & $8.9(5.7-19.5)$ & $1.2(0.7-2.0)$ & $0.3(0.2-0.7)$ & $<0.001$ \\
\hline Packed cell transfusion (units), median (IQR 25-75\%) & $10(7-13)$ & $0(0)$ & $0(0)$ & $<0.001$ \\
\hline Duration of surgery (min), median (IQR $25-75 \%$ ) & $390(328-448)$ & $157(135-199)$ & $90(75-120)$ & $<0.001$ \\
\hline \multicolumn{5}{|l|}{ Postoperative } \\
\hline In-hospital mortality, \% (n) & $15(8)$ & $8(2)$ & $0(0)$ & 0.24 \\
\hline ICU admission time (days), median (IQR 25-75\%) & $5(3-9)$ & $0(0-1)$ & $0(0-0)$ & $<0.001$ \\
\hline Duration of hospitalization (days), median (IQR 25-75\%) & $17(13-29)$ & $10(9-16)$ & $5(4-5)$ & $<0.001$ \\
\hline
\end{tabular}

Abbreviations: OR-TAA(A), open repair of a thoracic or thoracoabdominal aortic aneurysm; OR-AAA, open repair of an abdominal aortic aneurysm; EVAR, endovascular aneurysm repair, IQR, 25-75th interquartile range; n.a, not applicable; ICU, intensive care unit.

Four patients $(4.2 \%, 2$ OR-TAA(A) and 2 OR-AAA patients) developed lethal postoperative IN as confirmed by emergency laparotomy and histopathological analysis on the second or third postoperative day. In two patients it concerned small IN, in the other two the descending colon and sigmoid were affected. In all patients the inferior mesenteric artery was already occluded prior to surgery. None of the EVAR patients showed clinical signs of IN. Besides the two patients with IN, no other OR-AAA patient died (total in-hospital mortality $8 \%$ ). In-hospital mortality for OR-TAA(A) patients was $15 \%(N=8)$, and $0 \%$ in the EVAR group. Others causes of death in the OR$\operatorname{TAA}(\mathrm{A})$ group were sepsis and multiple organ failure (kidneys and lungs) in 4 patients (who died 7, 9, 13, and 14 days postoperatively), severe cerebral infarction in 1 patient, and hemorrhagic shock in 1 patient. 
Supplemental Table 2.1S Preoperative risk factors and outcome in OR-TAA(A), OR-AAA, and EVAR patients.

\begin{tabular}{|c|c|c|c|c|}
\hline Variable & $\begin{array}{c}\text { OR-TAA(A) } \\
(\mathrm{N}=55)\end{array}$ & $\begin{array}{l}\text { OR-AAA } \\
(\mathrm{N}=25)\end{array}$ & $\begin{array}{c}\text { EVAR } \\
(N=16)\end{array}$ & $\mathrm{p}$-value \\
\hline \multicolumn{5}{|l|}{ Preoperative } \\
\hline PAOD, $\%(n)$ & $13(7)$ & $44(11)$ & $19(3)$ & 0.005 \\
\hline Diabetes type II, \% ( $n$ ) & $6(3)$ & $4(1)$ & $6(1)$ & 0.24 \\
\hline Hypertension, \% (n) & $70(35)$ & $44(11)$ & $44(7)$ & 0.07 \\
\hline Smoking, \% (n) & $45(23)$ & $20(5)$ & $31(5)$ & 0.05 \\
\hline COPD, \% (n) & $18(10)$ & $20(5)$ & $31(5)$ & 0.52 \\
\hline Stroke, $\%(n)$ & $4(2)$ & $25(4)$ & $6(1)$ & 0.07 \\
\hline Previous coronary artery bypass grafting, $\%(n)$ & $13(4)$ & $22(2)$ & $13(2)$ & 0.26 \\
\hline Preoperative renal function (GFR, $\mathrm{ml} / \mathrm{min} / 1.73 \mathrm{~m}^{2}$ ), median (IQR $25-75 \%$ ) & $74(58-93)$ & $62(57-77)$ & $56(51-88)$ & 0.15 \\
\hline Preoperative chronic renal dysfunction (GFR<60), \% (n) & $28(15)$ & $29(5)$ & $50(8)$ & $<0.001$ \\
\hline Maximum aneurysm diameter (mm), median (IQR 25-75\%) & $68(56-77)$ & $64(59-76)$ & $63(58-68)$ & 0.75 \\
\hline \multicolumn{5}{|l|}{ Aneurysm extent } \\
\hline \multicolumn{5}{|l|}{ TAAA type (according to the Crawford classification) } \\
\hline Type I, \% (n) & $9(5)$ & n.a. & n.a. & - \\
\hline Type II, \% (n) & $20(11)$ & n.a. & n.a. & - \\
\hline Type III, \% (n) & $42(23)$ & n.a. & n.a. & - \\
\hline Type IV, \% (n) & $16(9)$ & n.a. & n.a. & - \\
\hline TAA, $\%(n)$ & $13(7)$ & n.a. & n.a. & - \\
\hline Infrarenal abdominal aortic aneurysm, \% ( $n$ ) & n.a. & $80(20)$ & $94(15)$ & 0.09 \\
\hline \multicolumn{5}{|l|}{ Postoperative } \\
\hline Uncomplicated postoperative course, \% ( $n$ ) & $40(21)$ & $55(10)$ & $88(14)$ & 0.003 \\
\hline Postoperative intestinal necrosis, \% ( $n$ ) & $4(2)$ & $8(2)$ & $0(0)$ & 0.62 \\
\hline Dialysis, \% (n) & $11(6)$ & $6(1)$ & $0(0)$ & 0.55 \\
\hline
\end{tabular}

Abbreviations: OR-TAA(A), open repair of a thoracic or thoracoabdominal aortic aneurysm; OR-AAA, open repair of an abdominal aortic aneurysm; EVAR, endovascular aneurysm repair, IQR, 25-75th interquartile range; n.a, not applicable; PAOD, peripheral arterial occlusive disease; COPD, chronic obstructive pulmonary disease; CVA, cerebrovascular accident; GFR, glomerular filtration rate.

\section{Open aortic aneurysm repair is associated with intestinal epithelial cell damage}

To study intestinal epithelial cell damage during surgery we analyzed plasma IFABP in all patient samples (Figure 2.2). Preoperative IFABP levels were similar between ORTAA(A), OR-AAA, and EVAR patients without postoperative IN (Figures 2.2A, 2.2C, and 2.2E) and with postoperative IN (Figures 2.2B and 2.2D). During surgery, IFABP levels increased in all patients undergoing open aortic aneurysm repair reaching peak levels at the end of surgery $(281 \pm 33 \mathrm{pg} / \mathrm{ml}$ to $2,298 \pm 490 \mathrm{pg} / \mathrm{ml}, p<0.001$, and $187 \pm 31 \mathrm{pg} / \mathrm{ml}$ to $641 \pm 176 \mathrm{pg} / \mathrm{ml}, \mathrm{p}<0.05$ for OR-TAA(A) and OR-AAA patients respectively (Figures $2.2 A$ and $\mathbf{2 . 2 C}$ ). The pattern of IFABP change during the study period was similar in OR-TAA(A) and OR-AAA patients. Nevertheless, peak IFABP concentrations were statistically significantly higher in the first group $(p<0.001$ and $p<0.005$, at the end of surgery and two hours after removal of the ACC / cessation of ECC, respectively). IFABP levels in EVAR-patients remained at baseline concentrations throughout the perioperative period ( $p>0.05$, Figure 2.2E). 

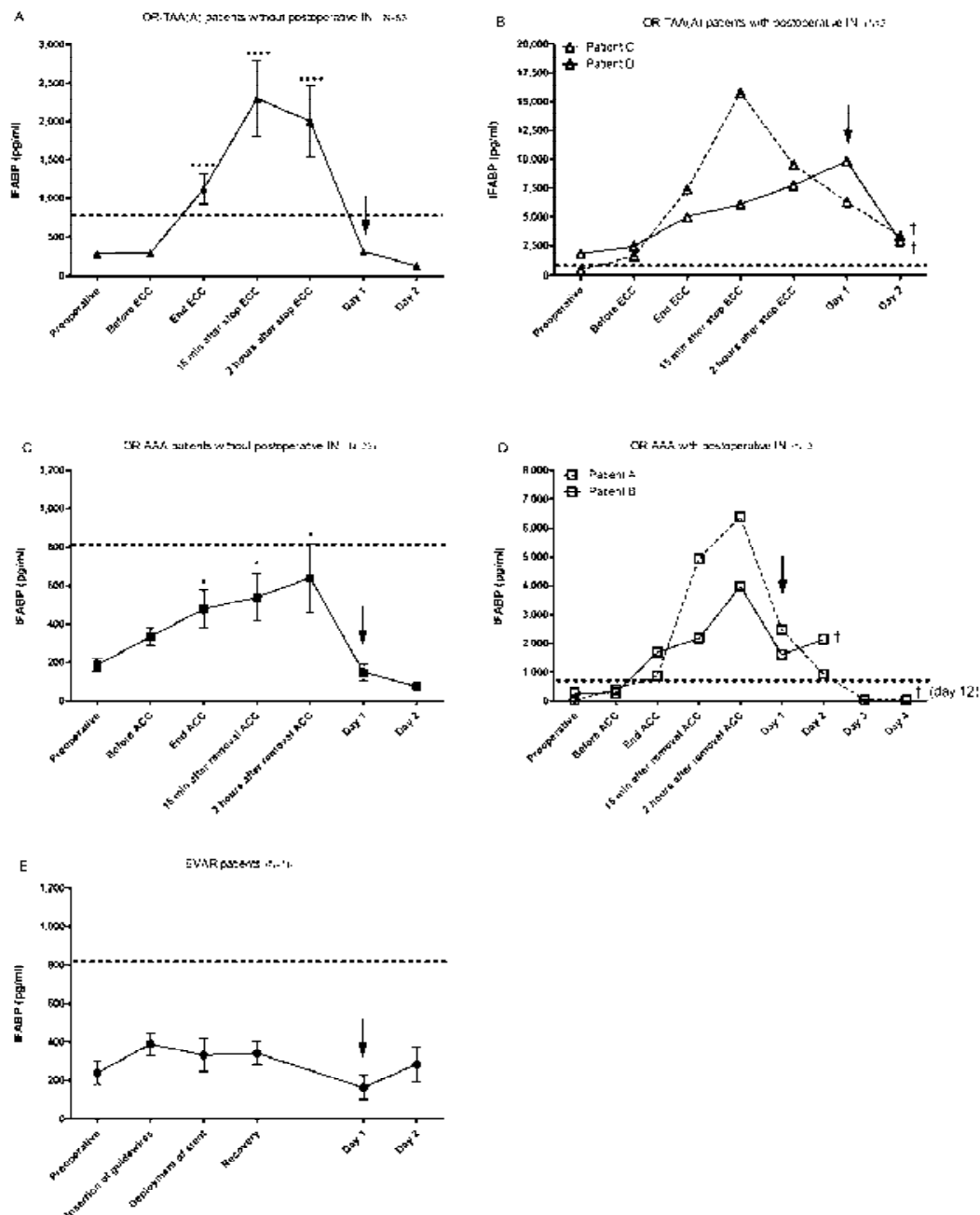

Figure 2.2 Plasma IFABP levels in patients undergoing aortic aneurysm repair with and without postoperative intestinal necrosis.

IFABP levels (mean \pm SEM) in patients undergoing open thoracoabdominal aortic aneurysm repair (2.2A/B), open abdominal aortic aneurysm repair (2C/D), and endovascular abdominal aortic aneurysm repair (2.2E). Figures $2.2 \mathrm{~B}$ and 2.2D depict the two OR-TAA(A) and two ORAAA patients who developed postoperative IN, respectively. These patients displayed significantly higher IFABP levels compared to patients without postoperative IN. Furthermore, plasma IFABP levels remained significantly increased at the first postoperative day. The dotted line is set at the upper reference limit of all patients $(815 \mathrm{pg} / \mathrm{ml})$. The black arrows indicate the difference between the high IFABP levels in patients with IN compared to patients without IN.

Abbreviations: IFABP, intestinal fatty acid binding protein; OR-TAA(A), open repair of a thoracic or thoracoabdominal aortic aneurysm; OR-AAA, open repair of an abdominal aortic aneurysm; EVAR, endovascular aortic aneurysm reconstruction; EVAR, endovascular aortic aneurysm reconstruction; IN, intestinal necrosis ; ACC, aortic cross clamp; min, minutes; ECC, extracorporeal circulation. 
As IFABP is renally filtered, we analyzed whether differences in preoperative renal clearance might have accounted for differences in IFABP levels between OR-TAA(A), OR-AAA and EVAR patients. Glomerular filtration rate did not correlate to IFABP levels during surgery; $R_{s}=0.11(p=0.31)$ and $R_{s}=0.006(p=0.96)$ for IFABP levels at the end of surgery and two hours after removal of the ACC / cessation of ECC, respectively (data not shown). In all patients without IN, plasma IFABP values returned to baseline levels on the first postoperative day When comparing IFABP levels between patients with and without IN, two results stand out. First, peak IFABP levels were markedly higher in patients with postoperative IN already during surgery, and second, plasma IFABP concentrations remained high on the first postoperative day in patients with IN.

\section{Plasma IFABP discriminates patients with and without intestinal necrosis at the end of surgery and on the first postoperative day}

The differences in plasma IFABP values between patients with and without postoperative IN already at the end of surgery, while IN was only clinically suspected two days later, substantiates its potential as an early biomarker of IN. Consequently, we compared the predictive power of plasma IFABP with two biochemical parameters commonly used in the diagnosis of intestinal ischemia: arterial $\mathrm{pH}$ and serum lactate. Although their sensitivity and specificity for IN is debated ${ }^{21,22}$, the lack of more specific biochemical markers still often compels clinicians to rely on these markers in clinical practice. In general, open aortic surgery was associated with a significant drop of arterial $\mathrm{pH}$ and increase in serum lactate (Figure 2.3), and these changes were more marked in patients undergoing OR-TAA(A). OR-AAA patients that later developed postoperative IN displayed significantly lower arterial $\mathrm{pH}$ at the end of surgery and on the first postoperative day compared to patients without postoperative IN $(p<0.05$, Figure 2.3C). This in contrast to OR-TAA(A) patients, in whom arterial $\mathrm{pH}$ levels were not statistically different between patients with and without IN on all studied timepoints (Figure 2.3A). Serum lactate concentrations were not statistically higher in patients with IN compared to patients without IN in both patient groups on all timepoints (Figures 2.3B and 2.3D).

Subsequently, we assessed ideal cut-off points and predictive value of each marker at their peak level at the end of surgery and on the first postoperative day (Tables 2.2A and 2.2B). Both arterial $\mathrm{pH}$ and serum lactate levels at the end of OR-AAA surgery allowed significant discrimination between patients with and without postoperative IN $(p=0.02$, and $p=0.04$ at the end of surgery and on the first postoperative day, respectively). Arterial $\mathrm{pH}$ still displayed significant discriminative power on the first day after surgery in this patient group $(p=0.04)$. In contrast, the discriminative power of arterial $\mathrm{pH}$ and lactate was markedly lower, and not statistically significant, in OR$\operatorname{TAA}(\mathrm{A})$ patients on both time-points. Lactate levels in OR-AAA patients on the first 
postoperative day were also non-discriminative. Lastly, we studied the discriminative power of plasma IFABP levels on the same time-points. Based on these data, detection of plasma IFABP levels above the cut-off points of $5,787 \mathrm{pg} / \mathrm{ml}$ (OR-TAA(A) patients) or $1,938 \mathrm{pg} / \mathrm{ml}$ (OR-AAA patients) at the end of surgery enabled good discrimination of patients with and without postoperative IN. Interestingly, plasma IFABP concentrations on the first postoperative day were able to discriminate patients with and without IN with $100 \%$ sensitivity and $100 \%$ specificity in both groups when IFABP levels exceeded $3,646 \mathrm{pg} / \mathrm{ml}$ or $1,121 \mathrm{pg} / \mathrm{ml}$ for OR-TAA(A) and OR-AAA patients respectively (Tables 2.2A and 2.2B). Summarizing; plasma IFABP has clear (additional) predictive value for detection of patients with postoperative IN after aortic surgery.

Table 2.2 Statistical accuracy of arterial $\mathrm{pH}$, serum lactate and plasma IFABP levels at the end of surgery and on the first postoperative day for the identification of patients with and without postoperative intestinal necrosis.

\begin{tabular}{lcccccc}
\hline A. OR-TAA(A) patients & \multicolumn{5}{c}{ End of surgery } & \multicolumn{3}{c}{$1^{\text {st }}$ postoperative day } \\
& Arterial pH & Plasma lactate & Plasma IFABP & Arterial pH & Plasma lactate & Plasma IFABP \\
\hline Cut-off value & $<7.245$ & $>5.3 \mathrm{mmol} / \mathrm{l}$ & $>5,787 \mathrm{pg} / \mathrm{ml}$ & $<7.255$ & $>7.2 \mathrm{mmol} / \mathrm{l}$ & $>3,646 \mathrm{pg} / \mathrm{ml}$ \\
Area under ROC-curve & 0.76 & 0.86 & 0.98 & 0.87 & 0.58 & 1.00 \\
P-value & 0.22 & 0.09 & 0.02 & 0.08 & 0.72 & 0.02 \\
Sensitivity (\%) & 100 & 100 & 100 & 100 & 50 & 100 \\
Specificity (\%) & 61.2 & 77.6 & 98.1 & 87.0 & 97.8 & 100 \\
Likelihood ratio + & 2.6 & 4.5 & 52.6 & 7.7 & 45.5 & $\infty$ \\
Likelihood ratio - & 0 & 0 & 0 & 0 & 0.5 & 0 \\
\hline
\end{tabular}

B. OR-AAA patients

\begin{tabular}{lcccccc} 
& \multicolumn{3}{c}{ End of surgery } & \multicolumn{3}{c}{$1^{\text {st }}$ postoperative day } \\
& Arterial pH & Plasma lactate & Plasma IFABP & Arterial pH & Plasma lactate & Plasma IFABP \\
\hline Cut-off value & $<7.215$ & $>3.8 \mathrm{mmol} / \mathrm{l}$ & $>1,938 \mathrm{pg} / \mathrm{ml}$ & $<7.255$ & $>3.6 \mathrm{mmol} / \mathrm{l}$ & $>1,121 \mathrm{pg} / \mathrm{ml}$ \\
Area under ROC-curve & 1.00 & 0.97 & 0.98 & 0.95 & 0.69 & 1.00 \\
P-value & 0.02 & 0.04 & 0.03 & 0.04 & 0.41 & 0.02 \\
Sensitivity (\%) & 100 & 100 & 100 & 100 & 50 & 100 \\
Specificity (\%) & 100 & 93.8 & 95.7 & 87.5 & 91.7 & 100 \\
Likelihood ratio + & $\infty$ & 16.1 & 23.3 & 8 & 12.0 & $\infty$ \\
Likelihood ratio - & 0 & 0 & 0 & 0 & 0.5 & 0 \\
\hline
\end{tabular}

Abbreviations: ROC, receiver operating curve; OR-TAA(A), open repair of a thoracic or thoracoabdominal aortic aneurysm; OR-AAA, open repair of an abdominal aortic aneurysm. 

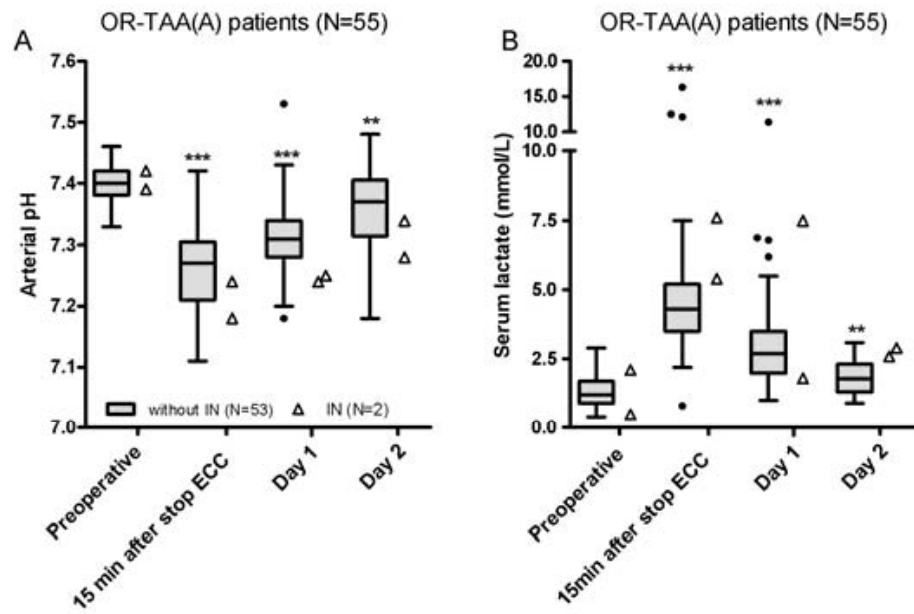

OR-AAA patients $(\mathrm{N}=25)$

OR-AAA patients $(\mathrm{N}=25)$
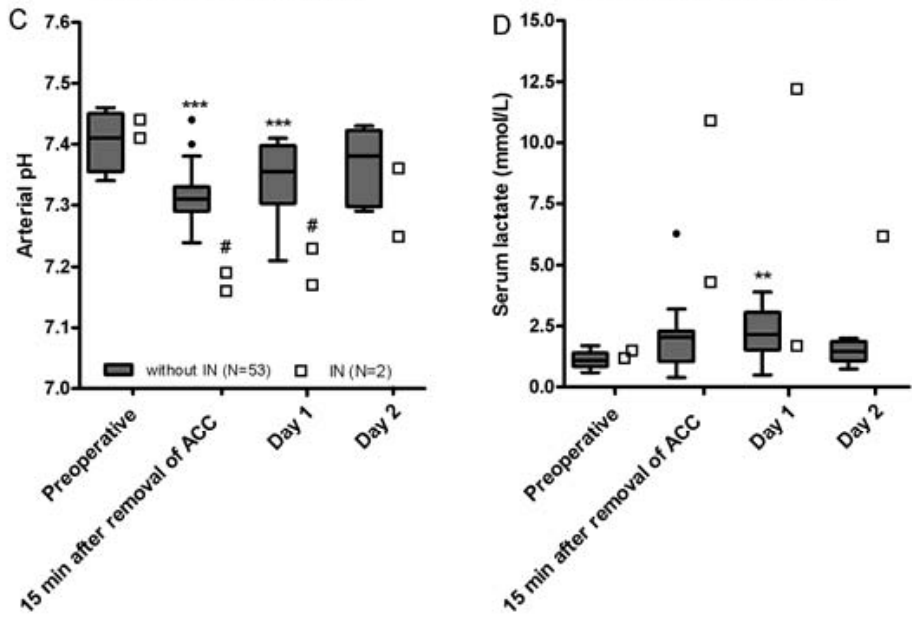

Figure 2.3 Change of arterial $\mathrm{pH}$ and serum lactate in patients undergoing open aortic surgery with and without postoperative intestinal necrosis.

Arterial $\mathrm{pH}$ and serum lactate was routinely measured preoperatively, at peak IFABP levels at the end of surgery, and on the first and second postoperative day. Data are presented using Tukey box-whisker plots indicating median, 1st and 3rd quartile (box), highest and lowest value within 1.5 interquartile range (IQR, whiskers), and values outside 1.5IQR (outliers). Patients with IN are presented separately ( $\triangle$ for OR-TAA(A) patients and $\square$ for OR-AAA patients). Figure $2.3 \mathrm{~A}$ and $2.3 \mathrm{~B}$ depict the change of arterial $\mathrm{pH}$ and serum lactate for OR-TAA(A) patients. Figure $2.3 \mathrm{C}$ and 2.3D for OR-AAA patients, respectively.

Abbreviations: IFABP, intestinal fatty acid binding protein; OR-TAA(A), open repair of a thoracic or thoracoabdominal aortic aneurysm; OR-AAA, open repair of an abdominal aortic aneurysm; IN, intestinal necrosis; ACC, aortic cross clamp; min, minutes; ECC, extracorporeal circulation; $* * / * * * \mathrm{p}<0.01$ and $\mathrm{p}<0.001$ compared to preoperative values of group without IN; $\# \mathrm{p}<0.05$ between groups (patients with IN versus patients without IN). 


\section{DISCUSSION}

Intraoperative intestinal damage and intestinal barrier dysfunction is implicated as an important inciting event in the development of postoperative complications. ${ }^{23}$ Indeed, loss of viable enterocytes and increased intestinal permeability result in enhanced systemic levels of pro-inflammatory cytokines and endotoxin; factors associated with adverse outcome. ${ }^{24,25}$ Transmural IN is the most deleterious form of intestinal damage and is related to significant morbidity and mortality, mainly attributed to diagnostic delay. Intestinal fatty acid binding protein is a promising marker of intestinal compromise in man. ${ }^{12,26}$ The aim of the current study was to investigate whether plasma IFABP enables timely identification of patients that develop clinically significant transmural IN after aortic surgery. To that end, the kinetic properties of plasma IFABP were studied in patients undergoing three types of aortic surgery. Furthermore, we compared the predictive value of IFAPB levels with two clinically used biochemical markers for IN; arterial $\mathrm{pH}$ and serum lactate.

In this study we showed a transient but significant increase in IFABP levels in all patients undergoing open aortic aneurysm surgery, indicating the development of intestinal damage. Moreover, we found higher IFABP concentrations in patients undergoing OR-TAA(A) compared to patients undergoing OR-AAA. The development of intestinal damage during aortic surgery can result from a temporary low-flow state of the mesenteric and hypogastric circulation due to anesthesia and hypovolemia, and from intestinal macro-infarction due to embolization of cholesterol plaques or intraluminal thrombus. ${ }^{5,26,27}$ Three specific factors may explain the differences in IFABP levels between OR-TAA(A) and OR-AAA patients. First, patients undergoing OR-TAA(A) experience a brief period of absolute intestinal ischemia when the extracorporeal circulation system and selective organ perfusion catheters are connected, causing profound ischemia-reperfusion injury to the entire intestinal epithelial lining. In contrast, patients undergoing OR-AAA do not experience a period of absolute intestinal ischemia, although (infrarenal) aortic cross clamping has been related to blood flow perturbations of the intestinal tract. ${ }^{28}$ Second, OR-TAA(A) is associated with significant intraoperative hemolysis due to the extracorporeal circulation, cell saver use and massive blood transfusion. ${ }^{29}$ Subsequent release of free hemoglobin causes intravascular nitric oxide scavenging which may result in organ perfusion perturbations and subsequent tissue injury. ${ }^{30}$ This way, hemolysis might significantly contribute to increased IFABP levels in OR-TAA(A) patients. To our knowledge, OR-AAA surgery is not associated with hemolysis. Third, splanchnic hypoperfusion during OR-TAA(A) is further aggravated by the extracorporeal circulation system itself. ${ }^{31}$ These intraoperative differences between the two patient groups may be responsible for more extensive intestinal injury in patients subjected to OR-TAA(A) surgery, thus resulting in higher 
cut-off values of IFABP for detection of postoperative IN compared to OR-AAA patients. Nevertheless, the cut-off value of IFABP of OR-AAA patients on the first postoperative day also enabled full discrimination of $\mathrm{OR}-\operatorname{TAA}(\mathrm{A})$ patients with and without IN.

Another key finding of this study was that patients with postoperative IN displayed exceptionally high IFABP levels at the end of surgery, and on the first postoperative day. In line, plasma IFABP concentrations carried significant prognostic power for postoperative IN on both time-points. Since plasma IFABP is a new marker of IN in this setting, we compared the predictive power of plasma IFABP levels to arterial $\mathrm{pH}$ and serum lactate concentrations. Interestingly, both arterial $\mathrm{pH}$ and serum lactate levels at the end surgery displayed similar predictive power to plasma IFABP for the identification of patients with IN in OR-AAA patients. This observation is in line with the fact that aberrant arterial $\mathrm{pH}$ and lactate values often reflect tissue hypoxia in situations such as lower limb ischemia due to aortic cross clamping, intestinal necrosis, the acute compartment syndrome, ischemic neurological injury, systemic hypoperfusion, shock, SIRS, and sepsis. ${ }^{32-35}$ In contrast to OR-AAA patients, arterial $\mathrm{pH}$ and lactate displayed only limited, and not significant, predictive power after OR$\operatorname{TAA}(\mathrm{A})$. We attribute this to the complex pathophysiological condition of patients after $\operatorname{OR}-\operatorname{TAA}(\mathrm{A})$. Nevertheless, the combination of the three parameters can provide the clinician with important information on intestinal cellular compromise. The decrease in arterial $\mathrm{pH}$ and simultaneous increase in lactate point to cellular hypoxia, however of unspecific origin. Additionally enhanced plasma IFABP values (as seen in our patients with IN) specifically indicate intestinal epithelial cell damage, making it very likely that the changes in arterial $\mathrm{pH}$ and lactate are a direct consequence of cellular hypoxemia of the intestinal mucosa.

Our results indicate that plasma IFABP could be a valuable (additional) marker for the early identification of patients with IN after aortic surgery. Ideally, measurement of plasma IFABP should not only serve as a handle in the identification of patients with IN, but also in the initiation of therapeutic measures to minimize further deterioration of intestinal integrity. As IFABP values were already discriminative at the end of surgery, thorough assessment of end-of-surgery bowel viability is imperative. Unfortunately, no sign of impaired bowel viability such as discoloration, absence of peristalsis or mesenteric pulsations, or presence of mucosal hemorrhage, are conclusive for the presence of irreversible IN at that early time-point. ${ }^{36}$ This implies that identification and resection of the (potentially) affected intestinal segment at the end of surgery will be challenging, if not impossible. Nevertheless, intraoperative IFABP concentrations can be used to identify patients who warrant additional surgical and clinical attention. Therapeutic interventions should be aimed at optimizing intestinal perfusion and prevent bacterial translocation for instance through reimplantation of the inferior 
mesenteric artery (although heavily debated), intra-arterial infusion of thrombolytic agents, strict (hemodynamic) monitoring, volume resuscitation, and administration of broad-spectrum antibiotics. ${ }^{37,38}$ Alfa adrenergic agents must be used cautiously since they can cause additional splanchnic vasoconstriction in high doses. ${ }^{39}$ Enteral feeding might increase intestinal metabolic demand and should be given conservatively until gut viability is confirmed. ${ }^{40} \mathrm{~A}$ second-look laparotomy or laparoscopy within 24-48 hours remains the golden standard to establish the full extent of non-viable bowel in patients suspected of $1 \mathrm{IN}^{36}$ However, selection of patients who would benefit from such an invasive procedure should be done cautiously as surgical re-exploration exposes patients to additional surgical morbidity. Currently, selection of these patients is challenging due to unreliable biochemical and clinical signs and symptoms. Our results indicate that IFABP levels on the first postoperative day are useful to identify those patients who would benefit from an early relaparotomy or relaparoscopy. In short; plasma IFABP based identification of patients with postoperative IN can be done 24-48 hours earlier than clinical selection criteria would currently allow. This is of great importance as early surgical intervention is associated with improved outcome in these patients. $^{41}$

A last interesting result from this study was that EVAR patients did not show any sign of intestinal cellular compromise. Also, none of the patients developed clinical postoperative IN. The absence of intestinal damage in EVAR patients is in line with the clinical observation that IN is less frequent in EVAR patients versus those undergoing open aortic repair. ${ }^{8}$ The absence of increased IFABP levels in EVAR patients may indicate a considerable role for intestinal manipulation in the release of IFABP during surgery. However, absence of intestinal manipulation in 20 children undergoing major spinal surgery was still accompanied by increased IFABP levels during surgery. ${ }^{26}$ Micro and macro embolization has been suggested to be the predominant factor in the development of intestinal injury during EVAR. ${ }^{27}$ We did not investigate the formation of (micro) emboli and can therefore not relate such emboli with the absence of enhanced IFABP levels. As significant blood loss is considered to hamper intestinal perfusion, the significantly lesser degree of blood loss during EVAR may favor optimal intestinal perfusion during surgery as compared to OR-AAA and OR-TAAA(A) patients. Furthermore, the absence of intestinal mucosal injury could have (in part) accounted for the overall improved postoperative outcome of patients undergoing EVAR surgery as IFABP levels have been shown to correlate with postoperative IL-6 and IL-8 concentrations. ${ }^{24}$ However, due to the limited number of EVAR patients, we can not substantiate this hypothesis statistically. Paradoxically we observed a higher incidence of preoperative chronic renal dysfunction in patients undergoing EVAR compared to open aortic surgery. Although this may indicate a selection bias, we have as yet no clear explanation for this result. 
Summarizing, this study offers two clinically significant findings. First, assessment of plasma IFABP levels enables early identification of patients developing IN after open aortic repair, irrespective of the type of surgery. Second, patients undergoing EVAR do not display detectable intestinal injury. As our study included only a relatively small number of patients with IN (although with a high number of negative controls), our results preclude definitive conclusions. Nevertheless, the current results encourage further study into the predictive value of plasma IFABP, especially combined with arterial $\mathrm{pH}$ and serum lactate levels, for the early identification of patients with postoperative IN. In conclusion, we consider assessment of plasma IFABP to be important in the early identification of patients with lethal postoperative IN, thus enabling reduction of the current surgical delay in the treatment of IN and improving patient outcome after aortic surgery. 


\section{REFERENCES}

1. Fink MP. Gastrointestinal mucosal injury in experimental models of shock, trauma, and sepsis. Crit Care Med 1991; 19:627-41.

2. Moore FA. The role of the gastrointestinal tract in postinjury multiple organ failure. Am J Surg 1999; 178:449-53.

3. Grotz MR, Deitch EA, Ding J, Xu D, Huang Q, Regel G. Intestinal cytokine response after gut ischemia: role of gut barrier failure. Ann Surg 1999; 229:478-86.

4. Brewster DC, Franklin DP, Cambria RP, Darling RC, Moncure AC, Lamuraglia GM, Stone WM, Abbott WM. Intestinal ischemia complicating abdominal aortic surgery. Surgery 1991; 109:447-54.

5. Bjorck M, Bergqvist D, Troeng $T$. Incidence and clinical presentation of bowel ischaemia after aortoiliac surgery--2930 operations from a population-based registry in Sweden. Eur J Vasc Endovasc Surg 1996; 12:139-44.

6. Achouh PE, Madsen K, Miller CC, 3rd, Estrera AL, Azizzadeh A, Dhareshwar J, Porat E, Safi HJ. Gastrointestinal complications after descending thoracic and thoracoabdominal aortic repairs: a 14year experience. J Vasc Surg 2006; 44:442-6.

7. Bjorck M, Troeng T, Bergqvist D. Risk factors for intestinal ischaemia after aortoiliac surgery: a combined cohort and case-control study of 2824 operations. Eur J Vasc Endovasc Surg 1997; 13:531-9.

8. Perry RJ, Martin MJ, Eckert MJ, Sohn VY, Steele SR. Colonic ischemia complicating open vs endovascular abdominal aortic aneurysm repair. J Vasc Surg 2008; 48:272-7.

9. Longo WE, Lee TC, Barnett MG, Vernava AM, Wade TP, Peterson GJ, Jacobs DL, Virgo KS, Johnson FE. Ischemic colitis complicating abdominal aortic aneurysm surgery in the U.S. veteran. J Surg Res 1996; 60:351-4.

10. Assadian A, Assadian O, Senekowitsch C, Rotter R, Bahrami S, Fürst W, Jaksch W, Hagmüller GW, Hübl W. Plasma D-lactate as a potential early marker for colon ischaemia after open aortic reconstruction. Eur J Vasc Endovasc Surg 2006; 31:470-4.

11. Houe T, Thorböll JE, Sigild U, Liisberg-Larsen O, Schroeder TV. Can colonoscopy diagnose transmural ischaemic colitis after abdominal aortic surgery? An evidence-based approach. Eur J Vasc Endovasc Surg 2000; 19:304-7.

12. Lieberman JM, Sacchettini J, Marks C, Marks WH. Human intestinal fatty acid binding protein: report of an assay with studies in normal volunteers and intestinal ischemia. Surgery 1997; 121:335-42.

13. Derikx JP, Matthijsen RA, de Bruïne AP, van Bijnen AA, Heineman E, van Dam RM, Dejong CH, Buurman WA. Rapid reversal of human intestinal ischemia-reperfusion induced damage by shedding of injured enterocytes and reepithelialisation. PLoS ONE 2008; 3:e3428.

14. Evennett NJ, Petrov MS, Mittal A, Windsor JA. Systematic review and pooled estimates for the diagnostic accuracy of serological markers for intestinal ischemia. World J Surg 2009; 33:1374-83.

15. Thuijls G, van Wijck K, Grootjans J, Derikx JP, van Bijnen AA, Heineman E, Dejong CH, Buurman WA, Poeze M. Early diagnosis of intestinal ischemia using urinary and plasma Fatty Acid binding proteins. Ann Surg 2011; 253:303-8.

16. Crawford ES. Thoraco-abdominal and abdominal aortic aneurysms involving renal, superior mesenteric, celiac arteries. Ann Surg 1974; 179:763-72.

17. Mehta RL, Kellum JA, Shah SV, Molitoris BA, Ronco C, Warnock DG, Levin A; Acute Kidney Injury Network. Acute Kidney Injury Network: report of an initiative to improve outcomes in acute kidney injury. Crit Care 2007; 11:R31.

18. Jacobs MJ, Mommertz G, Koeppel TA, Langer S, Nijenhuis RJ, Mess WH, Schurink GW. Surgical repair of thoracoabdominal aortic aneurysms. J Cardiovasc Surg (Torino) 2007; 48:49-58.

19. Woo K, Major K, Kohanzadeh S, Allins AD. Laparotomy for visceral ischemia and gangrene. Am Surg 2007; 73:1006-8.

20. Bossuyt PM, Reitsma JB, Bruns DE, Gatsonis CA, Glasziou PP, Irwig LM, Moher D, Rennie D, de Vet HC, Lijmer JG; Standards for Reporting of Diagnostic Accuracy. The STARD statement for reporting studies of diagnostic accuracy: explanation and elaboration. Clin Chem 2003; 49:7-18.

21. Block T, Nilsson TK, Bjorck M, Acosta S. Diagnostic accuracy of plasma biomarkers for intestinal ischaemia. Scand J Clin Lab Invest 2008; 68:242-8. 
22. Acosta S, Nilsson TK, Malina J, Malina M. L-lactate after embolization of the superior mesenteric artery. J Surg Res 2007; 143:320-8.

23. Swank GM, Deitch EA. Role of the gut in multiple organ failure: bacterial translocation and permeability changes. World J Surg 1996; 20:411-7.

24. Hanssen SJ, Derikx JP, Vermeulen Windsant IC, Heijmans JH, Koeppel TA, Schurink GW, Buurman WA, Jacobs MJ. Visceral injury and systemic inflammation in patients undergoing extracorporeal circulation during aortic surgery. Ann Surg 2008; 248:117-25.

25. Riddington DW, Venkatesh B, Boivin CM, Bonser RS, Elliott TS, Marshall T, Mountford PJ, Bion JF. Intestinal permeability, gastric intramucosal $\mathrm{pH}$, and systemic endotoxemia in patients undergoing cardiopulmonary bypass. JAMA 1996; 275:1007-12.

26. Derikx JP, van Waardenburg DA, Thuijls $G$, Willigers $H M$, Koenraads $M$, van Bijnen AA, Heineman E, Poeze M, Ambergen T, van Ooij A, van Rhijn LW, Buurman WA. New Insight in Loss of Gut Barrier during Major Non-Abdominal Surgery. PLoS One 2008; 3:e3954.

27. Dadian N, Ohki T, Veith FJ, Edelman M, Mehta M, Lipsitz EC, Suggs WD, Wain RA. Overt colon ischemia after endovascular aneurysm repair: the importance of microembolization as an etiology. J Vasc Surg 2001; 34:986-96.

28. Nakatsuka M. Assessment of gut mucosal perfusion and colonic tissue blood flow during abdominal aortic surgery with gastric tonometry and laser Doppler flowmetry. Vasc Endovascular Surg 2002; 36:193-8.

29. Vercaemst L. Hemolysis in cardiac surgery patients undergoing cardiopulmonary bypass: a review in search of a treatment algorithm. J Extra Corpor Technol 2008; 40:257-67.

30. Vermeulen Windsant IC, Snoeijs MG, Hanssen SJ, Altintas S, Heijmans JH, Koeppel TA, Schurink GW, Buurman WA, Jacobs MJ. Hemolysis is associated with acute kidney injury during major aortic surgery. Kidney Int 2010; 77:913-20.

31. Idu MM, Heintjes RJ, Scholten EW, Balm R, de Mol BA, Legemate DA. Visceral and renal tissue oxygenation during supraceliac aortic crossclamping and left heart bypass with selective organ perfusion. Eur J Vasc Endovasc Surg 2004; 27:138-44.

32. Kosir R, Moore FA, Selby JH, Cocanour CS, Kozar RA, Gonzalez EA, Todd SR. Acute lower extremity compartment syndrome (ALECS) screening protocol in critically ill trauma patients. J Trauma 2007; 63:268-75.

33. Woodman G, Croce MA, Fabian TC. Iliac artery ischemic: analysis of risks for ischemic complications. Am Surg 1998; 64:833-7.

34. Bashar AH, Suzuki K, Kazui T, Okada MY, Suzuki T, Washiyama N, Terada H, Yamashita K. Changes in cerebrospinal fluid and blood lactate concentrations after stent-graft implantation at critical aortic segment: a preliminary study. Interact Cardiovasc Thorac Surg 2008; 7:262-6.

35. Fall PJ, Szerlip HM. Lactic acidosis: from sour milk to septic shock. J Intensive Care Med 2005; 20:25571.

36. Meng $\mathrm{X}$, Liu L, Jiang $\mathrm{H}$. Indications and procedures for second-look surgery in acute mesenteric ischemia. Surg Today 2010; 40:700-5.

37. Mitchell KM, Valentine RJ. Inferior mesenteric artery reimplantation does not guarantee colon viability in aortic surgery. J Am Coll Surg 2002; 194:151-5.

38. Kozuch PL, Brandt LJ. Review article: diagnosis and management of mesenteric ischaemia with an emphasis on pharmacotherapy. Aliment Pharmacol Ther 2005; 21:201-15.

39. Bassiouny HS. Nonocclusive mesenteric ischemia. Surg Clin North Am 1997; 77:319-26.

40. de Aguilar-Nascimento JE, Dock-Nascimento DB, Bragagnolo R. Role of enteral nutrition and pharmaconutrients in conditions of splanchnic hypoperfusion. Nutrition 2010; 26:354-8.

41. Eltarawy IG, Etman YM, Zenati M, Simmons RL, Rosengart MR. Acute mesenteric ischemia: the importance of early surgical consultation. Am Surg 2009; 75:212-9. 

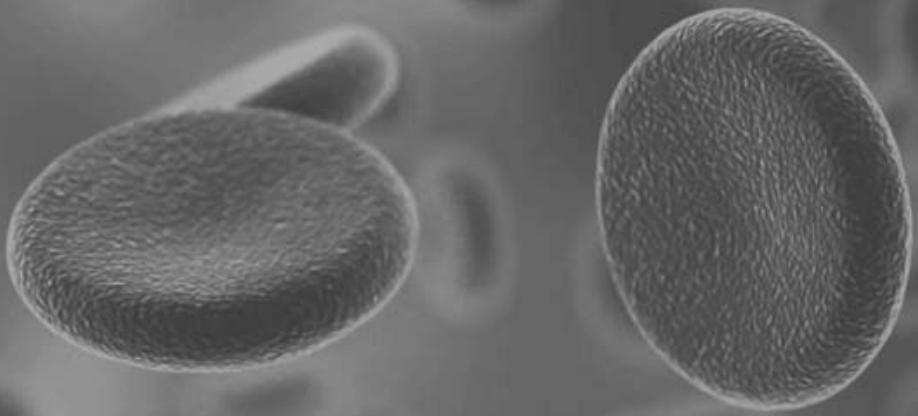


\section{Visceral injury and systemic inflammation in patients undergoing extracorporeal circulation during aortic surgery}

Sebastiaan J Hanssen, Joep P Derikx, Iris C Vermeulen Windsant, John H Heijmans, Thomas A Koeppel, Geert W Schurink, Wim A Buurman, Michael J Jacobs 


\section{ABSTRACT}

\section{Objectives}

Visceral injury and inflammation are evaluated in patients undergoing extracorporeal circulation (ECC) either with distal aortic perfusion (DAP) during thoracic aortic aneurysm (TAA) repair or DAP and selective organ perfusion (DAP \& SP) during thoracoabdominal aortic aneurysm (TAAA) repair.

\section{Summary background data}

Visceral hypoperfusion and subsequent visceral injury, mainly to the gut, have been implicated as central events in the development of systemic inflammatory response syndrome (SIRS) and organ dysfunction after major surgery. Patients undergoing DAP or DAP \& SP are exposed to artificial visceral perfusion, potentially leading to the development of intestinal injury and systemic inflammation.

\section{Methods}

To assess visceral injury arteriovenous differences of Fatty Acid Binding Proteins were measured for the gut (IFABP and LFABP) and left kidney (LFABP) along with systemic plasma concentrations. Systemic ALT was used as liver injury marker. Plasma IL-6 and IL-8 denoted systemic inflammation.

\section{Results}

During ECC systemic IFABP and LFABP levels increased in both groups, representing intestinal injury. Significantly elevated levels of IFABP $(p<0.001)$ and LFABP $(p<0.001)$ were found in the DAP \& SP group, after ECC was stopped and normal circulation restored. Liver and renal tubular cell injury was not detected. Significant increases in systemic IL- 6 and IL-8 values were measured only in patients undergoing DAP \& SP. Additionally, the extent of intestinal injury correlated positively with systemic inflammation.

\section{Conclusions}

This study shows the development of intestinal mucosal injury during ECC with DAP or DAP \& SP, indicative of insufficient intestinal perfusion. Intestinal injury was associated with a systemic pro-inflammatory response. 


\section{INTRODUCTION}

Open surgical repair of thoracic aortic aneurysms (TAA) and thoracoabdominal aortic aneurysms (TAAA) are extensive, complex procedures that are associated with significant post-operative morbidity and mortality. Post-operative complications include respiratory failure, renal and liver dysfunction, spinal cord injury, and gastrointestinal complications. ${ }^{1-3}$

Experimental studies of major surgery and trauma suggest that intestinal injury and hypoperfusion of visceral organs lead to initiation of a systemic pro-inflammatory response. ${ }^{4,5}$ Therefore, visceral protection during aortic surgery is warranted. ${ }^{6,7}$

The extracorporeal circulation (ECC) technique has been implemented in open TAA repair to provide (retrograde) distal aortic perfusion (DAP) via the femoral artery. In case of TAAA repair involving the origin of visceral arteries, ECC with DAP is combined with selective organ perfusion catheters (DAP \& SP) to provide designated visceral arteries directly with blood. ${ }^{8,9}$ The rationale behind DAP and DAP \& SP is to reduce ischemic injury of visceral organs, in particular the highly susceptible intestinal mucosa. ${ }^{10}$

The advantages of visceral protection notwithstanding, ECC during cardiac surgery provides antegrade aortic perfusion of visceral organs and is still associated with loss of intestinal barrier function seen as endotoxin translocation, indicating intestinal mucosal injury. ${ }^{11-13}$ The development of intestinal organ injury during antegrade aortic perfusion is strongly associated with gastrointestinal complications and mortality. ${ }^{14,15}$ Moreover, recent publications suggest ECC with antegrade aortic flow to result in a poorly understood state of 'functional' hypoperfusion of visceral organs, which is related to visceral injury and the induction of SIRS. ${ }^{14,16,17}$

The quantification of (subclinical) visceral injury during open TAA / TAAA repair could provide valuable information on the perfusion adequacy of ECC with either DAP or DAP \& SP. Therefore, in this study we measured intestinal and renal release of fatty acid binding proteins, small cytosolic proteins that leak from injured cells into the circulation, and systemic plasma alanine aminotransferase (ALT) to evaluate liver injury. The pro-inflammatory cytokines interleukin (IL)-6 and IL-8 were measured to assess systemic inflammation. The aim of the present study was to investigate the development of visceral injury in patients undergoing either DAP or DAP \& SP, and to evaluate the relation of visceral injury to the systemic inflammatory response in these patients. 


\section{METHODS}

\section{Patient population}

Patients that underwent elective open TAA or TAAA repair between January 2006 and April 2007 at the University Hospital Maastricht or the University Hospital Aachen were included in the study. The study was approved by the local Institutional Review Board of both institutes, and written informed consent was obtained from every patient. Pre-operative clinical data were prospectively collected from the patient's medical record. Crawford's classification was used to specify TAAA type. ${ }^{18}$

\section{Surgical procedure}

In all patients the same anesthetic protocol was used. The following anesthetic and surgical procedure has been described previously in detail. ${ }^{9,19}$ Collapse of the left lung in all patients except type IV TAAA was enabled by either a double-lumen endotracheal tube or a selective left main bronchial blocker. Induction of anesthesia was achieved with etomidate and sufentanil, and maintained with sufentanil and ketamine. All patients were placed in a left helical position, and thoracotomy or thoracolaparotomy through the sixth intercostal space (eighth intercostal in patients with TAAA type IV aneurysms) was performed.

After heparinization, $(0.5 \mathrm{mg} / \mathrm{kg})$, for all patients ECC with DAP was established after cannulation of the left pulmonary vein and the femoral artery, connected to a centrifugal pump. Alternatively, the femoral vein was cannulated with a long cannula placed in the vena cava inferior close to the right atrium; in all cases an oxygenator was part of the ECC. For DAP \& SP, a 4-branched tubing system was connected to the ECC and 4 catheters with inflatable tips and flow probes were used for selective perfusion of the celiac axis, the superior mesenteric artery and both renal arteries.

Typically, the aortic reconstruction was done from proximal to distal. During proximal cross-clamping, transsection of the aorta, and completion of the proximal anastomosis, DAP was maintained at a mean pressure of $60 \mathrm{mmHg}$ or higher. After abdominal aortotomy, all four selective perfusion catheters were installed in patients undergoing TAAA repair. In ten patients $(N=10)$ we evaluated directly after insertion the mean blood flow through each individual SP catheter (Table 3.1). In general, the celiac axis, superior mesenteric artery and the right renal artery were anastomosed simultaneously as an island in the aortic graft. Just before finishing the anastomosis, the perfusion catheters were removed, indicating that ischemic time is limited to the timeframes of insertion and removal of the catheters. In most cases, the left renal artery was treated with a selective graft using selective perfusion during end-to-end anastomosis. After completion of the anastomosis, the tip of the catheter was 
withdrawn into the graft, and perfusion continued, until implantation into the aortic tube graft was accomplished.

Table 3.1 Characteristics of patients undergoing open TAA / TAAA repair

\begin{tabular}{|c|c|c|c|}
\hline & $\begin{array}{l}\text { ECC with DAP } \\
(\mathrm{N}=8)\end{array}$ & $\begin{array}{c}\text { ECC with DAP \& SP } \\
(\mathrm{N}=22)\end{array}$ & P-value \\
\hline Total procedures (N) & 8 & 22 & \\
\hline TAA & 8 & - & \\
\hline TAAA $^{*}$ & - & 22 & \\
\hline TAAA II & - & 3 & \\
\hline TAAA III & - & 9 & \\
\hline TAAA IV & - & 10 & \\
\hline Male $(\mathrm{N})$ & 4 & 11 & 1.000 \\
\hline Dissection & 4 & 2 & 0.033 \\
\hline Mean age (yr) & $60.0(3.4)$ & $63.5(2.7)$ & 0.483 \\
\hline $\mathrm{BMI}^{* *}\left(\mathrm{~kg} / \mathrm{m}^{2}\right)$ & $26.9(1.2)$ & $23.9(0.8)$ & 0.058 \\
\hline Diabetes & - & 2 & 1.000 \\
\hline Hypertension & 5 & 17 & 0.643 \\
\hline Smoked & 4 & 19 & 0.395 \\
\hline Hypercholesterolemia & 1 & 11 & 0.099 \\
\hline Chronic renal failure & - & 2 & 1.000 \\
\hline $\mathrm{CAD}^{\wedge}$ & 1 & 2 & 1.000 \\
\hline $\mathrm{COPD}^{\wedge \wedge}$ & - & 5 & 0.280 \\
\hline $\mathrm{ACC}^{\#}$ time (min) & $86(9)$ & $86(7)$ & 0.986 \\
\hline ECC time (min) & $131(36)$ & $142(9)$ & 0.677 \\
\hline \multicolumn{4}{|l|}{ Flow SP catheter ${ }^{\dagger}(\mathrm{mL} / \mathrm{min})$} \\
\hline Celiac axis & - & $202.0(33.2)$ & \\
\hline Superior mesenteric artery & - & $311.6(30.4)$ & \\
\hline Left renal artery & - & $212.6(33.3)$ & \\
\hline Right renal artery & - & $186.4(27.7)$ & \\
\hline Total operation time (min) & $326(17)$ & 399 (15) & 0.015 \\
\hline
\end{tabular}

* Classification according to Crawford..$^{18 *} \mathrm{BMI}$, body mass index; ${ }^{*}$ CAD, coronary artery disease; COPD, chronic obstructive pulmonary disease. ${ }^{*} \mathrm{ACC}$, aorta cross clamp; Continues variables are expressed as mean (SEM). ${ }^{\dagger}$ Flow in SP catheter was measured in ten $(\mathrm{N}=10)$ patients undergoing ECC with DAP \& SP.

\section{Blood sampling}

Peripheral arterial blood was drawn at set time-points (Figure 3.1) from the radial artery pre-operatively (Pre-op), while creating access to the aorta, but before clamping the aorta and ECC was initiated (Cannulation), during ECC just before ending DAP or DAP \& SP (ECC), 15 minutes after the proximal aortic cross clamp was removed and reperfusion ( $R$ ) initiated ( $15 \mathrm{~min} R$ ), at 2 hours, 6 hours and 10 hours in the reperfusion phase ( $2 \mathrm{hrs} \mathrm{R}, 6 \mathrm{hrs} R$ and $10 \mathrm{hrs}$ R), as well as at day 1 and 2 postoperatively (Day 1 and Day 2). Whole blood was collected in EDTA vacutainers (Becton Dickinson, Franklin 
Lakes, NJ) and immediately put on ice. Blood was centrifuged and plasma was stored in aliquots at $-20^{\circ} \mathrm{C}$ until further analysis.

To enable venous blood sampling from the intestines and left kidney in eight patients $(\mathrm{N}=8)$ undergoing DAP \& SP, a $16 \mathrm{G}$ single lumen central venous catheter kit was used to cannulate the portal vein (Terumo Corporation, Tokyo, Japan), and a $18 \mathrm{G}$ intravenous catheter (Venflon, Becton Dickinson, Franklin Lakes, NJ) was used to cannulate the left renal vein prior to starting ECC. This enabled us to sample specific arterial and venous blood from the gut and the left kidney in order to calculate organ release and consumption of plasma proteins. Blood was taken from these cannulas before ECC, during ECC with DAP \& SP when a sample was taken from the arterial line of the ECC as well, and at 15 minutes reperfusion (Figure 3.1).

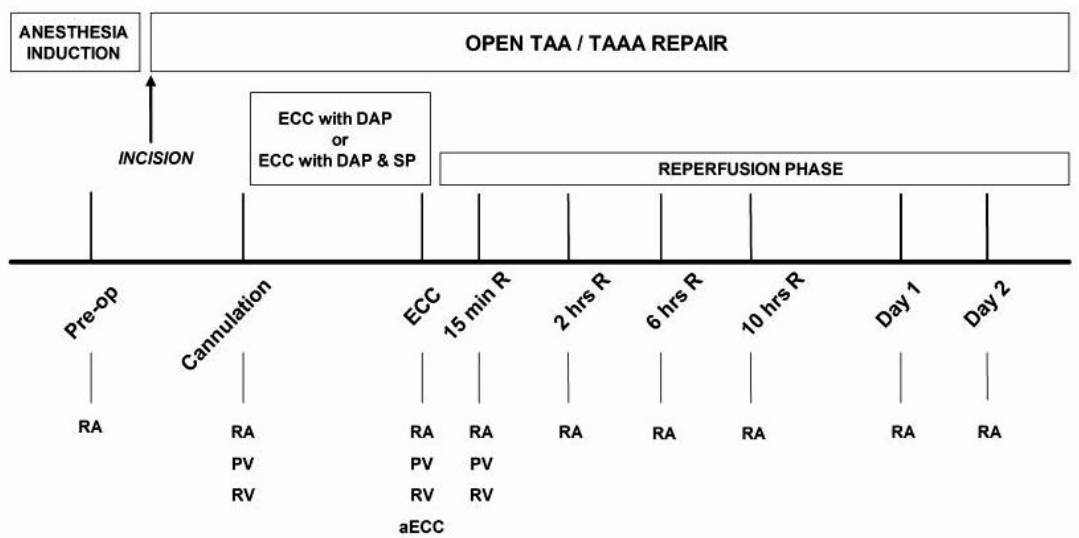

Figure 3.1 Timeline of blood sampling. At given time-points blood was drawn from the radial artery line and arterial line of the extracorporeal circulation (ECC). Patients undergoing open TAA repair received ECC with distal aortic perfusion (DAP - group), while ECC with DAP and selective organ perfusion was used in patients undergoing open TAAA repair (DAP \& SP - group). In order to enable simultaneous arterial and venous organ blood sampling, in eight patients receiving ECC with DAP \& SP, a venous catheter was inserted in the portal vein, as well as the left renal vein. This allowed specific calculation of arteriovenous concentration differences for the gut as well as the left kidney. Abbreviations: TAA, Thoracic Aortic Aneurysm; TAAA, Thoracoabdominal Aortic Aneurysm; ECC, extracorporeal circulation; DAP, distal aortic perfusion; SP, selective organ perfusion R, Reperfusion; RA, radial artery; PV, portal vein; RV, renal vein; $\mathrm{aECC}$, arterial line of ECC.

\section{Measurements}

\section{Visceral organ injury}

Fatty acid binding proteins (FABP) are small cytosolic proteins (15 kDa) that are abundantly expressed in visceral tissue and can be used as sensitive plasma markers to detect early cellular injury. ${ }^{20-22}$ Two types of FABP, intestinal-type FABP (IFABP) and 
liver-type (LFABP), are expressed at the tips of the villi of intestinal mucosal epithelial cells. IFABP is only present in intestinal mucosal cells; in contrast, LFABP is also expressed in hepatocytes, and to a lesser extent in renal tubular cells, and increased plasma levels could therefore represent hepatocyte or renal tubular cell injury as well. ${ }^{23}$ In order to evaluate hepatocellular injury systemic common liver injury marker ALT was measured. Furthermore, to study renal tubular cell injury as cause of elevated circulating LFABP levels, the arteriovenous concentration difference for the left kidney ([arterial concentration] - [venous concentration] / [arterial concentration] x 100\%) of LFABP was calculated in eight patients $(N=8)$ undergoing DAP \& SP.

Plasma IFABP and LFABP levels were analyzed using Enzyme Linked Immuno Sorbent Assays (ELISA). These commercially available ELISA kits were kindly provided by Hycult biotechnology (Uden, the Netherlands) and were used according to manufacture guidelines. The detection limit was $41 \mathrm{pg} / \mathrm{ml}$ for IFABP and $102 \mathrm{pg} / \mathrm{ml}$ for LFABP.

\section{Systemic inflammatory response}

The plasma levels of the cytokines IL- 6 and IL- 8 were assayed to determine the systemic inflammatory response following TAA / TAAA repair. IL-6 and IL-8 are commonly used as general inflammatory markers, amongst others produced by stimulated monocytes and activated endothelium, and considered key players in the development of SIRS after major trauma and surgical stress. ${ }^{17,24,25}$

IL-6 and IL-8 ELISA techniques have been described elsewhere. ${ }^{26}$ Briefly, 96-well plates (Greiner Bio-One, Kremsmünster, Austria) were coated overnight $\left(4^{\circ} \mathrm{C}\right)$ with the appropriate antibodies. Monoclonal antibodies 5E1 and 3E3 were used as coating for IL-6 and IL-8, respectively. Free sites were blocked with $1 \%$ bovine serum albumin in PBS. Samples and standard dilution series were incubated for 2 hours. Human recombinant IL-6 and IL-8 were used for standard titration curves. Washing buffer contained $0.1 \%$ Tween-20. Biotinylated anti-human IL-6 and IL-8 were developed in our own laboratory and used as detection antibodies. Finally, 3,3', 5,5'-tetramethylbenzidine (TMB) was used as a substrate and the reaction was stopped by adding $1 \mathrm{M}$ $\mathrm{H}_{2} \mathrm{SO}_{4}$. Plasma samples were analyzed in the same run spectrophotometrically $(450 \mathrm{~nm})$ using an automated ELISA reader. The detection limits for the assays were $12.3 \mathrm{pg} / \mathrm{ml}$ (IL-6) and $46.0 \mathrm{pg} / \mathrm{ml}$ (IL-8).

\section{Statistical analysis}

All data are expressed as mean \pm standard error of the mean (SEM). KolmogorovSmirnov test was used to test for Gaussian distribution. Student's T-test for independent-samples and Chi-square test, followed by Fisher's exact test when needed, were used to test differences between pre-operative patient characteristics. Changes in parameters over time were tested using repeated measures ANOVA, 
followed by paired Student's T-tests versus Pre-op values with post-hoc Bonferroni correction, if significant differences were found. In the same way changes in arteriovenous concentrations differences of plasma proteins were tested, with values measured during cannulation as reference. To characterize the total amount of intestinal injury and systemic inflammation during the study period, area under the curve (AUC) for IFABP and LFABP, as well as IL-6 and IL-8 was calculated for each patient. To assess association between intestinal mucosal cell injury and inflammation Spearman correlation analysis between $A \cup C_{\mathrm{IFABP}}, A \cup C_{\mathrm{LFABP}}, A \cup \mathrm{C}_{\mathrm{IL}-6}$, and $A \cup \mathrm{C}_{\mathrm{IL}-8}$ was performed. Mann Whitney $U$ test was used to calculate differences in AUC for each parameter between both patient groups. Statistical calculations were made using SPSS 15.0 for Windows (SPSS, Inc., Chicago, IL), and GraphPad Prism software (GraphPad Software, Inc. San Diego, CA). A p-value $<0.05$ was considered to indicate statistical significance.

\section{RESULTS}

\section{Patient characteristics and intra-operative data}

Thirty consecutive patients that underwent TAA $(N=8)$ or TAAA $(N=22)$ repair were included in the study. Table $\mathbf{3 . 1}$ shows pre-operative clinical data of patients undergoing ECC with DAP (TAA patients) or DAP \& SP (TAAA patients). No significant differences in pre-existing co-morbidities were present in the two patient groups studied, except for the co-existence of an aortic dissection (DAP N $=4$ / 8 versus DAP \& SP N $=2 / 22, p=0.033$ ). Nevertheless, aortic dissection did not influence the surgical approach to repair the aneurysm.

Aorta cross-clamp time (ACC), total ECC time and total operation time were noted during all procedures. ACC and total ECC time did not differ significantly between both groups. However, a significant difference in total operation time was found, reflecting the operative complexity of patients undergoing TAAA repair (DAP 326 (17) minutes, and DAP \& SP 399 (15) minutes, $p=0.015$ ).

\section{Extracorporeal circulation and intestinal mucosal injury}

Pre-operative IFABP levels (DAP 326.8 (84.8) pg/ml, and DAP \& SP 411.7 (82.4) pg/ml, Figure 3.2A) were comparable to the values measured in a healthy population, ${ }^{27}$ demonstrating the absence of intestinal mucosal cell injury. Manipulation of visceral organs to create access to the aorta, did not lead to elevated circulating IFABP levels. In contrast, during ECC IFABP levels increased in both groups representing the development of intestinal mucosal injury which was supported by statistically significant repeated measures ANOVA in both groups (DAP, $p<0.05$; DAP \& SP, 
$p<0.0001$, data not shown). Shortly after artificial circulation was terminated and normal circulation was restored, plasma IFABP levels increased further (DAP 763.9 (200.7) pg/ml, p > 0.05; DAP \& SP 2351.0 (378.1) pg/ml, p < 0.001) and remained elevated for six hours. The release of IFABP in patients undergoing DAP \& SP was clearly more pronounced than in patients undergoing DAP, indicating more intestinal injury in the DAP \& SP group. Total AUC of systemically measured IFABP was calculated for both groups and revealed significantly more IFABP release in the DAP \& SP patient group ( $p<0.05$, data not shown).

Intestinal mucosal cell injury leads next to IFABP release to LFABP release, although, plasma LFABP increase can also be caused by liver and renal tubular cell injury. LFABP plasma levels showed a similar pattern as I-FABP, potentially supporting intestinal injury (Figure 3.2B). The total calculated $A \cup C_{L F A B P}$ was significantly higher in patients undergoing DAP \& SP $(p<0.01$, data not shown).
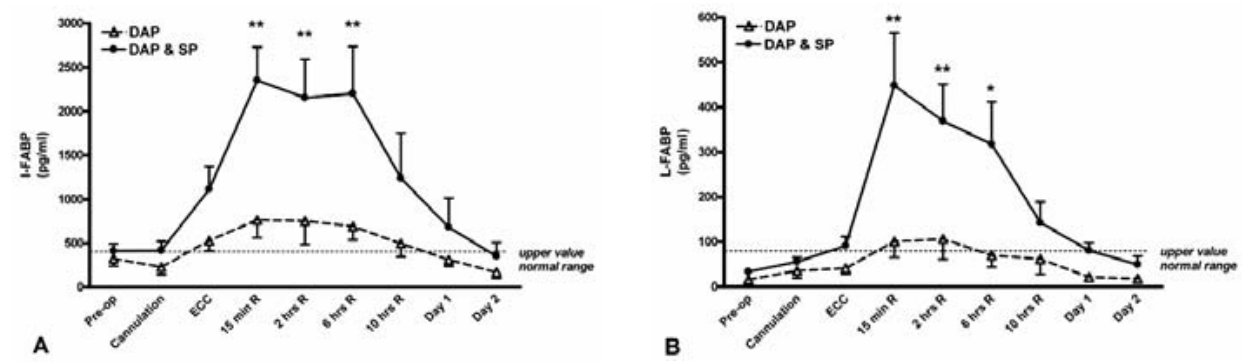

Figure 3.2 Elevated plasma IFABP and LFABP levels in patients undergoing DAP or DAP \& SP.

(A) Highest values for IFABP, reflecting intestinal injury, were found during reperfusion for both groups. (B) Systemic plasma LFABP values measured in both patient groups mimicked IFABP release, potentially representing intestinal injury. Values are presented as mean \pm SEM and are compared to pre-operative values. Data were analyzed using paired Student's T-tests with post-hoc Bonferroni correction. * $p<0.01 ; * * p<0.001$

Abbreviations: DAP, distal aortic perfusion; SP, selective perfusion; I-FABP, intestinal fatty acid binding protein; ECC, extracorporeal circulation; min, minutes; hrs, hours.

To ascertain the intestinal origin of the released IFABP and LFABP during and shortly after ECC, the arteriovenous concentration differences were measured in eight patients $(N=8)$ undergoing DAP \& SP (Figure 3.3A). In line with the systemic measurements, before starting ECC there was no fractional increase in IFABP indicating the absence of IFABP release (+ $0.3(1.8) \%)$. However, during ECC with DAP \& SP a significant release of IFABP was found $(+53.5(11.2) \%, p<0.001)$, which still occurred at 15 minutes after ECC had been stopped (+ 28.0 (3.3) \%, $p<0.05$ ). Similar to the IFABP release reported above, no detectable $L F A B P$ release from the gut was found before starting ECC with DAP \& SP (+ 1.9 (2.8) \%). During ECC with DAP \& SP, LFABP 
release from the intestinal mucosa increased significantly $(+103.0(17.5) \%, p<0.001)$ and release of LFABP, specifically indicating intestinal injury, was still statistically significant shortly after ECC perfusion was terminated and normal circulation was restored $(+51.5(13.9) \%, p<0.05)$.
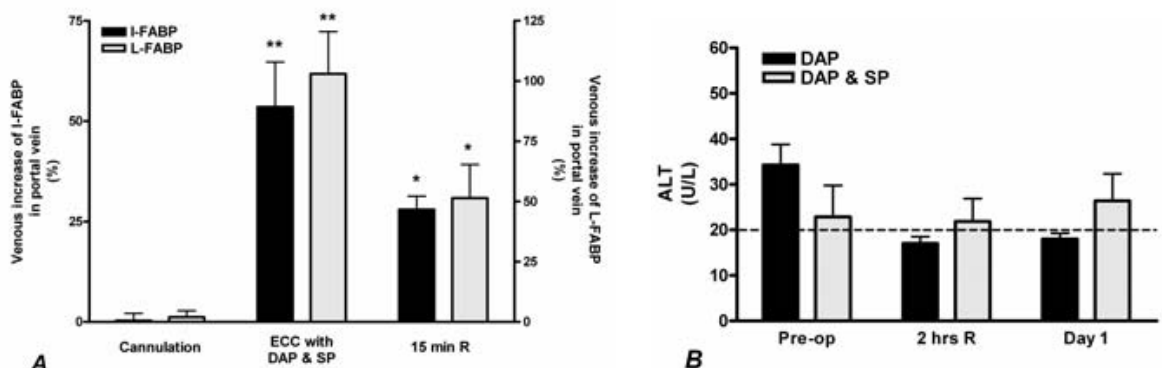

Figure 3.3 Intestinal IFABP and intestinal LFABP release was evaluated using arterio-venous concentration differences in eight patients undergoing ECC with DAP \& SP. Arterial blood from the radial artery (or the arterial line of the ECC) and the portal vein were simultaneously sampled and intestinal I-FABP and L-FABP release was calculated using the following formula: venous concentration minus arterial concentration divided by arterial concentration $\times 100 \%$. (A) Significant release of IFABP and LFABP from the gut was observed during ECC and directly in the reperfusion phase when normal visceral circulation was restored. (B) Circulating concentrations ALT, a specific liver enzyme was measured pre-operatively, at 2 hours reperfusion and at day 1 postoperatively. ALT levels showed no significant increase at the given time points, indicating no significant liver injury. Values are shown as mean \pm SEM and compared to pre-operative values (or values found during cannulation) using paired Student's T-tests with post-hoc Bonferroni correction. ${ }^{*} \mathrm{p}<0.05 ;{ }^{* *} \mathrm{p}<0.001$. Abbreviations: DAP, distal aortic perfusion; SP, selective perfusion; I-FABP, intestinal fatty acid binding protein; L-FABP, liver fatty acid binding protein; ALT, alanine transaminase; ECC, extracorporeal circulation; min, minutes; hrs, hours.

Since LFABP is next to the gut also expressed in liver and kidneys, we studied hepatocellular and renal tubular cell injury. To exclude liver injury, ALT was measured at three different time-points (Figure 3.3B); ALT, a cytosolic enzyme mainly expressed in the liver, was not elevated in the early reperfusion phase or at post-operative day 1. These data support the intestinal origin of LFABP release during open TAA / TAAA repair.

Potentially, renal tubular cell injury also results in elevated plasma LFABP concentrations. Therefore, to evaluate release from injured renal tubular cells, we measured arteriovenous concentration differences of LFABP for the left kidney from the same eight patients as reported above. The calculated mean arteriovenous concentration difference before going on ECC was - 21.5 (4.0)\%. During ECC with DAP \& SP (- $27.6(6.0) \%)$ and after ECC, when the patients were on normal visceral circulation again (- $22.8(4.4) \%)$, arteriovenous concentration differences were not 
significantly altered compared to values before ECC, indicating an absence of release from injured renal tubular cells (data not shown).

To analyze correlations between intestinal organ injury markers IFABP and LFABP, the total $A U C_{\text {IFABP }}$ and $A U C_{L F A B P}$, of all patients undergoing $E C C(N=30)$ were correlated (Figure 3.5). A strong positive correlation was found between $A U C_{\text {IFABP }}$ and $A U C_{L F A B P}$ $(r=0.70, p<0.0001)$.

Taken together, the circulating plasma levels of both I-FABP and L-FABP were elevated during ECC and a further increase was observed in the early phase of restored normal circulation in patients undergoing open TAA / TAAA repair. This indicates intestinal injury, with release of these proteins being more prominent when ECC with DAP \& SP was used.

\section{Systemic inflammatory response and extracorporeal circulation during TAA / TAAA repair}

Circulating pro-inflammatory cytokines IL-6 and IL-8 were measured in order to evaluate the inflammatory response associated with TAA / TAAA repair. Plasma concentrations of IL- 6 before ECC started were not significantly different from baseline values (Figure 3.4A). Although changes in plasma IL-6 levels were observed in both patient groups, the mean IL- 6 values measured in the DAP patients group were not statistically significantly altered during the studied period (ANOVA $p>0.05$, data not shown). During visceral perfusion using ECC combined with DAP \& SP plasma IL-6 levels increased significantly, indicating the development of a systemic inflammatory response (ANOVA $p<0.0001$, data not shown). Release of IL- 6 continued until peakvalues were reached 2 hours after reperfusion (DAP \& SP 295.7 (62.7) pg/ml, $\mathrm{p}<0.001$ ), whereas after 6 hours reperfusion and later plasma values lowered, but remained elevated until day 2 post-operative.

The pro-inflammatory cytokine IL-8, a strong neutrophil attractant, was detectable in pre-operatively taken blood samples from five out of twenty-two patients who underwent DAP \& SP (Figure 3.4B). Initially, plasma IL-8 curves mimicked IL-6 kinetics, starting to increase during the reperfusion phase in both groups. However, further increase in plasma IL-8 levels in patients who underwent ECC with DAP was relatively small (ANOVA $p>0.05$, data not shown), whereas increase in plasma IL-8 was significant in patients who underwent ECC with DAP \& SP (ANOVA $p<0.0001$, data not shown), with peak values found at 2 hours reperfusion $(227.4(43.5) \mathrm{pg} / \mathrm{ml}, \mathrm{p}<0.05)$, indicating a strong pro-inflammatory, chemotactic response in these patients. At postoperative day 2, plasma IL-8 had almost disappeared, being non-detectable in patients who underwent DAP, and only detectable in plasma from four out of twentytwo patients who underwent DAP \& SP. 

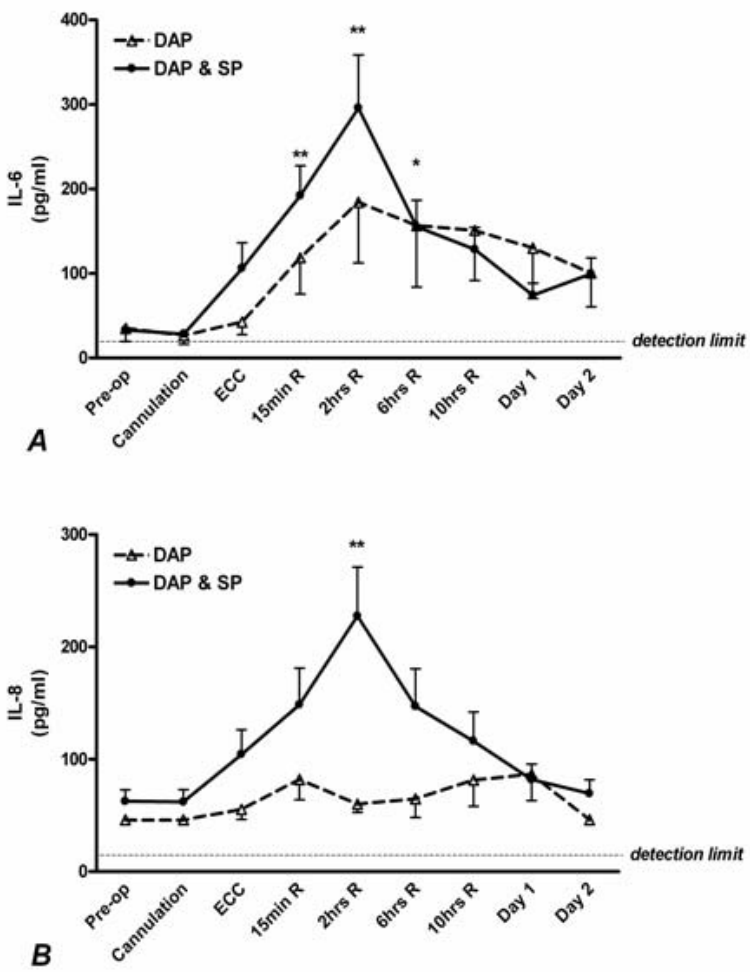

Figure 3.4 The systemic inflammatory response is initiated during ECC.

(A) Increased levels of the pro-inflammatory cytokine IL-6 are found in patients receiving DAP (TAA patients) or DAP \& SP (TAAA patients) during artificial visceral perfusion using ECC. Peak values were reached at 2 hours reperfusion ( $2 \mathrm{hrs} \mathrm{R}$ ). (B) Marked IL-8 release in patients receiving DAP \& SP. After initial release during ECC combined with DAP \& SP, peak plasma values for patients undergoing TAAA repair were found at 2 hours reperfusion ( $2 \mathrm{hrs} R$ ). Values are mean \pm SEM and compared to pre-operative values using paired Student's T-tests with post-hoc Bonferroni correction. $* p<0.05 ; * * p<0.001$. Abbreviations: DAP, distal aortic perfusion; SP, selective perfusion; I-FABP, intestinal fatty acid binding protein; L-FABP, liver fatty acid binding protein; ECC, extracorporeal circulation; min, minutes; hrs, hours.

The increase of IL- 6 and IL- 8 observed during TAA / TAAA repair, indicates the development of a systemic inflammatory response after DAP or DAP \& SP; IL-8 release was significant in patients undergoing DAP \& SP only, signifying a strong systemic neutrophil attractive response in this patient group. 


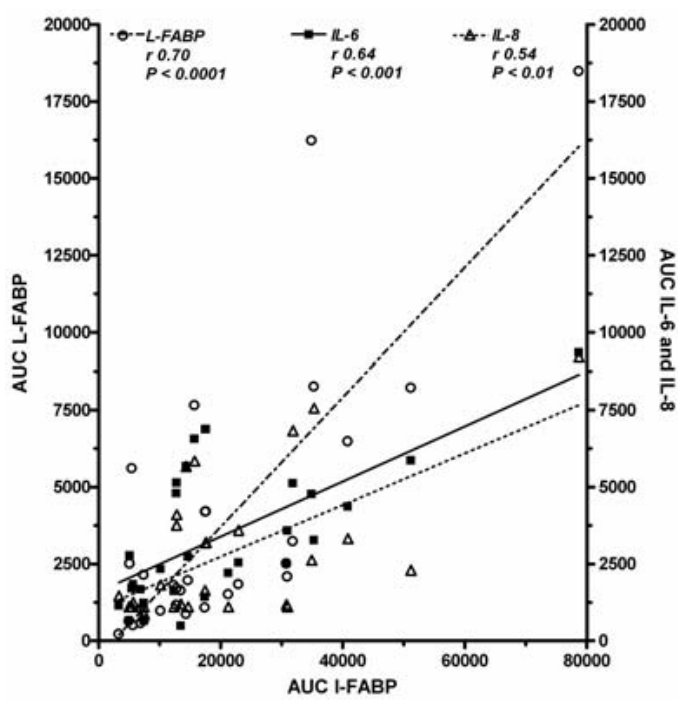

Figure 3.5 Association between intestinal mucosal cell injury and systemic inflammation in patients undergoing open TAA / TAAA repair. Patient's total AUCs of I-FABP, L-FABP, IL-6 and IL-8 were measured from pre-operative up until day 2 postoperative. Data are matched observations, and degree of correlation is represented by Spearman R. Visceral injury, denoted by AUC I-FABP, strongly correlated with $A \cup C_{\mathrm{L}-\mathrm{FABP}}, A \cup \mathrm{C}_{\mathrm{IL}-6}$, and $A \cup C_{\mathrm{IL}-8}$. These data suggest intestinal injury to play a significant role in systemic inflammation in patients undergoing open TAA / TAAA repair. Abbreviations: I-FABP, intestinal fatty acid binding protein; L-FABP, liver fatty acid binding protein; IL, interleukin; AUC, area under the curve; min, minutes; hrs, hours.

\section{Intestinal injury and systemic inflammation in patients undergoing extracorporeal circulation}

To investigate whether intestinal injury was related to the systemic inflammatory response, correlations of $A \cup C_{\mathrm{IFABP}}$ with $A \cup \mathrm{C}_{\mathrm{IL}-6}$ and $A \cup C_{\mathrm{IL}-8}$ (Figure 3.5) were analyzed in all patients undergoing ECC $(\mathrm{N}=30)$. $A \cup C_{\mathrm{IFABP}}$ correlated significantly with both $A \cup \mathrm{C}_{\mathrm{IL}-6}$ $\left(R_{s}=0.64, p<0.001\right)$ and $A \cup C_{\mid L-8}\left(R_{s}=0.54, p<0.01\right)$, indicating an association between the extent of intestinal organ injury and systemic inflammation, underlining the need for intestinal organ protection during TAA / TAAA repair.

\section{DISCUSSION}

In this study intestinal mucosal cell injury, but not hepatic or renal tubular cell injury, occurred in patients undergoing elective open TAA or TAAA repair, despite artificial visceral perfusion using ECC with either DAP (TAA patients) or ECC with DAP \& SP (TAAA patients). The extent of intestinal injury and pro-inflammatory reaction was 
more pronounced in patients undergoing DAP \& SP. Furthermore, intestinal injury correlated positively with markers of systemic inflammation.

Visceral perfusion by means of ECC is used to ensure volume and pressure controlled blood flow to abdominal organs, preventing the deleterious effects of intestinal injury. ${ }^{3}$ ECC with antegrade aortic perfusion is a well-known technique used in cardiac surgery and acknowledged to induce intestinal injury. ${ }^{11}$ Holmes et al. showed elevated urine IFABP levels following CABG surgery and suggested that intestinal mucosal injury plays a role in inducing a complicated post-operative course. ${ }^{14}$ The use of ECC with either DAP or DAP \& SP in patients undergoing open TAA / TAAA repair was first described in the 1980s, and these techniques have since been further refined. ${ }^{28,29}$ We described our first experiences with ECC and DAP or DAP \& SP in the mid-90s, and both were considered safe techniques to prevent postoperative renal injury, assessed by urine output and serum creatinine following TAA / TAAA repair, and possibly intestinal injury, by subjective observation of the intestines and intestinal motility peri- and postoperatively. $^{8,19}$

In the present study, the development of injury to visceral organs was investigated using measurements of plasma IFABP and LFABP for intestinal, ALT for hepatic, and LFABP for renal tubular injury. Our data show development of intestinal injury during artificial perfusion of the viscera using ECC, and shortly thereafter when normal perfusion to the viscera was restored. ECC with DAP caused elevated plasma levels of IFABP and LFABP, and ECC with DAP \& SP led to significantly elevated circulating IFABP and LFABP levels, despite the intended protective effect of artificial visceral perfusion in patients undergoing open TAA / TAAA repair. The arteriovenous concentration differences over the intestines demonstrate significant release of IFABP and LFABP in patients undergoing ECC with DAP \& SP. During reperfusion the systemic plasma concentration of both IFABP and LFABP initially further increased, suggesting either continued wash-out of these proteins from the injured gut mucosa or sustained hypoperfusion injury leading to continued enhanced release of both proteins. These data are in line with low flow states in patients with hypovolemic or cardiogenic shock and inherent blood flow redistribution towards the heart and central nervous system at the expense of visceral organs. The intestinal mucosal epithelial cells are due to the specific anatomy of the small intestinal villus more susceptible to visceral hypoperfusion than hepatocytes or renal epithelial cells. In particular the cells at the tip of the villus, which contain IFABP and LFABP, are due to the sympathetic innervation of the arterioles and vascular anatomy of the villus, most vulnerable to hypoperfusion. ${ }^{10,11}$

Total intestinal injury seen during ECC was assessed by $\mathrm{AUC}_{\mathrm{IFABP}}$, and correlated positively with the $A \cup C_{\mathrm{IL}-6}$ and $A \cup C_{\mathrm{IL}-8}$, suggesting an association between the extent of intestinal mucosal injury and the extent of systemic inflammation. Morariu et al. 
studied the alleged protective use of dexamethasone on the inflammatory response and intestinal injury after CABG surgery with the use of antegrade aortic perfusion. ${ }^{17}$ Even though the inflammatory response was attenuated by dexamethasone, no effect on intestinal injury markers was seen, hereby suggesting the inflammatory response to be a result and not so much a cause of intestinal injury.

Pharmacological approaches to reduce visceral hypoperfusion and its sequelae can be directed at either improvement of perfusion or reduction of ischemic injury. Increasing microcirculatory blood flow, especially in the intestines, by pharmacological intervention (e.g. ACE-inhibitors, ET-receptor antagonists or catecholamine therapy) has been shown beneficial in animal studies. ${ }^{30-32}$ Furthermore, also antioxidant therapy (e.g. nitroxide, ascorbic acid or mannitol) has been shown effective in reducing ischemic injury to the intestines in animals. ${ }^{33,34}$ Future studies are needed to evaluate such interventions in the human setting.

The differences in extent of intestinal injury that was observed between DAP during open TAA repair and DAP \& SP during open TAAA repair is not easily clarified. Aortic cross clamp times or total perfusion times were similar between the groups. The most likely explanation for the difference in intestinal injury is a more prominent hypoperfusion of the intestines during ECC with DAP \& SP. Idu et al. showed in a pig model a significant decrease in blood flow per minute to the cranial mesenteric artery when clamping the aorta and perfusion was taken over with ECC and selective organ perfusion. ${ }^{35}$ Also, Leijdekkers et al. calculated that the flow to visceral organs during ECC with DAP \& SP is limited and insufficient to maintain tissue perfusion due to the internal diameter in SP catheters used in patients undergoing open TAAA repair. ${ }^{36}$ The flow administered through the selective organ perfusion catheter system during aortic clamping may be too low in our patients, creating an absolute state of 'functional' hypoperfusion to the intestines. It is of interest, however, that during the reperfusion phase especially in the DAP \& SP group the intestinal injury further increases. This suggests that during ECC a process has been initiated that results in ongoing increased intestinal mucosal cell injury, potentially through a prolonged 'functional' hypoperfusion. The mechanisms leading to visceral hypoperfusion during and after ECC in patients undergoing open TAA / TAAA repair remain to be resolved. Such information will be instrumental in developing strategies to prevent the intestinal injury and subsequent systemic inflammatory response induced by ECC with DAP or DAP \& SP.

\section{Conclusion}

Increased plasma IFABP and LFABP levels, representative of intestinal injury, and elevated plasma IL-6 and IL-8 concentrations, indicative of systemic inflammation, were observed in patients undergoing open TAA / TAAA repair, despite ECC with either 
DAP or DAP \& SP. Our data show that intestinal injury precedes the development of a systemic inflammatory response and correlates positively with the extent of systemic inflammation, supporting the hypothesis that intestinal tissue injury is involved in the development and extent of a systemic inflammatory response. 


\section{REFERENCES}

1. Rectenwald JE, Huber TS, Martin TD, Ozaki CK, Devidas M, Welborn MB, Seeger JM. Functional outcome after thoracoabdominal aortic aneurysm repair. J Vasc Surg 2002; 35:640-7.

2. Gloviczki P. Surgical repair of thoracoabdominal aneurysms: patient selection, techniques and results. Cardiovasc Surg 2002; 10:434-41.

3. Achouh PE, Madsen K, Miller CC, 3rd, Estrera AL, Azizzadeh A, Dhareshwar J, Porat E, Safi HJ. Gastrointestinal complications after descending thoracic and thoracoabdominal aortic repairs: a 14year experience. J Vasc Surg 2006; 44:442-6.

4. Fink MP. Gastrointestinal mucosal injury in experimental models of shock, trauma, and sepsis. Crit Care Med 1991; 19:627-41.

5. Moore FA. The role of the gastrointestinal tract in postinjury multiple organ failure. Am J Surg 1999; 178:449-53.

6. MacArthur RG, Carter SA, Coselli JS, LeMaire SA. Organ protection during thoracoabdominal aortic surgery: rationale for a multimodality approach. Semin Cardiothorac Vasc Anesth 2005; 9:143-9.

7. Welborn MB, Oldenburg HS, Hess PJ, Huber TS, Martin TD, Rauwerda JA, Wesdorp RI, Espat NJ, Copeland EM 3rd, Moldawer LL, Seeger JM. The relationship between visceral ischemia, proinflammatory cytokines, and organ injury in patients undergoing thoracoabdominal aortic aneurysm repair. Crit Care Med 2000; 28:3191-7.

8. Jacobs MJ, de Mol BA, Legemate DA, Veldman DJ, de Haan P, Kalkman CJ. Retrograde aortic and selective organ perfusion during thoracoabdominal aortic aneurysm repair. Eur J Vasc Endovasc Surg 1997; 14:360-6.

9. Jacobs MJ, Mommertz G, Koeppel TA, Langer S, Nijenhuis RJ, Mess WH, Schurink GW. Surgical repair of thoracoabdominal aortic aneurysms. J Cardiovasc Surg (Torino) 2007; 48:49-58.

10. Takala J. Determinants of splanchnic blood flow. Br J Anaesth 1996; 77:50-8.

11. Ohri SK, Somasundaram S, Koak Y, Macpherson A, Keogh BE, Taylor KM, Menzies IS, Bjarnason I. The effect of intestinal hypoperfusion on intestinal absorption and permeability during cardiopulmonary bypass. Gastroenterology 1994; 106:318-23.

12. Riddington DW, Venkatesh B, Boivin CM, Bonser RS, Elliott TS, Marshall T, Mountford PJ, Bion JF. Intestinal permeability, gastric intramucosal $\mathrm{pH}$, and systemic endotoxemia in patients undergoing cardiopulmonary bypass. Jama 1996; 275:1007-12.

13. Rossi M, Sganga G, Mazzone M, Valenza V, Guarneri S, Portale G, Carbone L, Gatta L, Pioli C, Sanguinetti M, Montalto M, Glieca F, Fadda G, Schiavello R, Silveri NG. Cardiopulmonary bypass in man: role of the intestine in a self-limiting inflammatory response with demonstrable bacterial translocation. Ann Thorac Surg 2004; 77:612-8.

14. Holmes JHT, Lieberman JM, Probert CB, Marks WH, Hill ME, Paull DL, Guyton SW, Sacchettini J, Hall RA. Elevated intestinal fatty acid binding protein and gastrointestinal complications following cardiopulmonary bypass: a preliminary analysis. J Surg Res 2001; 100:192-6.

15. Bolcal C, lyem H, Sargin M, Mataraci I, Sahin MA, Temizkan V, Yildirim V, Demirkilic U, Tatar H. Gastrointestinal complications after cardiopulmonary bypass: Sixteen years of experience. Can J Gastroenterol 2005; 19:613-7.

16. Sato K, Sogawa M, Namura O, Hayashi J. Deterioration of body oxygen metabolism by vasodilator and/or vasoconstrictor administration during cardiopulmonary bypass. Asaio J 2006; 52:96-9.

17. Morariu AM, Loef BG, Aarts LP, Rietman GW, Rakhorst G, van Oeveren W, Epema AH. Dexamethasone: benefit and prejudice for patients undergoing on-pump coronary artery bypass grafting: a study on myocardial, pulmonary, renal, intestinal, and hepatic injury. Chest 2005; 128:2677-87.

18. Crawford ES. Thoraco-abdominal and abdominal aortic aneurysms involving renal, superior mesenteric, celiac arteries. Ann Surg 1974; 179:763-72.

19. Jacobs MJ, Eijsman L, Meylaerts SA, Balm R, Legemate DA, de Haan P, Kalkman CJ, de Mol BA. Reduced renal failure following thoracoabdominal aortic aneurysm repair by selective perfusion. Eur J Cardiothorac Surg 1998; 14:201-5.

20. Lieberman JM, Sacchettini J, Marks C, Marks WH. Human intestinal fatty acid binding protein: report of an assay with studies in normal volunteers and intestinal ischemia. Surgery 1997; 121:335-42. 
21. Niewold TA, Meinen M, van der Meulen J. Plasma intestinal fatty acid binding protein (I-FABP) concentrations increase following intestinal ischemia in pigs. Res Vet Sci 2004; 77:89-91.

22. Pelsers MM, Namiot Z, Kisielewski W, Namiot A, Januszkiewicz M, Hermens WT, Glatz JF. Intestinaltype and liver-type fatty acid-binding protein in the intestine. Tissue distribution and clinical utility. Clin Biochem 2003; 36:529-35.

23. Pelsers MM, Hermens WT, Glatz JF. Fatty acid-binding proteins as plasma markers of tissue injury. Clin Chim Acta 2005; 352:15-35.

24. Ytting H, Christensen IJ, Basse L, Lykke J, Thiel S, Jensenius JC, Nielsen HJ. Influence of major surgery on the mannan-binding lectin pathway of innate immunity. Clin Exp Immunol 2006; 144:239-46.

25. Fiane AE, Videm V, Lingaas PS, Heggelund L, Nielsen EW, Geiran OR, Fung M, Mollnes TE. Mechanism of complement activation and its role in the inflammatory response after thoracoabdominal aortic aneurysm repair. Circulation 2003; 108:849-56.

26. Dentener MA, Bazil V, Von Asmuth EJ, Ceska M, Buurman WA. Involvement of CD14 in lipopolysaccharide-induced tumor necrosis factor-alpha, IL-6 and IL-8 release by human monocytes and alveolar macrophages. J Immunol 1993; 150:2885-91.

27. Derikx JP, Poeze M, van Bijnen AA, Buurman WA, Heineman E. Evidence for intestinal and liver epithelial cell injury in the early phase of sepsis. Shock 2007; 28:544-8.

28. Laschinger JC, Cunningham JN, Jr., Nathan IM, Knopp EA, Cooper MM, Spencer FC. Experimental and clinical assessment of the adequacy of partial bypass in maintenance of spinal cord blood flow during operations on the thoracic aorta. Ann Thorac Surg 1983; 36:417-26.

29. Kazui T, Yamada O, Ito T, Kikuchi S, Komatsu S. Total graft replacement of the thoracoabdominal aorta with reconstruction of visceral branches, intercostal and lumbar arteries in expanding chronic dissecting aneurysms of the thoracoabdominal aorta. Nippon Kyobu Geka Gakkai Zasshi 1989; 37:1436-40.

30. Bailey RW, Bulkley GB, Hamilton SR, Hamilton SR, Morris JB, Smith GW. Pathogenesis of nonocclusive ischemic colitis. Ann Surg 1986; 203:590-9.

31. Krejci V, Hiltebrand LB, Erni D, Sigurdsson GH. Endothelin receptor antagonist bosentan improves microcirculatory blood flow in splanchnic organs in septic shock. Crit Care Med 2003; 31:203-10.

32. Sautner T, Wessely C, Riegler M, Sedivy R, Götzinger P, Losert U, Roth E, Jakesz R, Függer R. Early effects of catecholamine therapy on mucosal integrity, intestinal blood flow, and oxygen metabolism in porcine endotoxin shock. Ann Surg 1998; 228:239-48.

33. Gunel E, Caglayan F, Caglayan O, Dilsiz A, Duman S, Aktan M. Treatment of intestinal reperfusion injury using antioxidative agents. J Pediatr Surg 1998; 33:1536-9.

34. Udassin $R$, Haskel $Y$, Samuni A. Nitroxide radical attenuates ischaemia/reperfusion injury to the rat small intestine. Gut 1998; 42:623-7.

35. Idu MM, Heintjes RJ, Scholten EW, Balm R, de Mol BA, Legemate DA.. Visceral and renal tissue oxygenation during supraceliac aortic crossclamping and left heart bypass with selective organ perfusion. Eur J Vasc Endovasc Surg 2004; 27:138-44.

36. Leijdekkers VJ, Wirds JW, Vahl AC, van Genderingen HR, Siebenga J, Westerhof N, Tangelder GJ, Bulder $E R$, Rauwerda JA. The visceral perfusion system and distal bypass during thoracoabdominal aneurysm surgery: an alternative for physiological blood flow? Cardiovasc Surg 1999; 7:219-24. 

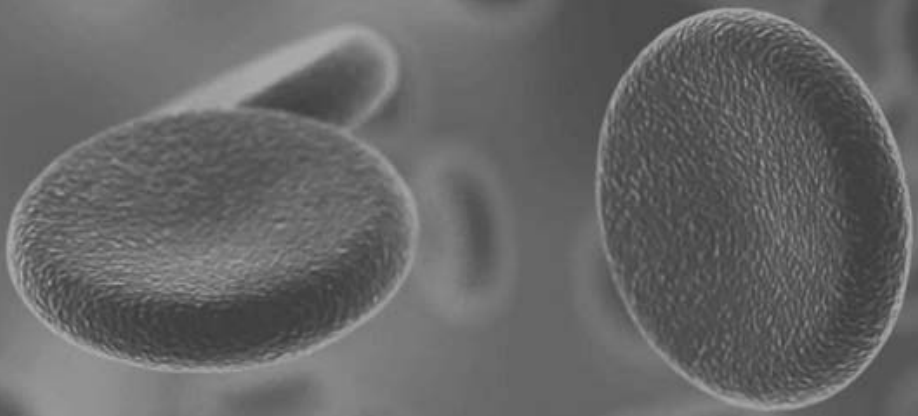


\section{Cardiovascular surgery and organ damage; time to reconsider the role of hemolysis}

Iris C Vermeulen Windsant*, Sebastiaan J Hanssen*,

Wim A Buurman, Michael J Jacobs

* These authors contributed equally to this review

Journal of Thoracic and Cardiovascular Surgery 2011;142:1-11 


\section{ABSTRACT}

Cardiovascular surgery with cardiopulmonary bypass is associated with postoperative organ injury which severely affects patient morbidity and mortality. Multiple cardiopulmonary bypass related mechanisms have been linked to the development of tissue damage including hypoperfusion, ischemia/reperfusion and induction of a pro-inflammatory response. Hemolysis, resulting in increased plasma free hemoglobin concentrations is considered an inevitable, but relatively harmless side-effect of cardiopulmonary bypass. Recently however, evidence is mounting that plasma free hemoglobin scavenges intravascular nitric oxide, thereby attenuating its bioavailability. A significant reduction in nitric oxide, the most important endogenous vasodilator, impairs tissue perfusion and induces organ injury development. Moreover, urinary free hemoglobin contributes to renal damage specifically by catalyzation of reactive oxygen species formation. In this review, the effects of increased free hemoglobin levels on nitric oxide metabolism are discussed. Additionally, we review the role of free hemoglobin in organ injury development, potential sources of free hemoglobin during cardiovascular surgery, as well as therapeutic options to attenuate the consequences of hemolysis. We propose that hemolysis is more than an innocent bystander effect of cardiopulmonary bypass assisted surgery. Therapeutic interventions attenuating the effects of hemolysis seem crucial in the reduction of postoperative morbidity and mortality after cardiovascular surgery. 


\section{INTRODUCTION}

Cardiovascular surgery with extracorporeal circulation is associated with considerable postoperative morbidity and mortality, especially in patients undergoing complex procedures like combined coronary artery bypass grafting (CABG) and valve surgery, Bentall procedures, and open repair of thoracic and thoracoabdominal aortic aneurysms. These patients are at high risk for developing major complications such as acute kidney injury, ${ }^{1-6}$ pulmonary dysfunction, ${ }^{7,8}$ sepsis, and multiple organ failure. ${ }^{9}$ The pathophysiology underlying these complications has been extensively studied in order to develop specific prevention and treatment strategies. The cardiopulmonary bypass (CPB) circuit has been associated with the development of tissue damage due to insufficient oxygen delivery through hemodilution, ${ }^{10}$ ischemia/reperfusion, ${ }^{11}$ and hypoperfusion. ${ }^{12,13}$ Cardiotomy suction during CPB has been shown to be a source of lipid microemboli forming small vascular occlusions in several tissues, including brain, kidney, spleen and muscle. ${ }^{14,15}$ Furthermore, the non-endothelial surface of the CPBsystem initiates a pro-inflammatory response which deteriorates cellular function, for instance the function of renal tubular cells. ${ }^{16,17}$ Indeed, the use of a minicardiopulmonary bypass system, reducing the pro-inflammatory contact surface area and hemodilution, attenuates the release of intestinal and renal tissue damage markers as compared to a normal CPB circuit in cardiac surgery patients. ${ }^{18}$ Similarly, the incidence of liver injury and kidney injury is significantly reduced in patients undergoing CABG without CPB (off-pump) in comparison with on-pump CABG. ${ }^{19,20}$ Nevertheless, although off-pump surgery has gained popularity world-wide, CPBassisted surgery is still widely used. To reduce CPB-related morbidity and mortality, successful efforts have been made to increase CPB biocompatibility and flow performance. Unfortunately, this has not led to a significantly decreased incidence of organ dysfunction after cardiovascular surgery. ${ }^{21}$ This underscores the need for further clarification of underlying pathophysiological mechanisms of tissue damage and dysfunction in this setting. ${ }^{21}$

A common consequence of CPB is hemolysis, considered an inevitable, but relatively harmless phenomenon. Hemolysis is principally caused by mechanical shear stress within the perfusion circuit and results in the release of hemoglobin into the circulation. ${ }^{22,23}$ The role of this cell-free plasma hemoglobin ( $\mathrm{fHb}$ ) in the development of organ injury has gained increasing interest since a direct relation between hemolysis, impaired vascular function, decreased organ perfusion, and organ dysfunction has been reproducibly shown in experimental animal models and in chronic hemolytic diseases in men. ${ }^{24,25}$ Most recently, Meyer et al. showed that $\mathrm{fHb}$ due to hemodialysis-induced hemolysis impaired vascular function in patients, indicating a role for $\mathrm{fHb}$ in the development of microcirculatory dysfunction during 
acute and transient hemolysis. ${ }^{26,27}$ Moreover, the results of Meyer et al. substantiate our recent findings that acute hemolysis during major aortic surgery was independently associated with proximal renal tubular damage and postoperative acute kidney injury. ${ }^{28}$ Therefore, we propose hemolysis to be an important, but generally unrecognized, contributor to the development of organ injury during surgical procedures associated with hemolysis, such as cardiovascular surgery.

The interfering role of $\mathrm{fHb}$ in intravascular nitric oxide (NO) metabolism is believed to play a critical role in the development of microcirculatory impairment, organ damage, and organ dysfunction. ${ }^{24}$ Therefore, in this review we will discuss a) the effects of $\mathrm{fHb}$ on intravascular nitric oxide bioavailability, b) the role of $\mathrm{fHb}$ in the induction of microcirculatory dysfunction and organ damage, c) the potential sources of $\mathrm{fHb}$ during cardiovascular surgery, and d) therapeutic options to attenuate the consequences of hemolysis during CPB-assisted surgery.

\section{INCREASED PLASMA FREE HEMOGLOBIN DUE TO HEMOLYSIS REDUCES INTRAVASCULAR NITRIC OXIDE BIOAVAILABILITY}

Upon intravascular destruction of red blood cells ( $\mathrm{RBC}$ ), fHb enters the circulation. $\mathrm{FHb}$ gets bound to either haptoglobin or is oxidized to methemoglobin. The hemoglobinhaptoglobin complex is rapidly cleared from the circulation through endocytosis by the surface scavenger receptor CD163 expressed on monocytes and tissue macrophages. This way, haptoglobin prevents accumulation of plasma $\mathrm{fHb}$ under physiological circumstances. $^{29}$ This effect was illustrated in patients undergoing cardiac surgery in whom intravenous administration of haptoglobin significantly reduced circulating $\mathrm{fHb}$ levels. ${ }^{30}$ Free heme, another by-product of hemolysis, is released during oxidation of free hemoglobin and is scavenged by circulating hemopexin. Subsequently, hemeoxygenase (HO)-1, activated due to reduced microcirculation, degrades heme to carbon monoxide, biliverdin, and iron mainly in the liver and spleen. ${ }^{31}$ This cytoprotective induction of $\mathrm{HO}-1$ by the microvasculature has been shown to modulate inflammation in patients after cardiac surgery with CPB, which may benefit patient recovery postoperatively; ${ }^{32}$ furthermore, the induction of $\mathrm{HO}-1$ inhibits vascular inflammation and vaso-occlusion in transgenic sickle mice. ${ }^{32,33}$ Since both haptoglobin and hemopexin are not recycled after clearance of hemoglobin-haptoglobin or hemehemopexin complexes, excessive RBC lysis rapidly exhausts their storage pools. This results in enhanced levels of $\mathrm{fHb}$ and free heme, both harmful products. First of all, free heme is able to react with endogenous hydrogen peroxide, thereby forming toxic free radicals which are involved in the induction of pro-oxidant damage. ${ }^{34}$ Secondly, oxygenated $\mathrm{fHb}$ has been shown to be a potent scavenger of $\mathrm{NO}$, the most important endogenous vasodilator. The fast $\left(6-8 \times 10^{7} \mathrm{~mol} / \mathrm{l} / \mathrm{s}\right)$ and irreversible reaction of 
oxygenated $\mathrm{fHb}$ with $\mathrm{NO}$ results in conversion of $\mathrm{fHb}$ to methemoglobin, and conversion of $\mathrm{NO}$ to nitrate. Circulating $\mathrm{fHb}$ is also present in a deoxygenated form. Such deoxygenated $\mathrm{fHb}$ also scavenges $\mathrm{NO}$, forming nitrosyl- $\mathrm{Hb}$, but this reaction is slower $\left(10^{7} \mathrm{~mol} / \mathrm{l} / \mathrm{s}\right)$ and reversible. ${ }^{24,29}$ As a result, hemolysis significantly impairs NObioavailability, potentially inducing microcirculatory dysfunction. ${ }^{35,36}$ In vivo, fHb associated NO-scavenging was correlated to systemic vasoconstriction and a reduction in renal function in a canine hemolysis model. ${ }^{25}$ In patients with chronic high $\mathrm{fHb}$ levels due to sickle cell disease, forearm blood flow responses were reduced by $80 \%$ after infusion of the nitric oxide donor sodium nitroprusside, compared to patients with below average $\mathrm{fHb}$ levels. ${ }^{24}$ Thirdly, hemolysis also results in release of arginase- 1 , an enzyme that converts L-arginine, the substrate for NO synthesis, to ornithine. ${ }^{37}$ This way, hemolysis causes not only scavenging of NO, but also, theoretically, prevents new NO formation. In practice, however, we showed that arginase-1 release during surgery with CPB does not affect the arginine-ornithine ratio (unpublished data). This implies that arginase levels during this type of surgery are not high enough to affect arginine levels and attenuate NO-synthesis. ${ }^{38}$

\section{CELL FREE HEMOGLOBIN CONTRIBUTES TO MICROCIRCULATORY DYSFUNCTION THROUGH NO-SCAVENGING, POTENTIALLY INDUCING HYPOXIC TISSUE DAMAGE}

The role of hemolysis in organ damage development was already described in the mid nineteen seventies. ${ }^{24,39}$ These studies focused on acute kidney injury, since glomerularly filtered urinary $\mathrm{fHb}$, instead of plasma $\mathrm{fHb}$, was considered the culprit of organ injury induction. Therefore, at that time, only the kidney was believed to be at risk for $\mathrm{fHb}$ induced damage. Two mechanisms were proposed to underlie the association between hemolysis and renal tissue damage development. First, urine $\mathrm{fHb}$ derived free iron and heme catalyze the generation of reactive oxygen species which damage the renal tubular epithelium. ${ }^{40}$ Indeed, administration of the iron scavenger deferoxamine attenuated glomerular and tubular dysfunction induced by intravenous $\mathrm{fHb}$ administration in rats. ${ }^{41}$ Similarly, a reduced intravascular iron scavenging capacity - reflected by low plasma ferritin concentrations - was associated with acute kidney injury after human cardiovascular surgery. ${ }^{42}$ Second, intra-tubular $\mathrm{fHb}$ precipitation and heme cast formation in the acidic ultrafiltrate was considered to obstruct the tubular lumen, reducing glomerular filtration. ${ }^{40,43}$ Subsequent prevention of cast formation by urine alkalanization reduced tubular injury and glomerular dysfunction after intravenous $\mathrm{fHb}$ infusion in rats. ${ }^{40}$

The discovery of NO-scavenging property of circulating plasma fHb by the group of Gladwin provided a complementary explanation for hemolysis-induced organ injury. ${ }^{24}$ 
For the first time, circulating $\mathrm{fHb}$ was recognized as a key player in the pathophysiology of complications in patients with chronic hemolytic disorders, such as sickle cell disease and malaria infection. ${ }^{24}$ Furthermore, the reported adverse effects associated with administration of hemoglobin based oxygen carriers - which basically consist of $\mathrm{fHb}$ - could be explained by intravascular NO-scavenging through $\mathrm{fHb}^{44}$ The negative effects of increased plasma $\mathrm{fHb}$ have been confirmed by many studies since 2002, in both animals and patients. For example, hemolysis induced by water infusion or direct intravascular $\mathrm{fHb}$ administration in dogs was associated with a significant increase in plasma NO consumption and simultaneous enhanced systemic vascular resistance. These effects were attenuated by NO-inhalation (which converts plasma fHb into the less bioactive molecule methemoglobin in the pulmonary circulation), supporting a causal role for NO-scavenging by $\mathrm{fHb}^{25}$ In humans, fore-arm blood flow responses to intra-arterial infusion of sodium nitroprusside, a NO-donor, were negatively correlated to plasma fHb levels in sickle cell patients. ${ }^{24,25}$

The potential role of plasma $\mathrm{fHb}$ in organ injury development is further supported by our observation that plasma $\mathrm{fHb}$ levels are significantly associated with renal proximal tubular damage during CPB-assisted major aortic surgery. ${ }^{26}$ Moreover peak plasma fHb levels significantly predicted postoperative acute kidney injury. We could not detect $\mathrm{fHb}$ in urine samples during the perioperative period, indicating that urine $\mathrm{fHb}$ is not a major contributor to renal tubular injury development in this setting. ${ }^{26}$ Also, fore-arm blood flow responses after infusion of sodium nitroprusside at the time of peak plasma $\mathrm{fHb}$ concentrations were significantly reduced, as compared to the response measured when $\mathrm{fHb}$-levels were normalized. This observation further underscores a potential causal role of $\mathrm{fHb}$-induced tissue perfusion impairment during surgery (unpublished data). In addition, we have shown that $\mathrm{fHb}$ induces intestinal microcirculatory dysfunction and tissue integrity loss in a rat hemolysis model. ${ }^{45}$

\section{SOURCES OF CIRCULATING FREE HEMOGLOBIN DURING CARDIOVASCULAR SURGERY WITH CARDIOPULMONARY BYPASS}

Hemolysis can principally be attributed to three sources during cardiovascular surgery; the $\mathrm{CPB}$, the cell saver system, and (massive) red blood cell transfusion.

\section{Cardiopulmonary bypass}

Cardiopulmonary bypass inflicts (sub)lethal RBC damage through turbulence and shear stress within the pump, tubes, connectors, cannula, reservoirs, and the oxygenator. ${ }^{23}$ Blood-air contact, blood-nonendothelial surface contact, wall impact forces, use of positive and negative pressures to assist venous drainage, and the use of an integrated cardiotomy suction reservoir all contribute to intraoperative hemolysis. ${ }^{23,46,47}$ Next to 
CPB-composition, CPB-duration is considered to influence the degree of hemolysis, with longer CPB-times resulting in increased RBC-lysis. ${ }^{48}$ In support of this phenomenon, we found a positive and statistically significant correlation between total $\mathrm{fHb}$ release in the perioperative period and CPB-time in a group of 54 patients undergoing CPB-assisted major aortic surgery (Figure 4.1). Next to direct red blood cell lysis, the CPB-system induces sub-lethal RBC-injury. ${ }^{49,50}$ Such sub-lethally damaged $\mathrm{RBC}$ are more prone to lysis in vivo. ${ }^{23,51}$ Delayed lysis of sub-lethally damaged RBCs could explain the continuing increase of plasma $\mathrm{fHb}$ after cessation of CPB (Figure 4.2).

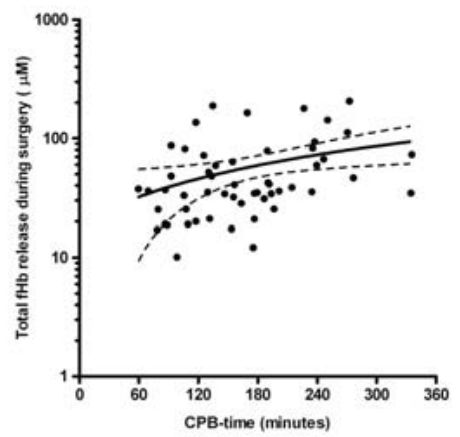

Figure 4.1 Association between cardiopulmonary bypass time and extent of hemolysis. A correlationanalysis between cardiopulmonary bypass time and total free hemoglobin release (defined as the area under the curve) was performed in fifty-four patients ( $N=54$ ) undergoing open surgical repair of thoracoabdominal aortic aneurysms with cardiopulmonary bypass. A significant correlation (Pearson $r=0.33, p<0.05$ ) was found between cardiopulmonary bypass time and plasma free hemoglobin release. Abbreviations: CPB, cardiopulmonary bypass; fHb, free haemoglobin.

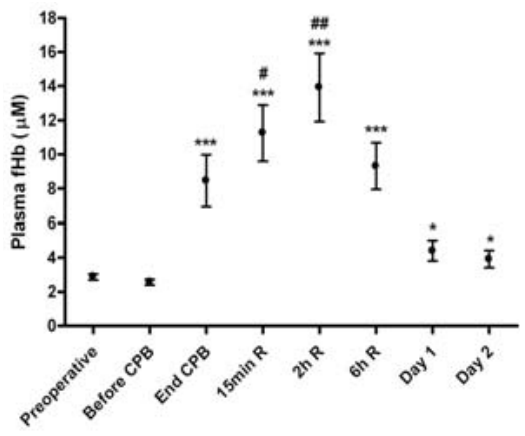

Figure 4.2 Hemolysis during open surgical repair of thoracoabdominal aortic aneurysms with cardiopulmonary bypass. Plasma free hemoglobin levels increased during surgery and continued to increase significantly in the early postoperative period. This indicates ongoing lysis of red blood cells after cardiopulmonary bypass has stopped. * / *** $p<0.05 / 0.001$ compared to preoperative levels. \#/ \# $p<0.05 / 0.01$ compared to end-CPB-levels. Abbreviations: $\mathrm{CPB}$, cardiopulmonary bypass; $\mathrm{fHb}$, free hemoglobin; $\mathrm{R}$, reperfusion 


\section{Cell saver}

Cell salvage devices are additional sources of $\mathrm{fHb}^{52,53}$ Washing and transfusion of damaged autologous shed blood could contribute to increased plasma fHb levels. Although modern cell saver systems are able to remove the major part of $\mathrm{fHb}$ during washing, they do not select between intact and damaged RBCs which are prone to lysis in vivo. ${ }^{54}$ This way, autologous blood transfusion could contribute to increased plasma $\mathrm{fHb}$ levels during surgery.

\section{Red blood cell transfusion}

A last potential source of $\mathrm{fHb}$ are stored RBC-concentrates. Storage of erythrocytes results in irreversible morphological changes like reduced membrane deformability and oxygen binding and delivery capacity, in addition to increased adhesiveness, aggregability, and accumulation of pro-inflammatory substances. ${ }^{55}$ These changes are considered to underlie the relation between RBC transfusion and adverse outcome, a phenomenon causing debate about the pros and cons of allogenic RBC administration. Additionally, storage duration of blood products appears to be a critical factor of transfusion-related morbidity and mortality. Transfusion of "old" blood (stored $>14$ days) was associated with a significantly higher mortality rate in patients undergoing cardiac surgery, compared to patients receiving RBCs stored for 14 days or less. Transfusion of "older" blood was also significantly related to prolonged ventilatory support, increased incidence of renal failure, septicemia or sepsis, and multiple organ failure. ${ }^{55}$ In line, RBC transfusion was the most reliable predictor of adverse outcome in 11.963 patients undergoing isolated CABG, with postoperative morbidity and mortality being dose-dependently related to RBC transfusion. ${ }^{56}$ We propose that high $\mathrm{fHb}$ concentrations due to RBC lysis in stored blood contribute to post-transfusion morbidity and mortality by inducing microcirculatory dysfunction through NOscavenging. In addition, the shear stress imposed on less viable RBCs within the transfusate, might cause an additional increase of $\mathrm{fHb}$ during and after infusion. To study the degree of direct hemolysis of packed RBCs, we measured $\mathrm{fHb}$ levels by derivate spectrophotometry ${ }^{57}$ in samples from sixty randomly collected and transfused packed RBC units $(330 \mathrm{ml} / \mathrm{U})$. FHb in the packed RBC supernatant levels averaged $36 \pm 2 \mu \mathrm{M}$ (mean $\pm \mathrm{SEM}$ ), indicating severe hemolysis. Moreover, storage time and $\mathrm{fHb}$ levels were significantly correlated (Figure 4.3).

This means that transfusion of especially aged packed RBCs can result in an additional increase in circulating $\mathrm{fHb}$ in patients undergoing cardiovascular surgery with CPB. Recently, it was reported that packed RBC transfusion indeed contributed to systemic $\mathrm{fHb}$ levels with $7.5 \mu \mathrm{M}$ increase per transfused unit. ${ }^{58}$ Importantly, the supernatant of the packed $\mathrm{RBC}$, which contains the $\mathrm{fHb}$ molecules was indeed able to consume NO, 
with a strong correlation between $\mathrm{fHb}$ levels and NO-consumption. ${ }^{58}$ The contributing effect of RBC transfusion to circulating plasma $\mathrm{fHb}$ concentrations may thus be considerable. The median transfusion requirement in a large cohort of cardiac surgery patients was found to be 2 packed RBC units, ${ }^{55}$ and 10 units for patients undergoing open repair for thoracoabdominal aortic aneurysms, respectively. ${ }^{28}$ Transfusion of 2 or 10 packed cells could increase plasma fHb levels with $15 \mu \mathrm{M}$ and $75 \mu \mathrm{M}$, respectively. These levels are in sharp contrast to the plasma $\mathrm{fHb}$ levels of 0.1-0.2 $\mu \mathrm{M}$ in normal healthy volunteers. ${ }^{24,58}$ Next to direct $\mathrm{fHb}$ administration via packed RBC transfusion, systemic $\mathrm{fHb}$ concentrations could additionally increase due to delayed lysis of sublethally damaged RBCs. Lastly, another consequence of RBC storage is that so-called Snitrosylated hemoglobin ( $\mathrm{SNO}-\mathrm{Hb}$; $\mathrm{NO}$ bound to intracellular hemoglobin) is rapidly depleted. RBCs containing SNO-Hb are believed to contribute to vasodilation under hypoxic conditions through release of NO. Indeed, the capacity of RBCs to induce vasodilation significantly diminished parallel to SNO-Hb depletion. Reconstitution of $\mathrm{SNO}-\mathrm{Hb}$ by exposure to aqueous NO restored the vasodilatory capacity of transfused RBCs, and improved cardiac blood flow in dogs. ${ }^{59}$

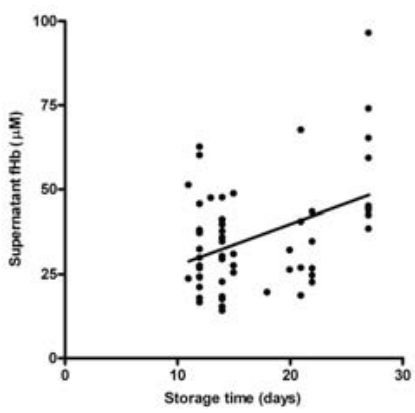

Figure 4.3 Association between storage time and free hemoglobin levels in packed red blood cell transfusion bags. A significant correlation (Pearson $r=0.43, p<0.001$ ) was found between packed red blood cell storage time and free hemoglobin concentration in packed red blood cell transfusion bags $(N=60)$ used for transfusion during cardiovascular surgery. These data indicate that prolonged storage time results in more red blood cell injury with concomitant more free hemoglobin being transfused into the patient. Abbreviations: $\mathrm{fHb}$, free hemoglobin

\section{THERAPEUTIC OPTIONS TO ATTENUATE THE ADVERSE EFFECTS OF FHB- MEDIATED NO-SCAVENGING}

The discovery of the NO-scavenging capacity of circulating $\mathrm{fHb}$ opened a new field of study on therapeutic options in diseases characterized by chronic hemolysis, such as sickle cell disease and malaria. ${ }^{60}$ In this paragraph, we present therapies that we consider to be of value for patients suffering from acute hemolytic episodes as occur during cardiovascular surgery (Table 4.1). 
Table 4.1 Potential therapeutic options to reduce hemolysis-associated morbidity in patients undergoing cardiovascular surgery

\begin{tabular}{|c|c|c|c|}
\hline Therapy & Main therapeutic mechanisms & Feasibility & References \\
\hline NO-inhalation & $\begin{array}{l}\text { Oxidates and inactivates } \mathrm{fHb} \text { in } \\
\text { the pulmonary circulation } \\
\text { reducing NO-scavenging. } \\
\text { Stimulates intrapulmonary } \\
\text { formation of NO-donors; } \\
\text { enhancing NO bio-availability. }\end{array}$ & $\begin{array}{l}\text { NO-inhalation already } \\
\text { applied in sickle cell patients } \\
\text { and patients who underwent } \\
\text { cardiac surgery. } \\
\text { Exact dose and duration of } \\
\text { inhalation needs to be } \\
\text { studied. }\end{array}$ & $\begin{array}{l}\text { Reiter et al. }{ }^{24}, \\
\text { Minneci et al. }{ }^{25}, \\
\text { Kato et al. }{ }^{60}, \\
\text { Cannon et al. }\end{array}$ \\
\hline $\begin{array}{l}\text { Nitrite } \\
\text { supplementation } \\
\text { (oral, } \\
\text { intravenously, by } \\
\text { inhalation) }\end{array}$ & $\begin{array}{l}\text { NO-donor during reduction, } \\
\text { especially during hypoxia and } \\
\text { low pH. } \\
\text { Mediates cytoprotection } \\
\text { through hypoxic vasodilation } \\
\text { and decreased formation of } \\
\text { reactive oxygen species. } \\
\text { Oxides fHb, hereby reducing } \\
\text { NO-scavenging. }\end{array}$ & $\begin{array}{l}\text { Nitrite successfully used in } \\
\text { experimental setting with } \\
\text { sickle cell patients. } \\
\text { Exact dose, duration, and } \\
\text { way of administration needs } \\
\text { to be assessed. }\end{array}$ & $\begin{array}{l}\text { Lundberg et al. }{ }^{62} \text {, } \\
\text { Shiva et al. }{ }^{69}, \\
\text { Piknova et al. }{ }^{71}, \\
\text { Minnecci et al. }\end{array}$ \\
\hline $\begin{array}{l}\text { Haptoglobin } \\
\text { administration }\end{array}$ & $\begin{array}{l}\text { Natural } \mathrm{fHb} \text { scavenger. } \\
\text { Accelerates fHb uptake by } \\
\text { monocytes/macrophages and } \\
\text { hepatic degradation. } \\
\text { Limits renal filtration of } \mathrm{fHb} \text {. }\end{array}$ & $\begin{array}{l}\text { Costs currently limit clinical } \\
\text { applicability. } \\
\text { Moreover, haptoglobin } \\
\text { potentially does not limit NO- } \\
\text { scavenging by fHb. }\end{array}$ & $\begin{array}{l}\text { Tanaka et al. }{ }^{30}, \\
\text { Lim et al. }{ }^{81}, \\
\text { Azarov et al. }{ }^{82}, \\
\text { Boretti et } a .^{83}\end{array}$ \\
\hline $\begin{array}{l}\text { Arginine and } \\
\text { citrulline } \\
\text { supplementation }\end{array}$ & $\begin{array}{l}\text { Enhances substrate delivery for } \\
\text { NO-formation through the } \\
\text { nitric oxide synthases. }\end{array}$ & $\begin{array}{l}\text { Arginine used experimentally } \\
\text { in } 10 \text { patients with sickle cell } \\
\text { disease. } \\
\text { Dose and duration of arginine } \\
\text { and citrulline administration } \\
\text { unknown. }\end{array}$ & $\begin{array}{l}\text { Morris et } a .^{86}, \\
{\text { Luiking et } a l^{88}}^{88}\end{array}$ \\
\hline $\begin{array}{l}\text { Carbon monoxide } \\
\text { inhalation }\end{array}$ & $\begin{array}{l}\text { Regulates vascular tone and } \\
\text { induces vasodilation at low } \\
\text { doses. } \\
\text { Reduces the pro-inflammatory } \\
\text { response. } \\
\text { Relatively inert and does not } \\
\text { form reactive oxygen species. }\end{array}$ & $\begin{array}{l}\text { No human data on } \\
\text { applicability in the setting of } \\
\text { cardiovascular surgery. }\end{array}$ & Belcher et $a .^{33}$ \\
\hline $\begin{array}{l}\text { Endothelin } \\
\text { receptor blockade }\end{array}$ & $\begin{array}{l}\text { Limits endothelin-1 induced } \\
\text { vasoconstriction. }\end{array}$ & $\begin{array}{l}\text { Only tested in a mouse sickle } \\
\text { cell model. }\end{array}$ & Sabaa et $a l^{90}$ \\
\hline
\end{tabular}

The direct (intravascular) therapeutic use of NO itself is greatly impeded by its extremely short half life of $0.05-1.8 \mathrm{msec}$. in vivo. ${ }^{61}$ Therefore, either inactivation of $\mathrm{fHb}$, or enhancement of the $\mathrm{NO}$ (-donor) pool, have potential in reducing the incidence and severity of complications of hemolytic diseases. We mainly focus on three potential therapeutic interventions (Figure 4.4); NO-inhalation, nitrite supplementation, and haptoglobin administration as we consider these therapeutic options to be most clinically relevant at this point of time. In addition, we will discuss 
three more experimental therapies: arginine and citrulline supplementation, COinhalation, and endothelin receptor blockade. For a more complete discussion of therapeutic options in chronic hemolytic disease we would like to refer to Kato et al. ${ }^{60}$ and Lundberg et al. ${ }^{62}$

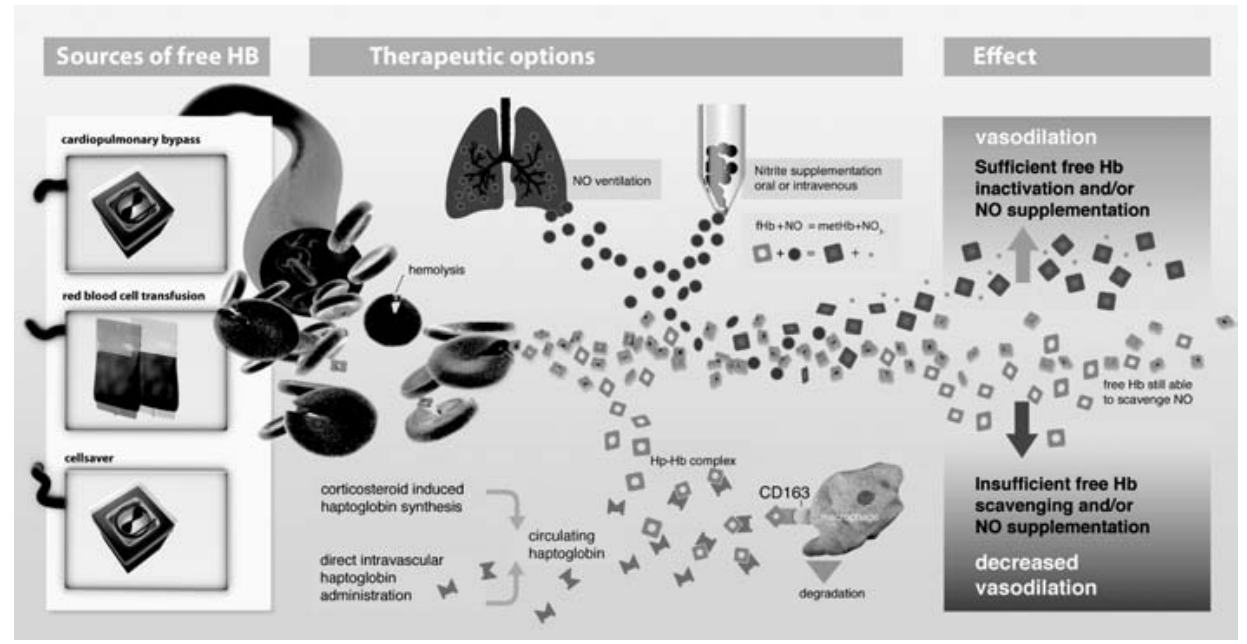

Figure 4.4 Potential sources and effects of plasma free hemoglobin during cardiovascular surgery with cardiopulmonary bypass, and therapeutic options to attenuate hemolysis-induced organ damage. Intravascular hemolysis during cardiovascular surgery can be attributed to the cardiopulmonary bypass, transfusion of red blood cells, and cell-saver use (left). Lysis of red blood cells results in increased circulating plasma free hemoglobin ( $\mathrm{fHb}$ ) levels (orange squares). Under physiological circumstances, $\mathrm{fHb}$ is rapidly cleared by the $\mathrm{fHb}$ scavenger haptoglobin. Haptoglobin-hemoglobin complexes bind to CD-163 expressed by monocytes and macrophages, initiating endocytosis and degradation (middle, bottom). Haptoglobin is not recycled so excessive hemolysis depletes haptoglobin storages rapidly. Non-scavenged fHb potently binds circulating nitric oxide (NO), thereby limiting its bioavailability. This way, high $\mathrm{fHb}$ levels increase the NO-scavenging capacity of blood, causing impaired vasodilation due to vascular NO-shortage. Decreased vasodilation contributes to impaired tissue perfusion and development of organ damage and organ dysfunction (right, bottom). The adverse effects of $\mathrm{fHb}$ may be counteracted by either increasing haptoglobin levels to support fHb scavenging, or enhancing the NO(-donor) pool to increase NO-bioavailability. Haptoglobin can be administered intravenously or haptoglobin synthesis may be up-regulated through corticosteroid administration (center, bottom). The NO(-donor) pool could be increased by oral or intravenous nitrite administration which is oxidized to NO under low oxygen tension and/or low $\mathrm{pH}$. NO-inhalation inactivates $\mathrm{fHb}$ in the pulmonary circulation (or oxygenator in the cardiopulmonary bypass circuit) by transforming $\mathrm{fHb}$ to bioinactive methemoglobin (center, top). This way, scavenging and inactivation of $\mathrm{fHb}$, and supplementation of $\mathrm{NO}$ prevents the adverse effects of plasma $\mathrm{fHb}$ during cardiovascular surgery (right, top). Abbreviations: $\mathrm{Hp}-\mathrm{Hb}-$ complex, haptoglobin-hemoglobin complex; $\mathrm{fHb}$, free hemoglobin; NO, nitric oxide; metHb, methemoglobin. See separate inlay for the colour figure. 


\section{NO-inhalation}

Intravascular conversion of plasma $\mathrm{fHb}$ into a less bioactive molecule is an interesting option to reduce the adverse consequences of increased $\mathrm{fHb}$ concentrations. NO gas inhalation results in pulmonary oxidation of $\mathrm{fHb}$ into methemoglobin, which does not scavenge NO, reducing NO consumption in plasma. In a canine hemolysis model, NOinhalation attenuated the pulmonary and systemic vasoconstrictor effects of $\mathrm{fHb}^{25}$ In patients with sickle cell disease, NO-inhalation of $80 \mathrm{ppm}$ for 1.5 hours reduced pain during vaso-occlusive crisis, diminished plasma NO-consumption and increased methemoglobin levels, indicating oxidation of $\mathrm{fHb} .{ }^{24}$ Moreover, inhalation of $80 \mathrm{ppm}$ NO for 4 hours in children with sickle cell disease was not associated with any toxic side-effects such as hypotension, clinically significant decreases in $\mathrm{SpO}_{2}$, significant increases in methemoglobin, or toxic concentrations of $\mathrm{NO}_{2}{ }^{63}$ Even continuous NOinhalation at 40 ppm for 3.2 days in a patient with sickle cell disease with multi-organ involvement was not associated with adverse side-effects and markedly improved her clinical state. ${ }^{64}$ Lastly, mixing of up to 20 ppm NO gas with normal ventilation gas showed therapeutic potential in adult patients with cardiac surgery associated pulmonary hypertension by reducing right ventricular afterload and prevention of right ventricular failure. ${ }^{65,66}$ Next to $\mathrm{fHb}$ oxidation, NO-gas inhalation also results in the formation of relatively stable NO-species in the lung. Longer intravascular half-times of these NO-carriers, such as nitrite, enable transport of NO in the blood, mediating extra pulmonary effects of NO-gas inhalation. ${ }^{67,68}$ In conclusion, we consider NO-inhalation a promising and potentially easy applicable, therapeutic option to attenuate the adverse effects of $\mathrm{fHb}$-mediated NO-scavenging during cardiovascular surgery. Ideally, the dose of NO-inhalation could even be adjusted based on intraoperative fHb measurements, which are already routinely performed at our institution.

\section{Nitrite supplementation}

Another promising candidate for therapeutic use is the anion nitrite $\left(\mathrm{NO}_{2}{ }^{-}\right)$, long believed to be merely an inert oxidation product of NO. Recent studies, however, provided evidence for the existence of multiple nitrite reducing pathways in which nitrite is converted back to NO, making nitrite an important NO-donor. ${ }^{62,69,70}$ Furthermore, nitrite is able to oxidize $\mathrm{fHb}$ in plasma, potentially limiting its capacity to scavenge NO. ${ }^{71}$ The enzymatic and non-enzymatic pathways of nitrite reduction include (free) deoxyhemoglobin and deoxymyoglobin, xanthine oxidoreductase, protons, ascorbate, and polyphenols. ${ }^{62}$ The process of NO-reduction is most efficient at low oxygen tension and low $\mathrm{pH}$ and thus occurs, preferably, during hypoxia and/or anoxia. ${ }^{70,72,73}$ This is of particular importance since NOS-activity is greatly limited at low-oxygen tensions. ${ }^{74}$ In adult patients suffering from sickle cell anemia, infusion of 
$0.4,4$, and $40 \mu \mathrm{M}$ nitrite into the brachial artery led to a dose-dependent increase in fore-arm blood flow up to $77 \% .^{75}$ In a canine hemolysis model, sodium nitrite increased blood flow in a similar way. ${ }^{76}$ Next to promoting vasodilation, nitrite has been shown to exert potent cytoprotection in the liver, heart, and brain in several animal models of ischemia-reperfusion. ${ }^{77}$ The way by which nitrite mediates cytoprotection in this setting is as yet unresolved but believed to be dual. First, nitrite enables hypoxic vasodilation as stated above. Second, nitrite is able to nitrosate complex I of the mitochondrial electron transport chain, inhibiting its activity and decreasing the formation of reactive oxygen species in the reperfusion phase. ${ }^{69}$ Considering these properties of nitrite, it has been suggested to have therapeutic value in various diseases, such as sickle cell disease, stroke, myocardial infarction, and organ transplantation. Nevertheless, the optimal nitrite dose for human systemic administration has not yet been clarified. Interestingly, the effect of nitrite may be greater at low plasma concentrations $(<200 \mathrm{nM})$ and is lost at high plasma levels exceeding $1000 \mu \mathrm{M} .^{78,79}$ Furthermore, it was reported that the reaction between oxyfHb (in contrast to deoxyfHb) and nitrite could initiate an autocatalytic free radical chain leading to unwanted oxidative damage. ${ }^{80}$ Piknova et al. addressed this issue and concluded that free radical formation in plasma during the reaction of pharmacological doses of nitrite (up to $120 \mu \mathrm{M}$ ) with clinically relevant levels of $\mathrm{fHb}(30 \mu \mathrm{M})$, would be highly unlikely. ${ }^{71}$ In conclusion, we consider nitrite to have potential in patients undergoing cardiovascular surgery to prevent and treat hemolysis-associated morbidity. Nevertheless, the optimal dose and application must be further studied.

\section{Haptoglobin administration}

Administration of haptoglobin, being the physiological fHb scavenger, appears to be a logical choice in reducing $\mathrm{fHb}$ concentrations. Haptoglobin targets $\mathrm{fHb}$ for degradation in the liver, monocytes and macrophages. Furthermore, haptoglobin prevents glomerular filtration of $\mathrm{fHb}$, reducing $\mathrm{fHb}$-induced kidney damage. Increased $\mathrm{fHb}$ levels during cardiac surgery have been associated with total depletion of haptoglobin, ${ }^{30}$ enhancing the NO-scavenging capacity of plasma. Indeed, haptoglobin knock-out mice were more sensitive to the adverse effects of phenylhydrazine-induced hemolysis. ${ }^{81}$ Renal DNA damage was significantly higher and glomerular filtration function (reflected by poorer renal clearance of ${ }^{3} \mathrm{H}$-inulin) was significantly lower in haptoglobin knock-out mice compared to haptoglobin ${ }^{+/+}$mice. Interestingly, administration of vasodilators restored glomerular filtration, implicating renal vasoconstriction to be the major contributor to hemolysis-induced acute kidney injury. This supports NOscavenging by plasma fHb. In addition, haptoglobin administration in patients undergoing cardiac surgery with plasma $\mathrm{fHb}$ levels surpassing $2.3 \mu \mathrm{M}$, was associated with a reduction of renal tubular damage. ${ }^{30}$ Nevertheless, this positive effect of 
haptoglobin was attributed to a decrease in urine $\mathrm{fHb}$ levels and a subsequent attenuation of oxidative renal damage.

Haptoglobin administration is an interesting therapeutic option, but its clinical application might be limited. First, it has been recently found that, in vitro, the hemoglobin - haptoglobin complex still potently scavenges NO at the same rate as $\mathrm{fHb}$. Although binding of $\mathrm{fHb}$ to haptoglobin increases the rate of uptake by monocytes and macrophages by 2-fold (hereby disabling NO-scavenging), it is questionable whether this increased uptake would affect NO-bioavailability. ${ }^{82}$ Second, the costs involved in retrieving or producing the amounts of haptoglobin necessary for clinical application currently limits wide-spread implementation. Recently, Boretti and et al. made use of the fact that the haptoglobin promoter gene contains glucocorticoidresponsive elements. Administration of $4 \mathrm{mg} / \mathrm{kg}$ prednisone twice daily for three days increased plasma haptoglobin levels 6-fold in dogs. ${ }^{83}$ Importantly, the glucocorticoid stimulation of haptoglobin synthesis prevented the $\mathrm{fHb}$-induced increase in mean arterial pressure in dogs after $\mathrm{fHb}$ infusion, most probably due to scavenging of $\mathrm{fHb}$ by haptoglobin. ${ }^{83}$ This sheds new light on the longstanding debate whether corticosteroid administration during cardiac and cardiovascular surgery is useful. ${ }^{84,85}$ In summary, haptoglobin could be useful to reduce kidney damage due to intratubular fHb toxicity. The effect on NO-scavenging may, however, be limited.

\section{OTHER POTENTIAL THERAPIES}

We consider NO-inhalation and nitrite supplementation to be promising therapeutic interventions since they can be used successfully in the acute setting of cardiovascular surgery. Notwithstanding, several other therapeutic modalities may be of value in patients at risk for acute hemolytic episodes.

\section{Arginine and citrulline supplementation}

L-arginine is the natural nitrogen donor for NO-synthesis and arginine supplementation enhances NO-formation. Arginine therapy at a dose of $0.1 \mathrm{~g} / \mathrm{kg}$ three times a day for 5 days in 10 adult patients with sickle cell anemia and pulmonary hypertension resulted in a significant decrease (15.2\%) of pulmonary arterial systolic pressures implicating vasodilation. ${ }^{86,87}$

Another interesting approach would be administration of citrulline, a substrate for de novo arginine synthesis. It has been suggested that in case of high arginase-1 levels, as occur during hemolysis, citrulline supplementation might restore the intracellular arginine balance and promote nitric oxide production. ${ }^{88}$ 
However, it remains unknown whether, and to what extent, arginine or citrulline supplementation is beneficial in patients with acute hemolysis during cardiovascular surgery.

\section{Carbon monoxide inhalation}

Carbon monoxide (CO) is produced during breakdown of the heme-ring of $\mathrm{fHb}$ which is mediated by HO-1. Inhaled CO, at low doses up to $250 \mathrm{ppm}$, has been shown to reduce vaso-occlusion in a mouse sickle cell model. CO even mimics some of the functions of NO like inhibition of platelet aggregation and activation, regulation of vascular tone, and reduction of a pro-inflammatory response. ${ }^{33} \mathrm{CO}$ is relatively inert in contrast to $\mathrm{NO}$, which is able to react with intravascular reactive oxygen species forming the highly reactive peroxynitrite $\left(\mathrm{ONOO}^{-}\right){ }^{89}$ Therefore, $\mathrm{CO}$ has been proposed to be even more effective in hemolytic disease than NO, but this has not been substantiated by human studies.

\section{Endothelin receptor blockade}

Endothelin-1 is a very potent vasoconstrictor and its secretion is repressed by NO. A diminished NO-bioavailability due to hemolysis counterbalances this negative feedback, resulting in enhanced endothelin-1 levels and vasoconstriction. A mouse sickle cell model provided evidence for beneficial effects of endothelin receptor blockade on renal blood flow, inflammation, and vascular congestion in the lungs and kidneys. ${ }^{90}$ Reduction of inflammation would be an additional positive effect in patients subjected to cardiopulmonary bypass, which induces a pro-inflammatory response. Nevertheless, further research is essential to find out whether short term endothelin receptor blockage is beneficial in this setting, since it is very different compared to sickle cell anemia.

In conclusion, there are several promising therapeutic interventions to attenuate the adverse effects of increased plasma $\mathrm{fHb}$ levels in patients suffering from acute hemolytic disease, including patients undergoing surgery with cardiopulmonary bypass, trauma patients, and patients necessitating long-term extracorporeal support

for instance extracorporeal membranous oxygenation (ECMO) or hemodialysis. ${ }^{91,92}$

\section{HEMOLYSIS-INDUCED ORGAN INJURY IN CARDIOVASCULAR SURGERY; SUMMARY AND FUTURE PERSPECTIVES}

As evaluated in this review, hemolysis during cardiopulmonary bypass harbors a latent adverse effect. The NO-scavenging effect of plasma $\mathrm{fHb}$ contributes to deleterious effects of CPB, such as hypoperfusion and ischemia/reperfusion, thereby further hampering tissue perfusion and resulting in organ injury and dysfunction. These 
findings shed new light on the pathophysiology and preventive measures of organ injury during on-pump cardiovascular surgery (Figure 4.4).

\section{CONCLUSION}

Evidence is mounting that enhanced circulating levels of plasma $\mathrm{fHb}$ are detrimental, not only in chronic hemolytic diseases, but also in the acute setting of cardiovascular surgery. FHb-induced perturbations in microcirculatory blood flow and subsequent hypoperfusion or even ischemic damage, complemented by urine fHb-induced oxidative stress to renal tissue cells, should be acknowledged as an important risk factor for organ injury development in patients undergoing cardiovascular surgery. Patients undergoing such procedures are at increased risk for developing postoperative organ injury with worse patient outcome. Circulating fHb appears to be an important determinant in organ injury development which offers a new therapeutic opportunity to reduce post-operative morbidity and mortality in patients. Interventional studies using NO-inhalation, nitrite administration or haptoglobin suppletion should be performed to establish the causal role between plasma fHb, NObioavailability, and organ injury in this particular setting. ${ }^{25,30,93,94}$ Furthermore, such interventional studies will provide valuable information for improvement of patient outcome. Lastly, the role of $\mathrm{fHb}$ in organ injury development is not only of importance for patients undergoing cardiovascular surgery but also for other patient groups at risk for hemolysis such as trauma patients, hemodialysis patients, and patients requiring long-term extracorporeal oxygenation or extracorporeal life-support. 


\section{REFERENCES}

1. Andersson LG, Ekroth R, Bratteby LE, Hallhagen S, Wesslén O. Acute renal failure after coronary surgery--a study of incidence and risk factors in 2009 consecutive patients. Thorac Cardiovasc Surg 1993; 41:237-41.

2. Conlon PJ, Stafford-Smith M, White WD, Newman MF, King S, Winn MP, Landolfo K. Acute renal failure following cardiac surgery. Nephrol Dial Transplant 1999; 14:1158-62.

3. Grayson AD, Khater M, Jackson M, Fox MA. Valvular heart operation is an independent risk factor for acute renal failure. Ann Thorac Surg 2003; 75:1829-35.

4. Provenchère $S$, Plantefève $G$, Hufnagel $G$, Vicaut $E$, De Vaumas $C$, Lecharny JB, Depoix JP, Vrtovsnik F, Desmonts JM, Philip I. Renal dysfunction after cardiac surgery with normothermic cardiopulmonary bypass: incidence, risk factors, and effect on clinical outcome. Anesth Analg 2003; 96:1258-64.

5. Achouh PE, Madsen K, Miller CC 3rd, Estrera AL, Azizzadeh A, Dhareshwar J, Porat E, Safi HJ. Gastrointestinal complications after descending thoracic and thoracoabdominal aortic repairs: a 14year experience. J Vasc Surg 2006; 44:442-6.

6. Jacobs MJ, de Mol BA, Legemate DA, Veldman DJ, de Haan P, Kalkman CJ. Retrograde aortic and selective organ perfusion during thoracoabdominal aortic aneurysm repair. Eur J Vasc Endovasc Surg 1997; 14:360-6.

7. Coselli JS, LeMaire SA, Conklin LD, Köksoy C, Schmittling ZC. Morbidity and mortality after extent II thoracoabdominal aortic aneurysm repair. Ann Thorac Surg 2002; 73:1107-15.

8. Rectenwald JE, Huber TS, Martin TD, Ozaki CK, Devidas M, Welborn MB, Seeger JM. Functional outcome after thoracoabdominal aortic aneurysm repair. J Vasc Surg 2002; 35:640-7.

9. Kieffer E, Chiche L, Godet G, Koskas F, Bahnini A, Bertrand M, Fléron MH, Goarin JP, Warnier de Wailly G, Benhamou AC. Type IV thoracoabdominal aneurysm repair: predictors of postoperative mortality, spinal cord injury, and acute intestinal ischemia. Ann Vasc Surg 2008; 22:822-8.

10. Vermeer H, Teerenstra S, de Sévaux RG, van Swieten HA, Weerwind PW. The effect of hemodilution during normothermic cardiac surgery on renal physiology and function: a review. Perfusion 2008; 23:329-38.

11. Fink MP. Thoracoabdominal aortic aneurysm repair: a human model of ischemia/reperfusion-induced cytokine-driven multiple organ dysfunction syndrome. Crit Care Med 2000; 28:3356-7.

12. Leijdekkers VJ, Wirds JW, Vahl AC, van Genderingen HR, Siebenga J, Westerhof N, Tangelder GJ, Bulder $E R$, Rauwerda JA. The visceral perfusion system and distal bypass during thoracoabdominal aneurysm surgery: an alternative for physiological blood flow? Cardiovasc Surg 1999; 7:219-24.

13. Kuttila K, Niinikoski J, Haglund U. Visceral and peripheral tissue perfusion after cardiac surgery. Scand J Thorac Cardiovasc Surg 1991; 25:57-62.

14. Brooker RF, Brown WR, Moody DM, Hammon JW Jr, Reboussin DM, Deal DD, Ghazi-Birry HS, Stump DA. Cardiotomy suction: a major source of brain lipid emboli during cardiopulmonary bypass. Ann Thorac Surg 1998; 65:1651-5.

15. Brondén B, Dencker M, Allers M, Plaza I, Jönsson H. Differential distribution of lipid microemboli after cardiac surgery. Ann Thorac Surg 2006; 81:643-8.

16. Hanssen SJ, Derikx JP, Vermeulen Windsant IC, Heijmans JH, Koeppel TA, Schurink GW, Buurman WA, Jacobs MJ. Visceral injury and systemic inflammation in patients undergoing extracorporeal circulation during aortic surgery. Ann Surg 2008; 248:117-25.

17. Rosner $\mathrm{MH}$, Okusa MD. Acute kidney injury associated with cardiac surgery. Clin J Am Soc Nephrol 2006; 1:19-32.

18. Huybregts RA, Morariu AM, Rakhorst G, Spiegelenberg SR, Romijn HW, de Vroege R, van Oeveren W. Attenuated renal and intestinal injury after use of a mini-cardiopulmonary bypass system. Ann Thorac Surg 2007; 83:1760-6.

19. Yamada T, Ochiai R, Takeda J, Kikuchi H, Ishibashi M, Watanabe K. Off-pump coronary artery bypass attenuates transient hepatocellular damage after myocardial revascularization. J Cardiothorac Vasc Anesth 2005; 19:603-7.

20. Nigwekar SU, Kandula P, Hix JK, Thakar CV. Off-pump coronary artery bypass surgery and acute kidney injury: a meta-analysis of randomized and observational studies. Am J Kidney Dis 2009; 54:413-23. 
21. Kelly KJ, Molitoris BA. Acute renal failure in the new millennium: time to consider combination therapy. Semin Nephrol 2000; 20:4-19.

22. Fransen EJ, Ganushchak YM, Vijay V, de Jong DS, Buurman WA, Maessen JG. Evaluation of a new condensed extra-corporeal circuit for cardiac surgery: a prospective randomized clinical pilot study. Perfusion 2005; 20:91-9.

23. Vercaemst L. Hemolysis in cardiac surgery patients undergoing cardiopulmonary bypass: a review in search of a treatment algorithm. J Extra Corpor Technol 2008; 40:257-67.

24. Reiter CD, Wang X, Tanus-Santos JE, Hogg N, Cannon RO 3rd, Schechter AN, Gladwin MT. Cell-free hemoglobin limits nitric oxide bioavailability in sickle-cell disease. Nat Med 2002; 8:1383-9.

25. Minneci PC, Deans KJ, Zhi H, Yuen PS, Star RA, Banks SM, Schechter AN, Natanson C, Gladwin MT, Solomon SB. Hemolysis-associated endothelial dysfunction mediated by accelerated NO inactivation by decompartmentalized oxyhemoglobin. J Clin Invest 2005; 115:3409-17.

26. Meyer C, Heiss C, Drexhage C, Kehmeier ES, Balzer J, Mühlfeld A, Merx MW, Lauer T, Kühl H, Floege J, Kelm M, Rassaf T. Hemodialysis-induced release of hemoglobin limits nitric oxide bioavailability and impairs vascular function. J Am Coll Cardiol 2010; 55:454-9.

27. Donadee CL, Gladwin MT. Hemodialysis hyperhemolysis. A novel mechanism of endothelial dysfunction and cardiovascular risk? J Am Coll Cardiol 2010; 55:460-2.

28. Vermeulen Windsant IC, Snoeijs MG, Hanssen SJ, Altintas S, Heijmans JH, Koeppel TA, Schurink GW, Buurman WA, Jacobs MJ. Hemolysis is associated with acute kidney injury during major aortic surgery. Kidney Int 2010; 77:913-20.

29. Rother RP, Bell L, Hillmen P, Gladwin MT. The clinical sequelae of intravascular hemolysis and extracellular plasma hemoglobin: a novel mechanism of human disease. Jama 2005; 293:1653-62.

30. Tanaka K, Kanamori Y, Sato T, Kondo C, Katayama Y, Yada I, Yuasa H, Kusagawa M. Administration of haptoglobin during cardiopulmonary bypass surgery. ASAIO Trans 1991; 37:M482-3.

31. Maines MD. The heme oxygenase system: a regulator of second messenger gases. Annu Rev Pharmacol Toxicol 1997; 37:517-54.

32. Philippidis P, Mason JC, Evans BJ, Nadra I, Taylor KM, Haskard DO, Landis RC. Hemoglobin scavenger receptor CD163 mediates interleukin-10 release and heme oxygenase-1 synthesis: antiinflammatory monocyte-macrophage responses in vitro, in resolving skin blisters in vivo, and after cardiopulmonary bypass surgery. Circ Res 2004; 94:119-26.

33. Belcher JD, Mahaseth H, Welch TE, Otterbein LE, Hebbel RP, Vercellotti GM. Heme oxygenase-1 is a modulator of inflammation and vaso-occlusion in transgenic sickle mice. J Clin Invest 2006; 116: 808-16.

34. Kristiansen M, Graversen JH, Jacobsen C, Sonne O, Hoffman HJ, Law SK, Moestrup SK. Identification of the haemoglobin scavenger receptor. Nature 2001; 409:198-201.

35. Liao JC, Hein TW, Vaughn MW, Huang KT, Kuo L. Intravascular flow decreases erythrocyte consumption of nitric oxide. Proc Natl Acad Sci U S A 1999; 96:8757-61.

36. Vaughn MW, Huang KT, Kuo L, Liao JC. Erythrocytes possess an intrinsic barrier to nitric oxide consumption. J Biol Chem 2000; 275:2342-8.

37. Morris CR, Kato GJ, Poljakovic M, Wang X, Blackwelder WC, Sachdev V, Hazen SL, Vichinsky EP, Morris SM Jr, Gladwin MT. Dysregulated arginine metabolism, hemolysis-associated pulmonary hypertension, and mortality in sickle cell disease. Jama 2005; 294:81-90.

38. van de Poll MC, Hanssen SJ, Berbée M, Deutz NE, Monbaliu D, Buurman WA, Dejong CH. Elevated plasma arginase-1 does not affect plasma arginine in patients undergoing liver resection. Clin Sci 2008; 114:231-41.

39. Burck HC, Diekman MA, Sedlaczek T. Acute renal failure after the infusion of hemoglobin solutions with or without red cell ghosts in rabbits. Res Exp Med 1975; 166:79-84.

40. Zager RA, Gamelin LM. Pathogenetic mechanisms in experimental hemoglobinuric acute renal failure. Am J Physiol 1989; 256:F446-55.

41. Paller MS. Hemoglobin- and myoglobin-induced acute renal failure in rats: role of iron in nephrotoxicity. Am J Physiol 1988; 255:F539-44.

42. Davis CL, Kausz AT, Zager RA, Kharasch ED, Cochran RP. Acute renal failure after cardiopulmonary bypass in related to decreased serum ferritin levels. J Am Soc Nephrol 1999; 10:2396-402.

43. Everse J, Hsia N. The toxicities of native and modified hemoglobins. Free Radic Biol Med 1997; 22:1075-99. 
44. Natanson C, Kern SJ, Lurie P, Banks SM, Wolfe SM. Cell-free hemoglobin-based blood substitutes and risk of myocardial infarction and death: a meta-analysis. Jama 2008; 299:2304-12.

45. Hanssen SJ, Lubbers T, Hodin CM, Prinzen FW, Buurman WA, Jacobs MJ. Hemolysis results in impaired intestinal microcirculation and intestinal epithelial cell injury. World J Gastroenterol 2011; 14:213-8.

46. Fabre O, Vincentelli A, Corseaux D, Juthier F, Susen S, Bauters A, Van Belle E, Mouquet F, Le Tourneau T, Decoene C, Crépin F, Prat A, Jude B. Comparison of blood activation in the wound, active vent, and cardiopulmonary bypass circuit. Ann Thorac Surg 2008; 86:537-41.

47. Mulholland JW, Massey W, Shelton JC. Investigation and quantification of the blood trauma caused by the combined dynamic forces experienced during cardiopulmonary bypass. Perfusion 2000; 15 : 485-94.

48. Cheung AT, Cruz-Shiavone GE, Meng QC, Pochettino A, Augoustides JA, Bavaria JE, Ochroch EA. Cardiopulmonary bypass, hemolysis, and nitroprusside-induced cyanide production. Anesth Analg 2007; 105:29-33.

49. Kameneva MV, Undar A, Antaki JF, Watach MJ, Calhoon JH, Borovetz HS. Decrease in red blood cell deformability caused by hypothermia, hemodilution, and mechanical stress: factors related to cardiopulmonary bypass. Asaio J 1999; 45:307-10.

50. Svenmarker S, Jansson E, Stenlund H, Engstrom KG. Red blood cell trauma during cardiopulmonary bypass: narrow pore filterability versus free haemoglobin. Perfusion 2000; 15:33-40.

51. Serrick CJ, Scholz M, Melo A, Singh O, Noel D. Quality of red blood cells using autotransfusion devices: a comparative analysis. J Extra Corpor Technol 2003; 35:28-34.

52. Nishiyama T, Hanaoka K. Free hemoglobin concentrations in patients receiving massive blood transfusion during emergency surgery for trauma. Can J Anaesth 2000; 47:881-5.

53. Yazer $\mathrm{MH}$, Waters JH, Elkin KR, Rohrbaugh ME, Kameneva MV. A comparison of hemolysis and red cell mechanical fragility in blood collected with different cell salvage suction devices. Transfusion 2008; 48:1188-91.

54. Sakota D, Sakamoto R, Sobajima H, Yokoyama N, Waguri S, Ohuchi K, Takatani S. Mechanical damage of red blood cells by rotary blood pumps: selective destruction of aged red blood cells and subhemolytic trauma. Artif Organs 2008; 32:785-91.

55. Koch CG, Li L, Sessler DI, Figueroa P, Hoeltge GA, Mihaljevic T, Blackstone EH. Duration of red-cell storage and complications after cardiac surgery. N Engl J Med 2008; 358:1229-39.

56. Koch CG, Li L, Duncan Al, Mihaljevic T, Cosgrove DM, Loop FD, Starr NJ, Blackstone EH. Morbidity and mortality risk associated with red blood cell and blood-component transfusion in isolated coronary artery bypass grafting. Crit Care Med 2006; 34:1608-16.

57. Cruz-Landeira A, Bal MJ, Quintela, Lopez-Rivadulla M. Determination of methemoglobin and total hemoglobin in toxicological studies by derivative spectrophotometry. J Anal Toxicol 2002; 26:67-72.

58. Gladwin MT, Kim-Shapiro DB. Storage lesion in banked blood due to hemolysis-dependent disruption of nitric oxide homeostasis. Curr Opin Hematol 2009; 16:515-23.

59. Reynolds JD, Ahearn GS, Angelo M, Zhang J, Cobb F, Stamler JS. S-nitrosohemoglobin deficiency: a mechanism for loss of physiological activity in banked blood. Proc Natl Acad Sci U S A 2007; 104:17058-62.

60. Kato GJ, Gladwin MT. Evolution of novel small-molecule therapeutics targeting sickle cell vasculopathy. Jama 2008; 300:2638-46.

61. Kelm M, Preik-Steinhoff H, Preik M, Strauer BE. Serum nitrite sensitively reflects endothelial NO formation in human forearm vasculature: evidence for biochemical assessment of the endothelial Larginine-NO pathway. Cardiovasc Res 1999; 41:765-72.

62. Lundberg JO, Weitzberg E, Gladwin MT. The nitrate-nitrite-nitric oxide pathway in physiology and therapeutics. Nat Rev Drug Discov 2008; 7:156-67.

63. Weiner DL, Hibberd PL, Betit P, Cooper AB, Botelho CA, Brugnara C. Preliminary assessment of inhaled nitric oxide for acute vaso-occlusive crisis in pediatric patients with sickle cell disease. JAMA 2003; 289:1136-42.

64. Chang WL, Corate LM, Sinclair JM, van der Heyde HC. Continuous inhaled nitric oxide therapy in a case of sickle cell disease with multiorgan involvement. J Investig Med 2008; 56:1023-7.

65. Lunn RJ. Inhaled nitric oxide therapy. Mayo Clin Proc 1995; 70:247-55.

66. Winterhalter M, Antoniou T, Loukanov T. Management of adult patients with perioperative pulmonary hypertension: technical aspects and therapeutic options. Cardiology 2010; 116:3-9. 
67. Cannon RO 3rd, Schechter AN, Panza JA, Ognibene FP, Pease-Fye ME, Waclawiw MA, Shelhamer JH, Gladwin MT. Effects of inhaled nitric oxide on regional blood flow are consistent with intravascular nitric oxide delivery. J Clin Invest 2001; 108:279-87.

68. Fox-Robichaud A, Payne D, Hasan SU, Ostrovsky L, Fairhead T, Reinhardt P, Kubes P. Inhaled NO as a viable antiadhesive therapy for ischemia/reperfusion injury of distal microvascular beds. J Clin Invest. 1998, 101:2497-505.

69. Shiva S, Gladwin MT. Nitrite mediates cytoprotection after ischemia/reperfusion by modulating mitochondrial function. Basic Res Cardiol 2009; 104:113-9.

70. Raat NJ, Noguchi AC, Liu VB, Raghavachari N, Liu D, Xu X, Shiva S, Munson PJ, Gladwin MT. Dietary nitrate and nitrite modulate blood and organ nitrite and the cellular ischemic stress response. Free Radic Biol Med 2009; 47:510-7.

71. Piknova B, Keszler A, Hogg N, Schechter AN. The reaction of cell-free oxyhemoglobin with nitrite under physiologically relevant conditions: Implications for nitrite-based therapies. Nitric Oxide 2009; 20: $88-94$.

72. Shiva S, Sack MN, Greer JJ, Duranski M, Ringwood LA, Burwell L, Wang X, MacArthur PH, Shoja A, Raghavachari N, Calvert JW, Brookes PS, Lefer DJ, Gladwin MT. Nitrite augments tolerance to ischemia/reperfusion injury via the modulation of mitochondrial electron transfer. J Exp Med 2007; 204:2089-102.

73. Dezfulian C, Raat N, Shiva S, Gladwin MT. Role of the anion nitrite in ischemia-reperfusion cytoprotection and therapeutics. Cardiovasc Res 2007; 75:327-38.

74. Zweier JL, Wang P, Samouilov A, Kuppusamy P. Enzyme-independent formation of nitric oxide in biological tissues. Nat Med 1995; 1:804-9.

75. Mack AK, McGowan Ii VR, Tremonti CK, Ackah D, Barnett C, Machado RF, Gladwin MT, Kato GJ.. Sodium nitrite promotes regional blood flow in patients with sickle cell disease: a phase I/II study. Br J Haematol 2008; 142:971-8.

76. Minneci PC, Deans KJ, Shiva S, Zhi H, Banks SM, Kern S, Natanson C, Solomon SB, Gladwin MT. Nitrite reductase activity of hemoglobin as a systemic nitric oxide generator mechanism to detoxify plasma hemoglobin produced during hemolysis. Am J Physiol Heart Circ Physiol 2008; 295:H743-54.

77. Lu P, Liu F, Yao Z, Wang CY, Chen DD, Tian Y, Zhang JH, Wu YH. Nitrite-derived nitric oxide by xanthine oxidoreductase protects the liver against ischemia-reperfusion injury. Hepatobiliary Pancreat Dis Int 2005; 4:350-5.

78. Duranski MR, Greer JJ, Dejam A, Jaganmohan S, Hogg N, Langston W, Patel RP, Yet SF, Wang X, Kevil CG, Gladwin MT, Lefer DJ. Cytoprotective effects of nitrite during in vivo ischemia-reperfusion of the heart and liver. J Clin Invest 2005; 115:1232-40.

79. Dimmeler S, Zeiher AM. Nitric oxide and apoptosis: another paradigm for the double-edged role of nitric oxide. Nitric Oxide 1997; 1:275-81.

80. Goldman DW, Breyer RJ 3rd, Yeh D, Brockner-Ryan BA, Alayash Al. Acellular hemoglobin-mediated oxidative stress toward endothelium: a role for ferryl iron. Am J Physiol 1998; 275:H1046-53.

81. Lim YK, Jenner A, Ali AB, Wang Y, Hsu SI, Chong SM, Baumman H, Halliwell B, Lim SK. Haptoglobin reduces renal oxidative DNA and tissue damage during phenylhydrazine-induced hemolysis. Kidney Int 2000; 58:1033-44.

82. Azarov I, He X, Jeffers A, Basu S, Ucer B, Hantgan RR, Levy A, Kim-Shapiro DB. Rate of nitric oxide scavenging by hemoglobin bound to haptoglobin. Nitric Oxide 2008; 18:296-302.

83. Boretti FS, Buehler PW, D'Agnillo F, Kluge K, Glaus T, Butt OI, Jia Y, Goede J, Pereira CP, Maggiorini M, Schoedon G, Alayash Al, Schaer DJ. Sequestration of extracellular hemoglobin within a haptoglobin complex decreases its hypertensive and oxidative effects in dogs and guinea pigs. J Clin Invest 2009; 119:2271-80.

84. Morariu AM, Loef BG, Aarts LP, Rietman GW, Rakhorst G, van Oeveren W, Epema AH. Dexamethasone: benefit and prejudice for patients undergoing on-pump coronary artery bypass grafting: a study on myocardial, pulmonary, renal, intestinal, and hepatic injury. Chest 2005; 128:2677-87.

85. Chaney MA. Corticosteroids and cardiopulmonary bypass : a review of clinical investigations. Chest 2002; 121:921-31.

86. Morris CR, Kuypers FA, Larkin S, Sweeters N, Simon J, Vichinsky EP, Styles LA. Arginine therapy: a novel strategy to induce nitric oxide production in sickle cell disease. Br J Haematol 2000;111:498-500. 
87. Morris CR, Morris SM Jr, Hagar W, Van Warmerdam J, Claster S, Kepka-Lenhart D, Machado L, Kuypers FA, Vichinsky EP. Arginine therapy: a new treatment for pulmonary hypertension in sickle cell disease? Am J Respir Crit Care Med 2003; 168:63-9.

88. Luiking YC, Poeze M, Ramsay G, Deutz NE. Reduced citrulline production in sepsis is related to diminished de novo arginine and nitric oxide production. Am J Clin Nutr 2009; 89:142-52.

89. Wolin MS, Davidson CA, Kaminski PM, Fayngersh RP, Mohazzab-H KM. Oxidant--nitric oxide signalling mechanisms in vascular tissue. Biochemistry (Mosc) 1998; 63:810-6.

90. Sabaa N, de Franceschi L, Bonnin P, Castier Y, Malpeli G, Debbabi H, Galaup A, Maier-Redelsperger M, Vandermeersch S, Scarpa A, Janin A, Levy B, Girot R, Beuzard Y, Leboeuf C, Henri A, Germain S, Dussaule JC, Tharaux PL. Endothelin receptor antagonism prevents hypoxia-induced mortality and morbidity in a mouse model of sickle-cell disease. J Clin Invest 2008; 118:1924-33.

91. Nijboer JM, van der Horst IC, Hendriks HG, ten Duis HJ, Nijsten MW. Myth or reality: hematocrit and hemoglobin differ in trauma. J Trauma 2007; 62:1310-2.

92. Polaschegg HD. Red blood cell damage from extracorporeal circulation in hemodialysis. Semin Dial 2009; 22:524-31.

93. Bryan NS, Calvert JW, Elrod JW, Gundewar S, Ji SY, Lefer DJ. Dietary nitrite supplementation protects against myocardial ischemia-reperfusion injury. Proc Natl Acad Sci U S A 2007; 104:19144-9.

94. Garg HK, Bryan NS. Dietary sources of nitrite as a modulator of ischemia/reperfusion injury. Kidney Int 2009; 75:1140-4. 

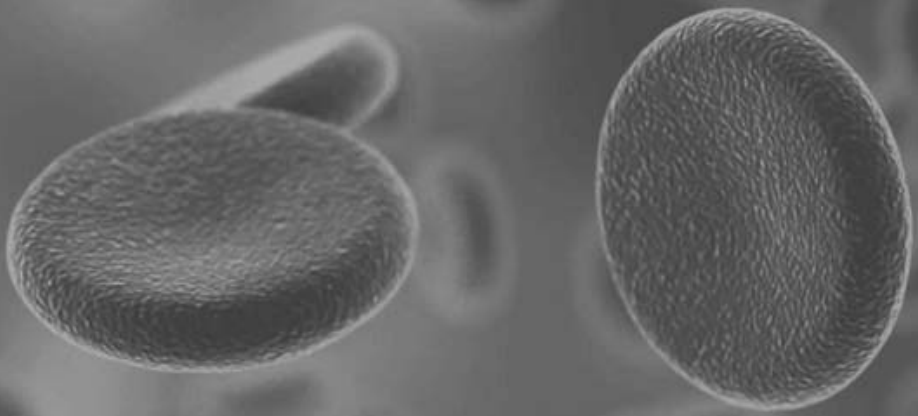


\section{Hemolysis compromises nitric oxide-dependent}

vasodilatory responses in patients undergoing major cardiovascular surgery

Sebastiaan J Hanssen, Marcel C van de Poll, Alfons J Houben, Iris C Vermeulen Windsant, Maarten G Snoeijs, Otto Bekers,

Wim A Buurman, Michael J Jacobs

The Thoracic and Cardiovascular Surgeon 2012;60:255-261 


\section{ABSTRACT}

\section{Background}

The hemolytic products cell-free oxyhemoglobin ( $\mathrm{fHb}$ ) and arginase-1 reduce nitric oxide (NO) bioavailability by scavenging of NO and by degrading the NO precursor arginine to ornithine, respectively. In this study we evaluated the relevance of hemolysis to NO-dependent blood flow in patients undergoing cardiovascular surgery.

\section{Methods}

Plasma $\mathrm{fHb}$, arginase- 1 and amino acid concentrations were measured perioperatively. Forearm blood flow (FBF) responses to the intra-arterial administered NO-donor sodium nitroprusside (SNP) and the endothelium-dependent vasodilator acetylcholine (Ach) were measured by venous occlusion plethysmography.

\section{Results}

When peak values plasma $\mathrm{fHb}$ and arginase- 1 were found, vascular dilatation to SNP, but not $\mathrm{ACh}$, was significantly reduced compared to 1 day postoperatively, when $\mathrm{fHb}$ had returned to baseline levels $(p<0.05)$. Interestingly, plasma $\mathrm{fHb}$ concentration was inversely correlated to FBF responses to SNP $\left(R_{s}=-0.93, p<0.001\right)$. In contrast, the increase in arginase- 1 was not biologically relevant since the ratio of plasma arginine to ornithine remained constant.

\section{Conclusion}

We conclude that hemolysis with concomitant release of $\mathrm{fHb}$ during cardiovascular surgery is associated with impaired NO-dependent forearm blood flow. 


\section{INTRODUCTION}

Intravascular hemolysis is associated with disturbances in endothelial nitric oxide (NO) metabolism, the key system in regulating vascular tone and microcirculatory blood flow. ${ }^{1}$ First, oxyhemoglobin $(\mathrm{fHb})$ released from injured erythrocytes reduces NO bioavailability by scavenging NO. Oxyhemoglobin in its ferrous form binds NO to generate ferric hemoglobin, also known as methemoglobin, and bioinactive nitrate $\left(\mathrm{HbFe}^{2+}-\mathrm{O}_{2}+\mathrm{NO} \rightarrow \mathrm{HbFe}^{3+}+\mathrm{NO}_{3}{ }^{-}\right)$. Second, arginase-1 release from hemolytic erythrocytes has been suggested to decrease NO production by depletion of plasma arginine, the precursor for NO synthesis, with a concomitant increase of plasma ornithine, the product of arginase- 1 activity. Both $\mathrm{fHb}$ and arginase-1 may impair NO bioavailability resulting in a compromised microcirculation. Evidence is mounting that hemolysis is an important factor in the pathogenesis of compromised microcirculation in chronic hereditary or acquired hemolytic diseases such as sickle cell disease and falciparum malaria infection. ${ }^{1}$

Hemolysis is unwanted but not uncommon in cardiovascular surgery. Extracorporeal circulation (ECC) is an inevitable part of open cardiac and thoracic- or thoracoabdominal aortic surgery and known to result in hemolysis. ${ }^{2}$ This type of surgery is also associated with considerable blood loss, leading to massive transfusion requirements. Hemolysis during storage of red blood cells intended for transfusion is associated with increased mortality rate in patients undergoing massive allogeneic transfusion. Furthermore, storage results in lower viability of erythrocytes intended for transfusion, which has been associated with clinical adverse events in the recipient such as postoperative infection, pulmonary and renal complications and multiple organ failure. ${ }^{3}$ Allogeneic transfusion requirements may be reduced by the application of cell-salvage devices during cardiovascular surgery. However, such devices lead to injury of red blood cells intended for autologous transfusion. ${ }^{4}$

Aim of the present study was first to investigate the extent of hemolysis and the concomitant release of $\mathrm{fHb}$ and arginase- 1 in patients undergoing cardiovascular surgery with extracorporeal circulation and massive transfusion including cell-salvage. Next, forearm vascular smooth muscle responses to exogenous NO in the presence of plasma $\mathrm{fHb}$ were evaluated. Lastly, the effect of elevated plasma arginase- 1 on plasma arginine and ornithine levels was evaluated.

\section{METHODS}

\section{Study subjects}

The local institutional review board approved the study and written informed consent was obtained from every patient $(N=19)$ prior to surgery. Patients, 18 years or older, 
undergoing open thoracic aortic aneurysm (TAA) or thoracoabdominal aortic aneurysm (TAAA) repair at the Maastricht University Medical Centre (Maastricht, the Netherlands) were continuously included in the study. Exclusion criteria were pregnancy, morbid obesity (> $120 \mathrm{~kg}$ or BMI > $35 \mathrm{~kg} / \mathrm{m}^{2}$ ), prolonged or high dose corticosteroid use, insulin-dependent diabetes mellitus, metastases, hematological malignancies or chemotherapy, pre-existent renal failure, liver cirrhosis, pre-existent urea cycle disorders, or any other condition that, in the physician's judgment, would make the patient an unsuitable candidate for participation in this study. In the first consecutive series of 10 patients plasma $\mathrm{fHb}$, arginase- 1 and amino acid levels were evaluated; then a consecutive series of 9 patients was included in the study to conduct forearm blood flow measurements as described below. This study design was chosen to eliminate possible confounding factors resulting from interference of the NO-donor sodium nitroprusside used in the forearm blood flow study on measurement of $\mathrm{fHb}$ levels and potentially NO metabolism, possibly affecting amino acid levels. In all cases ECC was applied using a centrifugal pump with oxygenation (Jostra Rotaflow with Jostra Quadrox, Maquet Cardiopulmonary AG, Hirrlingen, Germany) in combination with a cell-saver (CATS, Fresenius SE, Bad Homburg, Germany). Surgical procedures are extensively described elsewhere., Intraoperatively and post-operatively the motor evoked potentials were constantly monitored in our patients to evaluate spinal cord function. During ICU-stay, using inotropic drugs when necessary, the mean arterial pressure was kept between 70 and $90 \mathrm{mmHg}$, in general this was sufficient to reach adequate motor evoked potentials.

All patients had an indwelling radial artery catheter that was placed as part of standard anesthetic care. Postoperatively, all patients were transported to the Cardiothoracic Intensive Care Unit for postoperative monitoring and circulatory and ventilatory support. Patients were warmed up to $37^{\circ} \mathrm{C}$ before leaving the OR, and were kept at $37^{\circ} \mathrm{C}$ during their ICU stay, using filtered-air warming blankets when necessary. Patient characteristics and intraoperative data are reported in Table 5.1.

\section{Blood sampling, sample processing and laboratory analysis}

Arterial blood was drawn preoperatively and at several time points during and after surgery and collected in vacuum tubes containing EDTA (Becton Dickinson, Franklin Lakes, NJ). Whole blood was centrifuged ( $\left.3500 \times \mathrm{G}, 4^{\circ} \mathrm{C}, 15 \mathrm{~min}\right), 100 \mu \mathrm{l}$ plasma was deproteinized with $8 \mathrm{mg}$ sulphosalicylic acid (SSA) and stored at $-80^{\circ} \mathrm{C}$, the remainder was stored untreated $\left(-80^{\circ} \mathrm{C}\right)$ for $\mathrm{fHb}$ and arginase- 1 analysis. $\mathrm{fHb}$ concentrations were measured by derivative spectrometry as described elsewhere. ${ }^{7}$ Arginase- 1 concentrations were measured using Enzyme-Linked Immuno Sorbent Assay (ELISA) ${ }^{8}$ kindly provided by Hycult biotechnology, Uden, the Netherlands. The detection limits of the assays were $2 \mu \mathrm{mol} / \mathrm{l}(\mathrm{fHb})$ and $21 \mu \mathrm{g} / \mathrm{l}$ (arginase-1). Amino acid levels were 
analyzed in SSA samples by high performance liquid chromatography as described before. $^{9}$

Table 5.1 Characteristics of patients undergoing open TAA or TAAA repair

\begin{tabular}{lcc}
\hline & Initial study & FBF study \\
& $(\mathrm{N}=10)$ & $\mathrm{N}=9)$ \\
\hline Patients (N) & 10 & 2 \\
TAA & 0 & \\
TAA* & & 1 \\
TAAA I & 0 & 2 \\
TAAA II & 3 & 2 \\
TAAA III & 4 & 2 \\
TAAA IV & 3 & 5 \\
Male (N) & 7 & $63.7 \pm 2.0$ \\
Age (Years) & $68.0 \pm 2.2$ & 6 \\
(Ex-) Smoker with >10 pack-years (N) & 8 & 7 \\
Hypertension (N) & 8 & 4 \\
Dyslipidaemia (N) & 6 & - \\
NIDDM (N) & 1 & $100.6 \pm 28.4$ \\
ACC time (min) & $89.7 \pm 14.3$ & $139.9 \pm 35.5$ \\
ECC time (min) & $161.8 \pm 15.5$ & $2.8 \pm 0.6$ \\
Flow ECC (L/min) & $2.5 \pm 0.1$ & $0.24 \pm 0.01$ \\
Patient hematocrit during ECC (L/L) & $0.27 \pm 0.01$ & $14.3 \pm 5.1$ \\
Estimated blood loss (L) & $16.6 \pm 2.6$ & $1.7 \pm 0.7$ \\
Infused fresh frozen plasma (L) & $2.9 \pm 0.5$ & $5.4 \pm 0.9$ \\
Infused crystalloids (L) & $6.5 \pm 0.9$ & $3.4 \pm 0.7$ \\
Infused colloids (L) & $5.1 \pm 1.0$ & $3.3 \pm 1.0$ \\
Transfused allogeneic blood (L) & $3.3 \pm 0.5$ & $5.0 \pm 1.8$ \\
Transfused autologous cell-salvage blood (L) & $5.9 \pm 1.1$ & $400.4 \pm 44.8$ \\
Total operation time (min) & $424.2 \pm 25.5$ & \\
\hline
\end{tabular}

Abbreviations: TAA, thoracic aortic aneurysm; TAAA, thoracoabdominal aortic aneurysm; NIDDM, noninsulin dependent diabetes mellitus; ACC, aorta cross clamp; ECC, extracorporeal circulation. *TAAA classification is according to Crawford. Continues variables are expressed as mean \pm SEM.

\section{Forearm blood flow measurements and NO reactivity}

Forearm blood flow (FBF) served as a model for organ perfusion and was measured using venous occlusion plethysmography as described previously. ${ }^{10} \mathrm{FBF}$ measurements in the non-dominant arm were conducted immediately upon arrival at the Cardiothoracic Intensive Care Unit approximately 2 hours following cessation of ECC and massive transfusion including cell-salvage, and again 24 hours later.

FBF was measured before and during infusion of vasoactive substances in the brachial artery of the study arm. An endothelium-independent vasodilator (NO-donor sodium nitroprusside (SNP), Spruyt Hillen BV, IJsselstein, the Netherlands), as well as an endothelium-dependent vasodilator (Acetylcholine (ACh), Clinalfa, Läufelfingen, Switzerland) was used. Both substances were infused in two accumulating dosages 
(SNP $1 \mu \mathrm{g} / \mathrm{min}$ and $10 \mu \mathrm{g} / \mathrm{min}$; ACh $3 \mu \mathrm{g} / \mathrm{min}$ and $30 \mu \mathrm{g} / \mathrm{min} ; 3 \mathrm{~min} /$ dosage) in all patients, during which the mean arterial pressure at that time remained between $70-90 \mathrm{mmHg}$. The order of SNP and ACh was randomly chosen with a washout period of 30 minutes between SNP and ACh infusion.

\section{Statistics}

Changes versus preoperative values in plasma $\mathrm{fHb}$, arginase- 1 and amino acid concentrations were analyzed using repeated-measures ANOVA with post hoc Dunnet's multiple comparison test using pre-operative values as control. Changes in FBF measurements were tested using Wilcoxon signed rank tests. Statistical calculations were made using Prism 4.0 for Windows (GraphPad Software Inc. San Diego, CA). Data are expressed as mean \pm SEM. Results were considered significant at $p<0.05$

\section{RESULTS}

\section{Hemolysis during open TAA / TAAA repair}

Plasma levels of $\mathrm{fHb}$ and arginase-1, used as markers for hemolysis, were within normal ranges prior to surgery (Figure 5.1). After initiation of the ECC, fHb and arginase-1 levels increased and peak plasma levels were found at 2 hours in the reperfusion phase $(2 \mathrm{~h} R$ ), indicating ongoing lysis of red blood cells after cessation of ECC. Spearman correlation analysis between areas under the curve of each parameter for every individual patient revealed a significant association between $\mathrm{fHb}$ and arginase- 1 release $\left(R_{s}=0.83, p<0.01\right)$.

\section{Forearm vascular smooth muscle responses to exogenous NO}

Increased plasma concentrations of cell-free hemoglobin may limit NO-mediated vasodilatation. Therefore, we studied FBF in a series of nine consecutive patients undergoing TAAA repair (Figure 5.2). Plasma $\mathrm{fHb}$ levels were measured in these patients before FBF measurements began ( $2 \mathrm{~h} \mathrm{R}: 20.9 \pm 6.5 \mu \mathrm{mol} / \mathrm{l}$ vs. Day 1: $3.8 \pm 0.5 \mu \mathrm{mol} / \mathrm{l}, \mathrm{p}<0.05)$ and were comparable to those measured in the first series of patients (see Figure 5.1). 


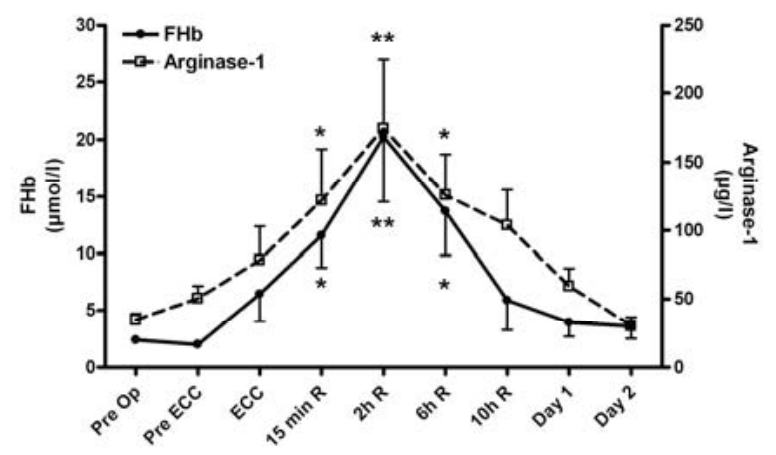

Figure 5.1 Markers of hemolysis in patients undergoing major cardiovascular surgery Circulating plasma $\mathrm{fHb}$ and arginase-1 during open thoracic - / thoracoabdominal aortic aneurysm repair reached peak values at 2 hours in the reperfusion phase $(2 h \mathrm{~h})$. Both markers of hemolysis had returned to preoperative range at the first postoperative day. Spearman correlation analysis revealed a significant association between both variables $\left(R_{s} 0.83, p<0.01\right)$. Abbreviations: Op, operation; ECC, extracorporeal circulation; R, reperfusion, ${ }^{*} p<0.05 ;{ }^{*} p<0.01$.

Blood flow responses to SNP, an endothelium-independent NO-donor, were measured postoperatively ( $2 \mathrm{~h} \mathrm{R}$ ) and at day 1 postoperative (Day 1 ). FBF responses to SNP were significantly reduced direct postoperatively when compared to the first postoperative day $(p<0.05$; Figure 5.2A). Interestingly, using Spearman correlation analysis at $2 \mathrm{~h} \mathrm{R}$, forearm blood flow was negatively correlated with plasma fHb for both dosages studied (SNP $1 \mu \mathrm{g} / \mathrm{min}$ Spearman $R_{\mathrm{s}}=-0.89, \mathrm{p}<0.01$; SNP $10 \mu \mathrm{g} / \mathrm{min} \mathrm{Rs}=-0.93$, $\mathrm{p}<0.001$, Figure 5.2B). To control for vasodilatory capacity the response to exogenous ACh, a vasodilator that induces hyperpolarization of the endothelial smooth muscle cells, was assessed at the same time points. The dose response reaction to ACh was not significantly different at $2 \mathrm{~h} R$ versus Day 1 , indicating unchanged potent vasodilatory capacity (Figure $\mathbf{5 . 2 C}$ ). All patients were cardiopulmonary stable before, during and after the FBF measurements in which the mean arterial pressure remained between $70-90 \mathrm{mmHg}$, regardless of the dosage SNP or Ach used.

Taken together, these data indicate a deleterious effect of hemolytic product $\mathrm{fHb}$ on NO-dependent blood flow responses, whereas NO-independent blood flow responses remained unchanged around cardiovascular surgery with ECC and massive transfusion including cell-salvage. 



Figure 5.2 High levels of $\mathrm{fHb}$ correlate with an impaired NO-bioactivity in vivo. (A) After infusion of the NO-donor sodium nitroprusside (SNP) forearm blood flow (FBF) measurements revealed reduced smooth muscle response at 2 hours reperfusion $(2 h R)$, when $\mathrm{fHb}$ levels peaked (see Figure 5.1). At the first postoperative day (Day 1) FBF was significantly higher after infusion of SNP, indicating smooth muscle relaxation to exogenous NO infusion was restored. (B) Single exponential decay curve-fit was evaluated by plotting individual FBF responses to SNP at $2 \mathrm{~h} R$ against plasma $\mathrm{fHb}$ levels. Using Spearman correlation test, increasing levels of $\mathrm{fHb}$ appeared negatively correlated with FBF responses to SNP for both dosages (SNP $1 \mu \mathrm{g} / \mathrm{min} \mathrm{R}_{\mathrm{s}}=-0.89, \mathrm{p}<$ 0.01; SNP $10 \mu \mathrm{g} / \mathrm{min} \mathrm{R}_{\mathrm{s}}=-0.93, \mathrm{p}<0.001$ ). Importantly, these findings reproduce data from Reiter et al. in 2002, evaluating plasma $\mathrm{fHb}$ versus SNP responses in sickle-cell disease patients $^{28}$. (C) Infusion with Acetylcholine (ACh), which acts predominantly via hyperpolarization induced vasodilatation, at $2 \mathrm{~h} R$ and Day 1 revealed a similar endothelial smooth muscle reaction to both dosages infused. Basal flow was set at $100 \%$ for every measurement. ${ }^{*} \mathrm{p}<0.05 ;{ }^{* *} \mathrm{p}<0.01$. 


\section{In vivo indices of arginase-1 activity}

Plasma arginase-1 activity potentially leads to a decreased plasma arginine concentration with a concomitant elevated plasma ornithine concentration. To test for arginase-1 activity, we measured plasma levels of arginine and ornithine. Also, for each individual patient plasma arginine / ornithine ratio was calculated at every time-point (Figure 5.3). Plasma arginine and ornithine levels decreased during and after the operation just as several other amino acids (data not shown). Despite increasing plasma levels of arginase-1 (see Figure 5.1) no significant changes in plasma arginine / ornithine ratio were observed during the studied period. Moreover, correlation analysis between the increase of plasma arginase- 1 and the decrease of plasma arginine levels for each individual patient revealed no association between both parameters (Spearman $R_{s}=0.55 ; p=0.105$ ). These results do not support increased plasma arginase- 1 activity in cardiovascular patients undergoing ECC with massive transfusion including cell-salvage.

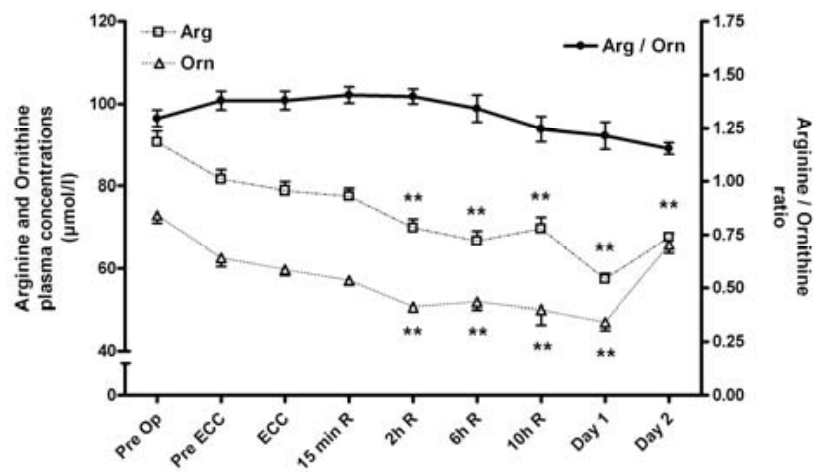

Figure 5.3 Plasma amino acid levels. To evaluate plasma arginase-1 activity the substrate plasma arginine (Arg) and product, plasma ornithine (Orn) levels were measured. Arginine / ornithine ratio (Arg / Orn) was calculated to appraise plasma arginase-1 activity. Arg / Orn ratio was not significantly altered during the study, indicating no increased plasma arginase- 1 activity. Abbreviations: Op, operation; ECC, extracorporeal circulation; R, reperfusion, h, hours; min, minutes, $* * p<0.01$.

\section{DISCUSSION}

In this study hemolysis, represented by elevated plasma $\mathrm{fHb}$ and arginase- 1 levels, was observed in cardiovascular patients who underwent ECC and massive transfusion including cell-salvage. NO is the central component in regulation of vasodilatation and maintaining adequate tissue oxygenation and function. Therefore, interference in NO 
metabolism, either by scavenging of $\mathrm{NO}$ via $\mathrm{fHb}$ or by depletion of the NO substrate arginine, may result in vasoconstriction, modulation of platelet activation, enhanced leukocyte adhesion and oxygen free-radical generation in the vascular compartment. ${ }^{11}$ These disturbances can lead to clinical symptoms such as systemic and pulmonary hypertension, intravascular thrombosis, ischemic cerebrovascular events, priapism and paroxysmal nocturnal hemoglobinuria; all these phenomena are associated with hemolytic crisis in experimental, hereditary or acquired chronic hemolytic diseases. ${ }^{12,13}$ This study is directed at investigating acute effects of hemolysis during and after surgery. We have now shown that hemolysis, in particular the release of $\mathrm{fHb}$, is associated with an acutely impaired NO-mediated vasodilatory capacity in cardiovascular patients undergoing ECC with massive transfusion and cell-salvage.

Elevated plasma $\mathrm{fHb}$ in patients undergoing ECC has been described previously; furthermore, $\mathrm{fHb}$ is commonly used as a hemolytic marker when ECC is used. Massive allogeneic transfusion, to cope for considerable blood loss during surgery, contributes to increased levels of plasma $\mathrm{fHb}$, whereas red blood cell damage occurring in cellsalvage devices is also likely to increase levels of circulating plasma $\mathrm{fHb}^{4,14}$ Surprisingly, peak plasma $\mathrm{fHb}$ levels were found 2 hours after cessation of the ECC when patients arrived at the Cardiothoracic Intensive Care Unit. Transfusion requirements, both red blood cell and plasma, at that time were minimal and cell-saver blood product had been administered to the patients before transportation to the Cardiothoracic Intensive Care Unit. These data suggest that hemolysis is ongoing after ECC is terminated and the observed increase is a result of exhaustion of natural $\mathrm{fHb}$ scavengers such as haptoglobin and CD163. ${ }^{15,16}$ Also, the fact that arginase-1, which has a plasma half-life of 40 minutes $^{17}$ increased in this time-period, suggests that ongoing hemolysis explains the increase in $\mathrm{fHb}$.

It is known that $\mathrm{fHb}$ can be filtered by the kidney under normal physiologic circumstances, as well as during impaired renal function. Therefore, an effect of renal dysfunction on the clearance of $\mathrm{fHb}$, leading to prolonged elevated $\mathrm{fHb}$ levels, cannot be excluded. Meyer et al. report in their study that in patients requiring hemodialysis $\mathrm{fHb}$ is elevated at baseline before hemodialyse $(12.2 \pm 9.1 \mu \mathrm{M})$ as compared with values reported for control subjects, who are in the nanomolar range. ${ }^{18}$ This suggests that in this patient population the renal clearance of $\mathrm{fHb}$ is impaired. However, this was measured in patients with end-stage renal failure, whereas in our study no patients were included with end-stage renal disease that needed pre-operative or post-operative dialysis.

Plasma $\mathrm{fHb}$ is thought to extravasate into the surrounding extracellular compartment, increasing its potential to interfere with endogenously produced NO thereby further challenging the vasodilatory capacity of vascular smooth muscle cells. ${ }^{19}$ Hence, we evaluated whether levels of $\mathrm{fHb}$ were correlated with reduced vascular smooth muscle 
reaction to exogenous NO. The results of our study show that the responses to the NOdonor SNP were significantly lower when plasma $\mathrm{fHb}$ was elevated compared with measurements 24 hours later, when plasma $\mathrm{fHb}$ had returned to baseline levels. The observed decreased responses to exogenous NO were strongly correlated with plasma $\mathrm{fHb}$ levels in a way similar to what has been reported by Reiter et al. in 2002 evaluating plasma $\mathrm{fHb}$ and SNP responses in patients with sickle cell disease. This indicates that across diseases, this process is reproducible.

To test for endothelial dysfunction we evaluated responses to the vasodilator ACh, which acts predominantly via hyperpolarization of endothelial smooth muscle cells resulting in $\mathrm{Ca}^{2+}$ influx with a concomitant vasodilatory response, and to a lesser extent via induction of NO synthesis. ${ }^{20}$ Near equally potent endothelial vasodilatory capacities at both time-points were found after ACh infusion, representing viable endothelial function. Taken together, these data show scavenging of exogenously infused NO (SNP) and support also the general hypothesis of endogenously produced NOscavenging by $\mathrm{fHb}$.

Arginase-1 release can be the result of both hemolysis and hepatocyte injury. Since the kinetics of arginase-1 release in the present study correlated significantly with the release of $\mathrm{fHb}$, hemolysis appears to be the primary cause of elevated plasma arginase1. Furthermore, recent data from our group indicate that the activity of plasma arginase-1, at concentrations found in our patients is too low to exert a substantial and lasting effect on plasma arginine, the substrate for NO metabolism. ${ }^{17}$ Only plasma arginase-1 levels of $1500 \mu \mathrm{g} / \mathrm{l}$ or higher, as found after deceased donor liver transplantation were able to reduce plasma arginine and increase plasma ornithine levels, potentially hampering NO metabolism. ${ }^{17}$ Plasma arginine levels in our patients decreased in parallel with ornithine and other amino acid concentrations as has been described previously after cardiovascular surgery with ECC. ${ }^{21}$ In line, Arg / Orn ratio in the present study remained unchanged. Moreover, we found no association between elevated plasma arginase-1 levels and decreased plasma arginine levels. We conclude therefore, that NO-production in our patient population was not hampered by plasma arginase-1 activity.

Whereas the potential consequences of hemolysis are recently reported for chronic hemolytic diseases, such as sickle cell disease, here we present data that hemolysis is likely to have also consequences for cardiovascular, cardiothoracic and trauma surgery patients. Data from our group show that cardiovascular surgery is associated with intestinal mucosal injury during the post-operative period ${ }^{6}$ as well as acute kidney injury, which are strongly associated with inflammation and worse patient outcome. ${ }^{22}$ Recently, we found that the total release of plasma $\mathrm{fHb}$ was independently correlated with the kidney injury marker $\mathrm{N}$-acetyl glucosaminidase, which in turn was independently associated with the postoperative increase in serum creatinine, used as 
marker for acute kidney injury. ${ }^{23}$ Further studies are underway to evaluate correlations between perioperative disturbances in vasoregulation and clinical outcome in cardiovascular surgical patients. Also, the potential effect of hemolysis on induction of vascular inflammation, oxidative stress and blood-pressure regulation during elevated levels of circulating $\mathrm{fHb}$ remains unclear and need to be addressed in future studies. In conclusion, our data show diminished vascular smooth muscle reactivity to NO during hemolysis in cardiovascular surgical patients, compromising forearm blood flow, which we attribute to elevated levels of circulating $\mathrm{fHb}$. Such acute disturbances in NO-dependent blood flow potentially contribute to organ injury after cardiovascular surgery. We therefore suggest that either hemolysis should be prevented, or the deleterious effects of $\mathrm{fHb}$ should be counteracted in clinical practice to restore NOdependent blood flow in cardiovascular patients undergoing ECC and massive transfusion including cell-salvage as was recently reviewed. ${ }^{24}$ 


\section{REFERENCES}

1. Rother RP, Bell L, Hillmen P, Gladwin MT. The clinical sequelae of intravascular hemolysis and extracellular plasma hemoglobin: a novel mechanism of human disease. Jama 2005;293:1653-62.

2. Maruyama O, Numata Y, Nishida M, Yamane T, Oshima I, Adachi Y, Masuzawa T. Hemolysis caused by surface roughness under shear flow. J Artif Organs 2005;8:228-36.

3. Koch CG, Li L, Sessler DI, Figueroa P, Hoeltge GA, Mihaljevic T, Blackstone EH. Duration of red-cell storage and complications after cardiac surgery. N Engl J Med 2008;358:1229-39.

4. Serrick CJ, Scholz M, Melo A, Singh O, Noel D. Quality of red blood cells using autotransfusion devices: a comparative analysis. J Extra Corpor Technol 2003;35:28-34.

5. Jacobs MJ, Mommertz G, Koeppel TA, Langer S, Nijenhuis RJ, Mess WH, Schurink GW. Surgical repair of thoracoabdominal aortic aneurysms. J Cardiovasc Surg (Torino) 2007;48:49-58.

6. Hanssen SJ, Derikx JP, Vermeulen Windsant IC, Heijmans JH, Koeppel TA, Schurink GW, Buurman WA, Jacobs MJ. Visceral injury and systemic inflammation in patients undergoing extracorporeal circulation during aortic surgery. Ann Surg 2008;248:117-25.

7. Cruz-Landeira A, Bal MJ, Quintela, Lopez-Rivadulla M. Determination of methemoglobin and total hemoglobin in toxicological studies by derivative spectrophotometry. J Anal Toxicol 2002;26:67-72.

8. Ikemoto M, Tsunekawa S, Awane M, Fukuda Y, Murayama H, Igarashi M, Nagata A, Kasai Y, Totani M. A useful ELISA system for human liver-type arginase, and its utility in diagnosis of liver diseases. Clin Biochem 2001;34:455-61.

9. van Eijk HM, Rooyakkers DR, Deutz NE. Rapid routine determination of amino acids in plasma by highperformance liquid chromatography with a 2-3 microns Spherisorb ODS II column. J Chromatogr 1993;620:143-8.

10. Houben AJ, Schaper NC, de Haan CH, Huvers FC, Slaaf DW, de Leeuw PW, Nieuwenhuijzen Kruseman C. Local 24-h hyperglycemia does not affect endothelium-dependent or -independent vasoreactivity in humans. Am J Physiol 1996;270:H2014-20.

11. Taddei S, Virdis A, Ghiadoni L, Versari D, Salvetti A. Which endothelium-derived factors are really important in humans? Biol Chem 2006;387:151-7.

12. Minneci PC, Deans KJ, Zhi H, Yuen PS, Star RA, Banks SM, Schechter AN, Natanson C, Gladwin MT, Solomon SB. Hemolysis-associated endothelial dysfunction mediated by accelerated NO inactivation by decompartmentalized oxyhemoglobin. J Clin Invest 2005;115:3409-17.

13. Morris CR, Kato GJ, Poljakovic M, Wang X, Blackwelder WC, Sachdev V, Hazen SL, Vichinsky EP, Morris $\mathrm{SM} J \mathrm{r}$, Gladwin MT. Dysregulated arginine metabolism, hemolysis-associated pulmonary hypertension, and mortality in sickle cell disease. Jama 2005;294:81-90.

14. Nishiyama T, Hanaoka K. Free hemoglobin concentrations in patients receiving massive blood transfusion during emergency surgery for trauma. Can J Anaesth 2000;47:881-5.

15. Tanaka K, Kanamori Y, Sato T, Kondo C, Katayama Y, Yada I, Yuasa H, Kusagawa M. Administration of haptoglobin during cardiopulmonary bypass surgery. ASAIO transactions / American Society for Artificial Internal Organs 1991;37:M482-3.

16. Schaer DJ, Schaer CA, Buehler PW, Boykins RA, Schoedon G, Alayash Al, Schaffner A. CD163 is the macrophage scavenger receptor for native and chemically modified hemoglobins in the absence of haptoglobin. Blood 2006;107:373-80.

17. van de Poll MC, Hanssen SJ, Berbée M, Deutz NE, Monbaliu D, Buurman WA, Dejong CH. Elevated plasma arginase-1 does not affect plasma arginine in patients undergoing liver resection. Clin Sci 2008;114:231-41.

18. Meyer C, Heiss C, Drexhage C, Kehmeier ES, Balzer J, Mühlfeld A, Merx MW, Lauer T, Kühl H, Floege J, Kelm M, Rassaf T. Hemodialysis-induced release of hemoglobin limits nitric oxide bioavailability and impairs vascular function. J Am Coll Cardiol 2010;55:454-9.

19. Schechter AN, Gladwin MT. Hemoglobin and the paracrine and endocrine functions of nitric oxide. $N$ Engl J Med 2003;348:1483-5.

20. Takaki A, Morikawa K, Tsutsui M, Murayama Y, Tekes E, Yamagishi H, Ohashi J, Yada T, Yanagihara N, Shimokawa H. Crucial role of nitric oxide synthases system in endothelium-dependent hyperpolarization in mice. J Exp Med 2008;205:2053-63. 
21. Barr FE, Beverley H, VanHook K, Cermak E, Christian K, Drinkwater D, Dyer K, Raggio NT, Moore JH, Christman B, Summar M. Effect of cardiopulmonary bypass on urea cycle intermediates and nitric oxide levels after congenital heart surgery. J Pediatr 2003;142:26-30.

22. Welborn MB, Oldenburg HS, Hess PJ, Huber TS, Martin TD, Rauwerda JA, Wesdorp RI, Espat NJ, Copeland EM 3rd, Moldawer LL, Seeger JM. The relationship between visceral ischemia, proinflammatory cytokines, and organ injury in patients undergoing thoracoabdominal aortic aneurysm repair. Crit Care Med 2000;28:3191-7.

23. Vermeulen Windsant IC, Snoeijs MG, Hanssen SJ, Altintas S, Heijmans JH, Koeppel TA, Schurink GW, Buurman WA, Jacobs MJ. Hemolysis is associated with acute kidney injury during major aortic surgery. Kidney Int 2010;77:913-20.

24. Vermeulen Windsant IC, Hanssen SJ, Buurman WA, Jacobs MJ. Cardiovascular surgery and organ damage; time to reconsider the role of hemolysis. J Thorac Cardiovasc Surg 2011; 142:1-11. 




\section{Hemolysis is associated with acute kidney injury}

\section{during major aortic surgery}

Iris C Vermeulen Windsant, Maarten G Snoeijs, Sebastiaan J Hanssen,

Sibel Altintas, John H Heijmans, Thomas A Koeppel, Geert Willem H Schurink, Wim A Buurman, Michael J Jacobs 


\section{ABSTRACT}

Acute kidney injury severely affects patient morbidity and mortality after on-pump cardiovascular surgery. Hemolysis is an inevitable side-effect of cardiopulmonary bypass and results in increased plasma free hemoglobin that may impair tissue perfusion by scavenging nitric oxide. We studied the effect of acute hemolysis on renal injury in 35 patients undergoing on-pump surgical repair of thoracic and thoracoabdominal aortic aneurysms. After surgery, 19 (54\%) patients suffered acute kidney injury (AKIN classification). During surgery, plasma free hemoglobin and the tubular injury marker urine $\mathrm{N}$-acetyl- $\beta$-D-glucosaminidase increased in patients with and without acute kidney injury, reaching peak levels at 2 hours and 15 minutes after reperfusion, respectively. Furthermore, plasma free hemoglobin was independently correlated with urine $\mathrm{N}$-acetyl- $\beta$-D-glucosaminidase $(\mathrm{p}=0.001)$, which in turn was independently associated with the postoperative increase in serum creatinine $(p=0.002)$. Importantly, peak plasma free hemoglobin and urine $\mathrm{N}$-acetyl- $\beta$-D-glucosaminidase concentrations had significant predictive value for postoperative acute kidney injury (area under the ROC-curve 0.73 and 0.76 , $p=0.04$ and $p=0.01$ respectively). The association between increased plasma free hemoglobin and renal injury cast new light on the pathophysiology of acute kidney injury and offers a novel therapeutic target to improve clinical outcome after on-pump cardiovascular surgery. 


\section{INTRODUCTION}

Acute kidney injury (AKI) is an important complication of major cardiovascular surgery that affects $3-48 \%$ of patients and is independently associated with mortality. ${ }^{1-3}$ Currently, specific therapies for postoperative acute kidney injury are not available and patients generally receive supportive care until renal function has recovered spontaneously. ${ }^{4}$ Development of novel interventions to reduce AKI after major cardiovascular surgery requires detailed knowledge of its pathophysiology, which is characterized by a complex interplay of renal vascular dysfunction, tubular epithelial injury and inflammation. ${ }^{5}$

In cardiovascular surgery, the use of cardiopulmonary bypass is associated with acute kidney injury. ${ }^{6,7}$ Hemolysis is a common consequence of cardiopulmonary bypass that is caused by mechanical stress in the perfusion circuit and results in the release of hemoglobin from lysed erythrocytes into the plasma. ${ }^{8,9}$ Cell-free oxyhemoglobin reacts with nitric oxide to form methemoglobin and nitrate. Since nitric oxide is an important vasodilator that plays a central role in blood flow regulation, reduction of nitric oxide bioavailability by free hemoglobin ( $\mathrm{fHb}$ ) may impair tissue perfusion. ${ }^{10}$ Indeed, addition of $6 \mu \mathrm{M}$ oxyhemoglobin to the perfusion solution of isolated rabbit hearts completely eliminates the activity of endothelium-derived nitric oxide. ${ }^{11}$ In line with this finding, patients with chronic hemolysis due to sickle cell disease are characterized by an attenuated rise in forearm blood flow after infusion of the nitric oxide donor sodium nitroprusside as compared to healthy volunteers; forearm blood flow response was reduced by $80 \%$ in patients with plasma $\mathrm{fHb}$ concentrations over $6 \mu \mathrm{M} .^{10,12}$ In addition, after glomerular ultrafiltration, urine $\mathrm{fHb}$ may cause acute kidney injury by generating reactive oxygen species and by aggregating into casts in the tubular lumen. ${ }^{13,14}$

Until now, human studies have focused on the association between urinary free hemoglobin and acute kidney injury. ${ }^{13}$ The vasoconstrictive effects of $\mathrm{fHb}$ in plasma may provide an additional explanation for hemolysis-induced renal injury. In the current study, we show that increased plasma $\mathrm{fHb}$ concentrations are independently associated with injury to the proximal tubular epithelium during open surgical repair of thoracic and thoracoabdominal aortic aneurysms with cardiopulmonary bypass. Moreover, plasma fHb levels 2 hours after surgery predicted acute kidney injury in the early postoperative period. This finding casts new light on the pathophysiology of AKI and offers a novel therapeutic target to improve clinical outcome after major cardiovascular surgery. 


\section{RESULTS}

\section{Open repair of thoracic and thoracoabdominal aortic aneurysms with cardiopulmonary bypass causes AKI}

We studied 35 consecutive patients undergoing open repair of a thoracic aortic aneurysm ( $\mathrm{N}=1$ ) or thoracoabdominal aortic aneurysm $(\mathrm{N}=34)$ with cardiopulmonary bypass. Clinical data are presented in Table 6.1. None of the patients were diagnosed with preoperative hemolytic disease. Overall in-hospital mortality was $20 \%(N=7)$, there were no intraoperative deaths. Nineteen patients (54\%) developed postoperative AKI (Table 6.1) as defined by the AKIN classification. Mortality was numerically higher in AKI patients compared to patients without AKI (32\%, N = 6; vs. $6 \%, N=1$ ), but this difference did not reach statistical significance $(p=0.10)$. Renal function fully recovered during hospitalization in $85 \%$ ( $N=11$ out of 13 ) of surviving AKI patients. In the two remaining AKI patients, renal function improved from Stage 3 to Stage 2. The impact of AKI on overall patient outcome was reflected by a trend towards longer hospitalization times (21 (13-34) days vs. 14 (12-16) days, $p=0.05$ ), and ICU-admission times (7 (4-28) days vs. 4 (3-7) days, $p=0.11$ ) in AKI vs. non-AKI patients, respectively. Baseline renal function (glomerular filtration rate (eGFR) estimated by the abbreviated Modification of Diet in Renal Disease (MDRD) equation $\left.{ }^{15}\right)$ did not differ between patients with or without postoperative AKI $(95 \pm 43$ and $77 \pm 30 \mathrm{ml} / \mathrm{min} / 1.73 \mathrm{~m}^{2}$ respectively, $\mathrm{p}=0.28$ ).

\section{Open repair of thoracic and thoracoabdominal aortic aneurysms results in hemolysis}

To study the development of hemolysis during surgery, plasma fHb levels were analyzed at 8 preset perioperative time-points from preoperative until the second postoperative day. Preoperative $\mathrm{fHb}$ levels were comparable to values measured in healthy subjects $(<4 \mu \mathrm{M})$. At the end of cardiopulmonary bypass, plasma $\mathrm{fHb}$ levels had risen significantly in AKI patients $(p<0.05)$ compared to baseline values (Figure 6.1A). Plasma fHb values further increased in both groups in the first few hours after cessation of cardiopulmonary bypass $(p<0.001)$ and remained elevated above the preoperative level during the first two postoperative days. Comparison of plasma fHb levels between patients with and without postoperative acute kidney injury (Figure 6.1B) showed that at two hours after reperfusion plasma $\mathrm{fHb}$ was significantly higher in AKI patients $(16.6 \pm 12.4 \mu \mathrm{M}$ vs. $7.9 \pm 4.2 \mu \mathrm{M}, \mathrm{p}<0.05)$. Overall, plasma fHb concentrations of $6 \mu \mathrm{M}$ or more, levels associated with a reduction in microcirculatory blood flow, were measured in $83 \%$ of patients at any time point during the study period. Urine $\mathrm{fHb}$ was undetectable $(<2 \mu \mathrm{M})$ in all patients, suggesting that glomerular 
filtration of $\mathrm{fHb}$ is unlikely to be a major contributor to acute kidney injury after cardiovascular surgery.

Table 6.1 Characteristics of patients undergoing open surgical repair for thoracic or thoracoabdominal aortic aneurysms with cardiopulmonary bypass.

\begin{tabular}{|c|c|c|c|}
\hline Preoperative variables* & $\begin{array}{l}\text { Non-AKI } \\
(\mathrm{N}=16)\end{array}$ & $\begin{array}{c}\text { AKI } \\
(N=19)\end{array}$ & $\mathrm{p}$-value \\
\hline Age (years), median (IQR) & $58(54-66)$ & $68(56-72)$ & 0.14 \\
\hline Male, $n(\%)$ & $9(56)$ & $14(74)$ & 0.31 \\
\hline Indication $n(\%)$ & & - & 0.04 \\
\hline TAA & $1(6)$ & $0(0)$ & \\
\hline TAAA type $I^{+}$ & $2(13)$ & $1(5)$ & \\
\hline TAAA type $\|^{+}$ & $2(13)$ & $9(47)$ & \\
\hline TAAA type $\mathrm{II}^{+}$ & $7(44)$ & $5(21)$ & \\
\hline TAAA type IV $^{+}$ & $1(6)$ & $0(0)$ & \\
\hline TAAA type $V^{+}$ & $3(19)$ & $5(26)$ & \\
\hline Concomitant aortic disease, $n(\%)$ & & - & 0.50 \\
\hline Type B-dissection (Stanford classification) & $2(13)$ & $4(21)$ & \\
\hline Marfan disease & $2(13)$ & $1(5)$ & \\
\hline Aortic stenosis (high grade) & $2(13)$ & $0(0)$ & \\
\hline eGFR $\left(\mathrm{ml} / \mathrm{min} / 1.73 \mathrm{~m}^{2}\right)^{\#}$, mean \pm s.d. & $77 \pm 30$ & $95 \pm 43$ & 0.28 \\
\hline Chronic Kidney Disease (eGFR<60), $n(\%)$ & $8(28)$ & $9(31)$ & 0.70 \\
\hline \multicolumn{4}{|l|}{ Intraoperative variables* } \\
\hline Selective organ perfusion, $n(\%)$ & $14(88)$ & $19(100)$ & 0.20 \\
\hline Total operation time (min), mean \pm s.d. & $369 \pm 92$ & $433 \pm 96$ & 0.06 \\
\hline Cardiopulmonary byass time $(\mathrm{min})$, mean \pm s.d. & $163 \pm 56$ & $195 \pm 64$ & 0.14 \\
\hline Aortic cross clamp time (min), mean \pm s.d. & $114 \pm 58$ & $144 \pm 71$ & 0.21 \\
\hline Blood loss (L), median (IQR) & $8(5-25)$ & $8(6-21)$ & 0.86 \\
\hline Packed cell transfusion ( $\mathrm{n} \times 350 \mathrm{ml}$ units), median (IQR) & $10(7-16)$ & $10(7-18)$ & 0.95 \\
\hline \multicolumn{4}{|l|}{ Postoperative variables* } \\
\hline In hospital mortality, $n(\%)$ & $1(6)$ & $6(31)$ & 0.10 \\
\hline Total intensive care unit stay (days), median (IQR) & $4(3-7)$ & $7(4-28)$ & 0.11 \\
\hline Total hospitalization time (days), median (IQR) & $14(12-16)$ & $21(13-34)$ & 0.06 \\
\hline Creatinine change $<48 \mathrm{~h}(\%)$, median (IQR) & $115(93-129)$ & $243(166-300)$ & $<.001$ \\
\hline $\begin{array}{l}\text { Acute kidney injury (Stage 1, 2, or } 3 \text { of AKIN-classification), } \\
n(\%)\end{array}$ & - & $19(100)$ & - \\
\hline Stage 1 & - & $6(32)$ & - \\
\hline Stage 2 & - & $4(21)$ & - \\
\hline Stage 3 & - & 9 (47) & - \\
\hline Dialysis & - & $7(37)$ & - \\
\hline
\end{tabular}

Abbreviations: IQR, interquartile range from the 25th until 75th percentile; TAA, thoracic aortic aneurysm, TAAA, thoracoabdominal aortic aneurysm; eGRF, estimated glomerular filtration rate; AKIN, Acute Kidney Injury Network. ${ }^{+}$Roman numerals refer to the TAAA classification system by Crawford ${ }^{37}$; see also Methods ${ }^{\#}$ Glomerular filtration rate was estimated by the abbreviated Modification of Diet in Renal Disease (MDRD) as recommended by the National Kidney Foundation ${ }^{15}$. 

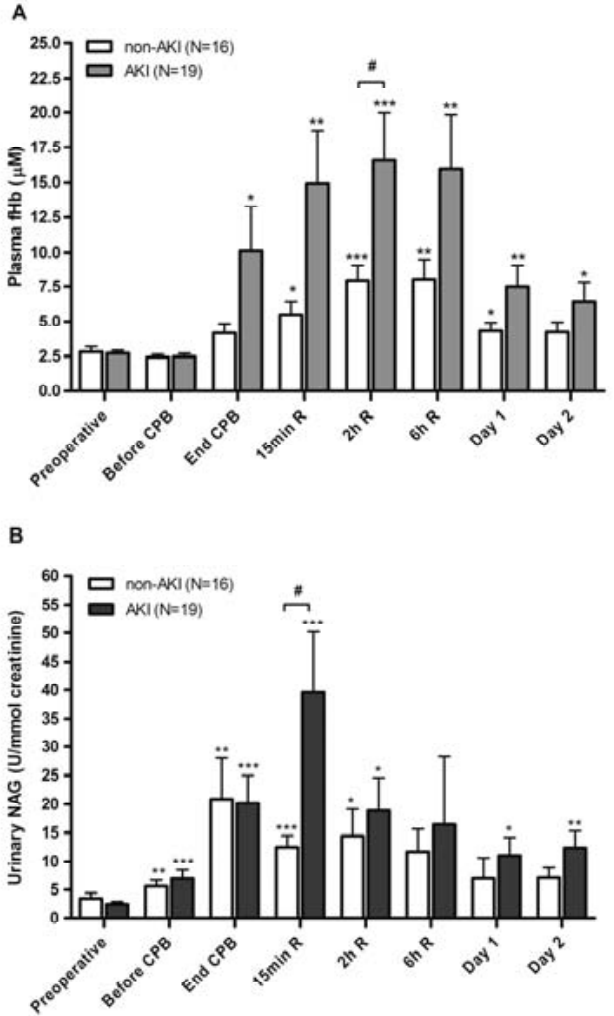

Figure 6.1 Hemolysis (A) and renal proximal tubular epithelial damage (B) during open thoracic or thoracoabdominal aortic repair in patients with $(N=19)$ and without $(N=16)$ acute kidney injury. Urinary NAG concentrations were corrected for urine creatinine values. ${ }^{*} p<0.05,{ }^{* *} p<$ $0.01, * * * \mathrm{p}<0.001$ compared to preoperative levels. ${ }^{\#} \mathrm{p}<0,05$ between AKI and non-AKI patients.

Abbreviations: NAG, N-acetyl- $\beta$-D-glucosaminidase; AKI, acute kidney injury; fHb, free hemoglobin; $C P B$, cardiopulmonary bypass; $R$, reperfusion; min, minutes; $h$, hours.

\section{Hemolysis is correlated with renal tubular injury during open repair of thoracic and thoracoabdominal aortic aneurysms}

To study renal tubular injury during surgery, urinary $\mathrm{N}$-acetyl-beta-(D)-glucosaminidase (NAG) concentration was measured and corrected for urinary creatinine. NAG is a lysosomal brush border enzyme present in proximal tubular epithelial cells that are particularly vulnerable to ischemic injury. ${ }^{16}$ Parallel to the development of hemolysis, a significant increase in urine NAG was observed during cardiopulmonary bypass (Figure 6.1B). NAG levels remained elevated above preoperative levels until the second postoperative day. Moreover, when comparing patients with and without AKI, 
significantly higher urine NAG levels were detected in patients with AKI at 15 minutes after reperfusion $(39.6 \pm 45.0 \mathrm{U} / \mathrm{mmol}$ creatinine vs. $12.5 \pm 7.7 \mathrm{U} / \mathrm{mmol}$ creatinine, $\mathrm{p}<0.05)$.

Next, we analyzed the association between hemolysis and renal tubular injury. To this end, the area under the curve of $\mathrm{fHb}\left(\mathrm{AUC}_{\mathrm{fHb}}\right)$ and $\mathrm{NAG}\left(\mathrm{AUC}_{\mathrm{NAG}}\right)$ was calculated, reflecting total $\mathrm{fHb}$ release and $\mathrm{NAG}$ excretion during the study period. $\mathrm{AUC}_{\mathrm{fHb}}$ and $A_{U C} C_{N A G}$ showed a strong positive correlation (Figure 6.2, Pearson $r=0.75, p<0.0001$ ). This correlation remained when the subgroups of AKI and non-AKI patients were analyzed separately (Pearson $r=0.79, p<0.001$, and $r=0.64, p<0.01$, respectively). Finally, $A \cup C_{\mathrm{fHb}}$ remained significantly associated with $A \cup C_{\mathrm{NAG}}(\mathrm{p}=0.001$, Table 6.2) after adjustment for cardiopulmonary bypass time - a potential confounder - in multivariable linear regression.

Table 6.2 Multivariable linear regression analysis for $A U C_{N A G}$

\begin{tabular}{lccc}
\hline Variable & Beta & $95 \% \mathrm{Cl}$ & $\mathrm{p}$-value \\
\hline Cardiopulmonary bypass time $(\mathrm{min})$ & 0.11 & $-2.30-2.51$ & 0.93 \\
$\mathrm{AUC}_{\mathrm{fHb}}$ & 1.31 & $0.57-2.05$ & 0.001 \\
\hline
\end{tabular}

Abbreviations: AUC, area under the curve; NAG, N-acetyl- $\beta$-D-glucosaminidase; fHb, plasma free hemoglobin; $\mathrm{Cl}, 95 \%$ confidence interval.

\section{Hemolysis and renal tubular injury are associated with postoperative renal dysfunction}

To assess whether intraoperative renal tubular injury was associated with postoperative AKI, we analyzed the relation between NAG levels (at 15 minutes reperfusion) and perioperative serum creatinine changes (highest value reached within the first two postoperative days as a percentage from baseline). Using multivariable linear regression we studied the association of NAG with creatinine rise independently of 3 established risk factors for AKI; preoperative age, preoperative eGFR and intraoperative cardiopulmonary bypass time. NAG levels $(p=0.002)$, preoperative eGFR $(p=0.03)$, and age $(p=0.01)$ were significantly associated with serum creatinine increases (Table 6.3).

To study the prognostic value of plasma $\mathrm{fHb}$ and urine NAG for postoperative AKI, we analyzed the sensitivity and specificity of peak plasma $\mathrm{fHb}$ and urine NAG using receiver operating characteristic (ROC) curves (Figure 6.3). Peak $\mathrm{fHb}$ and NAG values were observed at two hours reperfusion and at 15 minutes reperfusion, respectively. Peak plasma $\mathrm{fHb}$ and urine NAG both held significant diagnostic power for the prediction of acute kidney injury (AUC 0.73, $p=0.04$ and AUC 0.76, $p=0.01$, respectively). Optimal cut-off values to discriminate between patients with and without $\mathrm{AKI}$ were $10 \mu \mathrm{M}$ for plasma fHb (sensitivity: 79\%, specificity: $69 \%$ ) and 
$14 \mathrm{U} / \mathrm{mmol}$ creatinine for urinary NAG (sensitivity: 73\%, specificity: 72\%). This indicates that it is possible to differentiate between patients with and without postoperative AKI based on plasma fHb levels shortly after surgery.

Table 6.3 Multivariable linear regression analysis for perioperative creatinine change*

\begin{tabular}{lccc}
\hline Variable & Beta & $95 \% \mathrm{Cl}$ & $P$-value \\
\hline Age (years) & 3.34 & $0.97-5.71$ & 0.01 \\
Preoperative eGFR $\left(\mathrm{ml} / \mathrm{min} / 1.73 \mathrm{~m}^{2}\right)$ & 0.91 & $0.10-1.73$ & 0.03 \\
Cardiopulmonary bypass time $(\mathrm{min})$ & -0.01 & $-0.54-0.52$ & 0.97 \\
NAG $_{15 \min \mathrm{R}}(\mathrm{U} / \mathrm{mmol}$ creatinine) & 1.53 & $0.61-2.46$ & 0.002 \\
\hline
\end{tabular}

*Creatinine change expressed as change from baseline to highest value reached during the first two postoperative days in \%. Abbreviations: eGFR, estimated glomerular filtration rate; NAG, N-acetyl- $\beta$-Dglucosaminidase; $15 \mathrm{~min} \mathrm{R}, 15$ minutes after reperfusion; $\mathrm{Cl}, 95 \%$ confidence interval

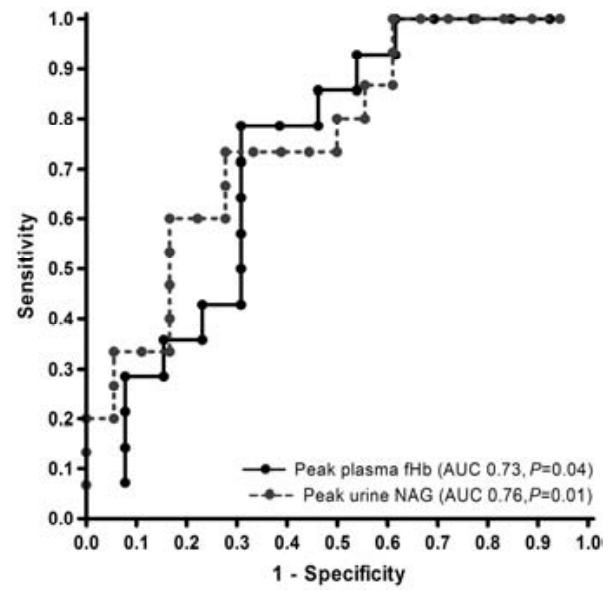

Figure 6.3 Receiver Operating Characteristics (ROC) Curve presenting sensitivity and 1 - specificity for peak plasma fHb levels at $\mathbf{2}$ hours reperfusion (black line) and peak urine NAG levels at 15 minutes reperfusion (dotted line). Abbreviations: AUC, area under the receiver operating characteristics curve; NAG, $\mathrm{N}$-acetyl- $\beta$-D-glucosaminidase; $\mathrm{fHb}$, free hemoglobin.

\section{DISCUSSION}

Acute kidney injury is a common complication after surgery using cardiopulmonary bypass with a profound impact on postoperative morbidity and mortality. ${ }^{17}$ Despite major improvements in biocompatibility and flow performance of the bypass circuits, the incidence of AKI after cardiovascular surgery has not decreased significantly over the past decade. ${ }^{18}$ Therefore, development of novel interventions to reduce AKI after major cardiovascular surgery requires further study of its pathophysiology. 
In the current study, we show that the concentrations of plasma $\mathrm{fHb}$ and urine NAG increased during on-pump repair of thoracic and thoracoabdominal aortic aneurysms, which indicates that hemolysis and tubular epithelial injury occurred. Hemolysis during cardiac surgery has previously been reported and is considered to be caused by cardiopulmonary bypass circuits, transfusion of stored red blood cells, and cell salvage devices. ${ }^{8,19-21}$ Interestingly, we found that the total release of plasma $\mathrm{fHb}$ was independently correlated with urine NAG, which in turn was independently associated with the postoperative increase in serum creatinine. This clinical observation is supported by rodent experiments in which intravenous infusion of $\mathrm{fHb}$ increased urine NAG concentrations 10 -fold while decreasing glomerular filtration rate by $30 \% .{ }^{22}$ Furthermore, scavenging of plasma $\mathrm{fHb}$ by infusion of haptoglobin in patients undergoing cardiac surgery was associated with a 4-fold reduction of urine NAG as compared to a historical cohort without haptoglobin infusion. ${ }^{23}$ In addition, cardiac surgery without cardiopulmonary bypass, which is expected to attenuate intravascular hemolysis, causes a significant reduction of postoperative acute kidney injury as compared to on-pump surgery. ${ }^{24}$ In our study, peak plasma fHb levels of $10 \mu \mathrm{M}$ or higher held a significant diagnostic value for the prediction of AKI. The sensitivity and specificity of this marker to predict AKI in clinical practice should be validated in future studies. Taken together, these findings indicate that plasma free hemoglobin is a risk factor for tubular epithelial damage and AKI after cardiovascular surgery.

The diagnosis of AKI using serum creatinine is difficult, since serum creatinine is a poor marker of early renal dysfunction in the non-steady state of the surgical patient. Since the impact of AKI on the outcome of the patient is profound, the quest for sensitive and specific biomarkers has been designated as priority. During the past decade several candidate biomarkers (such as neutrophil gelatinase-associated lipocalin, kidney injury molecule-1 and interleukin-18) were reported, however none has been generally accepted for clinical use. The diagnostic accuracy of urine NAG and plasma $\mathrm{fHb}$ in the current study might provide a valuable tool for early detection of postoperative $\mathrm{AKI}$, enabling timely therapeutic interventions. ${ }^{25}$ Nevertheless, sensitivity and specificity may be overestimated when calculated with the same data set that has been used to determine the optimal cut-off point for a diagnostic test. Therefore, the diagnostic accuracy of our suggested cut-off point for plasma fHb should be validated in future studies.

The observed relation between plasma $\mathrm{fHb}$ and renal damage in this human setting is important since earlier studies on hemolysis-induced AKI focussed traditionally on the role of filtered $\mathrm{fHb}$ in urine. ${ }^{13,26,27}$ Indeed, urine $\mathrm{fHb}$ and its catabolic products iron and heme catalyze the generation of reactive oxygen species that damage the tubular epithelium when present in the glomerular ultrafiltrate. ${ }^{14}$ In support, administration of the iron scavenger deferoxamine attenuated the glomerular and tubular dysfunction 
induced by intravenous administration of $\mathrm{fHb}$ in rats. $^{28}$ Similarly, reduced plasma ferritin concentrations - which may be associated with reduced iron scavenging - were associated with increased AKI after human cardiovascular surgery. ${ }^{21}$ Second, $\mathrm{fHb}$ may precipitate in the acidic ultrafiltrate, forming casts that obstruct the tubular lumen and reduce glomerular filtration. ${ }^{14,29}$ Prevention of cast formation by alkalanization of the urine reduced tubular injury and glomerular dysfunction after intravenous $\mathrm{fHb}$ infusion in rats. ${ }^{14}$ Since $\mathrm{fHb}$ was not detected in urine samples of our patients, we propose that glomerular filtration of $\mathrm{fHb}$ is unlikely to be a major contributor to AKI.

An additional and complementary explanation for the induction of renal injury by hemolysis is provided by the recent discovery that plasma oxy-fHb converts the vasodilator nitric oxide into biologically inactive nitrate. ${ }^{10}$ Since nitric oxide plays a central role in blood flow regulation, reduction of nitric oxide bioavailability by $\mathrm{fHb}$ may impair tissue perfusion and induce AKI. In line, induction of hemolysis by water infusion or direct administration of $\mathrm{fHb}$ in dogs increased plasma nitric oxide consumption and resulted in elevated systemic vascular resistance and reduced creatinine clearance. These hemodynamic effects of acute hemolysis were attenuated by nitric oxide inhalation which converts oxy-fHb into biologically inactive methemoglobin. ${ }^{12}$ Furthermore, in patients with chronic hemolytic disorders such as sickle cell disease and malaria, the extent of hemolysis was correlated with endothelial dysfunction, pulmonary hypertension and coagulation. ${ }^{30-32}$

In the light of these findings, we propose that the association between acute hemolysis and renal injury in patients undergoing on-pump cardiovascular surgery may be caused by scavenging of nitric oxide through $\mathrm{fHb}$. First, plasma $\mathrm{fHb}$ levels in our study are comparable to concentrations reported to reduce blood flow, nitric oxide bioavailability and impair renal function in animal experiments and men. ${ }^{10,12}$ Second, in patients after on-pump surgical repair of thoracic and thoracoabdominal aortic aneurysms, we found that the increase in forearm blood flow after infusion of the nitric oxide donor sodium nitroprusside was significantly lower at the time of peak plasma $\mathrm{fHb}$ concentration as compared to the increase at one day after surgery. Since the vascular response to acetylcholine - with vasodilatory effects that are largely independent of nitric oxide - was similar at these time points, the impaired reactivity to sodium nitroprusside is most likely not caused by vascular dysfunction but rather by reduced bioavailability of the administered nitric oxide donor (Hanssen et al., Thorac Cardiovasc Surg 2012, in press). These data, although providing indirect proof, support our findings and suggest that scavenging of nitric oxide by plasma $\mathrm{fHb}$ may contribute to the association between acute hemolysis and renal injury.

The major strength of the current study is its translation of experimental findings on the effects of hemolysis on renal function into the clinical setting of on-pump cardiovascular surgery. Patients undergoing open repair of thoracic and thoraco- 
abdominal aortic aneurysms are particularly suitable for clinical investigation of the pathophysiology of AKI since these individuals are at exceptionally high risk of postoperative renal dysfunction. The strong and significant correlations between hemolysis and renal injury in our patients should not be interpreted as causal relationships. The results from the current study ask for further analysis in larger patient groups, and interventional studies using haptoglobin infusion or nitric oxide inhalation to inactivate $\mathrm{fHb}$ or using nitrite administration to increase nitric oxide bioavailability may provide further support for a causal relationship between nitric oxide scavenging by plasma $\mathrm{fHb}$ and $\mathrm{AKI}$ after on-pump cardiovascular surgery. ${ }^{12,23,33,34}$ The pathophysiology of AKI is highly complex and involves multiple factors other than intravascular hemolysis such as ischemia and reperfusion, hemodilution, inflammation and baseline renal function. ${ }^{5}$ The current study provides additional insights into the pathophysiology of this condition relevant for the design of multivariable risk scores and future therapeutic studies.

In conclusion, we show that increased plasma $\mathrm{fHb}$ concentrations are independently associated with injury to the proximal tubular epithelium during surgery with cardiopulmonary bypass. Peak plasma fHb concentrations 2 hours after surgery were predictive of AKI within the first postoperative days. This finding casts new light on the pathophysiology of AKI during on-pump cardiovascular surgery that may also play a role in other conditions associated with acute hemolysis such as hemodialysis and major trauma. $^{35,36}$

\section{METHODS}

\section{Patients}

Patients admitted to Maastricht University Medical Center or University Hospital Aachen between May 2006 and November 2008 to undergo elective open repair of a thoracic aortic aneurysm or thoracoabdominal aortic aneurysm with cardiopulmonary bypass were included. The study was approved by the Institutional Review Board of both institutes and written informed consent was obtained from every patient prior to surgery. Patients requiring preoperative dialysis due to pre-existent renal failure were excluded. Preoperative clinical data were prospectively collected from the patient's medical record. Glomerular filtration rate (eGFR) was estimated by the abbreviated Modification of Diet in Renal Disease (MDRD) as recommended by the National Kidney Foundation. ${ }^{15}$ Thoracoabdominal aortic aneurysm type was classified according to Crawford's classification. Type I thoracoabdominal aortic aneurysms extend distally from the left subclavian artery, in any case above the 6th intercostal space, down to encompass the aorta at the origin of the celiac trunk and superior mesenteric artery. 
The renal arteries may also be involved, but the aneurysm does not extend into the infrarenal segment. Type II thoracoabdominal aortic aneurysms extend distally from the left subclavian artery until the aortic bifurcation. Type III thoracoabdominal aortic aneurysms begin in the distal half of the descending thoracic aorta, below the sixth intercostal space, and extend to the aortic bifurcation. Extent IV aneurysms involve the entire abdominal aorta from the diaphragm to the bifurcation. Type $V$ thoracoabdominal aortic aneurysms originate from the lower thoracic aorta to the aortic section just below the visceral arteries. ${ }^{37}$

\section{Surgical procedure}

An indwelling radial artery catheter was placed as part of standard anesthetic care. After induction, patients were placed in a left helical position. Thoracolaparotomy in type I, II, and III type thoracoabdominal aortic aneurysms was performed through the sixth intercostal space. In type IV thoracoabdominal aortic aneurysms a small thoracolaparotomy through the eighth intercostal space sufficed. In patients with an isolated thoracic aneurysm, a small laparotomy was performed. Surgical repair was typically done from proximal to distal. After heparinization $(0.5 \mathrm{mg} / \mathrm{kg})$, cardiopulmonary bypass was established using a centrifugal pump with membrane oxygenation (Jostra Rotaflow with Jostra Quadrox, Maquet Cardiopulmonary AG, Hirrlingen, Germany). Depending on the extent of the aneurysm, cardiopulmonary bypass was expanded with a 4-branched tubing system enabling pressure-controlled perfusion with oxygenated blood of the celiac trunk, superior mesenteric artery, renal arteries, and if necessary intercostal arteries, during aortic cross clamping (ACC). During ACC, renal blood flow and perfusion pressure was closely monitored and kept at $200-280 \mathrm{ml} / \mathrm{min}$, and $60-70 \mathrm{mmHg}$, respectively. A cell-salvage device (CATS, Fresenius SE, Bad Homburg, Germany) was used in every patient. The exact surgical protocol was identical in both institutions and has been described in detail elsewhere. ${ }^{38,39}$ Postoperatively, all patients were transported to the Cardiothoracic Intensive Care Unit for postoperative monitoring, circulatory and ventilatory support.

\section{Preoperative kidney dysfunction and postoperative acute kidney injury}

All individuals with a GFR $<60 \mathrm{ml} / \mathrm{min} / 1.73 \mathrm{~m}^{2}$, irrespective of the presence or absence of kidney damage, were classified as having chronic kidney disease (CKD) in accordance with the National Kidney Foundation Guidelines. ${ }^{40}$ Postoperative Acute Kidney Injury (AKI) was defined according to the AKI Network (AKIN) classification (Table 6.1). ${ }^{41}$ The AKIN classification provides three grades of postoperative AKI of increasing severity (Stage 1, Stage 2, and Stage 3) and is based on relative changes in either serum creatinine or urine output (whichever is worst) compared to baseline (preoperative) levels. All patients requiring (transient) postoperative dialysis were classified as Stage 3 
AKI, irrespective of creatinine change. We stratified patients into the AKIN stages based on creatinine changes due to the fact that urine output data was not sufficiently recorded in all patients.

\section{Blood sampling, urine sampling and sample processing}

Arterial blood was drawn preoperatively and at 8 pre-set perioperative time points; T1, preoperative; T2, before start cardiopulmonary bypass; T3, end cardiopulmonary bypass; T4, 15 minutes reperfusion (15 minutes after cessation of cardiopulmonary bypass); T5, 2 hours reperfusion; T6, 6 hours reperfusion; T7, Day 1 postoperatively; T8, Day 2 postoperatively. Whole blood was collected in EDTA vacutainers (Becton Dickinson, Franklin Lakes, NJ). Simultaneously a fresh spot urine sample was taken from the bladder catheter. Whole blood and urine samples were immediately put on ice and centrifuged within 15 minutes after collection $\left(1500 \mathrm{~g}\right.$ at $4^{\circ} \mathrm{C}$ for $\left.15 \mathrm{~min}\right)$, aliquoted and stored at $-80^{\circ} \mathrm{C}$ until further analysis.

\section{Laboratory analysis of hemolysis and renal tubular damage}

$\mathrm{FHb}$ concentrations, indicating hemolysis, were measured in all patients ( $N=35$ ) by derivative spectrometry as described elsewhere. ${ }^{42}$ The detection limit of the assay was $2 \mu \mathrm{M}$.

To assess renal tubular damage, urinary NAG concentrations were determined by means of an enzyme colorimetric assay according to manufacturer's instructions (HaemoScan, Groningen, the Netherlands). NAG is excreted predominantly by the proximal renal tubular cells. Due to its relatively large molecular weight ( $>130 \mathrm{kD}$ ), high levels of urinary NAG preclude glomerular filtration. Therefore, increased levels of NAG imply renal tubular damage. Furthermore, NAG is not reabsorbed by the tubules. ${ }^{43}$ Results were normalized to urinary creatinine values and expressed as $\mathrm{U} / \mathrm{mmol}$ creatinine.

\section{Statistics}

Continuous data were presented as median (interquartile range; IQR from the 25th-75th percentile) or mean \pm s.d, depending on Gaussian distribution (checked using histograms and normal Q-Q plots), and as $\mathrm{N}$ (\%) for dichotomous data. Differences in patient characteristics between study groups were compared using Pearson Chi-square test with Fisher's correction, when appropriate, for dichotomous variables. Continuous data were analyzed using independent sample T-test or MannWhitney-U test depending on Gaussian distribution. Subsequently, changes in $\mathrm{fHb}$ and NAG levels compared to preoperative values were tested using the paired T-test. To characterize the total amount of hemolysis and tubular injury during the study period, the area under the curve $(A \cup C)$ for log-normalized $f H b\left(A \cup C_{f H b}\right)$ and $N A G\left(A \cup C_{N A G}\right)$ was 
calculated for each patient using trapezoidal analysis with time as a baseline. Subsequently, the correlation between hemolysis and tubular injury was analyzed using Pearson correlation in the total patient population $(\mathrm{N}=35)$ and subgroups of AKI and non-AKI. To correct for other risk factors, the relation between $A U C_{N A G}$ and $A U C_{f H b}$, and the relation between NAG values and changes in perioperative serum creatinine levels was assessed by multivariable linear regression analysis (raw data were used). Based on the number of included patients, we could adjust for 3 other covariates in the latter multivariable linear regression analysis. In order to analyze the predictive value of plasma free hemoglobin and urinary NAG for AKI, receiver operating characteristics (ROC) curves were drawn by plotting sensitivity versus against 1 specificity for all possible thresholds. Overall accuracy of the markers in detecting AKI was represented by area under the curve (AUC). Best cutoff points were defined as the maximum sum of sensitivity and specificity. Statistical calculations were made using SPSS 15.0 for Windows (SPSS, Inc., Chicago, IL), and Prism 4.03 for Windows (GraphPad Software Inc. San Diego, CA). A p-value $<0.05$ was considered to indicate statistical significance. 


\section{REFERENCES}

1. Abu-Omar Y, Ratnatunga C. Cardiopulmonary bypass and renal injury. Perfusion 2006; 21:209-13.

2. Achouh PE, Madsen K, Miller CC, 3rd, et al. Gastrointestinal complications after descending thoracic and thoracoabdominal aortic repairs: a 14-year experience. J Vasc Surg 2006; 44:442-6.

3. Jacobs MJ, de Mol BA, Legemate DA, Veldman DJ, de Haan P, Kalkman CJ. Retrograde aortic and selective organ perfusion during thoracoabdominal aortic aneurysm repair. Eur J Vasc Endovasc Surg 1997; 14:360-6.

4. Zacharias M, Gilmore IC, Herbison GP, Sivalingam P, Walker RJ, Hovhannisyan K. Interventions for protecting renal function in the perioperative period. Cochrane Database Syst Rev 2005:CD003590.

5. Schrier RW, Wang W, Poole B, Mitra A. Acute renal failure: definitions, diagnosis, pathogenesis, and therapy. J Clin Invest 2004; 114:5-14.

6. Rosner MH, Okusa MD. Acute kidney injury associated with cardiac surgery. Clin J Am Soc Nephrol 2006; 1:19-32.

7. Damman J, Schuurs TA, Ploeg RJ, Seelen MA. Complement and renal transplantation: from donor to recipient. Transplantation 2008; 85:923-7.

8. Fransen EJ, Ganushchak YM, Vijay V, de Jong DS, Buurman WA, Maessen JG. Evaluation of a new condensed extra-corporeal circuit for cardiac surgery: a prospective randomized clinical pilot study. Perfusion 2005; 20:91-9.

9. Vercaemst L. Hemolysis in cardiac surgery patients undergoing cardiopulmonary bypass: a review in search of a treatment algorithm. J Extra Corpor Technol 2008; 40:257-67.

10. Reiter CD, Wang X, Tanus-Santos JE, Hogg N, Cannon RO 3rd, Schechter AN, Gladwin MT. Cell-free hemoglobin limits nitric oxide bioavailability in sickle-cell disease. Nat Med 2002; 8:1383-9.

11. Pohl U, Lamontagne D. Impaired tissue perfusion after inhibition of endothelium-derived nitric oxide. Basic Res Cardiol 1991; 86 Suppl 2:97-105.

12. Minneci PC, Deans KJ, Zhi H, Yuen PS, Star RA, Banks SM, Schechter AN, Natanson C, Gladwin MT, Solomon SB. Hemolysis-associated endothelial dysfunction mediated by accelerated NO inactivation by decompartmentalized oxyhemoglobin. J Clin Invest 2005; 115:3409-17.

13. Haase M, Haase-Fielitz A, Bagshaw SM, et al. Cardiopulmonary bypass-associated acute kidney injury: a pigment nephropathy? Contrib Nephrol 2007; 156:340-53.

14. Zager RA, Gamelin LM. Pathogenetic mechanisms in experimental hemoglobinuric acute renal failure. Am J Physiol 1989; 256(3 Pt 2):F446-55.

15. Levey AS, Bosch JP, Lewis JB, Greene T, Rogers N, Roth D. A more accurate method to estimate glomerular filtration rate from serum creatinine: a new prediction equation. Modification of Diet in Renal Disease Study Group. Ann Intern Med 1999; 130:461-70.

16. Liangos O, Perianayagam MC, Vaidya VS, Han WK, Wald R, Tighiouart H, MacKinnon RW, Li L, Balakrishnan VS, Pereira BJ, Bonventre JV, Jaber BL. Urinary N-acetyl-beta-(D)-glucosaminidase activity and kidney injury molecule-1 level are associated with adverse outcomes in acute renal failure. J Am Soc Nephrol 2007; 18:904-12.

17. Chertow GM, Levy EM, Hammermeister KE, Grover F, Daley J. Independent association between acute renal failure and mortality following cardiac surgery. Am J Med 1998; 104:343-8.

18. Kelly KJ, Molitoris BA. Acute renal failure in the new millennium: time to consider combination therapy. Semin Nephrol 2000; 20:4-19.

19. Nishiyama T, Hanaoka K. Free hemoglobin concentrations in patients receiving massive blood transfusion during emergency surgery for trauma. Can J Anaesth 2000; 47:881-5.

20. Yazer $\mathrm{MH}$, Waters JH, Elkin KR, Rohrbaugh ME, Kameneva MV..A comparison of hemolysis and red cell mechanical fragility in blood collected with different cell salvage suction devices. Transfusion 2008; 48:1188-91.

21. Davis CL, Kausz AT, Zager RA, Kharasch ED, Cochran RP. Acute renal failure after cardiopulmonary bypass in related to decreased serum ferritin levels. J Am Soc Nephrol 1999; 10:2396-402.

22. Tam SC, Wong JT. Impairment of renal function by stroma-free hemoglobin in rats. J Lab Clin Med 1988; 111:189-93.

23. Tanaka K, Kanamori Y, Sato T, Kondo C, Katayama Y, Yada I, Yuasa H, Kusagawa M. Administration of haptoglobin during cardiopulmonary bypass surgery. ASAIO Trans 1991; 37:M482-3. 
24. Nigwekar SU, Kandula P, Hix JK, Thakar CV. Off-pump coronary artery bypass surgery and acute kidney injury: a meta-analysis of randomized and observational studies. Am J Kidney Dis 2009; 54:413-23.

25. Coca SG, Yalavarthy R, Concato J, Parikh CR. Biomarkers for the diagnosis and risk stratification of acute kidney injury: a systematic review. Kidney Int 2008; 73:1008-16.

26. Cheung AT, Cruz-Shiavone GE, Meng QC, Pochettino A, Augoustides JA, Bavaria JE, Ochroch EA. Cardiopulmonary bypass, hemolysis, and nitroprusside-induced cyanide production. Anesth Analg 2007; 105:29-33.

27. Lim YK, Jenner A, Ali AB, Wang Y, Hsu SI, Chong SM, Baumman H, Halliwell B, Lim SK. Haptoglobin reduces renal oxidative DNA and tissue damage during phenylhydrazine-induced hemolysis. Kidney Int 2000; 58:1033-44.

28. Paller MS. Hemoglobin- and myoglobin-induced acute renal failure in rats: role of iron in nephrotoxicity. Am J Physiol 1988; 255:F539-44.

29. Everse J, Hsia N. The toxicities of native and modified hemoglobins. Free Radic Biol Med 1997; 22:1075-99.

30. Ataga KI, Moore CG, Hillery CA, Jones S, Whinna HC, Strayhorn D, Sohier C, Hinderliter A, Parise LV, Orringer EP. Coagulation activation and inflammation in sickle cell disease-associated pulmonary hypertension. Haematologica 2008; 93:20-6.

31. Morris CR, Kato GJ, Poljakovic M, Wang X, Blackwelder WC, Sachdev V, Hazen SL, Vichinsky EP, Morris SM Jr, Gladwin MT. Dysregulated arginine metabolism, hemolysis-associated pulmonary hypertension, and mortality in sickle cell disease. Jama 2005; 294:81-90.

32. Yeo TW, Lampah DA, Gitawati R, Tjitra E, Kenangalem E, McNeil YR, Darcy CJ, Granger DL, Weinberg JB, Lopansri BK, Price RN, Duffull SB, Celermajer DS, Anstey NM. Impaired nitric oxide bioavailability and Larginine reversible endothelial dysfunction in adults with falciparum malaria. J Exp Med 2007; 204:2693-704.

33. Bryan NS, Calvert JW, Elrod JW, Gundewar S, Ji SY, Lefer DJ. Dietary nitrite supplementation protects against myocardial ischemia-reperfusion injury. Proc Natl Acad Sci U S A 2007; 104:19144-9.

34. Garg HK, Bryan NS. Dietary sources of nitrite as a modulator of ischemia/reperfusion injury. Kidney Int 2009; 75:1140-4.

35. Polaschegg HD. Red Blood Cell Damage from Extracorporeal Circulation in Hemodialysis. Semin Dial 2009; 22:524-31.

36. Nijboer JM, van der Horst IC, Hendriks HG, ten Duis HJ, Nijsten MW..Myth or reality: hematocrit and hemoglobin differ in trauma. J Trauma 2007; 62:1310-2.

37. Crawford ES. Thoraco-abdominal and abdominal aortic aneurysms involving renal, superior mesenteric, celiac arteries. Ann Surg 1974; 179:763-72.

38. Jacobs MJ, Mommertz G, Koeppel TA, Langer S, Nijenhuis RJ, Mess WH, Schurink GW.Surgical repair of thoracoabdominal aortic aneurysms. J Cardiovasc Surg (Torino) 2007; 48:49-58.

39. Hanssen SJ, Derikx JP, Vermeulen Windsant IC, Heijmans JH, Koeppel TA, Schurink GW, Buurman WA, Jacobs MJ..Visceral injury and systemic inflammation in patients undergoing extracorporeal circulation during aortic surgery. Ann Surg 2008; 248:117-25.

40. Levey AS, Coresh J, Balk E, Kausz AT, Levin A, Steffes MW, Hogg RJ, Perrone RD, Lau J, Eknoyan G. National Kidney Foundation practice guidelines for chronic kidney disease: evaluation, classification, and stratification. Ann Intern Med 2003; 139:137-47.

41. Mehta RL, Kellum JA, Shah SV, Molitoris BA, Ronco C, Warnock DG, Levin A. Acute Kidney Injury Network: report of an initiative to improve outcomes in acute kidney injury. Crit Care 2007; 11:R31.

42. Cruz-Landeira A, Bal MJ, Quintela, Lopez-Rivadulla M. Determination of methemoglobin and total hemoglobin in toxicological studies by derivative spectrophotometry. J Anal Toxicol 2002; 26:67-72.

43. Dittrich S, Kurschat K, Dahnert I, Vogel M, Müller C, Alexi-Meskishvili V, Lange PE. Renal function after cardiopulmonary bypass surgery in cyanotic congenital heart disease. Int J Cardiol 2000; 73:173-9. 

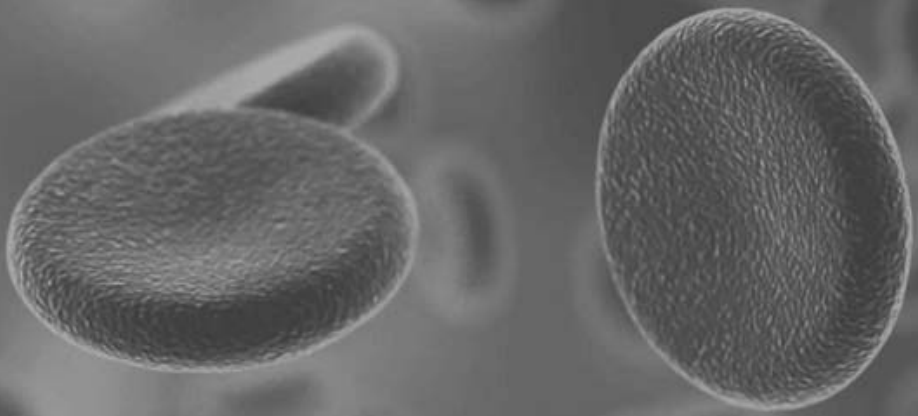
Hemolysis increases nitric oxide consumption and visceral tissue damage after cardiac surgery

Iris C Vermeulen Windsant, Norbert CJ de Wit, Jonas TC Sertorio, Annemarie M van Bijnen, Yuri M Ganushchak, John H Heijmans, Jose E Tanus - Santos, Michael J Jacobs, Jos G Maessen, Wim A Buurman 


\section{ABSTRACT}

\section{Background}

Visceral injury and AKI negatively impact patient outcome after cardiac surgery. Enhanced nitric oxide (NO) consumption, leading to reduced NO-bioavailability, as a consequence of cardiopulmonary bypass-induced hemolysis, may play an important pathophysiological role in this setting.

\section{Methods and results}

Hemolysis (by plasma free hemoglobin; $\mathrm{fHb}$ ), plasma NO-consumption, haptoglobin ( $\mathrm{Hp}$ ), renal tubular injury (using urinary N-Acetyl- $\beta$-D-glucosaminidase; NAG), intestinal mucosal injury (through plasma intestinal fatty acid binding protein; IFABP), and AKI were studied in patients undergoing off-pump cardiac surgery (OPCAB, $N=7$ ), on-pump coronary artery bypass grafting (CABG, $N=30)$, or $C A B G+V a l v e$ surgery $(N=30)$. FHb and NO-consumption significantly increased, while $\mathrm{Hp}$ decreased significantly, in CABG and CABG+Valve patients $(p<0.0001)$. The extent of hemolysis and NO-consumption correlated significantly $\left(r^{2}=0.75, p<0.0001\right)$. Also, NAG and IFABP increased in both groups ( $p<0.0001$, and $p<0.001$, respectively) indicating significant visceral tissue injury, and both were significantly associated with hemolysis $\left(R_{s}=0.70\right.$, $p<0.0001$, and $R_{s}=0.26, p=0.04$, respectively) and NO-consumption $\left(R_{s}=0.55, p=0.002\right.$, and $R_{s}=0.41, p=0.03$, respectively), also after multivariable logistic regression analysis. OPCAB patients did neither show increased $\mathrm{fHb}$, enhanced NO-consumption, nor visceral tissue damage or AKI. Patients suffering from AKI $(\mathrm{N}=9,13.4 \%)$ displayed significantly higher $\mathrm{fHb}$ and NAG levels already during surgery compared to non-AKI patients.

\section{Conclusions}

This study shows that hemolysis is an independent risk factor for visceral injury during cardiac surgery by limiting NO-bioavailability. This observation offers a novel diagnostic and therapeutic target to improve outcome after cardiothoracic surgery. 


\section{INTRODUCTION}

Cardiac surgery has become common practice world-wide. Nevertheless, the more complex cardiac procedures are still associated with a relatively high incidence of postoperative complications. Visceral complications, such as renal tubular damage and loss of intestinal wall integrity during surgery, significantly contribute to increased morbidity and mortality in this setting. ${ }^{1,2}$ Also, acute kidney injury (AKI) is a common and serious postoperative complication with incidence rates varying between $5 \%-30 \%{ }^{3,4}$ AKI-associated morbidity and mortality is high, especially when patients require dialysis. ${ }^{5}$

The use of cardiopulmonary bypass ( $\mathrm{CPB}$ ) contributes to the development of renal tubular damage and intestinal mucosal injury through induction of (microcirculatory) blood flow alterations, ischemia-reperfusion injury, hemodilution, and a proinflammatory response. ${ }^{6-8}$ Hemolysis is another common consequence of CPB and results in the circulatory release of cell free hemoglobin $(\mathrm{fHb}) .{ }^{9}$ The recent discovery of the potent nitric oxide (NO) scavenging property of $\mathrm{fHb}$ has been associated with systemic and pulmonary hypertension, decreased organ perfusion, and increased mortality during exacerbations of diseases characterized by chronic hemolysis. ${ }^{10,11}$ Recently, it has been shown that also acute increases of plasma $\mathrm{fHb}$ during hemodialysis lead to intravascular NO depletion, and impaired vascular function in patients. ${ }^{12}$ These results substantiated our previous findings that acutely enhanced plasma $\mathrm{fHb}$ concentrations were independently associated with renal proximal tubular injury and postoperative AKI after CPB-assisted major aortic surgery. ${ }^{13}$

The identification of risk factors for the development of visceral injury during cardiac surgery is imperative for the development of specific treatment strategies to improve patient outcome. In the present study we aimed to test the hypothesis that the development of hemolysis during cardiac surgery is principally a consequence of CPB, leads to increased intravascular consumption of NO (reflecting decreased NObioavailability ${ }^{10}$ ), and contributes to the development of both visceral tissue damage during surgery, and to postoperative renal dysfunction. In order to investigate the impact of CPB use on the development of intraoperative hemolysis, we studied changes of $\mathrm{fHb}$, haptoglobin (the physiologic intravascular $\mathrm{fHb}$ scavenger), plasma NOconsumption, and markers of renal tubular damage and intestinal mucosal injury in three groups of patients undergoing cardiac surgery associated with increasing perfusion times: off-pump coronary artery bypass grafting CABG (OPCAB), CABG with $\mathrm{CPB}$, and combined $\mathrm{CABG}$ and valve surgery with $\mathrm{CPB}(\mathrm{CABG}+\mathrm{Valve})$. 


\section{METHODS}

\section{Patients}

Based on a pilot study, power analysis indicated that inclusion of 30 patients per study group enabled detection of statistical significant differences in $\mathrm{fHb}$ levels. As we hypothesized that the duration of cardiopulmonary bypass time influences the extent of hemolysis, we included 30 consecutive adult patients undergoing elective on-pump CABG surgery and 30 consecutive patients undergoing elective CABG+Valve surgery (reconstruction and/or replacement of any valve), meeting the inclusion and exclusion criteria. Patients undergoing OPCAB surgery were included to serve as a control group as we expected that hemolysis does not develop in this patient group. However, as OPCAB surgery is infrequently performed at our institution, we included all OPCAB patients meeting the inclusion and exclusion criteria during the inclusion period of the CABG and $C A B G+V a l v e$ patients. This resulted in the final inclusion of 7 OPCAB patients. In total, sixty-seven adult patients undergoing elective cardiac surgery at the Department of Cardiothoracic Surgery of the Maastricht University Medical Center+ between November 2009 and January 2011 were studied. The study was approved by the Institutional Review Board and written informed consent was obtained from every patient prior to surgery. Exclusion criteria were preoperative estimated glomerular filtration rate $(e G F R)<60 \mathrm{ml} / \mathrm{min} / 1.73 \mathrm{~m}^{2}$, diabetes as these patients display higher baseline levels of $\mathrm{N}$-Acetyl- $\beta$-D-glucosaminidase (NAG), or presence of chronic hemolytic disease. The cardiac surgery protocol as performed at our institution has been described in more detail elsewhere. ${ }^{14}$

\section{Study endpoints}

The primary study endpoint was to investigate whether the extent of hemolysis, reflected by plasma $\mathrm{fHb}$ concentrations, is able to cause a significant increase in intravascular NO-consumption during cardiac surgery, thus impairing NObioavailability. Second, we evaluated the extent of visceral tissue injury which develops during $O P C A B$ surgery, $C A B G$ surgery and $C A B G+V a l v e$ surgery. In addition, the correlation between increased plasma $\mathrm{fHb}$ levels, increased NO-consumption, visceral tissue damage as indicated by increased urinary and plasma levels of renal and intestinal damage, respectively, and postoperative AKI was investigated. Lastly, we investigated circulatory levels of Haptoglobin, an important $\mathrm{fHb}$ binding protein involved in clearance of $\mathrm{fHb}$.

\section{Definition of postoperative acute kidney injury}

Postoperative AKI was defined according to the AKI Network (AKIN) classification using serum creatinine changes within the first 2 postoperative days. ${ }^{15}$ The AKIN 
classification provides three grades of postoperative AKI of increasing severity (Stage 1, Stage 2, and Stage 3). Patients requiring (transient) postoperative dialysis were classified as Stage 3, irrespective of creatinine change.

\section{Blood sampling, urine sampling, and sample processing}

Arterial blood and a fresh spot urine sample were obtained at 8 pre-set perioperative time points; 1 , preoperatively, after induction but prior to sternotomy; 2 , before start $\mathrm{CPB} ; 3$, end CPB; 4, 15 minutes reperfusion (15 minutes after cessation of CPB); 5, 2 hours reperfusion; 6, 4 hours reperfusion; 7, Day 1 postoperatively; 8, Day 2 postoperatively. Whole blood was collected in EDTA vacutainers (Becton Dickinson, Franklin Lakes, NJ). All samples were immediately put on ice and centrifuged within 15 minutes after collection (1500g at $4^{\circ} \mathrm{C}$ for $15 \mathrm{~min}$ without brake), aliquoted, and stored at $-80^{\circ} \mathrm{C}$ until further analysis.

\section{Analysis of hemolysis, haptoglobin, renal tubular damage, and intestinal damage}

Plasma $\mathrm{fHb}$ concentrations were measured by derivative spectrometry as previously described. ${ }^{16}$ The lower detection limit of the assay was $2 \mu \mathrm{M}$. Since intravascular hemolysis can lead to consumption of plasma haptoglobin $(\mathrm{Hp})$, the physiological $\mathrm{fHb}$ scavenger $^{17}$, the course of plasma Hp during surgery was also studied. Plasma Hp was measured on a validated Beckman LX20 clinical chemistry analyzer (Beckman Coulter, Brea, CA) via a turbidimetric method by the Central Diagnostic Laboratory of the Maastricht University Medical Center. To assess renal tubular damage, urinary NAG concentrations were determined by an enzyme colorimetric assay according to the manufacturer's instructions (HaemoScan, Groningen, The Netherlands). NAG is excreted predominantly by the proximal renal tubular cells. Owing to its relatively large molecular weight (4130 kDa), high levels of urinary NAG preclude glomerular filtration. Furthermore, NAG is not reabsorbed by the tubules. Therefore, increased urinary levels of NAG imply renal tubular damage. ${ }^{18}$ Results were normalized to urinary creatinine to correct for dilution and expressed as $\mathrm{U} / \mathrm{mmol}$ creatinine. Intestinal mucosal damage was studied using plasma concentrations of intestinal fatty acid binding protein (IFABP) which were assessed by an in-house human IFABP ELISA with a detection limit of $12.5 \mathrm{pg} / \mathrm{mL}$. IFABP is a small (15 kDa) cytosolic protein exclusively expressed by mature enterocytes, and is rapidly released into the circulation upon enterocyte damage where it can be readily measured. IFABP is an early, sensitive, and specific marker of clinically relevant intestinal mucosal damage. ${ }^{19}$

As the extent of hemodilution during surgery differed between the three study groups, impairing optimal comparison of the studied plasma proteins $\mathrm{fHb}, \mathrm{Hp}$, and IFABP, we corrected these values for plasma hematocrit at the moment of blood sampling. 


\section{NO consumption assay}

To evaluate the NO-consuming capacity of plasma by $\mathrm{fHb}$, we randomly selected 29 patients (5 OPCAB, 12 CABG, and 12 CABG+Valve patients) using SPSS. The complete NO consumption protocol is described elsewhere. ${ }^{10,11}$ Briefly, a $40 \mu \mathrm{M}$ solution of the NO-donor, DETA NONOate (Cayman Chemical, Ann Harbor, MI) was prepared in PBS ( $\mathrm{pH}$ 7.4) in a glass vessel purged with nitrogen in-line with a NO chemiluminescence analyzer (Sievers Model 280i, GE, Boulder, CO). The subsequent decay of DETA NONOate, releasing NO, produced a steady state NO signal of about 50$70 \mathrm{mV}$. When the signal became stable, $50 \mu \mathrm{L}$ of plasma was injected into the DETA NONOate solution, decreasing the NO signal in case of NO-consumption. Data were analyzed with the software program ORIGIN Version 6.1 (OriginLab, Northampton, $M A)$ for analysis of the area under the curve (AUC) of decreasing NO-signal over time. The amount of NO consumption by plasma was quantified by comparison of the AUC with that of NO gas standards (produced from injections of nitrite into triiodide).

\section{Statistics}

Continuous data are presented as median and interquartile range (IQR, 25th-75th percentile) or mean \pm SEM, depending on Gaussian distribution (checked using histograms and normal Q-Q plots). Dichotomous data are depicted as $\%(\mathrm{~N})$. Differences between study groups were compared using Pearson Chi-square test with Fisher's correction when appropriate (dichotomous variables), or independent sample T-test or Kruskal-Wallis test (for continuous variables). Overall changes in $\mathrm{fHb}$, NOconsumption, $\mathrm{Hp}, \mathrm{NAG}$, and IFABP levels within groups were tested using the Friedman test for repeated data. If this test yielded a significant result, a Wilcoxon signed ranks test with Bonferroni's correction was used for the post-hoc analysis. To characterize total release of $\mathrm{fHb}$, plasma NO- consumption, urinary NAG and plasma IFABP, the area under the curve $\left(A \cup C_{\mathrm{FHb}}, A \cup C_{N O}, A \cup C_{N A G}\right.$, and $\left.A \cup C_{I F A B P}\right)$ was calculated for each patient using trapezoidal analysis with time as a baseline. Univariate correlations were Spearman correlations $\left(R_{s}\right)$ and linear regression analysis $\left(r^{2}\right)$. Multivariable linear regression analysis enabled correction for other confounding risk factors. Statistical calculations were made using SPSS 15.0 (SPSS, Inc., Chicago, IL), and Prism 4.03 (GraphPad Software Inc. San Diego, CA). Values of $p<0.05$ were considered to be statistically significant.

\section{RESULTS}

\section{Patient characteristics and outcome}

Patients were predominantly male $(\mathrm{N}=57,85.1 \%)$ and middle-aged (mean age 66.5 
years, range 38 - 82 years). Baseline demographic patient data did not differ significantly among patients undergoing OPCAB, CABG, or CABG+Valve surgery (Supplemental Table S7.1). Preoperative renal function was significantly lower in the latter two patient groups $(p=0.003)$. In total, 9 patients developed AKI (13.4\%). Renal function recovered in all AKI patients prior to discharge and none required (temporary) dialysis. Serious gastro-intestinal complications such as bowel ischemia did not occur. Two patients (3.0\%) developed a postoperative ileus which was successfully, nonsurgically, treated. Overall in-hospital mortality was $1.5 \%(\mathrm{~N}=1)$ and cause of death was respiratory failure with major neurological injury.

Supplemental table S7.1 Perioperative patient characteristics.

\begin{tabular}{|c|c|c|c|c|}
\hline Characteristics & $\begin{array}{c}\text { OPCAB } \\
(\mathrm{N}=7)\end{array}$ & $\begin{array}{l}\text { CABG } \\
(N=30)\end{array}$ & $\begin{array}{l}\text { CABG + Valve } \\
\quad(N=30)\end{array}$ & $p$-value \\
\hline Male & $71.4(5)^{*}$ & $90.0(27)$ & $83.3(25)$ & 0.367 \\
\hline Age (years) & $64(39-67)$ & $71(60-73)$ & $72(62-77)$ & 0.054 \\
\hline $\mathrm{BMI}\left(\mathrm{kg} / \mathrm{m}^{2}\right)$ & $25.0(23.5-26.3)$ & $27.7(25.5-31.0)$ & $26.3(26.5-30.6)$ & 0.138 \\
\hline Hypertension & $57.1(4)$ & $90.0(27)$ & $83.3(25)$ & 0.067 \\
\hline Currently smoking & $0.0(0)$ & $16.7(5)$ & $16.7(5)$ & 0.631 \\
\hline Hypercholesterolemia & $57.1(4)$ & $86.7(26)$ & $86.7(26)$ & 0.074 \\
\hline Myocardial infarction & $14.3(1)$ & $40.0(12)$ & $26.7(8)$ & 0.283 \\
\hline PAOD & $28.6(2)$ & $16.7(5)$ & $10.0(3)$ & 0.078 \\
\hline COPD & $0.0(0)$ & $16.7(5)$ & $13.3(4)$ & 0.596 \\
\hline Stroke & $14.3(1)$ & $6.7(2)$ & $13.3(4)$ & 0.614 \\
\hline Ejection fraction $<50 \%$ & $28.6(2)$ & $30.0(9)$ & $43.3(13)$ & 0.116 \\
\hline Serum creatinine ( $\mu \mathrm{mol} / \mathrm{L})$ & $75(69-78)$ & $85(78-91)$ & $87(77-97)$ & 0.012 \\
\hline Estimated GFR $\left(\mathrm{ml} / \mathrm{min} / 1.73 \mathrm{~m}^{2}\right)$ & $88(86-102)$ & $76(71-86)$ & $71(64-85)$ & 0.003 \\
\hline Duration of surgery (min) & $120(108-179)$ & $191(158-240)$ & $233(188-263)$ & $<0.001$ \\
\hline ACC time (min) & - & $40(35-70)$ & $106(73-122)$ & $<0.001$ \\
\hline Duration of CPB (min) & - & $68(55-112)$ & $145(101-160)$ & $<0.001$ \\
\hline Transfused pRBCs (units) & $0.0(0)$ & $1.5(1.0-2.0)$ & $2.0(1.5-4.0)$ & $<0.001$ \\
\hline Use of pericardial suction & $0.0(0)$ & $3.3(1)$ & $100.0(30)$ & $<0.001$ \\
\hline Urine production (ml) & $300(92-720)$ & $443(264-593)$ & $360(273-493)$ & 0.454 \\
\hline Blood loss during surgery $(\mathrm{ml})$ & $175(150-300)$ & $200(120-300)$ & $300(190-530)$ & 0.122 \\
\hline In hospital mortality & $0(0)$ & $0(0)$ & $3.3(1)$ & 0.545 \\
\hline $\begin{array}{l}\text { Increase of serum creatinine }<48 \mathrm{~h} \\
\text { compared to preoperative value }(\%)\end{array}$ & $103(94-109)$ & $109(96-118)$ & $114(101-125)$ & 0.160 \\
\hline Acute kidney injury & & & & 0.603 \\
\hline Stage $O$ (no AKI) & $100.0(7)$ & $90.0(27)$ & $80.0(24)$ & \\
\hline Stage 1 & $0.0(0)$ & $10.0(3)$ & $16.7(5)$ & \\
\hline Stage 2 & $0.0(0)$ & $0.0(0)$ & $3.3(1)$ & \\
\hline Stage 3 & $0.0(0)$ & $0.0(0)$ & $0.0(0)$ & \\
\hline Duration of ICU admittance (days) & $1.0(1-1)$ & $1.0(1.0-1.0)$ & $1.0(1.0-2.0)$ & 0.090 \\
\hline Duration of hospitalization (days) & $6.0(6.0-8.0)$ & $7.0(6.8-9.0)$ & $7(6.5-13.0)$ & 0.148 \\
\hline
\end{tabular}

*Values are $\%(\mathrm{~N})$ or median (25th-75th IQR). Abbreviations: OPCAB, off-pump coronary artery bypass grafting; $C A B G$, on-pump coronary artery bypass grafting; $C A B G+V a l v e$, on-pump coronary artery bypass grafting and any type of valve reconstruction or replacement; $P A O D$, peripheral arterial occlusive disease; COPD, chronic obstructive pulmonary disease; GFR, glomerular filtration rate; ACC, aortic cross clamp; CPB, cardiopulmonary bypass; IC, intensive care unit. 


\section{CPB-assisted surgery causes acute hemolysis, increased plasma NO- consumption, and depletion of plasma haptoglobin}

Baseline $\mathrm{fHb}$ levels were comparable between the three patient groups $(p=0.78$, Figure 7.1A). During surgery, plasma $\mathrm{fHb}$ levels increased significantly in patients subjected to $C P B$ ( $p<.0001$ for $C A B G$, and $C A B G+V a l v e$ surgery patients), peaking at the end of CPB $(6.5 \pm 0.9 \mu \mathrm{mol} / \mathrm{L}, \mathrm{p}=0.041$ compared to baseline for CABG patients, and $18.6 \pm 2.9 \mu \mathrm{mol} / \mathrm{L}, \mathrm{p}<0.0001$, for $\mathrm{CABG}+$ Valve patients). After cessation of CPB, plasma $\mathrm{fHb}$ concentrations gradually decreased over time in these patient groups. Both peak $\mathrm{fHb}$ levels and total release of $\mathrm{fHb}\left(\mathrm{AUC}_{\mathrm{fHb}}\right)$ was significantly correlated to CPB-duration $\left(R_{s}=0.50, p<0.001\right.$, and $R_{s}=0.55, p<0.001$, respectively). Hemolysis did not occur in OPCAB patients (change of plasma fHb over time: $p=0.22$ ). The kinetics of plasma NO-consumption was similar to that of plasma $\mathrm{fHb}$ in all study groups (Figure 7.1B). Plasma NO-consumption only significantly increased in patients subjected to on-pump surgery ( $p<0.001$ for CABG and CABG+Valve patients), while baseline NO-consumption was statistically equal between the study groups $(p=0.18)$. The NO-consuming capacity of plasma peaked at the end of CPB, having increased 2.4 fold in CABG patients, and 7.9 fold in CABG+Valve surgery patients. Consistent with the potent NO-scavenging property of $\mathrm{fHb}$, the $\mathrm{AUC}_{\mathrm{fHb}}$ correlated significantly to total plasma NO-consumption ( $A \cup C_{N O}, r^{2}=0.75, p<0.0001$, Figure 7.1C).

Physiologically, the plasma protein $\mathrm{Hp}$ acts as a buffer against increases in plasma $\mathrm{fHb}$ levels through the formation of $\mathrm{Hp}-\mathrm{fHb}$ complexes resulting in $\mathrm{fHb}$ clearance from the circulation. ${ }^{17}$ This way, excessive hemolysis can potentially result in a significant reduction of $\mathrm{Hp}$ bioavailability. ${ }^{20}$ Indeed, plasma $\mathrm{Hp}$ dropped significantly over time in CABG and CABG+Valve surgery patients ( $p<0.0001$, for both groups) suggestive of $\mathrm{Hp}$ $\mathrm{fHb}$ complex clearance. Loss of circulating $\mathrm{Hp}$ was most marked in CABG+Valve surgery patients compared to CABG patients, which related to the higher plasma fHb levels in this patient group. The first statistically significant decrease in plasma $\mathrm{Hp}$ was measured at the end of $\mathrm{CPB}$, and concentrations further declined during the postoperative period reaching lowest levels 2 hours and 4 hours after cessation of $C P B$ in $C A B G$ and $C A B G+V a l v e$ surgery patients $(0.69 \pm 0.11 \mathrm{~g} / \mathrm{L}, \mathrm{p}<0.0001$, and $0.47 \pm 0.07 \mathrm{~g} / \mathrm{L}, \mathrm{p}<0.0001$, respectively). The maximum increase of plasma $\mathrm{fHb}$ correlated significantly to the maximum decrease of $\mathrm{Hp}\left(r^{2}=0.28, \mathrm{p}<0.0001\right.$, data not shown). Similar to $\mathrm{fHb}$ and NO-consumption, $\mathrm{Hp}$ levels remained relatively constant in OPCAB patients throughout surgery $(p=0.059)$. The observed increase of $\mathrm{Hp}$ after reaching lowest levels 4 hours after cessation of CPB was suggestive of enhanced $\mathrm{Hp}$ production and subsequent release of $\mathrm{Hp}$ into the circulation. 



Figure 7.1 Acute hemolysis is associated with increased plasma NO-consumption and loss of Hp. Plasma levels of $\mathrm{fHb}(\mathrm{A})$, and NO-consumption $(\mathrm{B})$ increased significantly during surgery in patients undergoing $C A B G+V a l v e(\bullet)$, and CABG $(\bullet)$ surgery. Levels did not significantly change in OPCAB patients $(\boldsymbol{\Delta})$. The total release of $\mathrm{fHb}$ and change in NO-consumption (C), estimated using the area under the curve (AUC) during surgery were significantly correlated $\left(r^{2}=0.75, p<\right.$ 0.0001). Figure D depicts the change in perioperative $\mathrm{Hp}$ levels in all groups. All values were corrected for hematocrit because of significant intraoperative hemodilution. Values are mean $\pm \operatorname{SEM}(A, B$, and $D)$ or a scatter plot with mean (black line) $\pm 95 \%$ confidence interval (dotted line, C). Stars indicate significant changes compared to baseline within groups: ${ }^{*}=p<0.05, * *$ $=\mathrm{p}<0.01, * * *=\mathrm{p}<0.001, * * * *=\mathrm{p}<0.0001$. Numbers $1-8$ refer to sample times of blood specimens (methods). CPB was not used in OPCAB patients.

\section{CPB-induced hemolysis is associated with visceral injury and clinical acute kidney injury}

The development of renal tubular injury and intestinal mucosal injury was studied using urinary NAG (Figure 7.2A) and plasma IFABP (Figure 7.2B). Both parameters were similar in all groups at baseline $(p=0.859$, and $p=0.697$, respectively), and increased significantly during CABG and CABG+Valve surgery $(p<0.0001$, and $p<0.001$ for NAG and IFABP, respectively). OPCAB patients did not display significant changes of NAG or IFABP over time ( $p=0.235$ and $p=0.062$, respectively). The potential relation between acute hemolysis and visceral organ injury in patients undergoing cardiac surgery was 
studied by correlation of $A U C_{F H b}, A U C_{N A G}$, and $A U C_{I F A B P}$ (Figure 7.2C and Figure 7.2D). Both renal injury and intestinal damage were significantly correlated with the extent of hemolysis during surgery $\left(R_{s}=0.70, p<0.0001\right.$, and $R_{s}=0.26, p=0.04$, respectively), albeit this correlation was stronger for renal tubular injury. Importantly, the correlation between hemolysis, renal tubular damage and intestinal injury remained statistically significant after correction for four other potential confounders using multivariable logistic regression (Table 7.1 and Table 7.2, respectively). The correlation between NO-consumption and both tissue injury markers was comparable to their correlation with $\mathrm{fHb}\left(R_{s}=0.55, p=0.002\right.$, and $R_{s}=0.41, p=0.03$, for NAG and IFABP respectively, data not shown), suggestive of a causal role of $\mathrm{fHb}$-induced NOscavenging in the development of visceral injury during cardiac surgery.
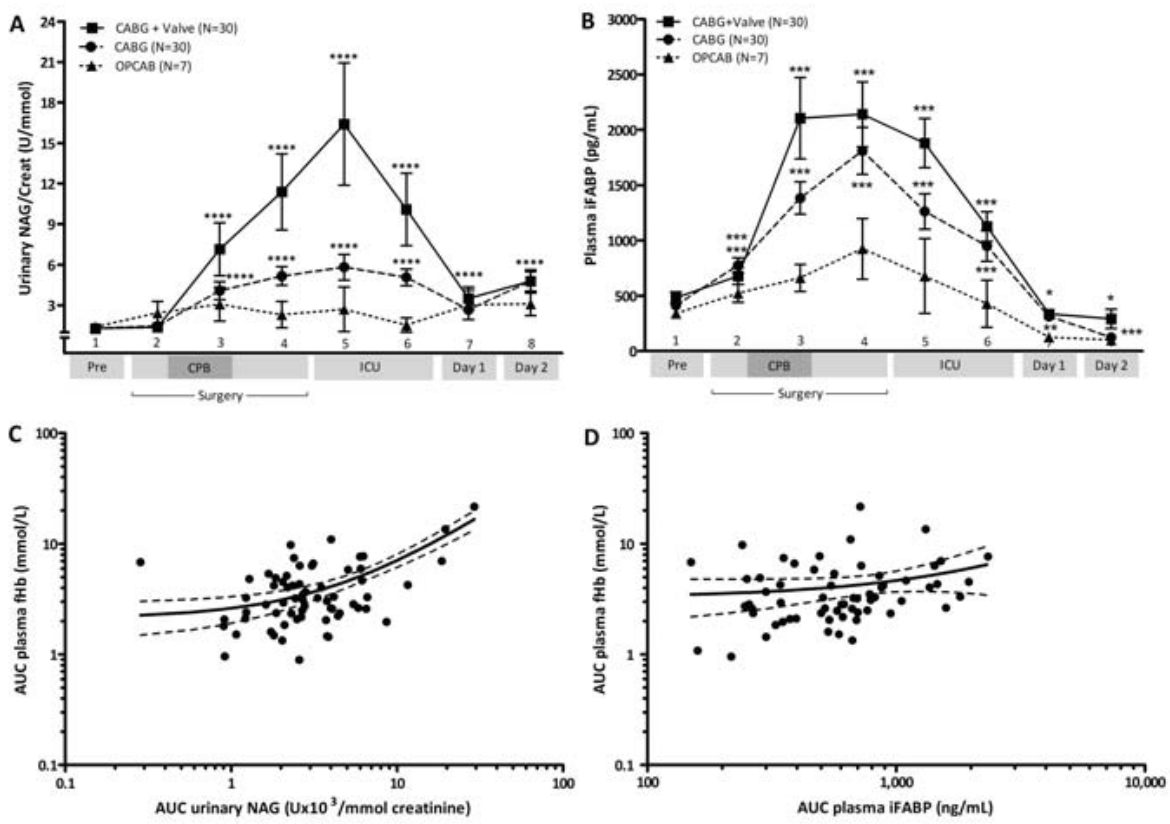

Figure 7.2 Acute hemolysis is significantly correlated to renal tubular injury and intestinal mucosal damage. Levels of urinary NAG (A) and plasma IFABP (B) changed significantly in patients undergoing $C A B G+V a l v e(\square)$, and $C A B G(\bullet)$ surgery, and in patients undergoing $C A B G+V a l v e$, CABG, and OPCAB patients $(\boldsymbol{\Delta})$, respectively. The total release (estimated using the area under the curve (AUC) of $\mathrm{fHb}$ and NAG (C), and $\mathrm{fHb}$ and IFABP (D) were significantly correlated $\left(R_{s}=\right.$ $0.70, p<0.0001$, and $R_{s}=0.26, p=0.04$, respectively). Plasma IFABP values were corrected for hematocrit because of significant intraoperative hemodilution, urinary NAG levels were corrected for urine creatinine values. Values are mean \pm SEM $(A$, and $B)$ or a scatter plot with mean (black line) $\pm 95 \%$ confidence interval (dotted line, $C$ and D). Stars indicate significant changes compared to baseline within groups: ${ }^{*}=p<0.05, * *=p<0.01, * * *=p<0.001, * * * *=$ $p<0.0001$.. Numbers $1-8$ in refer to sample times of blood specimens (methods). CPB was not used in OPCAB patients. 
Table 7.1 Multivariable linear regression for $\mathrm{AUC}_{\mathrm{NAG}}$.

\begin{tabular}{lccc}
\hline Variable & Beta & $95 \% \mathrm{Cl}$ & $\mathrm{p}$ value \\
\hline Age (years) & -0.04 & $-122.14-84.49$ & 0.72 \\
Preoperative eGFR $\left(\mathrm{ml} / \mathrm{min} / 1.73 \mathrm{~m}^{2}\right)$ & 0.01 & $-72.26-76.18$ & 0.96 \\
Duration of CPB (min) & -0.08 & $-21.82-10.19$ & 0.47 \\
Need for packed red blood cell transfusion (yes) & 0.12 & $-1200.34-3530-49$ & 0.33 \\
$\mathrm{AUC}_{\mathrm{fHb}}$ & 0.77 & $0.70-1.32$ & $<0.0001$ \\
\hline
\end{tabular}

Table 7.2 Multivariable linear regression for $\mathrm{AUC}_{\mathrm{iFABP}}$.

\begin{tabular}{lccc}
\hline Variable & Beta & Confidence Interval (95\%) & p value \\
\hline Age (years) & 0.16 & $-5763.55-191117.38$ & 0.28 \\
Cardiac Ejection Fraction (\%) & 0.24 & $-86399.79-544968.51$ & 0.15 \\
Intraoperative blood loss (mL) & -0.03 & $-401.87-339.21$ & 0.87 \\
Number of blood transfusions (units) & -0.15 & $-182970.49-78106.15$ & 0.42 \\
AUC $_{\mathrm{fHb}}$ & 0.30 & $0.60-120.77$ & 0.04 \\
\hline
\end{tabular}

Finally, we studied the relation between hemolysis and development of AKI as defined by an increase in serum creatinine $\geq 150 \%$ compared to preoperative values within 48 hours after surgery. ${ }^{15}$ Clinical characteristics of AKI and non-AKI patients are depicted in Supplemental Table S7.2. Patients developing postoperative AKI were already identifiable during surgery as they displayed significantly higher $\mathrm{fHb}$ levels at the end of CPB compared to non-AKI patients $(24.4 \pm 7.6 \mu \mathrm{mol} / \mathrm{L}$ vs. $9.6 \pm 1.2 \mu \mathrm{mol} / \mathrm{L}, \mathrm{p}<0.01$, Figure 7.3A). AKI patients also showed significantly higher NAG levels at the end of $\mathrm{CPB}$, indicating more profound renal tubular injury compared to non-AKI patients $(11.9 \pm 5.7 \mathrm{U} / \mathrm{mmol}$ vs $4.2 \pm 0.5 \mathrm{U} / \mathrm{mmol}, \mathrm{p}<0.05$, Figure 7.3B). We could not analyze NO-consumption in AKI and non-AKI patients due to small patient numbers as NOconsumption was only assessed in a (random) selection of patients. 
Supplemental table 7.2 Clinical characteristics of AKI and non-AKI patients.

\begin{tabular}{lccc}
\hline Characteristic & Non-AKI (N=58) & AKI (N =9) & p value \\
\hline Type of surgery & & & 0.176 \\
OPCAB & $12.1(7)^{*}$ & $0.0(0)$ & \\
CABG & $46.6(27)$ & $33.3(3)$ & \\
CABG+Valve & $41.4(24)$ & $66.7(6)$ & 0.614 \\
Male & $86.2(50)$ & $77.8(7)$ & 0.107 \\
Age (years) & $68(57-73)$ & $73(66-77)$ & 0.119 \\
Ejection fraction <50\% & $23.1(12)$ & $33.3(3)$ & 0.334 \\
Hypertension & $81.0(47)$ & $100.0(9)$ & 0.465 \\
PAOD & $13.8(8)$ & $22.2(2)$ & 0.797 \\
Serum creatinine ( $\mu$ mol/L) & $83(77-94)$ & $83(75-96)$ & 0.659 \\
Estimated GFR (ml/min/1.73m $\left.{ }^{2}\right)$ & $77(69-86)$ & $80(62-92)$ & 0.147 \\
Duration of surgery (min) & $195(160-240)$ & $245(181-270)$ & 0.255 \\
ACC time (min) & $69(39-106)$ & $78(53-120)$ & 0.431 \\
Duration of CPB (min) & $105(63-148)$ & $118(79-159)$ & 0.010 \\
Transfusion requirement with stored blood & $25.9(15)$ & $6(66.7)$ & 0.070 \\
Use of pericardial suction & $41.4(24)$ & $77.8(7)$ & 0.800 \\
Urine production (ml) & $388(263-568)$ & $415(331-496)$ & 0.542 \\
Blood loss (ml) & $245(150-360)$ & $200(188-750)$ & 1.000 \\
In hospital mortality & $1.7(1)$ & $0.0(0)$ & 0.111 \\
Duration of ICU admittance (days) & $1(1-1)$ & $1(1-5)$ & 0.007 \\
Duration of hospitalization (days) & $7(6-8)$ & $9(8-14)$ & \\
\hline
\end{tabular}

*Values are \% $(\mathrm{N})$ or median (25th-75th IQR). Abbreviations: OPCAB, off-pump coronary artery bypass grafting; $C A B G$, on-pump coronary artery bypass grafting; $C A B G+V a l v e$, on-pump coronary artery bypass grafting and any type of valve reconstruction or replacement; $P A O D$, peripheral arterial occlusive disease; GFR, glomerular filtration rate; ACC, aortic cross clamp; CPB, cardiopulmonary bypass; ICU, intensive care unit.
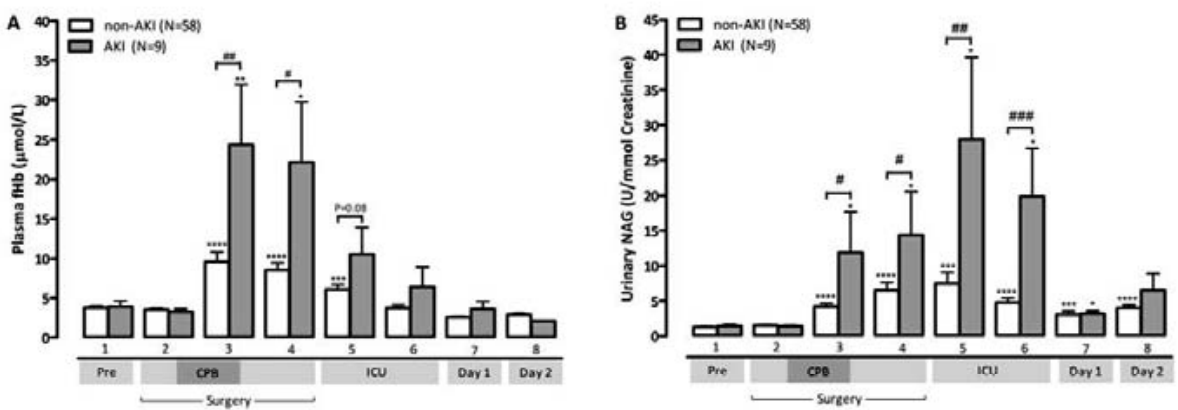

Figure 7.3 Patients with postoperative AKI display significantly more hemolysis and renal tubular injury during surgery. Patients with postoperative AKI (grey bars) display significantly higher fHb (A) and urinary NAG levels (B), compared to non-AKI patients (white bars). Values are mean + SEM. Stars indicate significant changes compared to baseline within groups: ${ }^{*}=p<0.05, * *=p$ $<0.01, * * *=p<0.001, * * * *=p<0.0001$.. Hash symbols indicate significant differences between groups: $\#=p<0.05, \# \#=p<0.01, \# \#=p<0.001$. Numbers $1-8$ refer to sample times of blood specimens (methods). CPB was not used in OPCAB patients. 


\section{DISCUSSION}

The current study demonstrates that hemolysis occurring during cardiothoracic surgery significantly increases plasma NO-consumption. Moreover, hemolysis is independently correlated to the development of visceral organ injury and AKI. Patients subjected to more complex types of cardiac surgery, such as combined bypass and cardiac valve surgery, appear to be at highest risk.

The adverse effect of hemolysis on the intravascular NO-metabolism is increasingly appreciated as an important pathophysiological mechanism in the development of complications in various clinical settings. The discovery of oxygenated plasma $\mathrm{fHb}$ $\left(\mathrm{HbFe}^{2+} \mathrm{O}_{2}\right)$ as a potent scavenger of endothelial-derived NO (in a 1:1 stoichiometric and irreversible reaction) has provided an explanation for the development of gastrointestinal smooth muscle dystonias, vasculopathy, endothelial dysfunction, renal injury, pulmonary hypertension, and increased coagulation in patients with chronic hemolytic disease. ${ }^{10,11}$ In the present study, acutely enhanced $\mathrm{fHb}$ concentrations during surgery caused a 2.4 -fold increase in plasma NO-consuming capacity in CABG patients (compared to preoperative levels), and a 7.9-fold increase in CABG+Valve patients, in whom NO-consumption levels of $266 \mu \mathrm{mol}$ per liter of plasma were observed. As plasma NO-consumption levels of approximately 10-15 $\mu \mathrm{mol} / \mathrm{L}$ already have been related to a significant impairment in NO-dependent fore-arm blood flow response in patients, the extent of NO-consumption measured in these patients is of clinical significance. ${ }^{10,12}$ Such a decrease in NO-bioavailability promotes vasoconstriction, platelet aggregation, upregulation of adhesion molecule expression, and stimulation of vascular leucocyte adhesion and inflammation. ${ }^{10}$

Hemolysis is a well-recognized, although considered relatively harmless, consequence of CPB, and has been shown to increase with longer perfusion times. ${ }^{9,21}$ Three factors principally contribute to the development of CPB-induced hemolysis: 1) exposure of RBCs to mechanical forces, particularly shear stress ${ }^{9}, 2$ ) contact of blood with air or non-endothelial surfaces ${ }^{22}$, and 3) use of suction pressures. $^{23}$ In addition, the development of sublethal RBC damage, which promotes premature intravascular RBC disintegration and worse, alters the rheological properties of blood contributing to increased $\mathrm{fHb}$ levels during surgery. ${ }^{24}$ Besides $\mathrm{CPB}$ the use of autotransfusion devices and transfusion of stored red blood cells may contribute to increased $\mathrm{fHb}$ levels during cardiac surgery. Autotransfusion devices remove $\mathrm{fHb}$ from the salvaged blood, but cause significant sublethal damage to red blood cells. ${ }^{9}$ Retransfusion of such "lessviable" cells may increases plasma $\mathrm{fHb}$ levels after premature intravascular lysis. Prolonged storage of blood results in both hemolysis and sublethal damage of erythrocytes. ${ }^{25}$ Therefore, transfusion of stored red blood cell products could cause a direct (transfusion of the $\mathrm{fHb}$-containing storage medium), and delayed (disintegration 
of less viable $\mathrm{RBCs}$ ) increase of $\mathrm{fHb}$ in the patient (Vermeulen Windsant et al, Crit Care 2012;15:R95). In line, we measured highest $\mathrm{fHb}$ levels in CABG+Valve surgery patients who were exposed to the longest $C P B$ times, and required the highest number of stored red blood cell units, while OPCAB patients did not display significant changes of plasma fHb over time.

As the development of hemolysis during CPB is well known, there have been several, albeit a few, studies reporting on the adverse relation between intraoperative hemolysis and patient outcome after cardiovascular surgery. These studies all focused on the direct toxic effect of $\mathrm{fHb}$ on the renal epithelium by $\mathrm{fHb}$-induced generation of damaging reactive oxygen species (catalyzed by free heme and iron), and formation of obstructive casts. ${ }^{26-30}$ As $\mathrm{fHb}$ was believed to be merely nephrotoxic after glomerular filtration, a correlation between hemolysis and injury of other organs in the context of CPB has, to our knowledge, never been reported. The additional NO-scavenging property of $\mathrm{fHb}$, next to its nephrotoxic effect, could however explain the stronger correlation between hemolysis and renal injury compared to the correlation between hemolysis and intestinal injury in this study. The fact that in this setting hemolysis correlates with injury of two independent organ systems has significant implications for the (potential) harmful effect of $\mathrm{fHb}$ on other tissues. It has been reported that $\mathrm{fHb}$ impairs left ventricular function and coronary blood flow in neonatal rabbit hearts, particularly following ischemia and reperfusion. ${ }^{31}$ Furthermore, the correlation between hemolysis and pulmonary hypertension in the setting of chronic hemolysis is well established. ${ }^{32}$

The results of this study offer a window of opportunity to reduce surgery related morbidity and mortality, particularly in high risk patients. Inactivation of $\mathrm{fHb}$ or increasing NO-bioavailability may maintain vascular homeostasis, stimulate microcirculatory blood flow, and thus limit tissue injury during CPB-assisted cardiac surgery. Three therapeutic options are of particular interest in the current setting. First, prophylactic and/or therapeutical administration of (recombinant) $\mathrm{Hp}$ could counteract the depletion of $\mathrm{Hp}$ which we observed during and after surgery. In fact, administration of $\mathrm{Hp}$ significantly reduced urinary NAG levels and prevented hemoglobinuria in 14 patients undergoing CABG surgery with $\mathrm{CPB} .^{27}$ Unfortunately, high costs currently limit clinical implementation of routine $\mathrm{Hp}$ supplementation, though plasma transfusion could be an option. Second, administration of NO-gas via the oxygenator or ventilation gas, analogous to inhaled NO (iNO), may prove to be beneficial. iNO, already at very low concentrations (80ppm), inactivates $\mathrm{fHb}$ in the pulmonary vasculature through oxidation, and reduces the NO-consuming capacity of plasma. ${ }^{10}$ iNO enhances the formation of NO-metabolites, such as nitrate and nitrite, which are important for intravascular NO transport, and cytoprotection. ${ }^{33}$ Also, iNO decreases shear stress induced sublethal RBC damage. ${ }^{34}$ Inhaled NO is already clinically 
used in various settings ${ }^{35}$, and it neither alters NO-consumption in healthy volunteers nor results in significant methemoglobinemia. ${ }^{10}$ Finally, the direct oral or intravenous administration of nitrite or nitrate to increase the plasma NO-donor pool could be worth investigating. ${ }^{33}$

The main strength of our study is the inclusion of patients undergoing different types of cardiac surgery of various complexity. This allowed the identification of the group of patients at highest risk for hemolysis-induced organ injury who may benefit from hemolysis-targeted therapeutic interventions. Furthermore, the exclusion of patients with preoperative impaired renal function prevented confounding on the outcome measures renal tubular injury and postoperative AKI. The main limitations are inherent to the observational nature of the study. The strong and significant correlations between hemolysis, impaired NO-bioavailability, renal tubular injury, intestinal damage, and AKI should not be interpreted as causal relationships. Also, the number of adverse clinical events (AKI or significant intestinal complications) was relatively low, and thus precludes firm conclusions as to the impact of hemolysis on adverse clinical outcome. Finally, other potential mechanisms underlying the relation between intravascular hemolysis and kidney damage, such as heme induced oxidative damage were not investigated and may be important in this setting. ${ }^{30}$

\section{CONCLUSIONS}

This study supports an adverse relation between enhanced plasma fHb levels, decreased plasma NO-bioavailability, and organ integrity loss during cardiac surgery. Furthermore, this study illustrates that patients with high intraoperative $\mathrm{fHb}$ levels are at higher risk for the development of postoperative AKI. The current results are of clinical importance as they aid in the identification of high risk patients who may benefit from therapeutic interventions aimed at the adverse effects of $\mathrm{fHb}$. Preoperative plasma $\mathrm{Hp}$ could serve as a novel preoperative diagnostic and screening tool in the selection of patients with a low buffer capacity to increased $\mathrm{fHb}$. Additionally, patients with impaired pre-operative renal function, undergoing complex cardiac surgery associated with long perfusion times and high transfusion requirements may be at particular high risk for the development of $\mathrm{fHb}$-induced visceral tissue injury and AKI. These results call for increased awareness for the adverse consequences of even modest increases in plasma $\mathrm{fHb}$ during cardiac surgery. Finally, our study suggests that inactivation of $\mathrm{fHb}$ or supplementation of NO may significantly attenuate the development of visceral tissue injury and $\mathrm{AKI}$, and improve patient outcome after CPB-assisted cardiac surgery. 


\section{REFERENCES}

1. Huybregts RA, Morariu AM, Rakhorst G, Spiegelenberg SR, Romijn HW, de Vroege R, van Oeveren W. Attenuated renal and intestinal injury after use of a mini-cardiopulmonary bypass system. Ann Thorac Surg 2007;83:1760-1766

2. Grotz MR, Deitch EA, Ding J, Xu D, Huang Q, Regel G. Intestinal cytokine response after gut ischemia: Role of gut barrier failure. Ann Surg 1999;229:478-486

3. Lassnigg A, Schmidlin D, Mouhieddine M, Bachmann LM, Druml W, Bauer P, Hiesmayr M. Minimal changes of serum creatinine predict prognosis in patients after cardiothoracic surgery: A prospective cohort study. J Am Soc Nephrol 2004;15:1597-1605

4. Conlon PJ, Stafford-Smith M, White WD, Newman MF, King S, Winn MP, Landolfo K. Acute renal failure following cardiac surgery. Nephrol Dial Transplant 1999;14:1158-1162

5. Rosner $\mathrm{MH}$, Okusa MD. Acute kidney injury associated with cardiac surgery. Clin J Am Soc Nephrol 2006;1:19-32

6. Schrier RW, Wang W, Poole B, Mitra A. Acute renal failure: Definitions, diagnosis, pathogenesis, and therapy. J Clin Invest 2004;114:5-14

7. Loef BG, Epema AH, Navis G, Ebels T, van Oeveren W, Henning RH. Off-pump coronary revascularization attenuates transient renal damage compared with on-pump coronary revascularization. Chest 2002;121:1190-1194

8. Kameneva MV, Undar A, Antaki JF, Watach MJ, Calhoon JH, Borovetz HS. Decrease in red blood cell deformability caused by hypothermia, hemodilution, and mechanical stress: Factors related to cardiopulmonary bypass. Asaio J 1999;45:307-310

9. Vercaemst L. Hemolysis in cardiac surgery patients undergoing cardiopulmonary bypass: A review in search of a treatment algorithm. J Extra Corpor Technol 2008;40:257-267

10. Reiter CD, Wang X, Tanus-Santos JE, Hogg N, Cannon RO, 3rd, Schechter AN, Gladwin MT. Cell-free hemoglobin limits nitric oxide bioavailability in sickle-cell disease. Nat Med 2002;8:1383-1389

11. Rother RP, Bell L, Hillmen P, Gladwin MT. The clinical sequelae of intravascular hemolysis and extracellular plasma hemoglobin: A novel mechanism of human disease. Jama 2005;293:1653-1662

12. Meyer C, Heiss C, Drexhage C, Kehmeier ES, Balzer J, Muhlfeld A, Merx MW, Lauer T, Kuhl H, Floege J, Kelm M, Rassaf T. Hemodialysis-induced release of hemoglobin limits nitric oxide bioavailability and impairs vascular function. J Am Coll Cardiol 2010;55:454-459

13. Vermeulen Windsant IC, Snoeijs MG, Hanssen SJ, Altintas S, Heijmans JH, Koeppel TA, Schurink GW, Buurman WA, Jacobs MJ. Hemolysis is associated with acute kidney injury during major aortic surgery. Kidney Int 2010;77:913-920

14. Heijmans JH, Liem KS, Damoiseaux GM, Maessen JG, Roekaerts PM. Pulmonary function and inflammatory markers in patients undergoing coronary revascularisation with or without cardiopulmonary bypass. Anaesthesia 2007;62:1233-1240

15. Mehta RL, Kellum JA, Shah SV, Molitoris BA, Ronco C, Warnock DG, Levin A. Acute kidney injury network: Report of an initiative to improve outcomes in acute kidney injury. Crit Care 2007;11:R31

16. Cruz-Landeira A, Bal MJ, Quintela, Lopez-Rivadulla M. Determination of methemoglobin and total hemoglobin in toxicological studies by derivative spectrophotometry. J Anal Toxicol 2002;26:67-72

17. Kristiansen M, Graversen JH, Jacobsen C, Sonne O, Hoffman HJ, Law SK, Moestrup SK. Identification of the haemoglobin scavenger receptor. Nature 2001;409:198-201

18. Dittrich S, Kurschat K, Dahnert I, Vogel M, Muller C, Alexi-Meskishvili V, Lange PE. Renal function after cardiopulmonary bypass surgery in cyanotic congenital heart disease. Int J Cardiol 2000;73:173-179

19. Lieberman JM, Sacchettini J, Marks C, Marks WH. Human intestinal fatty acid binding protein: Report of an assay with studies in normal volunteers and intestinal ischemia. Surgery 1997;121:335-342

20. Tabbara IA. Hemolytic anemias. Diagnosis and management. Med Clin North Am 1992;76:649-668

21. Cheung AT, Cruz-Shiavone GE, Meng QC, Pochettino A, Augoustides JA, Bavaria JE, Ochroch EA. Cardiopulmonary bypass, hemolysis, and nitroprusside-induced cyanide production. Anesth Analg 2007;105:29-33

22. Vermeulen Windsant IC, Hanssen SJ, Buurman WA, Jacobs MJ. Cardiovascular surgery and organ damage: Time to reconsider the role of hemolysis. The Journal of thoracic and cardiovascular surgery 2011;142:1-11 
23. Gregoretti S. Suction-induced hemolysis at various vacuum pressures: Implications for intraoperative blood salvage. Transfusion 1996;36:57-60

24. Watanabe N, Arakawa Y, Sou A, Kataoka H, Ohuchi K, Fujimoto T, Takatani S. Deformability of human red blood cells exposed to a uniform shear stress as measured by a cyclically reversing shear flow generator. Physiol Meas 2007;28:531-545

25. Kim-Shapiro DB, Lee J, Gladwin MT. Storage lesion: Role of red blood cell breakdown. Transfusion 2011;51:844-851

26. Haase M, Haase-Fielitz A, Bagshaw SM, Ronco C, Bellomo R. Cardiopulmonary bypass-associated acute kidney injury: A pigment nephropathy? Contrib Nephrol 2007;156:340-353

27. Tanaka K, Kanamori Y, Sato T, Kondo C, Katayama Y, Yada I, Yuasa H, Kusagawa M. Administration of haptoglobin during cardiopulmonary bypass surgery. ASAIO Trans 1991;37:M482-483

28. Zager RA, Gamelin LM. Pathogenetic mechanisms in experimental hemoglobinuric acute renal failure. Am J Physiol 1989;256:F446-455

29. Davis CL, Kausz AT, Zager RA, Kharasch ED, Cochran RP. Acute renal failure after cardiopulmonary bypass in related to decreased serum ferritin levels. J Am Soc Nephrol 1999;10:2396-2402

30. Billings FTt, Ball SK, Roberts LJ, 2nd, Pretorius M. Postoperative acute kidney injury is associated with hemoglobinemia and an enhanced oxidative stress response. Free radical biology \& medicine 2011;50:1480-1487

31. Nemeto S, Aoki M, Dehua C, Imai Y. Free hemoglobin impairs cardiac function in neonatal rabbit hearts. Ann Thorac Surg 2000;69:1484-1489

32. Gladwin MT, Sachdev V, Jison ML, Shizukuda Y, Plehn JF, Minter K, Brown B, Coles WA, Nichols JS, Ernst I, Hunter LA, Blackwelder WC, Schechter AN, Rodgers GP, Castro O, Ognibene FP. Pulmonary hypertension as a risk factor for death in patients with sickle cell disease. N Engl J Med 2004;350: 886-895

33. Lundberg JO, Weitzberg E, Gladwin MT. The nitrate-nitrite-nitric oxide pathway in physiology and therapeutics. Nat Rev Drug Discov 2008;7:156-167

34. Baskurt OK, Uyuklu M, Meiselman HJ. Protection of erythrocytes from sub-hemolytic mechanical damage by nitric oxide mediated inhibition of potassium leakage. Biorheology 2004;41:79-89

35. Bloch KD, Ichinose F, Roberts JD, Jr., Zapol WM. Inhaled no as a therapeutic agent. Cardiovasc Res 2007;75:339-348 

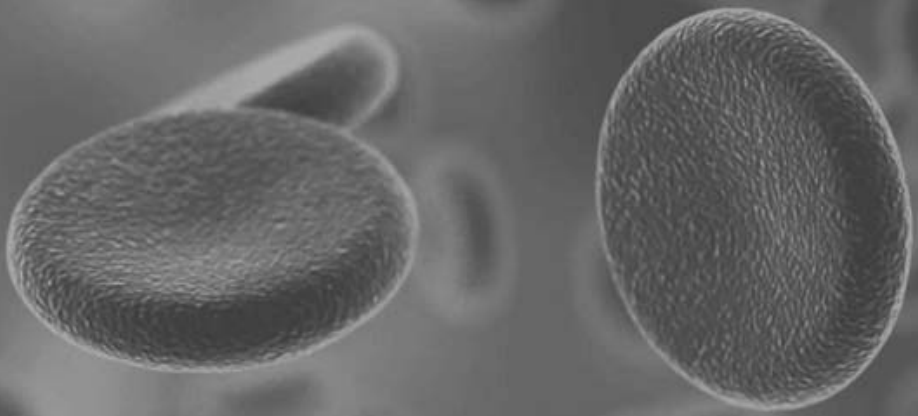
Blood transfusions increase circulating plasma free hemoglobin levels and plasma nitric oxide consumption: a prospective observational pilot study Jose E Tanus-Santos, Michael J Jacobs, Wim A Buurman 


\begin{abstract}

\section{Introduction}

The increasing number of reports on the relation between transfusion of stored red blood cells (RBC) and adverse patient outcome has sparked an intense debate on the benefits and risks of blood transfusions. Meanwhile, the pathophysiological mechanisms underlying this postulated relation remain unclear. The development of hemolysis during storage might contribute to this mechanism by release of free hemoglobin ( $\mathrm{fHb}$ ), a potent nitric oxide (NO) scavenger, which may impair vasodilation and microcirculatory perfusion after transfusion. The objective of this prospective observational pilot study was to establish whether RBC transfusion results in increased circulating $\mathrm{fHb}$ levels and plasma NO-consumption. In addition, the relation between increased $\mathrm{fHb}$ values and circulating haptoglobin, its natural scavenger, was studied.
\end{abstract}

\title{
Methods
}

Thirty patients electively received one $(\mathrm{N}=8)$ or two $(\mathrm{N}=22)$ stored packed red blood cell units. Blood samples were drawn to analyze plasma levels of $\mathrm{fHb}$ levels, haptoglobin, and NOconsumption prior to transfusion, and 15 minutes, 30minutes, 60minutes, 120 minutes, and 24hours after transfusion. Differences were compared using Pearson Chi-square or Fisher's exact test for dichotomous variables, or independent sample t-test or Mann-Whitney-U-test for continuous data. Continuous, multiple time-point, data were analyzed using the repeated oneWay ANOVA or Kruskall-Wallis test. Correlations were analyzed using the Spearman correlation.

\section{Results}

Storage duration correlated significantly with $\mathrm{fHb}$ concentrations and NO-consumption within the storage medium $(R=0.48, p<0.001$, and $R=0.54, p<0.01$ ). FHb also significantly correlated with NO-consumption directly $(R=0.62, p=0.002)$. Transfusion of 2 red blood cell units significantly increased circulating $\mathrm{fHb}$ and NO-consumption in the recipient $(\mathrm{p}<0.001$ and $p<$ 0.05 , respectively), in contrast to transfusion of 1 stored red blood cell unit. Storage duration of the blood products did not correlate with changes in $\mathrm{fHb}$ and NO-consumption in the recipient. In contrast, pre-transfusion recipient plasma haptoglobin levels inversely influenced posttransfusion $\mathrm{fHb}$ concentrations.

\section{Conclusions}

These data suggest that RBC transfusion can signficantly increase post-transfusion plasma $\mathrm{fHb}$ levels and plasma NO-consumption in the recipient. This may contribute to the potential pathophysiological mechanism underlying the much discussed adverse relation between blood transfusions and patient outcome. This observation may be of particular importance for patients with substantial transfusion requirements. 


\section{INTRODUCTION}

Transfusion of stored red blood cells is a common medical procedure, particularly in the context of critical care, with approximately 70 million packed red blood cells ( $p R B C$ ) being transfused worldwide each year. ${ }^{1}$ The rationale of $\mathrm{pRBC}$ administration is enhancement of intravascular oxygen carrying capacity and thus improvement of tissue oxygenation. However, recent insights into pathological changes of RBC functionality and integrity during storage, collectively known as the "storage lesion", has drawn attention to the potential negative consequences of pRBC transfusion as it limits the post-transfusion survival of RBCs in vivo. ${ }^{2}$ The storage lesion includes decreased RBC viability and deformability, increased RBC aggregability and adhesiveness, enhanced susceptibility to oxidative damage, formation of membrane vesicles resulting in loss of surface area, and increased cell density. ${ }^{2-4}$ Furthermore, several changes to the RBC microenvironment (the storage medium) have been reported; a decrease in $\mathrm{pH}$, accumulation of pro-inflammatory substances, hemoglobin-derived free iron, and microvescicles containing large amounts of free hemoglobin $(\mathrm{fHb})^{5}$, and increased levels of hemolysis markers such as potassium, arginase -1 , and $\mathrm{fHb}$ in the storage medium. ${ }^{2,6-8}$ Generally, increasing storage duration aggravates the storage lesion. ${ }^{2}$

The profound beneficial effects of transfusion cannot be understated. Nevertheless, the number of studies reporting on the potential adverse effects of (massive) pRBC transfusion on patient morbidity and mortality has increased significantly in recent years which has initiated an intense debate on the benefits and risks of pRBCs, particularly focusing on the effects of "younger" versus "older" pRBCs. ${ }^{9-14}$ Although the exact mechanisms underlying the adverse effects of pRBC administration have not yet been fully elucidated, the release of $\mathrm{fHb}$ and its influence on the intravascular nitric oxide (NO) metabolism after transfusion has been attributed an important role. ${ }^{5} \mathrm{FHb}$ was found to be a potent scavenger of NO, the most important endogenous vasodilator. ${ }^{15}$ In line, increased $\mathrm{fHb}$ levels in patients with chronic and acute hemolysis have been associated with decreased NO-bioavailability within the microcapillary bed, decreased organ perfusion and increased organ injury. ${ }^{15-17}$ Similarly, transfusion of stored $\mathrm{pRBC}$ units may enhance $\mathrm{fHb}$ concentrations in patients after transfusion, for instance as a consequence of premature intravascular rupture of the transfused erythrocytes, or due to the transfusion of the $\mathrm{fHb}$-containing storage medium. ${ }^{7}$ In line with this hypothesis, it was recently shown that transfusion of $\mathrm{fHb}$-containing supernatant of stored erythrocytes in rats caused a significant increase in blood pressure which correlated with the $\mathrm{fHb}$ levels in the supernatant. ${ }^{5}$

This prospective observation pilot study aimed to investigate if transfusion of 1 or $2 \mathrm{pRBC}$ units can result in enhanced circulating $\mathrm{fHb}$ levels and plasma NO-consumption 
in the recipient. In addition, we studied whether pRBC storage duration or pretransfusion recipient plasma haptoglobin $(\mathrm{Hp})$ levels - the physiological fHb scavenger influenced the change of plasma $\mathrm{fHb}$ in the recipient after transfusion.

\section{MATERIALS AND METHODS}

\section{Patients}

Based on previous experiments, we calculated that inclusion of thirty patients would provide sufficient power to detect significant increases in plasma fHb levels in the recipient after a blood transfusion. To that end, fifty-eight patients admitted to the Department of Hematology and Oncology of the Maastricht University Medical Center between May $1^{\text {st }} 2010$ and November $1^{\text {st }} 2010$ were screened for eligibility for study participation using predetermined inclusion and exclusion criteria. This resulted in the inclusion of thirty patients providing written informed consent at least 24 hours before transfusion. The study protocol was approved by the local ethical review board in accordance with the Declaration of Helsinki (amended in Seoul, 2008). We only included adult patients ( $\geq 18$ years) with normal kidney function, and normal liver function, who were in a stable clinical phase of their disease. Normal kidney function was defined as an estimated glomerular filtration rate of $60 \mathrm{ml} / \mathrm{min} / 1.73 \mathrm{~m}^{2}$ or higher, assessed by the abbreviated Modification of Diet in Renal Disease as recommended by the National Kidney Foundation. ${ }^{18}$ Normal liver function was indicated by normal pretransfusion bilirubin levels. Furthermore, presence of a central venous line (in the jugular or subclavian vein) was mandatory to enable non-traumatic blood sampling, thus minimizing sampling-induced hemolysis. C-reactive protein levels exceeding $10 \mathrm{mg} / \mathrm{L}$ were reason for patient exclusion since an active inflammatory process may lead to increased $\mathrm{Hp}$ levels. As $\mathrm{Hp}$ is the physiological $\mathrm{fHb}$ scavenger, patients with increased $\mathrm{Hp}$ concentrations may be able to clear $\mathrm{fHb}$ more readily compared to patients with normal plasma Hp levels $(0.25-1.9 \mathrm{~g} / \mathrm{L})$. As $\mathrm{Hp}$ is not routinely measured in patients prior to blood transfusion at our hospital we were not able to use $\mathrm{Hp}$ concentrations directly to include or exclude patients. Other exclusion criteria included pre-existent hemolytic disease, and transfusion of pRBCs within 72 hours prior to inclusion. We chose a time-frame of 72 hours on the basis of previous (unpublished) data showing that even after strong increases of plasma $\mathrm{fHb}$, these levels are back to normal values at 24 hours after peak fHb levels were observed (in a stable clinical condition without ongoing hemolysis). The investigators did not have any influence on the selection of the transfused $\mathrm{pRBC}$ with regard to storage duration or any other parameter. 


\section{Red blood cell products}

All transfused pRBCs were collected and prepared for transfusion by the Sanquin Blood Supply Foundation, the Netherlands. The maximum storage duration of pRBC units allowed in the Netherlands after the collection date is 35 days. All pRBC units were pre-storage leucodepleted, according to standard protocol. The storage solution consisted of a mixture of saline, adenine, glucose and mannitol. Mean volume and hematocrit of the transfused pRBC units were $275 \mathrm{~mL}$ and 0.60 , respectively. The pRBCs were subsequently distributed to and stored by Central Diagnostic Laboratory of the Maastricht University Medical Center until use. In case 2 pRBC were administered, the storage duration of both $\mathrm{PRBC}$ units was never more than 2 days apart. The majority of transfused pRBCs were of blood type $0(\mathrm{~N}=32,61.5 \%)$ and were Rh-negative $(\mathrm{N}=33,63.5 \%)$. The remainder of $\mathrm{pRBC}$ units were either of blood type $A$ $(N=16,30.8 \%)$ or $B(N=4,7.7 \%)$. Eight patients were transfused with irradiated (25Gy) pRBCs. Each pRBC unit was administered in a 60-90 min time-frame. None of the patients received fresh frozen plasma or platelets during the study period.

\section{Blood sampling and sample processing}

Central venous blood was drawn from the venous line by an experienced nurse at 6 pre-set time points; pre-transfusion (blood sample taken on the morning of transfusion in the context of routine patient care), 15 minutes after transfusion (T15) of all pRBC (1 or 2), 30 minutes after transfusion (T30), 60 minutes after transfusion (T60), 120 minutes after transfusion (T120), and the morning after transfusion (T24). Prior to every sample collection, the central venous line was flushed with sterile saline to prevent sampling of the previously administered pRBC (which was given via the same line) or remnants of previously collected blood sample. Whole blood was gently collected using sterile syringes, instead of standard blood collection tubes (vacutainers), to prevent vacuum-induced hemolysis. After collection of two syringes, the blood from the second syringe (not contaminated with sterile saline) was immediately transferred to an EDTA-containing blood collection tube without vacuum (Becton Dickinson, Franklin Lakes, NJ), carefully mixed by gentle rotation, and subsequently stored for a maximum of 1 hour at $4^{\circ} \mathrm{C}$, until further processing. After centrifugation (1500g at $4^{\circ} \mathrm{C}$ for 15 minutes without brake), plasma was aliquoted and stored at $-20^{\circ} \mathrm{C}$ until further analysis.

\section{Laboratory analysis}

\section{Free hemoglobin}

$\mathrm{FHb}$ concentrations, indicating hemolysis, were measured in all patient plasma samples $(\mathrm{N}=30)$ and in the storage medium of every administered pRBC $(\mathrm{N}=52)$. FHb was 
analyzed by derivative spectrometry as described in more detail elsewhere. ${ }^{19}$ The detection limit of this assay was $2 \mu \mathrm{mol} / \mathrm{L}$.

\section{Haptoglobin}

Plasma Hp concentrations of all patient samples and Hp levels in the storage medium of all transfused pRBC were measured on a validated Beckman LX20 clinical chemistry analyzer (Beckman Coulter, Brea, CA) via a turbidimetric method by the Laboratory of Hematology of the Maastricht University Medical Center.

\section{NO-consumption assay}

To evaluate whether increased $\mathrm{fHb}$ levels influenced the NO-consuming capacity of plasma after transfusion, we analyzed NO-consumption in all plasma samples of 13 randomly selected patients from our total patient group of 30 (40\%; 4 patients transfused with 1 pRBC, 9 patients transfused with 2 pRBC units), and in the storage medium of the 22 pRBCs administered to these patients. Random selection of patients was done using the statistical program SPSS 15.0 for Windows (SPSS, Inc., Chicago, IL). Unfortunately, we were not able to analyze every sample from the total patient group due to time and cost constraints. The complete protocol of the NO-consumption assay is described in more detail elsewhere. ${ }^{15,20}$ In short, a $40 \mu \mathrm{M}$ solution of the NO-donor, Diethylenetriamine NONOate (DETA NONOate, Cayman Chemical, Ann Harbor, MI) was prepared in PBS (pH 7.4) in a glass vessel purged with nitrogen in-line with a NO chemiluminescence analyzer (Sievers Model 280i, GE, Boulder, CO). The subsequent decay of DETA NONOate, releasing NO, produced a steady state NO signal of about 50 $70 \mathrm{mV}$. When the signal became stable, $50 \mu \mathrm{L}$ of plasma samples or standards were injected into the DETA NONOate solution, decreasing the NO signal in case of NOconsumption. Data were transferred to the software program ORIGIN Version 6.1 (OriginLab, Northampton, MA) for analysis of the area under the curve of decreasing NO-signal over time. The amount of NO consumption by plasma is quantified by comparison of the area under the curve with that of NO gas standards (produced from injections of nitrite into triiodide).

\section{Statistical analysis}

Continuous data in tables are presented as median and interquartile range (IQR, ranging the 25th-75th percentile), and as $\mathrm{N}$ (\%) for dichotomous data. Continuous data presented in figures are depicted as mean \pm standard error of the mean (S.E.M). Differences in patient characteristics between study groups were compared using Pearson Chi-square test for dichotomous variables, with Fisher's correction when appropriate, and the independent sample t-test or Mann-Whitney U-test for continuous data depending on Gaussian distribution (checked using histograms and normal $Q-Q$ plots). Continuous data with multiple time-points were analyzed using the 
repeated one-Way ANOVA with Bonferroni post-hoc correction, or the Kruskall-Wallis test with post-hoc Dunn's correction, depending on Gaussian distribution. Correlations were analyzed using the Spearman correlation (indicated as $R_{s}$ ). Statistical calculations were made using SPSS, and Prism 4.03 for Windows (GraphPad Software Inc. San Diego, CA). A p-value $<0.05$ was considered to indicate statistical significance.

\section{RESULTS}

Thirty patients were prospectively studied. Mean age of the total patient group was 52.4 years and the majority of patients were male $(\mathrm{N}=25,83.3 \%)$. Most patients had been diagnosed with acute myeloid leukemia $(N=21,70 \%)$ and all patients were in a stable clinical phase of their disease. Eight patients (26.7\%) were transfused with $1 \mathrm{pRBC}$, and 22 patients (73.3\%) with 2 pRBC units. Interestingly, the increase in $\mathrm{Hb}$ following transfusion was similar in patients receiving 1 or 2 pRBC units: $8.2 \mathrm{~g} / \mathrm{L}$ to $9.7 \mathrm{~g} / \mathrm{L}$. Also, other baseline and $\mathrm{PRBC}$ unit characteristics did not statistically differ between the two groups (Table 8.1).

\section{Prolonged storage of $\mathrm{pRBC}$ results in elevated $\mathrm{fHb}$ levels and increased NO- consuming capacity of the storage medium}

In total, 52 pRBCs were administered. The mean storage duration of the pRBC units was 17.2 days (ranging 2 - 32 days, Figure 8.1A), which was similar to previous reports. ${ }^{11}$ Of all transfused units, 4 pRBC (7.2\%) were younger than 1 week while 11 units $(21.2 \%)$ had been stored for 3 weeks or longer. To analyze the degree of hemolysis within the $\mathrm{pRBC}$ during storage, we measured $\mathrm{fHb}$ concentrations in the storage medium of each transfused unit. The mean $\mathrm{fHb}$ level of the storage medium was $25.9 \pm 2.2 \mu \mathrm{mol} / \mathrm{L}$, with a peak level of $96.7 \mu \mathrm{mol} / \mathrm{L}$. Corresponding to previous reports ${ }^{5,7}$, prolonged storage duration correlated with $\mathrm{fHb}$ concentrations within the storage medium $\left(R_{s}=0.48, p<0.001\right.$, Figure 8.1B). As $f H b$ is a potent NO-scavenger, we hypothesized that $\mathrm{fHb}$ concentrations within the storage medium would positively correlate with the level of NO-consumption of the storage medium. NO-consumption of the storage medium averaged $76.0 \mu \mathrm{mol} / \mathrm{L}$ (ranging $8.6-175.1 \mu \mathrm{mol} / \mathrm{L}$ ), and was significantly correlated with $\mathrm{fHb}$ levels of the storage medium $\left(R_{s}=0.62, p=0.002\right.$, Figure 8.1C), and storage duration of the $p R B C\left(R_{s}=0.54, p=0.01\right.$, data not shown). 
Table 8.1 Patient and packed red blood cell unit characteristics.

\begin{tabular}{|c|c|c|c|}
\hline & $\begin{array}{c}\text { Patients receiving } \\
1 \mathrm{pRBC} \\
(\mathrm{N}=8) \\
\end{array}$ & $\begin{array}{c}\text { Patients receiving } \\
2 \mathrm{pRBC} \\
(\mathrm{N}=22) \\
\end{array}$ & $p$-value \\
\hline \multicolumn{4}{|l|}{ Patient characteristics } \\
\hline Age (years), median (IQR 25\%-75\%) & $51.0(23.0-61.0)$ & $58.5(43.5-68.0)$ & 0.118 \\
\hline Male, $\%(N)$ & $87.5(7)$ & $81.8(18)$ & 1.000 \\
\hline Disease \% (N) & & & 0.530 \\
\hline Acute myeloid leukemia & $75.0(6)$ & $68.2(15)$ & \\
\hline Multiple myeloma & $12.5(1)$ & - & \\
\hline Burkitt's lymphoma & - & $4.5(1)$ & \\
\hline Acute lymphoblastic leukemia & - & $4.5(1)$ & \\
\hline Testis carcinoma & $12.5(1)$ & - & \\
\hline Myeloid sarcoma & - & $4.5(1)$ & \\
\hline Non-Hodgkin B-cell lymphoma & - & $9.1(2)$ & \\
\hline Myelodysplastic lymphoma & - & $9.1(2)$ & \\
\hline Pre-transfusion $\mathrm{Hb}(\mathrm{g} / \mathrm{dL})$, median (IQR 25\%-75\%) & $8.2(7.8-8.5)$ & $8.2(7.5-8.4)$ & 0.383 \\
\hline Post-transfusion $\mathrm{Hb}(\mathrm{g} / \mathrm{dL})$, median (IQR 25\%-75\%) & $9.7(9.0-10.0)$ & $9.7(9.2-10.2)$ & 0.459 \\
\hline $\begin{array}{l}\text { Pre-transfusion plasma haptoglobin (g/L), median } \\
\text { (IQR 25\%-75\%) }\end{array}$ & $2.1(1.3-3.8)$ & $2.4(1.5-2.8)$ & 0.784 \\
\hline $\begin{array}{l}\text { Pre-transfusion serum bilirubin ( } \mu \mathrm{mol} / \mathrm{L}), \text { median } \\
\text { (IQR } 25 \%-75 \%)\end{array}$ & $16.8(12.2-28.0)$ & $15.0(13.4-22.3)$ & 0.872 \\
\hline $\begin{array}{l}\text { Pre-transfusion serum AST (IU/L), median } \\
\text { (IQR 25\%-75\%) }\end{array}$ & $16.0(14.0-44.0)$ & $14.0(11.0-21.0)$ & 0.231 \\
\hline $\begin{array}{l}\text { Pre-transfusion serum ALT (IU/L), median } \\
\text { (IQR 25\%-75\%) }\end{array}$ & $28.0(17.0-50.0)$ & $24.5(14.8-35.3)$ & 0.507 \\
\hline $\begin{array}{l}\text { Pre-transfusion serum creatinine }(\mathrm{mmol} / \mathrm{L}), \text { median } \\
\text { (IQR 25\%-75\%) }\end{array}$ & $65.0(57.0-75.0)$ & $67.0(58.3-85.5)$ & 0.508 \\
\hline \multicolumn{4}{|l|}{ pRBC characteristics } \\
\hline Blood type, \% (N) & & & 1.000 \\
\hline $\mathrm{O}$ & $75.0(6)$ & $59.1(13)$ & \\
\hline A & $25.0(2)$ & $31.8(7)$ & \\
\hline B & - & $9.1(2)$ & \\
\hline$A B$ & - & - & \\
\hline Rh negative, $\%(N)$ & $62.5(5)$ & $59.1(13)$ & 1.000 \\
\hline
\end{tabular}

Abbreviations: IQR, interquartile range; GFR, estimated glomerular filtration rate, calculated according to the MDRD; $\mathrm{Hb}$, hemoglobin; AST, aspartate transaminase; ALT, alanine transaminase; pRBC, packed red blood cell unit. There were no significant changes between the study groups for any of the variables shown. 
A

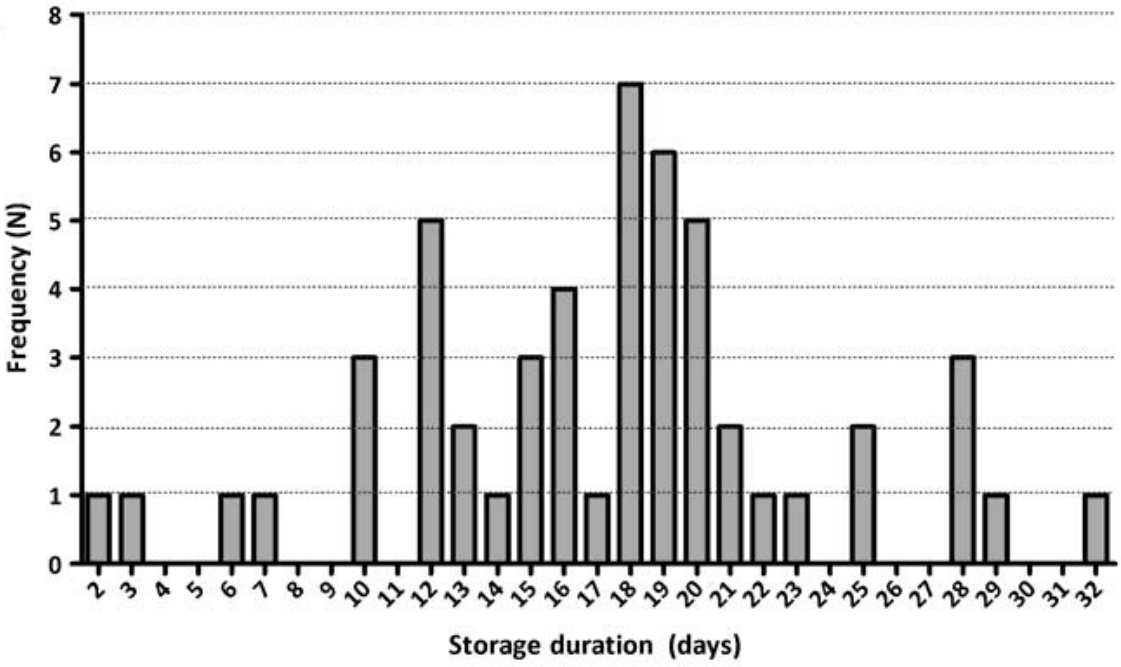

B

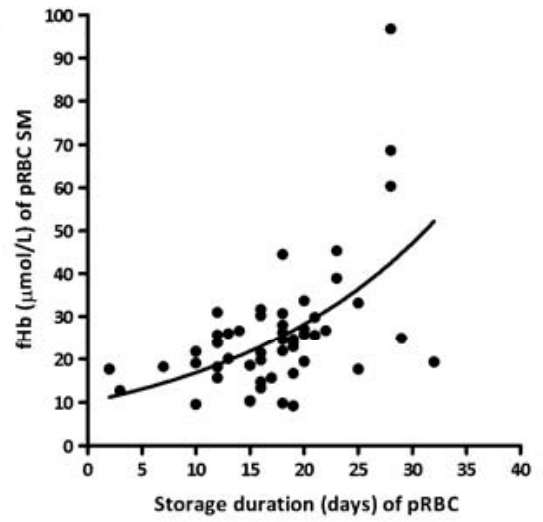

C

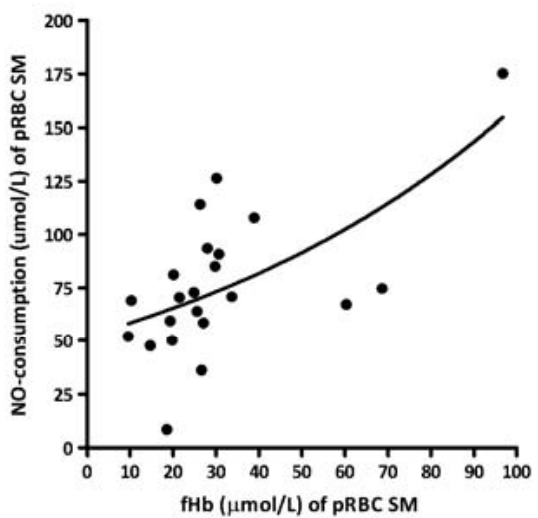

Figure 8.1 Storage duration of packed RBCs is correlated with increased fHb-concentrations and NOconsumption within storage medium. (A) Histogram of storage duration of all transfused pRBC units $(N=52)$. Mean storage duration was 17.2 days (ranging 2 - 32 days). (B) Correlation between storage duration and the $\mathrm{fHb}$ concentrations of the storage medium of each $\mathrm{pRBC}$ unit $(\mathrm{N}=52)$. The black line depicts a non-linear regression (exponential) curve. (C) Correlation between the $\mathrm{fHb}$ concentration and NO-consumption within the storage medium in a random selection 22 pRBC units. The black line depicts a non-linear regression (exponential) curve.

Abbreviations: pRBC, packed red blood cells; $\mathrm{fHb}$, free hemoglobin; NO, nitric oxide; SM, storage medium. 


\section{Transfusion of 2 pRBCs results in increased plasma fHb concentrations and NO-consumption in patients}

Next, we studied the effect of pRBC transfusion on plasma $\mathrm{fHb}$ levels of the 30 recipients. Figure $\mathbf{8 . 2 A}$ depicts the baseline and post-transfusion $\mathrm{fHb}$ concentrations, grouped according to transfusion of 1 or 2 pRBC units. This subdivision was made based on the notion that the latter group would (theoretically) be subjected to a higher $\mathrm{fHb}$ load and could thus display higher plasma $\mathrm{fHb}$ values after transfusion. Baseline plasma $\mathrm{fHb}$ levels were statistically similar between both groups. Interestingly, plasma $\mathrm{fHb}$ values increased significantly in patients receiving $2 \mathrm{pRBCs}$ compared to baseline concentrations as early as 15 minutes after transfusion (from $2.6 \pm 0.2 \mu \mathrm{mol} / \mathrm{L}$ to $4.6 \pm 0.5 \mu \mathrm{mol} / \mathrm{L}$, respectively, $\mathrm{p}<0.001$ ), and $\mathrm{fHb}$ levels remained significantly enhanced compared to baseline values throughout the next two hours. After 24 hours, fHb levels had returned to pre-transfusion levels. Plasma $\mathrm{fHb}$ concentrations in patients transfused with 1 pRBC unit did not change significantly over time. Both storage duration and $\mathrm{FHb}$ concentrations of the storage medium of the administered $\mathrm{pRBCs}$ were similar between patients transfused with 1 or 2 pRBC units ( $p=0.63$ and $p=0.97$, respectively), and it is therefore less likely that these factors confound the observed differences in plasma $\mathrm{fHb}$ concentrations after transfusion between both groups. It has been reported that irradiation of stored PRBC increases the storage lesion, especially membrane permeability. ${ }^{6}$ To exclude the potential confounding effect of $\mathrm{pRBC}$ irradiation on posttransfusion $\mathrm{fHb}$ concentrations in patients, we compared $\mathrm{fHb}$ concentrations in the storage medium of irradiated $(\mathrm{N}=13)$ and non-irradiated pRBC units $(\mathrm{N}=39)$; which were $23.6 \pm 2.7 \mu \mathrm{mol} / \mathrm{L}$ and $26.7 \pm 2.7 \mu \mathrm{mol} / \mathrm{L}$, respectively $(p=0.97$ ). Moreover, posttransfusional $\mathrm{fHb}$ concentrations in plasma were not significantly different between patients receiving irradiated blood products versus patients receiving non-irradiated blood products ( $p>0.05$ on all time-points, data not shown).

Subsequently, NO-consumption was measured in all plasma samples of a randomly selected subgroup of 13 patients (Figure 8.2B). In line with the fHb-data, plasma NOconsumption rose significantly in patients receiving $2 \mathrm{pRBCs}$ from $6.1 \pm 1.5 \mu \mathrm{mol} / \mathrm{L}$ at baseline to $7.9 \pm 1.3 \mu \mathrm{mol} / \mathrm{L} 15$ minutes after transfusion $(p=0.03)$, remaining elevated during the first hour after transfusion $(p=0.06)$. Plasma NO-consumption did not significantly change in patients receiving $1 \mathrm{pRBC}$ unit. Overall, NO-consumption in plasma correlated significantly with plasma fHb concentrations $\left(R_{s}=0.35, p=0.003\right.$, data not shown).

Summarizing, the storage medium of stored pRBC units is a potent NO-consuming medium as it contains high levels of $\mathrm{fHb}$. In line, plasma levels of $\mathrm{fHb}$ and NOconsumption increased significantly in patients after transfusion of 2 pRBC units. 

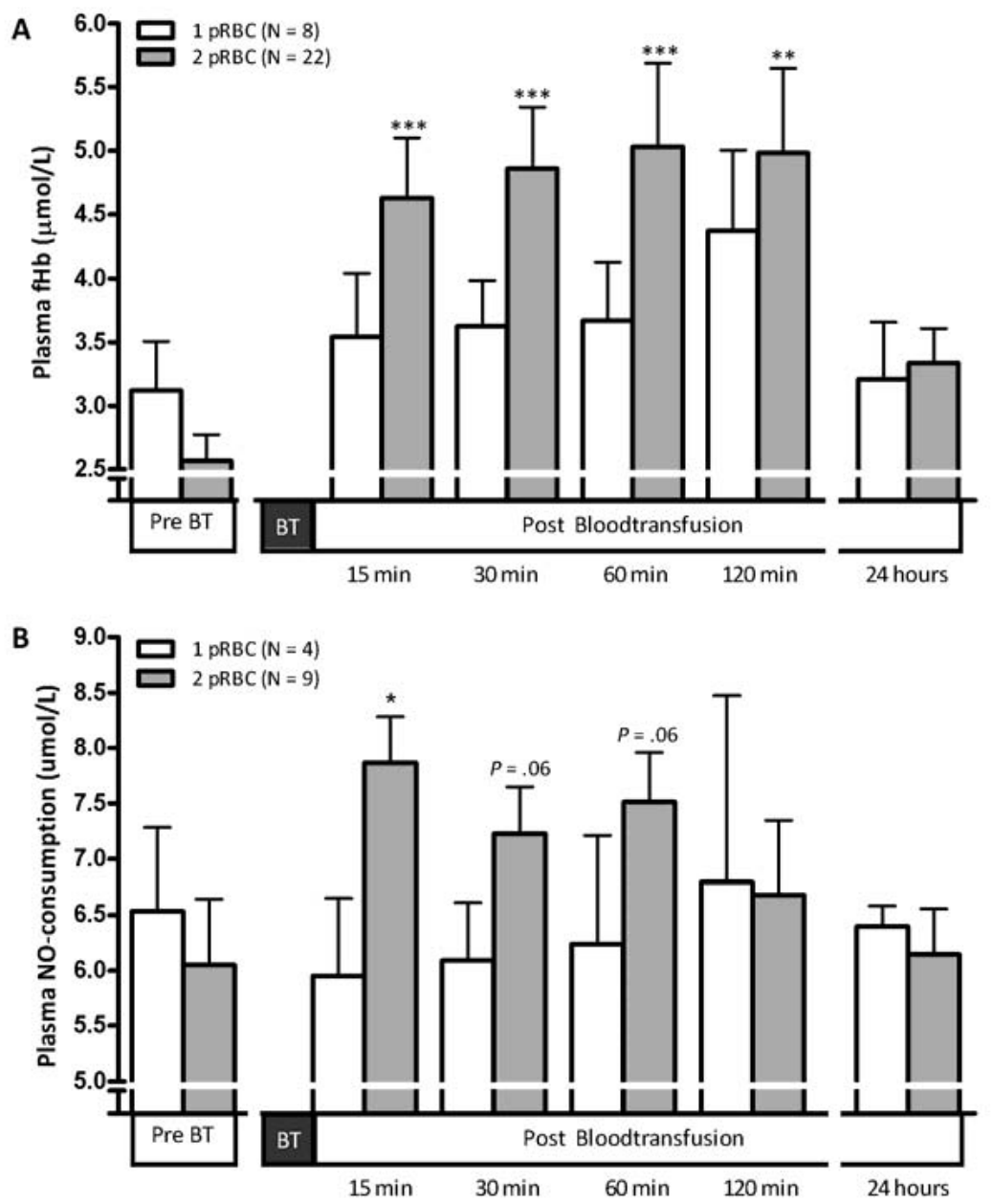

Figure 8.2 Transfusion of (multiple) stored RBC units significantly increases plasma fHb and NOconsumption in patients. (A) Course of plasma $\mathrm{fHb}$ in patients receiving 1 (white bars) or 2 (grey bars) pRBC units from baseline levels (before blood transfusion) to 15 minutes, 30 minutes, 60 minutes, 120 minutes, and 24 hours after blood transfusion. Stars indicate significant changes of $\mathrm{fHb}$ levels within groups compared to baseline $\mathrm{fHb}$ concentrations; $* * *: p<0.001$ ). (B) Course of plasma NO-consumption in a random selection of 4 patients transfused with 1 pRBC, and 9 patients transfused with 2 pRBC. Stars indicate significant differences of $\mathrm{fHb}$ levels within groups compared to baseline $\mathrm{fHb}$ concentrations; $*$ : $\mathrm{p}<0.05$ ). Abbreviations: BT, blood transfusion; pRBC, packed red blood cells; fHb, free hemoglobin; NS, non-significant; min, minutes. 


\section{Pre-transfusion haptoglobin levels influences post-transfusion plasma $\mathrm{fHb}$ concentrations in patients}

The current debate concerning the assumed negative effect of transfusion of pRBC units on patient outcome mainly focuses on storage-related factors such as storage duration. As we found a significant effect of storage duration on $\mathrm{fHb}$ levels and NOconsumption within the storage medium, we studied whether storage duration of the $\mathrm{pRBC}$ units influenced post-transfusion $\mathrm{fHb}$ concentrations in vivo. Surprisingly, in our study, the storage duration of the PRBC unit did not correlate with post-transfusion $\mathrm{fHb}$ concentrations or NO-consumption in the recipient, even after correction for the number of pRBCs transfused, and $\mathrm{fHb}$ concentrations of the storage medium (data not shown). Next, we studied the effect of pRBC transfusion on post-transfusion $\mathrm{Hp}$ concentrations in the recipient. As $\mathrm{Hp}$ is the physiological scavenger protein for $\mathrm{fHb}$, and considering the significant increase of circulating $\mathrm{fHb}$ concentrations following transfusion of 2 pRBC units, we expected decreased post-transfusion Hp levels in these patients. However, $\mathrm{Hp}$ levels did not change significantly after transfusion in patients receiving 1 pRBC or 2 pRBC units (Figure 8.3A). We subsequently investigated whether pre-transfusion $\mathrm{Hp}$ concentrations of the recipient influenced post-transfusion $\mathrm{fHb}$ levels, as patients with low pre-transfusion haptoglobin levels may have a lower capacity to clear $\mathrm{fHb}$. To that end, we divided patients into three groups based on their pre-transfusion plasma haptoglobin level. Eighteen patients (60\%) displayed high pretransfusion haptoglobin concentrations exceeding $1.9 \mathrm{~g} / \mathrm{L}$ (upper normal level). In contrast, 3 patients (10\%) had haptoglobin concentrations below $0.75 \mathrm{~g} / \mathrm{L}$. Posttransfusion $\mathrm{fHb}$ concentrations showed a more pronounced increase from pretransfusion levels in patients with lowest pre-transfusion $\mathrm{Hp}$ concentrations, compared to patients with higher pre-transfusion haptoglobin levels ( $p<0.05$, Figure 8.3B). Storage duration of the administered pRBCs was similar between the three groups $(p=$ 0.20 ), as was the mean number of pRBC transfused ( 1 or $2, p=0.85$ ), and mean $\mathrm{fHb}$ concentration of the storage medium of the pRBC units $(p=0.53)$. Furthermore, similar results were obtained when patients receiving 1 or 2 pRBC units were analyzed separately (data not shown). Unfortunately, the study was not sufficiently powered to allow statistical analysis of changes in post-transfusion plasma NO-consumption based on pre-transfusion Hp levels. 

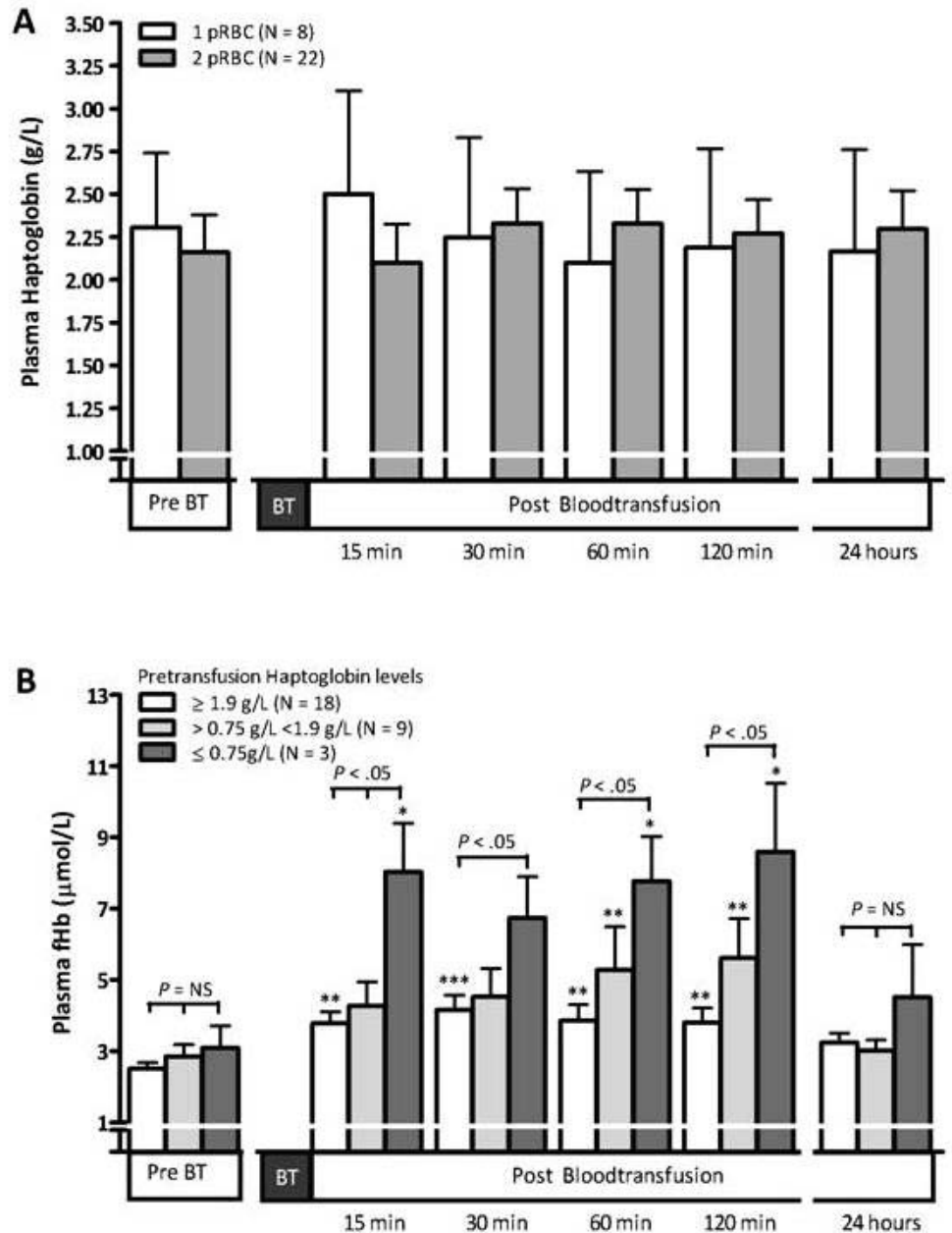

Figure 8.3 Course of plasma $\mathrm{Hp}$ after blood transfusion, and impact of pre-transfusion Hp on posttransfusion $\mathrm{fHb}$ and NO-consumption levels. (A) Change of plasma haptoglobin in patients receiving 1 (white bars) or 2 (grey bars) pRBC units from levels before blood transfusion (BT) to 15 minutes, 30 minutes, 60 minutes, 120 minutes, until 24 hours after blood transfusion. (B) Change of plasma $\mathrm{fHb}$ in patients with pre-transfusion haptoglobin plasma concentrations of $1.9 \mathrm{~g} / \mathrm{L}$ or higher (white bars), between $0.75 \mathrm{~g} / \mathrm{L}$ and $1.9 \mathrm{~g} / \mathrm{L}$ (light grey bars), or $0.75 \mathrm{~g} / \mathrm{L}$ or lower (dark grey bars). Stars indicate significant changes of $\mathrm{fHb}$ levels within groups compared to baseline (pre-transfusion) levels $\left({ }^{*}, \mathrm{p}<0.05 ; * *, \mathrm{p}<0.01 ; * *, \mathrm{p}<0.001\right)$. Statistical differences between groups are indicated with the black bars and according $p$-values.

Abbrevaitions: BT, blood transfusion; NS, non-significant; $\mathrm{fHb}$, free hemoglobin; min, minutes. 


\section{DISCUSSION}

The relation between transfusion of stored blood and adverse outcome in patients is subject of intense debate. Although the development of functional and structural changes of the RBC during storage is undisputed, it remains controversial whether these changes carry any clinical relevance. In recent years, several studies reported on the association between increased storage duration of pRBCs (reflecting increased storage lesion) and adverse outcome in trauma patients ${ }^{21}$, septic patients ${ }^{12,22}$ the critically $\mathrm{ill}^{23}$, and patients undergoing cardiac surgery. ${ }^{11,24}$ In contrast, other investigators did not find such associations. ${ }^{13,14,25,26}$ The development of hemolysis within the pRBC unit, with release of the NO-scavenging protein $\mathrm{fHb}$, may contribute to the potential adverse relation between blood transfusions and patient outcome. ${ }^{5}$

This observational pilot study investigated if 1 ) transfusion of 1 or 2 stored pRBC units can result in increased $\mathrm{fHb}$ concentrations and plasma NO-consumption in the recipient, and 2 ) whether the increase in $\mathrm{fHb}$ levels is dependent on storage duration of the pRBC unit(s) or on pre-transfusion recipient Hp levels. First, we demonstrated that prolonged storage significantly increased $\mathrm{fHb}$ concentrations and NOconsumption within the $\mathrm{pRBC}$ storage medium, which was in line with previous reports. ${ }^{7,27}$ Second, we were able to demonstrate for the first time that transfusion of 2 pRBCs significantly enhanced plasma $\mathrm{fHb}$ concentrations and NO-consumption in patients. Third, the increase in post-transfusion $\mathrm{fHb}$ concentrations was most profound in patients with low pre-transfusion $\mathrm{Hp}$ levels and was absent in patients with highest $\mathrm{Hp}$ concentrations, irrespective of the number of transfused pRBCs, storage duration of the transfused units, and $\mathrm{fHb}$ concentrations within the storage medium.

To date, studies reporting on the postulated adverse effects of pRBC transfusion on patient outcome principally focused on the contribution of pRBC-related factors, with most attention being paid to the effect of storage duration. We could not confirm a correlation between prolonged storage and increased $\mathrm{fHb}$ levels (or increased NOconsumption) in our patients. It could be that the uneven distribution of the storage duration of the PRBC units and the relatively small number of patients prevented us from finding such a relation. Interestingly however, we were able to show an effect of pre-transfusion plasma $\mathrm{Hp}$ levels of the recipient on changes of $\mathrm{fHb}$ following transfusion. High plasma $\mathrm{Hp}$ levels prior to transfusion may improve the physiological buffer capacity of the recipient to increased plasma fHb concentrations. It could even be hypothesized that patients displaying increased Hp levels, such as patients with profound systemic inflammation ${ }^{28,29}$, may be better protected against the potential adverse effects of transfused $\mathrm{fHb}$. In contrast, patients undergoing (complex) cardiovascular surgery could be particularly sensitive to transfusion-induced, $\mathrm{fHb}$ - 
mediated, NO-consumption, as these patients frequently suffer $\mathrm{Hp}$-depletion during surgery. ${ }^{30}$

Our data may be of significant importance for patients who require massive transfusion, such as critical care patients, trauma patients or patients undergoing major aortic, cardiac, orthopedic, or gynecologic surgery. ${ }^{17,31}$ Transfusion of multiple pRBC units may result in a significant increase of plasma $\mathrm{fHb}$ levels and NOconsumption. Since plasma $\mathrm{fHb}$ concentrations of $6 \mu \mathrm{mol} / \mathrm{L}$ have been shown to significantly impair the NO-metabolism in vivo ${ }^{15}$, and levels over $10 \mu \mathrm{mol} / \mathrm{L}$ have been linked to the development of renal injury and renal dysfunction ${ }^{17}$, excessive pRBC transfusion may potentially decrease microcirculatory blood flow and contribute to organ compromise in these patients. Indeed, it has been shown that transfusion of pRBCs to treat anemia during CPB was independently associated with increased urinary markers of intestinal damage, renal injury, and deterioration of kidney function compared to untreated anemic patients. ${ }^{32,33} \mathrm{~A}$ similar independent association between PRBC transfusions and worse outcome was found in anemic critically ill patients. $^{34}$

Although the presented associations between the number of transfused pRBC units and increased levels of $\mathrm{fHb}$ and NO-consumption do not imply causality, the results of the current study elicit an interesting dilemma regarding blood transfusions. On the one hand, refraining from transfusing a (seriously) anemic patient might further impair blood oxygen carrying capacity and tissue oxygenation, possibly causing tissue ischemia and organ failure. On the other hand, (massive) transfusion of pRBC units, containing high amounts of $\mathrm{fHb}$, could significantly increase plasma $\mathrm{fHb}$ concentrations and NO-consumption in the recipient. This could hamper microcirculatory blood flow and may ultimately lead to cellular damage and organ failure as well. As the beneficial effects of blood transfusions are undisputed, and safe alternatives to blood storage are still lacking, efforts should be made to minimize the unwanted effects of stored red blood cell transfusion. If our results are confirmed by larger studies, the current study provides opportunities for the development of preventive or treatment strategies.

Although we were able to demonstrate significant results, the relatively small patient population prevented correction for the confounding variables such as disease severity. Therefore, future studies are essential to provide additional insight into the (causal) relationships between transfusion of stored blood, increased plasma $\mathrm{fHb}$ concentrations and plasma NO-consumption, decreased microcirculatory perfusion, and clinical outcome of the recipient. Furthermore, we did not study the contribution of RBC microvescicles, known to be released during hemolysis and known to contain high concentrations of $\mathrm{fHb}$, on post-transfusional $\mathrm{fHb}$ concentrations in the recipient. ${ }^{35}$ In addition, the role of increased free (non-transferrin-bound) iron levels was not studied $^{36}$. Notwithstanding, we consider that the results of this pilot study provides 
important additional insight into the much discussed relationship between stored blood transfusion and adverse outcome in patients, and warrants additional investigation.

\section{CONCLUSIONS}

Our data indicate that transfusion of 2 units of stored red blood cells significantly increases plasma $\mathrm{fHb}$ and NO-consumption in the recipient. These data are of interest in light of the ongoing debate and evaluation of the proposed negative association between pRBC transfusions and patient outcome, and may serve as a tool to improve patient morbidity and mortality after transfusion. 


\section{REFERENCES}

1. Shaz $\mathrm{BH}$, Hillyer $\mathrm{CD}$ : Is there transfusion-related acute renal injury? Anesthesiology 2010;113: 1012-1013.

2. Bennett-Guerrero E, Veldman TH, Doctor A, Telen MJ, Ortel TL, Reid TS, Mulherin MA, Zhu H, Buck RD, Califf RM, McMahon TJ. Evolution of adverse changes in stored RBCs. Proc Natl Acad Sci U S A 2007;104: 17063-17068.

3. Wolfe LC. Oxidative injuries to the red cell membrane during conventional blood preservation. Semin Hematol 1989; 26:307-312.

4. Ho J, Sibbald WJ, Chin-Yee IH. Effects of storage on efficacy of red cell transfusion: when is it not safe? Crit Care Med 2003;31:S687-697.

5. Donadee C, Raat NJ, Kanias T, Tejero J, Lee JS, Kelley EE, Zhao X, Liu C, Reynolds H, Azarov I, Frizzell S, Meyer EM, Donnenberg AD, Qu L, Triulzi D, Kim-Shapiro DB, Gladwin MT. Nitric Oxide Scavenging by Red Blood Cell Microparticles and Cell-Free Hemoglobin as a Mechanism for the Red Cell Storage Lesion. Circulation 2011;26:465-476.

6. Zubair AC. Clinical impact of blood storage lesions. Am J Hematol 2010;85:117-122.

7. Gladwin MT, Kim-Shapiro DB. Storage lesion in banked blood due to hemolysis-dependent disruption of nitric oxide homeostasis. Curr Opin Hematol 2009;16:515-523.

8. Hod EA, Spitalnik SL.Harmful effects of transfusion of older stored red blood cells: iron and inflammation. Transfusion 2011;51:881-885.

9. Lee JS, Gladwin MT. Bad blood: the risks of red cell storage. Nat Med 2010;16:381-382.

10. Adamson JW. New blood, old blood, or no blood? N Engl J Med 2008; 358:1295-1296.

11. Koch CG, Li L, Sessler DI, Figueroa P, Hoeltge GA, Mihaljevic T, Blackstone EH. Duration of red-cell storage and complications after cardiac surgery. N Engl J Med 2008; 358:1229-1239.

12. Marik PE, Sibbald WJ. Effect of stored-blood transfusion on oxygen delivery in patients with sepsis. JAMA 1993; 269:3024-3029.

13. Edgren G, Kamper-Jorgensen M, Eloranta S, Rostgaard K, Custer B, Ullum H, Murphy EL, Busch MP, Reilly $M$, Melbye $M$, Hjalgrim $H$, Nyrén O. Duration of red blood cell storage and survival of transfused patients (CME). Transfusion 2010; 50:1185-1195.

14. Walsh TS, McArdle F, McLellan SA, Maciver C, Maginnis M, Prescott RJ, McClelland DB. Does the storage time of transfused red blood cells influence regional or global indexes of tissue oxygenation in anemic critically ill patients? Crit Care Med 2004; 32:364-371.

15. Reiter CD, Wang X, Tanus-Santos JE, Hogg N, Cannon RO, 3rd, Schechter AN, Gladwin MT. Cell-free hemoglobin limits nitric oxide bioavailability in sickle-cell disease. Nat Med 2002; 8:1383-1389.

16. Minneci PC, Deans KJ, Zhi H, Yuen PS, Star RA, Banks SM, Schechter AN, Natanson C, Gladwin MT, Solomon SB. Hemolysis-associated endothelial dysfunction mediated by accelerated NO inactivation by decompartmentalized oxyhemoglobin. J Clin Invest 2005; 115:3409-3417.

17. Vermeulen Windsant IC, Snoeijs MG, Hanssen SJ, Altintas S, Heijmans JH, Koeppel TA, Schurink GW, Buurman WA, Jacobs MJ. Hemolysis is associated with acute kidney injury during major aortic surgery. Kidney Int 2010; 77:913-920.

18. Levey AS, Bosch JP, Lewis JB, Greene T, Rogers N, Roth D. A more accurate method to estimate glomerular filtration rate from serum creatinine: a new prediction equation. Modification of Diet in Renal Disease Study Group. Ann Intern Med 1999; 130:461-470.

19. Cruz-Landeira A, Bal MJ, Quintela, Lopez-Rivadulla M. Determination of methemoglobin and total hemoglobin in toxicological studies by derivative spectrophotometry. J Anal Toxicol 2002; 26:67-72.

20. Wang X, Tanus-Santos JE, Reiter CD, Dejam A, Shiva S, Smith RD, Hogg N, Gladwin MT. Biological activity of nitric oxide in the plasmatic compartment. Proc Natl Acad Sci U S A 2004; 101:11477-11482.

21. Zallen G, Offner PJ, Moore EE, Blackwell J, Ciesla DJ, Gabriel J, Denny C, Silliman CC. Age of transfused blood is an independent risk factor for postinjury multiple organ failure. Am J Surg 1999; 178:570-572.

22. Purdy FR, Tweeddale MG, Merrick PM. Association of mortality with age of blood transfused in septic ICU patients. Can J Anaesth 1997; 44:1256-1261.

23. Offner PJ, Moore EE, BiffI WL, Johnson JL, Silliman CC. Increased rate of infection associated with transfusion of old blood after severe injury. Arch Surg 2002; 137:711-717. 
24. Ranucci M, Carlucci C, Isgro G, Boncilli A, De Benedetti D, De la Torre T, Brozzi S, Frigiola A. Duration of red blood cell storage and outcomes in pediatric cardiac surgery: an association found for pump prime blood. Crit Care 2009; 13:R207.

25. van de Watering L, Lorinser J, Versteegh M, Westendord R, Brand A. Effects of storage time of red blood cell transfusions on the prognosis of coronary artery bypass graft patients. Transfusion 2006;46:1712-1718.

26. Vamvakas EC, Carven JH. Length of storage of transfused red cells and postoperative morbidity in patients undergoing coronary artery bypass graft surgery. Transfusion 2000; 40:101-109.

27. Salzer U, Zhu R, Luten M, Isobe H, Pastushenko V, Perkmann T, Hinterdorfer P, Bosman GJ. Vesicles generated during storage of red cells are rich in the lipid raft marker stomatin. Transfusion 2008; 48:451-462.

28. Nielsen MJ, Moestrup SK. Receptor targeting of hemoglobin mediated by the haptoglobins: roles beyond heme scavenging. Blood 2009; 114:764-771.

29. Oliviero S, Cortese R. The human haptoglobin gene promoter: interleukin-6-responsive elements interact with a DNA-binding protein induced by interleukin-6. EMBO J 1989; 8:1145-1151.

30. Tanaka K, Kanamori Y, Sato T, Kondo C, Katayama Y, Yada I, Yuasa H, Kusagawa M. Administration of haptoglobin during cardiopulmonary bypass surgery. ASAIO Trans 1991; 37:M482-483.

31. Hanssen SJ, Derikx JP, Vermeulen Windsant IC, Heijmans JH, Koeppel TA, Schurink GW, Buurman WA, Jacobs MJ. Visceral injury and systemic inflammation in patients undergoing extracorporeal circulation during aortic surgery. Ann Surg 2008; 248:117-125.

32. Habib RH, Zacharias A, Schwann TA, Riordan CJ, Engoren M, Durham SJ, Shah A. Role of hemodilutional anemia and transfusion during cardiopulmonary bypass in renal injury after coronary revascularization: implications on operative outcome. Crit Care Med 2005; 33:1749-1756.

33. Huybregts RA, de Vroege R, Jansen EK, van Schijndel AW, Christiaans HM, van Oeveren W. The association of hemodilution and transfusion of red blood cells with biochemical markers of splanchnic and renal injury during cardiopulmonary bypass. Anesth Analg 2009; 109:331-339.

34. Pelletier MM, Kleinbongard P, Ringwood L, Hito R, Hunter CJ, Schechter AN, Gladwin MT, Dejam A. The measurement of blood and plasma nitrite by chemiluminescence: pitfalls and solutions. Free radical biology \& medicine 2006; 41:541-548.

35. Darrow WW, Montanea JE, Fernandez PB, Zucker UF, Stephens DP, Gladwin H. Eliminating disparities in HIV disease: community mobilization to prevent HIV transmission among Black and Hispanic young adults in Broward County, Florida. Ethn Dis 2004; 14:S108-116.

36. Hod EA, Brittenham GM, Billote GB, Francis RO, Ginzburg YZ, Hendrickson JE, Jhang J, Schwartz J, Sharma S, Sheth S, Sireci AN, Stephens HL, Stotler BA, Wojczyk BS, Zimring JC, Spitalnik SL. Transfusion of human volunteers with older, stored red blood cells produces extravascular hemolysis and circulating non-transferrin-bound iron. Blood 2011; 118:6675-82. 

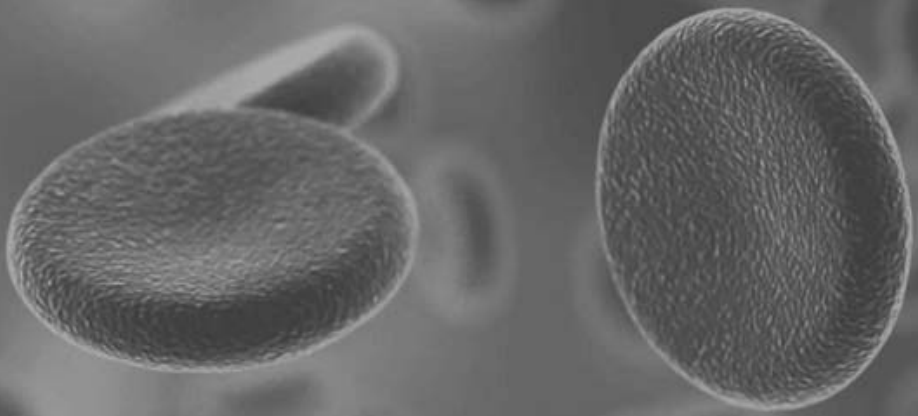
Hemolysis-induced organ damage is reduced by nutritional activation of the vagal anti-inflammatory reflex

Jacco-Juri de Haan, Iris C Vermeulen Windsant, Tim Lubbers, Sebastiaan J Hanssen,

Mohammed Hadfoune, Frits W Prinzen, Jan Willem M Greve, Wim A Buurman 


\section{ABSTRACT}

\section{Background}

Acute hemolysis is a common clinical event associated with organ damage and inflammation and forms as such a target for intervention. Recently, stimulation of the cholecystokinin-1 receptor (CCK-1R)-dependent vagal anti-inflammatory reflex with lipid-rich enteral nutrition was demonstrated to preserve organ integrity and attenuate inflammation.

\section{Objective}

To investigate the effects of nutritional activation of the vagal anti-inflammatory reflex on tissue integrity and inflammation following acute hemolysis.

\section{Methods}

Intravascular hemolysis in male Sprague-Dawley rats was simulated by continuous infusion of cell-free hemoglobin ( $\mathrm{fHb}$ ). Animals were fasted or received lipid-rich enteral nutrition prior to $\mathrm{fHb}$ administration. CCK-1R agonist pegylated (PEG)-CCK9, CCK-1R antagonist A70104 and nicotinic acetylcholine receptor ( $\mathrm{nAChR}$ ) antagonist chlorisondamine were applied to investigate involvement of the vagal anti-inflammatory reflex. Blood and tissue were harvested at 2 hours post-fHb to assess organ integrity and inflammatory status. Microcirculatory changes at organ level were evaluated using fluorescent microspheres.

\section{Results}

Induction of clinically relevant plasma $\mathrm{fHb}$ concentrations resulted in organ compromise and systemic inflammation. Nutritional intervention attenuated renal tubular cell damage $(p<0.05)$, hepatocyte damage $(p<0.05)$, ileal leakage of horseradish peroxidase $(p<0.01)$ and bacterial translocation $(p<0.05)$ compared with fasted controls. Also circulatory IL-6 levels were decreased by enteral nutrition $(p<0.05)$. A70104 as well as chlorisondamine reversed the protective nutritional effects $(p<0.05)$, whereas PEG-CCK9 mimicked the impact of enteral feeding in fasted animals $(p<0.05)$. Moreover, nutritional intervention promoted renal, hepatic and intestinal perfusion $(p<0.05)$

\section{Conclusions}

Lipid-rich nutrition preserves organ integrity and attenuates inflammation following $\mathrm{fHb}$ administration. These protective effects are CCK-1R- and nAChR-dependent, indicating a crucial role for the vagal anti-inflammatory reflex. These findings define intervention with enriched enteral nutrition as a potential therapy in patients prone to develop hemolysis. 


\section{INTRODUCTION}

Intravascular hemolysis occurs in diverse critical care settings, e.g. in patients undergoing extracorporeal circulation or membrane oxygenation or in patients with a sickle cell crisis or autoimmune hemolytic anemia. Increased circulatory levels of cellfree hemoglobin ( $\mathrm{fHb}$ ), as observed during hemolysis, have been associated with the development of endothelial dysfunction and organ injury. ${ }^{1-4}$ Crucial in the toxic effects of oxygenated $\mathrm{fHb}$ is its ability to irreversibly react with nitric oxide (NO), leading to the formation of methemoglobin (metHb) and nitrate. ${ }^{5,6} \mathrm{NO}$ is a pivotal signal molecule in the regulation of smooth muscle relaxation, endothelial adhesion molecule expression, and platelet activation and aggregation. Massive NO scavenging leads to an impaired vascular function, decreased organ perfusion and eventually to tissue damage. ${ }^{7-9}$ In addition, elevated $\mathrm{fHb}$ levels limit the formation of NO carrier S-nitrosohemoglobin and decrease the availability of L-arginine, the principal NO donor. ${ }^{10-12}$ The deficit of $\mathrm{NO}$, which functions as a potent antiinflammatory mediator, as well as the presence of organ damage as a result of compromised organ perfusion, may contribute to the proinflammatory state observed in hemolytic disease. Therefore, therapies are needed to counteract the detrimental consequences of hemolysis.

Nutritional activation of the vagal anti-inflammatory reflex is a novel approach to reduce organ damage and counteract excessive inflammation. ${ }^{13,14}$ Lipid-rich enteral nutrition activates the autonomic nervous system via activation of cholecystokinin-1 receptors (CCK-1R) on afferent vagal fibers. ${ }^{14}$ In turn, parasympathetic outflow suppresses cytokine release via binding of cholinergic neurotransmitters to nicotinic acetylcholine receptors (nAChR) on inflammatory cells. ${ }^{13,15,16}$ Compelling evidence of improved outcome by nutritional, pharmacological and electrical stimulation of this neuroimmune axis, designated the cholinergic anti-inflammatory pathway, has been provided in diverse experimental models of acute and chronic inflammation. ${ }^{17-19}$

In addition to its neural and inflammatory properties, acetylcholine is recognised as a potent vasodilator acting largely independent of $\mathrm{NO}^{20-22}$ Since the sensibility for NOindependent vasoactive mechanisms is increased in hemolytic disease, we hypothesize that nutritional vagus stimulation resulting in acetylcholine release counteracts the vasoconstrictive effects of NO depletion, thus preventing the development of organ compromise. ${ }^{23,24}$

The current study investigates the effects of lipid-rich enteral nutrition on renal, hepatic and intestinal organ perfusion and organ integrity in a setting of acute hemolysis. Also the nutritional effects on hemolysis-induced inflammation are assessed. Involvement of the vagal anti-inflammatory reflex is determined using CCK$1 R$ agonists and antagonists and $n A C h R$ antagonists. The clinical scenario of ongoing hemolysis is mimicked in rodents by continuous infusion of $\mathrm{fHb}$ and other erythrocyte 
constituents. Together, using a physiological and straightforward nutritional approach, this study may contribute to the development of novel means to decrease hemolysisrelated complications in critical care patients.

\section{MATERIALS AND METHODS}

\section{Animals}

Male Sprague-Dawley rats, weighing 380 - $430 \mathrm{~g}$, were purchased from Charles River Laboratories (Maastricht, the Netherlands) and housed under controlled conditions of temperature and humidity. Prior to the experiments, rats were fed standard rodent chow ad libitum and had free access to water. The experimental protocols were approved by the Animal Ethics Committee of the Maastricht University Medical Centre+.

\section{Acute hemolysis model}

The hemolysis model in rodents was based on a canine model described by Minneci and colleagues. ${ }^{1}$ After induction with $4 \%$ isoflurane, anesthesia was maintained at $2 \%$ throughout the procedure. Acute hemolysis was simulated by administration of a $300 \mu \mathrm{M} \mathrm{fHb}$ bolus of $0.65 \mathrm{~mL} / 100 \mathrm{~g}$ body weight followed by continuous intravenous infusion of $300 \mu \mathrm{M} \mathrm{fHb}$ for 1 hour (1.3 mL / $100 \mathrm{~g}$ body weight). The left femoral artery was dissected and cannulated with polyethylene tubing (PE-10) containing heparinized saline $(10 \mathrm{IU} / \mathrm{mL})$. The cannule was connected to a computer-assisted external pressure transducer to register the mean arterial pressure (Kent Scientific, Torrington, $\mathrm{CT}$ ). Animals were sacrificed at 2 hours after start of $\mathrm{fHb}$ administration (Figure 9.1).

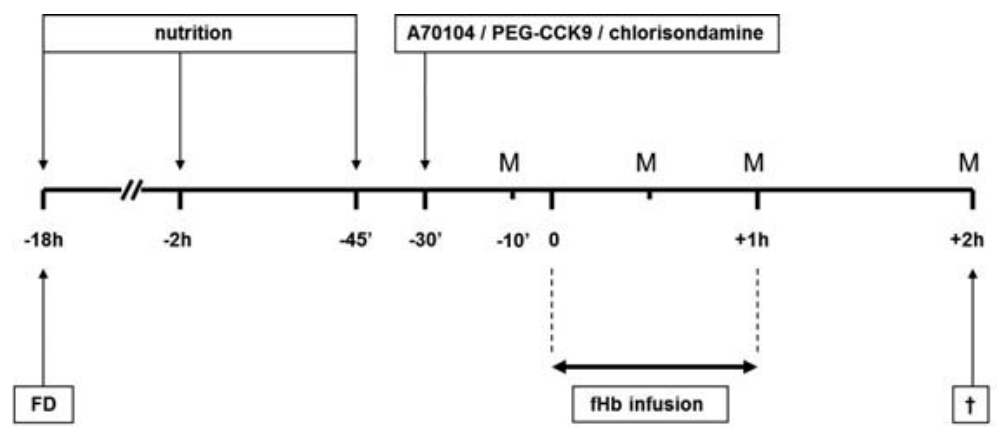

Figure 9.1 Experimental design. Rats were food deprived (FD) 18 hours before start of free hemoglobin $(\mathrm{fHb})$ infusion or received lipid-rich enteral nutrition at -18 hours, -2 hours and -45 mins. At 30 mins before $\mathrm{fHb}$ infusion, A70104, PEG-CCK9, chlorisondamine or vehicles were administered. Animals received $\mathrm{fHb}$ infusion for 1 hour and were sacrificed at +2 hours $(+)$. Microspheres (M) were administered at four time points. 


\section{Generation and measurement of $\mathrm{fHb}$}

To generate $\mathrm{fHb}$ for infusion, fresh blood samples were obtained from healthy male Sprague Dawley rats through aortic punction. After diluting whole blood 1:2 in saline containing $10 \mathrm{IU} / \mathrm{mL}$ heparin, erythrocytes were isolated by centrifugation $(2,750 \mathrm{~g}$, 15 minutes, $4^{\circ} \mathrm{C}$ ). Plasma and buffy coat were carefully discarded and the remaining erythrocytes were washed three times in sterile saline $(1: 3 \mathrm{v} / \mathrm{v})$ to remove all plasma components. To induce hemolysis, the erythrocytes underwent three freeze-thaw cycles after the final washing step. Erythrocyte membranes were removed by ultracentrifugation $\left(20,000 \mathrm{~g}, 30 \mathrm{mins}, 4^{\circ} \mathrm{C}\right)$. Next, the supernatant was passed through a micropore filter (diameter $0.22 \mu \mathrm{m}$, Millipore, Billerica, MA). The final concentration was adjusted with sterile saline to $300 \mu \mathrm{M}$ for infusion. Routine spectrophotometry (Department of Clinical Chemistry) was used to assess the percentages of oxygenated hemoglobin and methemoglobin of total $\mathrm{fHb}$. The $\mathrm{fHb}$ concentrations in infusate and plasma were measured by derivative spectrophotometry. ${ }^{25}$

To investigate the role of $\mathrm{NO}$ scavenging by $\mathrm{fHb}$ in the development of organ damage in our hemolysis model, we hypothesized that exposure of $\mathrm{fHb}$ to NO before infusion, resulting in the formation of methemoglobin, would subsequently reduce the ability of $\mathrm{fHb}$ to scavenge NO in vivo. Therefore, a batch of $\mathrm{fHb}$ was pre-saturated with NO gas (Linde Gas, Dieren, the Netherlands) using a hollow fiber oxygenator (CAPIOX RX, Terumo, Somerset, NJ). The oxygenation level before and after exposure to NO gas was measured using routine spectrophotometry.

\section{Interventions}

Before $\mathrm{fHb}$ infusion, rats were fasted overnight (18 hours) or treated with liquid nutrition enriched with phospholipids given per oral gavage at three time points as described previously (Figure 9.1). ${ }^{13}$. The feeding contained 50.4 energy percent (en\%) lipid, 8.7 en $\%$ protein, and 40.9 en\% carbohydrates. The fat fraction contained $30 \%$ phospholipids. The lipid source was lecithin. Omega 3 and omega 6 fatty acids constituted less than 5 wt\% (weight percent, $<5 \mathrm{~g} / 100 \mathrm{~mL}$ ). Proteins were derived from lean milk powder, containing $80 \%$ casein and $20 \%$ whey protein. The carbohydrate source was a mixture of sucrose and maltodextrins (Glucidex 19DE). The total nutrition provided constituted 10.0 en\% of daily intake.

To investigate the role of peripheral CCK-1R in the nutritional effects on hemolytic damage, fed rats received A70104, also known as A65186 (100 $\mu \mathrm{g} / \mathrm{kg}$ kindly provided by Abbott Laboratories, Abbott Park, IL), a CCK-1R antagonist that does not cross the blood-brain barrier. $^{26}$ A70104 was dissolved in sterile saline with $1 \%$ dimethyl sulfoxide. The role of CCK-1R was further assessed in fasted animals by administration of $6 \mu \mathrm{g} / \mathrm{kg}$ PEG-CCK9 (kindly provided by Dr Verbaeys, Interdisciplinary Research 
Center, Campus Kortrijk, Katholieke Universiteit Leuven, Kortrijk, Belgium) dissolved in sterile saline. PEG-CCK9 specifically binds to CCK-1R and does not cross the blood brain barrier. ${ }^{27}$ Involvement of peripherally localized nAChR was studied by administration of nAChR antagonist chlorisondamine diiodide (125 $\mathrm{\mu g} / \mathrm{kg}$; Sigma, St. Louis, MO), dissolved in saline. Antagonists and agonists were administered intravenously at 30 minutes before fHB infusion (Figure 9.1).

\section{Parameters of organ integrity}

To assess renal tubular damage, urinary $\mathrm{N}$-acetyl- $\beta$-D-glucosaminidase (NAG) was measured by an enzyme colorimetric assay according to the manufacturer's instructions (HaemoScan, Groningen, the Netherlands). NAG, excreted predominantly by proximal renal tubular cells, is a relatively large molecule (130 kDa), precluding glomerular filtration. Furthermore, NAG is not reabsorbed by the tubules. Therefore, high levels of urinary NAG indicate renal tubular damage. ${ }^{28}$ Results were normalized to urinary creatinine values and expressed as Units/mmol creatinine.

Liver fatty acid binding protein (L-FABP) concentrations in plasma were assessed as a marker of liver damage. L-FABP was determined using a standard ELISA for rat L-FABP (Hycult Biotech, Uden, the Netherlands). L-FABP is an abundant cytosolic protein in hepatocytes. Lower concentrations are expressed in the intestine, kidney, lung and stomach. $^{29,30}$

Intestinal permeability for macromolecules was assessed by measuring translocation of the $44 \mathrm{kD}$ enzym horseradish peroxidase (HRP) through the ileal wall. ${ }^{31}$ Segments of distal ileum $(8 \mathrm{~cm})$ were washed, everted, filled with $1 \mathrm{ml}$ of Tris buffer $(125 \mathrm{mmol} / \mathrm{L}$ $\mathrm{NaCl}, 10 \mathrm{mmol} / \mathrm{L}$ fructose, $30 \mathrm{mmol} / \mathrm{L}$ Tris; $\mathrm{pH} \mathrm{7.5)}$ and ligated at both ends. The filled segments were incubated in Tris buffer containing $40 \mu \mathrm{g} / \mathrm{mL}$ of HRP (Sigma). After incubation at room temperature for 45 minutes, ileal content was carefully collected. HRP activity was measured spectrophotometrically at $405 \mathrm{~nm}$ after addition of tetramethylbenzidine as a substrate.

Bacterial translocation to mesenteric lymph nodes, liver and spleen was determined as described previously. ${ }^{32}$

\section{Systemic inflammation}

Systemic inflammation was assessed by detection of interleukin-6 (IL-6) concentrations in arterial blood using a standard ELISA for rat IL-6 (R\&D Systems, Minneapolis, MN).

\section{Microcirculatory blood flow}

Assessment of microcirculatory blood flow was performed using fluorescent microspheres (diameter $15 \mu \mathrm{m}$ ) as described previously. ${ }^{33,34}$ Fluorescent microspheres $\left(2.5 \times 10^{5}\right.$, Dye-Trak, Triton Technology, San Diego, CA) were infused at 10 minutes 
before $\mathrm{fHb}$ (lemon) and at 30 minutes (persimmon), 60 minutes (orange) and 120 minutes (yellow) after start of fHb infusion via a PE-10 cannula inserted in the right femoral artery that was transferred into the aortic arch (Figure 9.1). A reference blood sample from the femoral artery was taken at every time point. After sacrifice, 1.5 - 2 gram of kidney, liver and small intestine was harvested for microsphere retrieval. Following organ lysis in potassium hydroxide, the fluorescent dye was dissolved in diethylene glycol monoethyl ether acetate (Sigma). Fluorescence was measured using an automated fluorospectrometer (PerkinElmer LS 50B, Perkin Elmer, Waltham, MA) and the flow to each individual organ was calculated. The flow before $\mathrm{fHb}$ infusion was set at $100 \%$ and flow changes at organ level during the experiments were determined for each individual subject.

\section{Statistical analysis}

All groups consisted of 6 animals. For between-group comparisons, a two-tailed MannWhitney $U$ test was used. Differences were considered statistically significant at $p<0.05$. Data are displayed as mean \pm SEM. Prism 5.02 for Windows (GraphPad Software Inc., San Diego, CA) was used for computations.

\section{RESULTS}

\section{Cell-free hemoglobin results in loss of organ integrity via impairment of nitric oxide bioavailability}

Continuous administration of $\mathrm{fHb}$ resulted in strongly enhanced plasma $\mathrm{fHb}$ levels at 30 minutes $(40 \pm 3 \mu \mathrm{M})$ that remained stable until termination of $\mathrm{fHb}$ infusion at 1 hour $(43 \pm 4 \mu \mathrm{M})$. At 120 minutes, fHb concentrations dropped to $16 \pm 1 \mu \mathrm{M}$, indicating that the half time of $\mathrm{fHb}$ in circulation is approximately 40 minutes. Next, we investigated whether the observed circulatory $\mathrm{fHb}$ levels compromised organ integrity. Infusion of $\mathrm{fHb}$ resulted in renal tubular cell damage, as indicated by strongly increased urinary NAG levels compared to sham controls ( $p<0.01$; Figure 9.2A). Next, enhanced plasma levels of L-FABP following $\mathrm{fHb}$ infusion indicated hepatocyte damage $(\mathrm{p}<0.01$; Figure 9.2B). Loss of intestinal wall integrity after $\mathrm{fHb}$ administration was demonstrated by increased ileal leakage of HRP ( $p<0.01$; Figure 9.2C) and augmented translocation of luminal bacteria to mesenteric lymph nodes, liver and spleen ( $p<0.001$; Figure 9.2D).

Previous studies identified the conversion of hemoglobin and NO to methemoglobin and nitrate and the subsequent decrease of NO bioavailability as a principal cause of hemolysis-related organ damage. ${ }^{1,6}$ Therefore, the effect of pre-exposure of $\mathrm{fHb}$ to NO gas on $\mathrm{fHb}$-induced loss of organ integrity was investigated. Spectrophotometrical 
analysis demonstrated that freshly generated $\mathrm{fHb}$ was oxygenated for $75 \%$. Presaturation with $\mathrm{NO}$ gas reduced the $\mathrm{fHb}$ oxygenation level to $51 \%$ and increased methemoglobin levels from $0.3 \%$ to $49 \%$. Administration of $\mathrm{fHB}$ that was pre-saturated with NO resulted in a significant reduction of renal, hepatic and intestinal compromise compared with administration of $\mathrm{fHb}$ that was not saturated with NO (NAG $p<0.05$; L-FABP $p<0.05$; HRP $p<0.01$; bacterial translocation $p<0.01$; Figure 9.2A-D), suggesting a crucial role for $\mathrm{NO}$ scavenging in the development of fHb-related organ compromise.
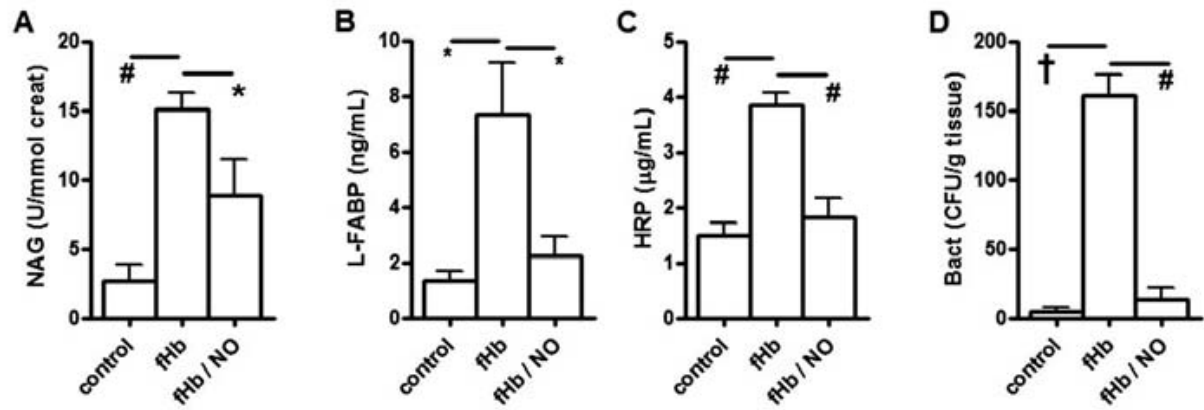

Figure 9.2 Increased levels of circulatory cell-free hemoglobin induce loss of organ integrity via nitric oxide scavenging. $\mathrm{fHb}$ infusion resulted in renal $(\mathrm{A})$ and hepatic (B) cell damage and increased translocation of HRP (C) and bacteria (D) through the intestinal wall. Administration of $\mathrm{fHb}$ that was pre-saturated with NO prevented renal $(A)$ and hepatic $(B)$ cell damage and improved gut wall barrier (C-D) compared with animals that were infused with unsaturated $\mathrm{fHb} .{ }^{*} \mathrm{p}<0.05$; \# $\mathrm{p}<0.01 ;+\mathrm{p}<0.001$.

Abbreviations: NAG, N-acetyl- $\beta$-D-glucosaminidase; $\mathrm{fHb}$, free haemoglobin; L-FABP, liver fatty acid binding protein; HRP, horseradish peroxidase; NO, nitric oxide.

Protective nutritional effects on organ integrity following acute hemolysis are mediated by peripheral cholecystokinin-1 receptors and nicotinic acetylcholine receptors. Enteral lipid-rich nutrition strongly decreased urinary NAG levels following $\mathrm{fHb}$ infusion compared with fasted controls, indicating a reduction of renal cell damage $(p<0.05$; Figure 9.3A). Next, hepatocyte damage as assessed by circulating LFABP levels was significantly reduced by nutritional intervention ( $p<0.05$; Figure 9.3B). In previous studies, the intestine was identified as an early target organ of nutritional vagus activation. ${ }^{31}$ Here, pre-treatment with lipid-rich nutrition significantly reduced gut leakiness to HRP ( $p<0.01$; Figure 9.3C) and bacterial translocation $(p<0.05$; Figure 9.3D) following $\mathrm{fHb}$ infusion, indicating preservation of intestinal integrity by lipid-rich nutrition.

To investigate the involvement of the CCK-1R-dependent vagal pathway in the nutritional impact on hemolysis-induced loss of organ integrity, an antagonist (A70104) and an agonist (PEG-CCK9) to peripheral CCK-1R were applied. Administration of 
A70104 abrogated the protective effects of lipid-rich nutrition on hepatic and intestinal integrity (all $p<0.05$; Figure 9.3B-D), but did not significantly affect the nutritional inhibition of renal damage. Next, PEG-CCK9 decreased urinary NAG levels, ameliorated leakage of HRP through the gut wall and reduced bacterial translocation in fasted animals compared with vehicle (all $p<0.05$; Figure 9.3A,C,D). Furthermore, a trend towards reduced hepatocyte damage was observed in fasted animals receiving PEGCCK9 ( $p=0.08$; Figure 9.3B).

The role of the vagal reflex was further assessed by administration of chlorisondamine, an antagonist of peripheral nAChR. Chlorisondamine administered prior to $\mathrm{fHb}$ abrogated the protective effects of enteral nutrition on renal, hepatic and intestinal organ integrity (all $p<0.05$; Figure 9.3A-D), pointing at a crucial role for $n A C h R$ in the protective effects of nutritional intervention.
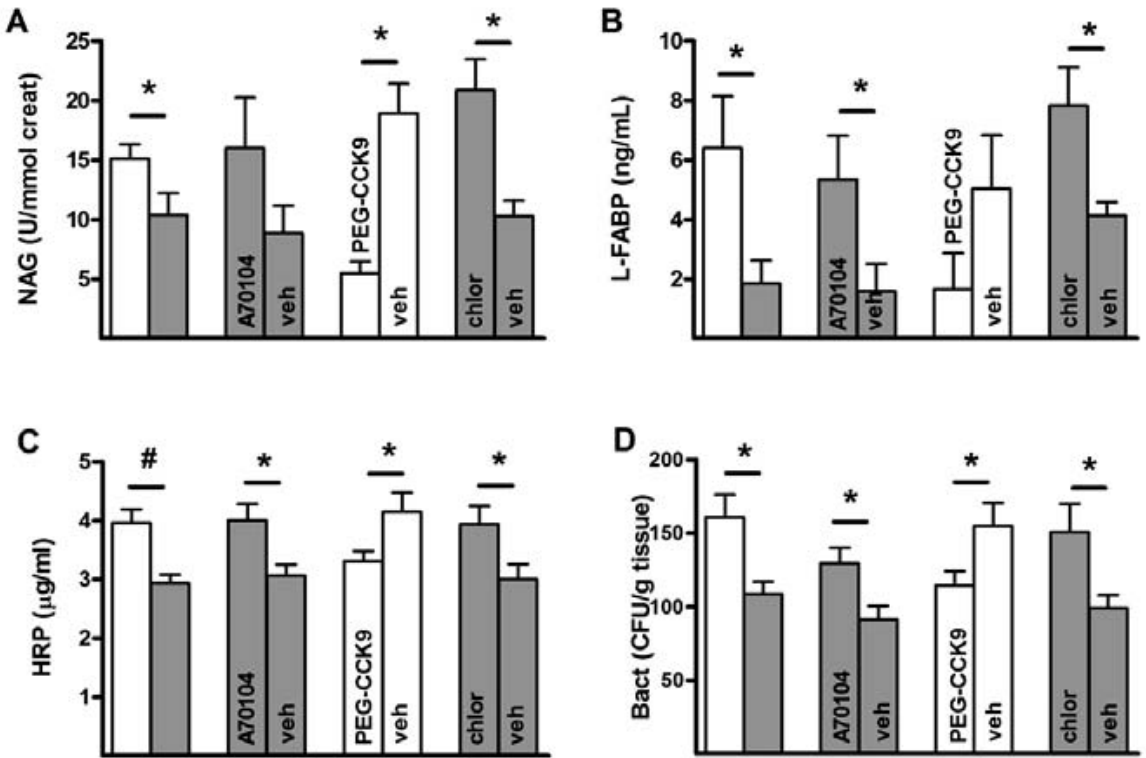

fasted

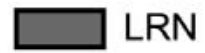

Figure 9.3 Enteral lipid-rich nutrition (LRN) improves organ integrity after fHb infusion via activation of peripheral cholecystokinin-1 and nicotinic acetylcholine receptors. Renal (A) and hepatic (B) cell damage were reduced by lipid-rich nutrition compared with fasted controls. Also gut wall permeability to HRP (C) and bacterial translocation (D) was significantly reduced in lipid-rich fed animals. The organ-preserving effects of lipid-rich nutrition were abrogated by A70104, an antagonist of peripheral CCK-1R, and mimicked by CCK-1R agonist PEG-CCK9. The nAChR antagonist chlorisondamine abrogated the nutritional impact on hemolysis-induced organ damage. ${ }^{*} \mathrm{p}<0.05 ; \# \mathrm{p}<0.01$. 


\section{Lipid-rich nutrition reduces systemic inflammation induced by cell-free haemoglobin}

Infusion of $\mathrm{fHb}$ resulted in a marked increase of IL-6 plasma levels at 2 hours. Enteral nutrition significantly reduced IL-6 levels (Figure 9.4, $p<0.05$ ), which is in coherence with previous studies on the anti-inflammatory effects of short-term intervention with enteral nutrition. ${ }^{13}$ Next, the importance of CCK-1R in the nutritional impact on haemolysis-induced inflammation was measured. CCK-1R antagonist A70104 abrogated the nutritional anti-inflammatory effects $(p<0.05)$, whereas CCK-1R agonist PEG-CCK9 reduced IL-6 levels in fasted animals $(p<0.05)$. Next to crucial involvement of the CCK-1R, also the $n A C h R$ was shown to be critical, since nAChR antagonist chlorisondamine abrogated the anti-inflammatory effects of lipid-rich nutrition $(p<0.01)$.

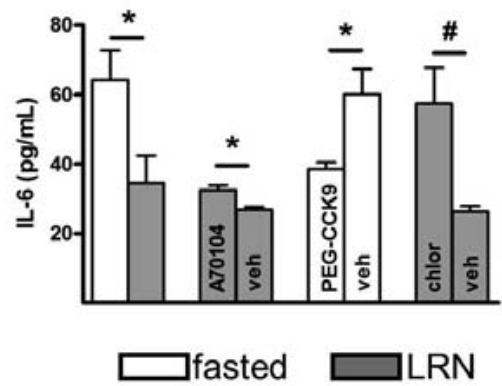

Figure 9.4 Systemic inflammation following cell-free hemoglobin infusion is reduced by nutritional intervention. Circulatory IL-6 concentrations are reduced by enteral lipid-rich nutrition (LRN). CCK-1R antagonist A70104 and nAChR antagonist abrogated the nutritional effects, whereas CCK-1R agonist PEG-CCK9 reduced inflammation in fasted animals. ${ }^{*} p<0.05 ; \# p<0.01$. Abbreviations: IL, interleukin; veh, vehicle; chlor, chlorisondamine.

\section{Nutritional intervention improves renal, hepatic and intestinal perfusion during acute hemolysis}

Since impaired perfusion as a consequence of NO scavenging is considered critical in the development of organ injury during hemolysis, next organ perfusion was assessed following nutritional intervention. In fasted animals, organ perfusion tended to be decreased in the liver and ileum compared with pre-fHb values, whereas renal perfusion was unaffected. Enteral nutrition significantly improved renal and intestinal perfusion at 30 and 60 minutes (all $p<0.05$; Figure 9.5AC) and hepatic perfusion at 60 minutes ( $p<0.05$; Figure 9.5B). A trend towards improved hepatic perfusion was observed at 30 minutes $(p=0.06)$. Administration of CCK-1R antagonist A70104 abrogated the nutritional impact on hepatic perfusion at 30 and 60 minutes (both 
$p<0.01)$ and ileal perfusion at 30 minutes $(p<0.05)$. Next, a trend towards a significant perfusion reduction by $\mathrm{A} 70104$ was seen in the kidneys (30 minutes: $p=0.09$ and 60 minutes: $p=0.06)$ and at 60 minutes in ileum $(p=0.06)$. Chlorisondamine prevented the effects of lipid-rich nutrition on renal perfusion ( $p<0.05$ at 30 and 60 minutes; Figure 9.5A), but did not affect the improvement of hepatic and intestinal perfusion by lipid-rich nutrition (Figure 9.5B-C). In fed animals that received chlorisondamine, hepatic and intestinal perfusion was significantly increased compared with fasted animals and lipid-rich treated animals that received A70104 ( $p<0.05$ at 30 and 60 minutes; Figure 9.5BC). At 120 minutes, no differences were observed between groups.
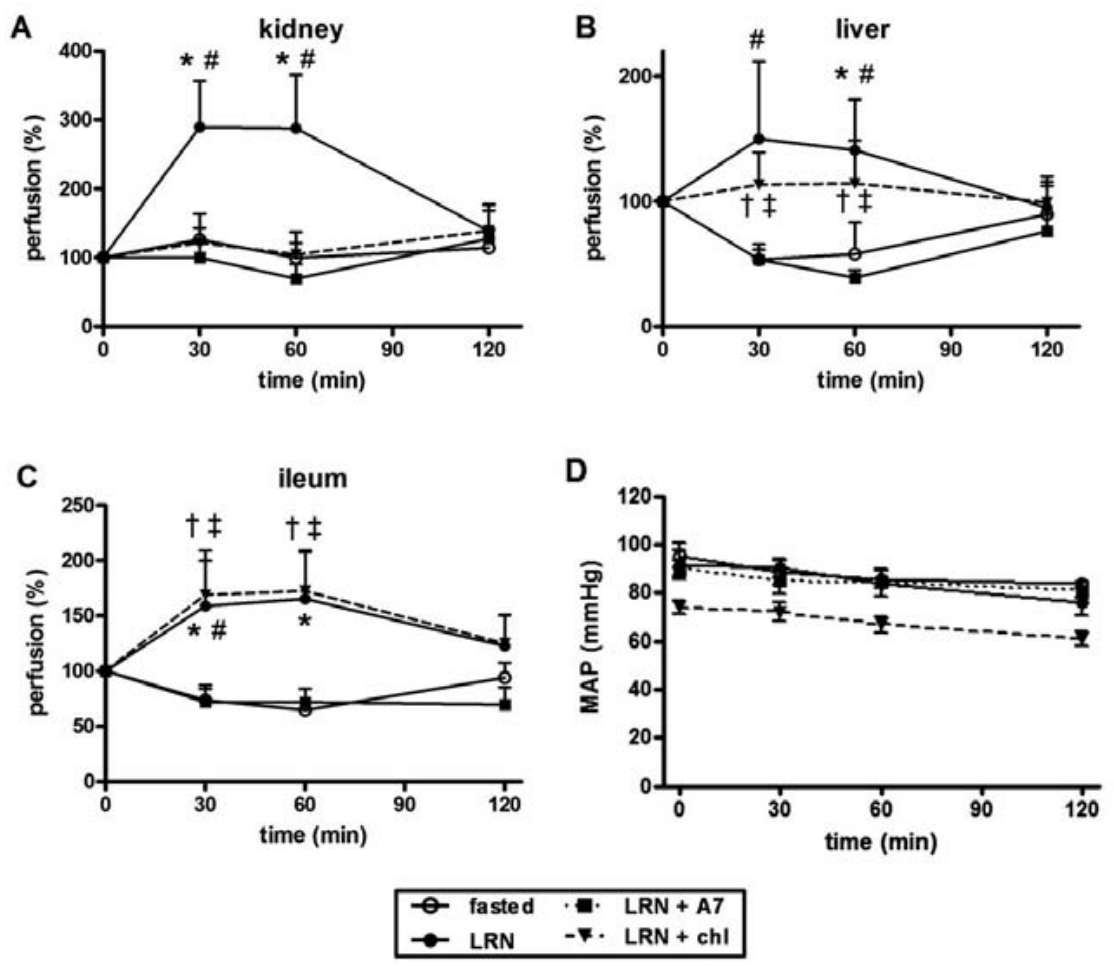

Figure 9.5 Enteral nutrition improves splanchnic perfusion. A. Lipid-rich nutrition improved renal perfusion at 30 and 60 minutes. Nicotinic acetylcholine receptor antagonist chlorisondamine (chl) abrogated the nutritional effects. B. Nutritional intervention improved hepatic perfusion at 60 minutes. A70104 (A7) but not chlorisondamine abrogated the nutritional impact. C. Ileal perfusion was significantly increased in lipid-rich treated animals at 30 and 60 minutes. A70104 inhibited the nutritional impact at 30 minutes. Chlorisondamine did not affect hepatic perfusion in fed animals. D. The mean arterial pressure decreased moderately during and following $\mathrm{HFb}$ infusion. Blood pressure in animals receiving chlorisondamine was reduced compared with other groups at all time points. ${ }^{*} p<0.05$ LRN vs. fasted; \# $p<0.05$ LRN vs. LRN + A70104; $+p<0.05$ LRN + chlorisondamine vs fasted; $¥ p<0.05$ LRN + chlorisondamine vs. LRN + A70104. 
Next, we investigated whether the observed alterations of organ perfusion were reflected in changes in systemic blood pressure. Continuous $\mathrm{fHb}$ infusion resulted in a moderate decrease of the mean arterial pressure after 2 hours (fasted: $p<0.05$, lipidrich: $p=0.07$, lipid-rich + A70104: $p=0.09$ and lipid-rich + chlorisondamine: $p<0.01$; Figure 9.5D). No differences in mean arterial pressure were observed between fasted and lipid-rich fed animals. Chlorisondamine significantly depressed blood pressure at all time points in animals that received lipid-rich nutrition (Figure 9.5D) or were fasted (data not shown), which is in line with previous reports. ${ }^{35}$

\section{DISCUSSION}

Intravascular hemolysis, a common phenomenon at intensive care units, is growingly recognized as an independent source of tissue damage and poor clinical outcome. ${ }^{6,36}$ The current manuscript is first to demonstrate protective effects on organ integrity by stimulation of the vagal anti-inflammatory reflex with lipid-rich nutrition in a setting of acute hemolysis.

In the current study, hemolysis was simulated in rodents by infusion of cell-free hemoglobin derived from lysed erythrocytes. ${ }^{1}$ The obtained median plasma level of $43 \mu \mathrm{M}$ is comparable to the fHb concentrations following cardiovascular surgery in which a cardiopulmonary bypass is used or in patients suffering from a sickle cell crisis or paroxysmal nocturnal hemoglobinuria. ${ }^{2,37-39}$ Furthermore, these levels surpassed the critical thresholds of $6 \mu \mathrm{M} \mathrm{fHb}$, reported to produce vasoconstriction in sickle cell patients ${ }^{5}$, and $10 \mu \mathrm{M} \mathrm{fHb}$, associated with renal damage in patients undergoing aorta repair surgery. ${ }^{2}$ The current model mimics the clinical setting of hemolysis since not only $\mathrm{fHb}$ but also other constituents from lysed erythrocytes were infused. Within 2 hours, this procedure led to rapid compromise of renal, hepatic and intestinal integrity.

Here, short-term intervention with enriched enteral nutrition was demonstrated to reduce renal and hepatic cell damage and preserve gut barrier function shortly following acute hemolysis. The applied feeding regimen and nutritional composition were previously shown to be protective in several experimental models of acute inflammation, including hemorrhagic shock, bacterial DNA exposure and postoperative ileus. ${ }^{13,17,40}$ In addition, the present study demonstrates that lipid-rich nutrition significantly reduces hemolysis-induced systemic inflammation, assessed as circulatory IL-6 concentrations. Critical involvement of the vagal anti-inflammatory reflex was demonstrated by agonists and antagonists of peripheral CCK-1R (A70104 and PEG-CCK9 respectively). The finding that $\mathrm{nAChR}$ antagonist chlorisondamine abrogated the nutritional effects on hemolytic damage provides further evidence for the vagal anti-inflammatory reflex as the underlying mechanism. In addition to nutritional 
intervention, the vagal pathway has also been stimulated by pharmacological and electrical means in various experimental settings ${ }^{19}$, however to our knowledge not in the context of acute hemolysis.

During massive hemolysis, the pool of endogenous scavengers of cell-free hemoglobin such as haptoglobin rapidly becomes depleted. ${ }^{41}$ Subsequent NO scavenging by oxygenated hemoglobin is considered pivotal in the development of organ damage in hemolytic disease. ${ }^{1,6}$ The importance of NO scavenging is confirmed in the current rodent hemolysis study, as pre-saturation of $\mathrm{fHb}$ with $\mathrm{NO}$ gas, resulting in decreased oxygenated hemoglobin levels and enhanced methemoglobin formation, considerably reduced organ damage compared with animals that received non-saturated $\mathrm{fHb}$. In line with our findings, saturation of circulatory $\mathrm{fHb}$ with inhaled NO was shown to improve tissue perfusion in a canine hemolysis model. ${ }^{1}$

Using fluorescent microspheres, lipid-rich nutrition was demonstrated to improve renal, hepatic and intestinal perfusion after hemolysis compared with fasted controls. The alterations of organ perfusion were not reflected by changes in mean arterial pressure. Over two hours, a gradual and moderate decrease of mean arterial pressure was observed in both fasted and fed animals, which is conform observations in a model of sickle cell disease. ${ }^{8}$ CCK-1 receptor antagonist A70104 abrogated the nutritional effects on renal, hepatic and intestinal perfusion, indicating that the nutritional improvement of organ perfusion was transferred by the vagal antiinflammatory reflex.. Since CCK has also been reported to improve mesenteric blood flow via non-neural pathways ${ }^{42,43}$, we investigated whether nicotinic receptor antagonist chlorisondamine was able to blunt the nutritional impact on organ perfusion. The finding that chlorisondamine abrogated the nutritional effect on renal perfusion is consistent with a previous report on the markedly increased $\mathrm{nAChR}$ expression on the endothelium of peritubular capillairies and the decrease of tubular damage following administration of cholinergic agonists in a setting of renal ischemia and reperfusion ${ }^{44}$. Interestingly, although chlorisondamine effectively abrogated the effects of lipid-rich nutrition on hepatic and intestinal integrity, it did not affect the nutritional effects on intestinal and hepatic perfusion. Therefore, based on the data of he present study, the protective potential of lipid-rich nutrition cannot be attributed to the improvement of organ perfusion. Arguably, the protective effects on organ integrity in the present hemolysis setting may be caused by direct vagal inhibition of the local inflammatory response. ${ }^{45,46}$

A range of interventions aimed at reducing hemolysis-related organ damage is currently under investigation. ${ }^{36}$ The present study indicates that enteral administration of limited quantities of a well-designed nutritional composition, being a physiological approach, may be of additional value to limit the detrimental sequelae of hemolysis. Such nutritional intervention fits in the current guidelines and recommendations that 
favor early start of enteral feeding in critical care and surgical patients. ${ }^{47,48}$ Since also post-treatment with lipid-rich nutrition was previously shown to attenuate inflammation and preserve organ integrity, further studies should clarify whether nutritional intervention is also applicable when hemolysis is already manifested. ${ }^{32}$ In addition, the findings of this study may be relevant for polytrauma settings considered the shared NO-scavenging properties between hemoglobin and myoglobin, the later being massively released following myocyte damage. ${ }^{49}$

In summary, lipid-rich nutrition preserves renal, hepatic and intestinal integrity and reduces systemic inflammation in a CCK-1R and $n A C h R$-dependent manner in a rodent model of acute hemolysis. In addition, nutritional intervention significantly improves perfusion of these organs during hemolysis. These data expand the potential applicability of nutritional activation of the vagal anti-inflammatory reflex to patients prone to develop hemolysis. 


\section{REFERENCES}

1. Minneci PC, Deans KJ, Zhi H, Yuen PS, Star RA, Banks SM, Schechter AN, Natanson C, Gladwin MT, Solomon SB. Hemolysis-associated endothelial dysfunction mediated by accelerated NO inactivation by decompartmentalized oxyhemoglobin. J Clin Invest 2005;115:3409-17.

2. Vermeulen Windsant IC, Snoeijs MG, Hanssen SJ, Altintas S, Heijmans JH, Koeppel TA, Schurink GW, Buurman WA, Jacobs MJ. Hemolysis is associated with acute kidney injury during major aortic surgery. Kidney Int 2010;77:913-20.

3. Hanssen SJ, Lubbers T, Hodin CM, Prinzen FW, Buurman WA, Jacobs MJ. Hemolysis results in impaired intestinal microcirculation and intestinal epithelial cell injury. World J Gastroenterol 2011;17:213-8.

4. Meyer C, Heiss C, Drexhage C, Kehmeier ES, Balzer J, Mühlfeld A, Merx MW, Lauer T, Kühl H, Floege J, Kelm M, Rassaf T. Hemodialysis-induced release of hemoglobin limits nitric oxide bioavailability and impairs vascular function. J Am Coll Cardiol 2010;55:454-9.

5. Reiter CD, Wang X, Tanus-Santos JE, Hogg N, Cannon RO, 3rd, Schechter AN, Gladwin MT. Cell-free hemoglobin limits nitric oxide bioavailability in sickle-cell disease. Nat Med 2002;8:1383-9.

6. Rother RP, Bell L, Hillmen P, Gladwin MT. The clinical sequelae of intravascular hemolysis and extracellular plasma hemoglobin: a novel mechanism of human disease. JAMA 2005;293:1653-62.

7. Doherty DH, Doyle MP, Curry SR, Vali RJ, Fattor TJ, Olson JS, Lemon DD. Rate of reaction with nitric oxide determines the hypertensive effect of cell-free hemoglobin. Nat Biotechnol 1998;16:672-6.

8. Hsu LL, Champion HC, Campbell-Lee SA, Bivalacqua TJ, Manci EA, Diwan BA, Schimel DM, Cochard AE, Wang X, Schechter AN, Noguchi CT, Gladwin MT. Hemolysis in sickle cell mice causes pulmonary hypertension due to global impairment in nitric oxide bioavailability. Blood 2007;109:3088-98.

9. Yeo TW, Lampah DA, Tjitra E, Gitawati R, Kenangalem E, Piera K, Granger DL, Lopansri BK, Weinberg JB, Price RN, Duffull SB, Celermajer DS, Anstey NM. Relationship of cell-free hemoglobin to impaired endothelial nitric oxide bioavailability and perfusion in severe falciparum malaria. J Infect Dis 2009;200:1522-9.

10. Gow AJ, Luchsinger BP, Pawloski JR, Singel DJ, Stamler JS. The oxyhemoglobin reaction of nitric oxide. Proc Natl Acad Sci U S A 1999;96:9027-32.

11. McMahon TJ, Moon RE, Luschinger BP, Carraway MS, Stone AE, Stolp BW, Gow AJ, Pawloski JR, Watke $P$, Singel DJ, Piantadosi CA, Stamler JS. Nitric oxide in the human respiratory cycle. Nat Med 2002;8:711-17.

12. Rassaf T, Preik M, Kleinbongard P, Lauer T, Heiss C, Strauer BE, Feelisch M, Kelm M. Evidence for in vivo transport of bioactive nitric oxide in human plasma. J Clin Invest 2002;109:1241-8.

13. Luyer MD, Greve JW, Hadfoune M, Jacobs JA, Dejong $\mathrm{CH}$, Buurman WA. Nutritional stimulation of cholecystokinin receptors inhibits inflammation via the vagus nerve. J Exp Med 2005;202:1023-9.

14. Lubbers T, de Haan JJ, Luyer MD, Verbaeys I, Hadfoune M, Dejong CH, Buurman WA, Greve JW. Cholecystokinin/Cholecystokinin-1 receptor-mediated peripheral activation of the afferent vagus by enteral nutrients attenuates inflammation in rats. Ann Surg 2010;252:376-82.

15. Wang H, Yu M, Ochani M, Amella CA, Tanovic M, Susarla S, Li JH, Wang H, Yang H, Ulloa L, Al-Abed Y, Czura CJ, Tracey KJ. Nicotinic acetylcholine receptor alpha7 subunit is an essential regulator of inflammation. Nature 2003; 421:384-8.

16. Borovikova LV, Ivanova S, Zhang M, Yang H, Botchkina GI, Watkins LR, Wang H, Abumrad N, Eaton JW, Tracey KJ. Vagus nerve stimulation attenuates the systemic inflammatory response to endotoxin. Nature 2000;405:458-62.

17. Lubbers T, Luyer MD, de Haan JJ, Hadfoune M, Buurman WA, Greve JW. Lipid-rich enteral nutrition reduces postoperative ileus in rats via activation of cholecystokinin-receptors. Ann Surg 2009; 249:481-7.

18. Lubbers T, De Haan JJ, Hadfoune M, Zhang Y, Luyer MD, Grundy D, Buurman WA, Greve JW. Lipidenriched enteral nutrition controls the inflammatory response in murine Gram-negative sepsis. Crit Care Med. 2010;38:1996-2002.

19. Tracey KJ. Reflex control of immunity. Nat Rev Immunol 2009;9:418-28.

20. Imaeda K, Yamamoto Y, Fukuta H, Koshita M, Suzuki H. Hyperpolarization-induced dilatation of submucosal arterioles in the guinea-pig ileum. Br J Pharmacol 2000;131:1121-8. 
21. Eguchi S, Miyashita S, Kitamura Y, Kawasaki H. Alpha3beta4-nicotinic receptors mediate adrenergic nerve- and peptidergic (CGRP) nerve-dependent vasodilation induced by nicotine in rat mesenteric arteries. Br J Pharmacol 2007;151:1216-23.

22. Baile EM, McKay K, Wang L, Bai TR, Pare PD. NO does not mediate inhibitory neural responses in sheep airway and bronchial vascular smooth muscle. J Appl Physiol 1998;84:809-14.

23. Gladwin MT, Schechter AN, Ognibene FP, Coles WA, Reiter CD, Schenke WH, Csako G, Waclawiw MA, Panza JA, Cannon RO, $3^{\text {rd }}$. Divergent nitric oxide bioavailability in men and women with sickle cell disease. Circulation 2003;107:271-8.

24. Gatt M, MacFie J, Anderson AD, Howell G, Reddy BS, Suppiah A, Renwick I, Mitchell CJ. Changes in superior mesenteric artery blood flow after oral, enteral, and parenteral feeding in humans. Crit Care Med 2009;37:171-6.

25. Cruz-Landeira A, Bal MJ, Quintela, Lopez-Rivadulla M. Determination of methemoglobin and total hemoglobin in toxicological studies by derivative spectrophotometry. J Anal Toxicol 2002, 26(2):67-72.

26. Ebenezer IS, Parrott RF. A70104 and food intake in pigs: implication for the CCK 'satiety' hypothesis. Neuroreport 1993;4:495-8.

27. Verbaeys I, Leon-Tamariz F, Buyse J, De Cuyper M, Pottel H, Van Boven M, Cokelaere M. PEGylated cholecystokinin prolongs satiation in rats: dose dependency and receptor involvement. Br J Pharmacol 2007;152:396-403.

28. Dittrich S, Kurschat K, Dahnert I, Vogel M, Muller C, Alexi-Meskishvili V, Lange PE. Renal function after cardiopulmonary bypass surgery in cyanotic congenital heart disease. Int J Cardiol 2000;73:173-9.

29. Furuhashi M, Hotamisligil GS. Fatty acid-binding proteins: role in metabolic diseases and potential as drug targets. Nat Rev Drug Discov 2008;7:489-503.

30. Pelsers MM, Hermens WT, Glatz JF. Fatty acid-binding proteins as plasma markers of tissue injury. Clin Chim Acta 2005;352:15-35.

31. de Haan JJ, Thuijls G, Lubbers T, Hadfoune M, Reisinger K, Heineman E, Greve JW, Buurman WA. Protection against early intestinal compromise by lipid-rich enteral nutrition through cholecystokinin receptors. Crit Care Med. 2010;38:1592-7.

32. de Haan JJ, Lubbers T, Hadfoune M, Luyer MD, Dejong CH, Buurman WA, Greve JW. Postshock intervention with high-lipid enteral nutrition reduces inflammation and tissue damage. Ann Surg 2008; 248:842-8.

33. Prinzen FW, Bassingthwaighte JB. Blood flow distributions by microsphere deposition methods. Cardiovasc Res 2000;45:13-21.

34. Raab S, Thein E, Harris AG, Messmer K. A new sample-processing unit for the fluorescent microsphere method. Am J Physiol 1999;276:H1801-6.

35. Chadman KK, Woods JH. Cardiovascular effects of nicotine, chlorisondamine, and mecamylamine in the pigeon. J Pharmacol Exp Ther 2004;308:73-8.

36. Vermeulen Windsant IC, Hanssen SJ, Buurman WA, Jacobs MJ. Cardiovascular surgery and organ damage: Time to reconsider the role of hemolysis. J Thorac Cardiovasc Surg 2011;142:1-11.

37. Davis CL, Kausz AT, Zager RA, Kharasch ED, Cochran RP. Acute renal failure after cardiopulmonary bypass in related to decreased serum ferritin levels. J Am Soc Nephrol 1999;10:2396-402.

38. Hartmann RC, Jenkins DE, Jr., McKee LC, Heyssel RM. Paroxysmal nocturnal hemoglobinuria: clinical and laboratory studies relating to iron metabolism and therapy with androgen and iron. Medicine (Baltimore) 1966;45:331-63.

39. Ergul S, Brunson CY, Hutchinson J, Tawfik A, Kutlar A, Webb RC, Ergul A. Vasoactive factors in sickle cell disease: in vitro evidence for endothelin-1-mediated vasoconstriction. Am J Hematol 2004;76:245-51.

40. Luyer MD, Derikx JP, Beyaert R, Hadfoune M, van Kuppevelt TH, Dejong CH, Heineman E, Buurman WA, Greve JW. High-fat nutrition reduces hepatic damage following exposure to bacterial DNA and hemorrhagic shock. J Hepatol 2009;50:342-50.

41. Nielsen MJ, Moller HJ, Moestrup SK. Hemoglobin and heme scavenger receptors. Antioxid Redox Signal. 2010;12:261-73.

42. Sanchez-Fernandez C, Gonzalez MC, Beart PM, Mercer LD, Ruiz-Gayo M, Fernandez-Alfonso MS. A novel role for cholecystokinin: regulation of mesenteric vascular resistance. Regul Pept 2004;121: 145-53. 
43. Yamada Y, Iwasaki M, Usui H, Ohinata K, Marczak ED, Lipkowski AW, Yoshikawa M. Rapakinin, an antihypertensive peptide derived from rapeseed protein, dilates mesenteric artery of spontaneously hypertensive rats via the prostaglandin IP receptor followed by CCK(1) receptor. Peptides. 2010; 31:909-14.

44. Yeboah MM, Xue X, Javdan M, Susin M, Metz CN. Nicotinic acetylcholine receptor expression and regulation in the rat kidney after ischemia-reperfusion injury. Am J Physiol Renal Physiol 2008; 295:F654-61.

45. van der Zanden EP, Snoek SA, Heinsbroek SE, Stanisor OI, Verseijden C, Boeckxstaens GE, Peppelenbosch MP, Greaves DR, Gordon S, De Jonge WJ. Vagus nerve activity augments intestinal macrophage phagocytosis via nicotinic acetylcholine receptor alpha4beta2. Gastroenterology 2009; 137:1029-39, 1039 e1021-4.

46. de Haan JJ, Thuijls G, Lubbers T, Hadfoune M, Reisinger K, Heineman E, Greve JW, Buurman WA. Protection against early intestinal compromise by lipid-rich enteral nutrition through cholecystokinin receptors. Crit Care Med 2010;38:1592-7.

47. Guidelines for the use of parenteral and enteral nutrition in adult and pediatric patients. JPEN J Parenter Enteral Nutr 2002;26(1 Suppl):1SA-138SA.

48. Kreymann KG, Berger MM, Deutz NE, Hiesmayr M, Jolliet $P$, Kazandjiev G, Nitenberg G, van den Berghe G, Wernerman J; DGEM (German Society for Nutritional Medicine), Ebner C, Hartl W, Heymann C, Spies C; ESPEN (European Society for Parenteral and Enteral Nutrition). ESPEN Guidelines on Enteral Nutrition: Intensive care. Clin Nutr 2006;25:210-23.

49. Hendgen-Cotta UB, Kelm M, Rassaf T. A highlight of myoglobin diversity: the nitrite reductase activity during myocardial ischemia-reperfusion. Nitric Oxide. 2010;22:75-82. 

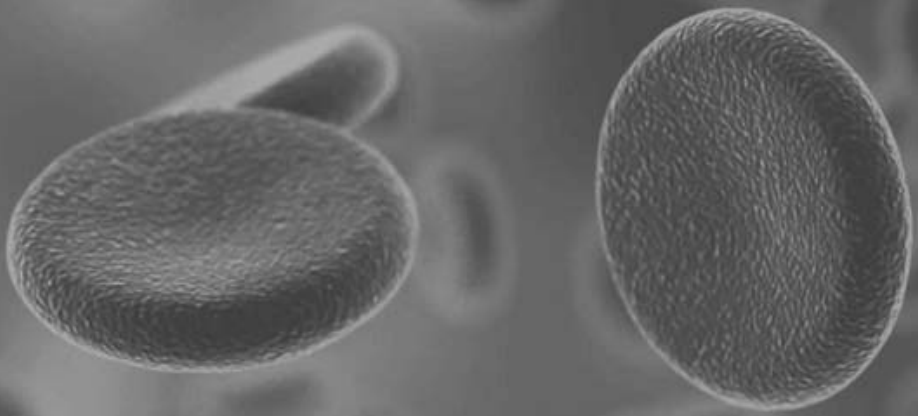
Summary and discussion




Prevention and limitation of tissue damage is desirable during every surgical procedure as organ injury is independently associated with adverse patient outcome. In the setting of (complex) cardiovascular surgery, the development of intestinal mucosal injury and renal tubular damage is frequently reported and associated with increased morbidity and mortality. ${ }^{1-16}$ Insight into the pathophysiological mechanisms underlying the development of tissue damage is essential for the development of specific treatment and prevention strategies in this setting.

The cardiopulmonary bypass ( $C P B)$ is considered to play an important role in the development of tissue injury during cardiovascular surgery. CPB-induced ischemiareperfusion injury, hypoperfusion injury, enhanced coagulation, inflammation, and hemodilution are all considered to play a role in impaired organ perfusion and tissue injury development during surgery. ${ }^{17-23} \mathrm{CPB}$ also leads to red blood cell injury and hemolysis, causing the release of hemoglobin into the circulation. ${ }^{24}$ The adverse effects of hemolysis on microcirculatory blood flow and organ compromise has gained increasing interest in patients with chronic hemolytic disease as it was found that cellfree hemoglobin $(\mathrm{fHb})$ is a potent scavenger of intravascular nitric oxide (NO). ${ }^{25-27}$ The $\mathrm{fHb}$-induced decrease in NO-bioavailability has been related to increased endothelial dysfunction, decreased (microcirculatory) blood flow, and tissue injury in both animal models and human studies. ${ }^{25,26,28}$ Hemolysis is a known consequence of cardiopulmonary bypass, however the impact of increased $\mathrm{fHb}$ concentrations on tissue injury development in the setting of on-pump cardiovascular surgery is not well studied. This thesis aimed to investigate whether hemolysis contributes to the development of intestinal and renal injury during and after cardiovascular surgery, and, in addition, if scavenging of intravascular NO played a pathophysiological role in this association.

The first aim of this thesis was to investigate the extent of intestinal and renal injury development during (on-pump) aortic surgery and cardiac surgery. Damage to the intestinal epithelium and renal tubular cells is of clinical importance. Intestinal tissue damage has been frequently associated with the development of the systemic inflammatory response syndrome (SIRS), sepsis, and multiple organ failure. ${ }^{29,30}$ Loss of intestinal wall integrity facilitates translocation of microbiota and microbiotal-derived toxins from the gut lumen to the systemic circulation where several potent signaling cascades are triggered (NF-kB, AKT-phosphatidylinositol-3'-kinase, and mitogen activated protein kinase pathways). This subsequently results in the release of proinflammatory substances like interleukin 6 (IL-6), IL-8, and TNF- $\alpha$, cytokines which are considered to be key players in the development of the systemic inflammatory response. $^{31-36}$ Also, damage to the (proximal) renal tubular epithelium has been independently correlated with increased morbidity. Postoperative acute kidney injury 
(AKI) was reported to be the strongest postoperative risk factor for death (odds ratio of 7.9) in patients undergoing cardiac surgery. ${ }^{37,38}$ However, not only gross changes in postoperative renal function but even small alterations of serum creatinine have been independently linked to adverse outcome in this setting, indicating the importance of preventing postoperative renal dysfunction after cardiovascular surgery. ${ }^{39}$

Using plasma intestinal fatty acid binding protein (IFABP), a sensitive and specific marker of intestinal mucosal injury ${ }^{40-51}$, and urinary $\mathrm{N}$-acetyl- $\beta$-D-glucosaminidase, a marker of proximal tubular epithelial damage ${ }^{52}$, we were able to demonstrate the development of intestinal mucosal injury and renal tubular damage in patients undergoing open surgical repair of an abdominal aortic aneurysm (OR-AAA) or thoraco(abdominal)aortic aneurysm (OR-TAA(A)) in Chapter 2, Chapter 3, and Chapter 6 , and in patients subjected to on-pump cardiac surgery (coronary artery bypass grafting ( $C A B G)$, and combined CABG and valve surgery (CABG+Valve)) in Chapter 7. In addition, the extent of mucosal injury appeared to be significantly correlated to the increase of plasma IL- 6 and IL-8 concentrations in patients undergoing OR-TAA(A) surgery (Chapter 3 ), supporting the previously stated association between intestinal damage and the systemic inflammatory response.

Next to the fact that plasma IFABP was able to indicate intestinal mucosal injury (present vs. not-present) during cardiovascular surgery, the total increase in IFABP levels also provided valuable information on the extent and severity of intestinal mucosal injury (Chapter 2). Patients developing lethal postoperative intestinal necrosis displayed exceptionally high levels of plasma IFABP already at the end of surgery. In fact, determination of plasma IFABP enabled identification of patients with postoperative intestinal necrosis one to two days prior to the clinical diagnosis with high sensitivity and specificity. Tissue hypoperfusion and ischemia, with subsequent inadequate tissue oxygenation, is considered to play a crucial role in the development of (intraoperative) intestinal tissue damage and intestinal barrier loss. ${ }^{53,54}$ Our observation that low arterial $\mathrm{pH}$ and increased plasma lactate concentrations, suggestive of tissue hypoxia ${ }^{55}$, had additional value in the identification of patients with transmural intestinal necrosis after OR-AAA surgery, supports this theory. Furthermore, the fact that patients subjected to on-pump cardiovascular surgery (OR$\operatorname{TAA}(A), C A B G$, and $C A B G+V a l v e$ surgery) displayed highest IFABP levels during surgery suggests more profound visceral perfusion derangements in these patients, consistent with previous reports on the adverse effect of CPB on splanchnic perfusion. ${ }^{14,17,18}$ Regarding renal outcome, the perioperative course of urinary NAG displayed similar kinetics to plasma IFABP; with highest levels measured in patients subjected to onpump cardiovascular surgery. Furthermore, patients with postoperative AKI displayed 
(a trend towards) increased in-hospital mortality and hospitalization time (Chapter 6 and 7) compared to non-AKI patients.

Summarizing, these results indicate the clinical importance of prevention of intestinal mucosal injury, intestinal necrosis, renal tubular damage and AKI-development during and after cardiovascular surgery. Patients undergoing on-pump surgery appear to be at highest risk for these complications. In contrast, patients undergoing endovascular exclusion of an abdominal aortic aneurysm (EVAR) or off-pump CABG (OPCAB) did neither display significant increases in plasma IFABP nor urinary NAG during the perioperative period. Although this is in line with many clinical observations ${ }^{56-58}$, also contrary results have been published reporting on a similar or even increased risk of postoperative intestinal or renal complications in EVAR or OPCAB patients compared to patients requiring on-pump surgery. ${ }^{10,59-61}$

In 2002, Reiter and co-workers published a landmark paper on the adverse effect of hemolysis on microcirculatory perfusion and fore-arm blood flow in patients with sickle cell disease, a chronic hemolytic disorder. ${ }^{25}$ Release of the hemolytic products $\mathrm{fHb}$ and arginase-1 from the erythrocyte was suggested to impair NO-bioavailability (the most important regulator of vascular tone) through intravascular NO-scavenging and degradation of the NO-substrate arginine, respectively. Since then, a series of papers substantiated this observation and provided additional evidence for the potent $\mathrm{NO}$-scavenging property of $\mathrm{fHb}$. Release of $\mathrm{fHb}$ during intravascular hemolysis is now believed to underlie the adverse effect of hemolysis on tissue perfusion and patient outcome in several acquired and hereditary (chronic) hemolytic diseases. ${ }^{26-28,62-70}$

Hemolysis is a relatively common phenomenon during cardiovascular surgery and generally attributed to the $\mathrm{CPB}^{24,71}$, cell-saver ${ }^{72}$, and (massive) red blood cell transfusions ${ }^{73,74}$. Increased $\mathrm{fHb}$ levels have been postulated to contribute to renal injury through intratubular release of free heme and free iron after glomerular filtration of $\mathrm{fHb}^{75}$ In contrast, the effects of hemolysis on the intravascular NOmetabolism in this setting has, to our knowledge, not been studied before. The second aim of this thesis was therefore to investigate the extent of acute hemolysis during cardiovascular surgery, in addition to the effects of increased plasma $\mathrm{fHb}$ levels on the intravascular NO-metabolism. Chapter 4 elaborately discusses the potential sources and effects of hemolysis during cardiovascular surgery. Also, several therapeutic options to attenuate the adverse effects of hemolysis are highlighted. Chapter 5, Chapter 6, and Chapter 7 demonstrate the development of hemolysis, indicated by increased plasma $\mathrm{fHb}$, in patients undergoing on-pump $\operatorname{OR}-\operatorname{TAA}(\mathrm{A})$, and cardiac surgery. In addition, arginase-1 levels were analyzed in OR-TAA(A) patients in Chapter 5. FHb and arginase-1 levels increased significantly after initiation of CPB, peaking at 
the end of CPB to two hours after cessation of CPB. The impact of the CPB on the induction of hemolysis was demonstrated by inclusion of a group of patients undergoing off-pump coronary surgery (OPCAB) who did not show significant changes in $\mathrm{fHb}$. Furthermore, perfusion time was significantly correlated to both peak $\mathrm{fHb}$ levels and total release of $\mathrm{fHb}$ during the study period (estimated using the area under the curve), as was consistent with previous reports on CPB-induced hemolysis. ${ }^{24,76}$

The total release of $\mathrm{fHb}$ and the arginase-1 levels correlated significantly. However, the increase in arginase-1 levels was not sufficient to significantly alter the ratio between arginine and ornithine plasma levels. This observation suggests that arginase- 1 release does not reduce arginine availability, and therefore does not (significantly) contribute to a reduction of NO-bioavailability during cardiovascular surgery. These results were in line with the results of van de Poll et al, who did not find a significant effect of increased arginase-1 levels (mean levels $185 \mathrm{ng} / \mathrm{ml}$ which was comparable to concentrations found in this study) on circulating arginine levels during liver resection. ${ }^{77}$ Using in vitro experiments, they concluded that arginase-1 levels had to exceed $2000 \mathrm{ng} / \mathrm{ml}$ to significantly reduce plasma arginine concentrations. ${ }^{77}$ In contrast, Morris et al reported on a significant reduction of the arginine/ornithine ratio in 209 patients with sickle cell disease (compared to 36 controls) which was significantly (inversely) correlated with increased plasma arginase-1 activity. ${ }^{69}$ The fact that actual $\mathrm{fHb}$ and arginase-1 levels were not reported prevented us however from comparing these findings with the presented results in Chapter 5. The contribution of arginase-1 release to decreased NO-bioavailability during cardiovascular surgery remains therefore to be further clarified.

In our patients, we observed mean (peak) fHb levels varying between $10 \mu \mathrm{mol} / \mathrm{I}$ and $25 \mu \mathrm{mol} / \mathrm{l}$. In the literature, $\mathrm{fHb}$ levels over $6 \mu \mathrm{mol} / \mathrm{I}$ are considered to be (clinically) relevant as these levels have been associated with significant derangements in the NOmetabolism in animal studies and in patients. ${ }^{25,78}$ Considering this "threshold" level, we hypothesized that the increased $\mathrm{fHb}$ levels as observed in our patients would (significantly) impair NO-bioavailability as well. To that end, plasma NO-consumption was studied in patients undergoing cardiac surgery. Chapter 7 describes the significant increase in plasma NO-consumption during surgery in patients subjected to CABG or $\mathrm{CABG}+\mathrm{Valve}$ surgery. Consistent with the NO-scavenging property of $\mathrm{fHb}$, the total release of $\mathrm{fHb}$ was significantly correlated to total plasma NO-consumption. NOconsumption increased 2.4-fold in CABG-patients, and almost 8-fold in CABG+Valve patients, in whom NO-consumption levels of $266 \mu \mathrm{mol} / \mathrm{l}$ per liter of plasma were observed. As levels of plasma NO consumption of $10-15 \mu \mathrm{mol} / \mathrm{I}$ have been related to a significant impairment of NO-dependent fore-arm blood flow, we consider the extent of NO-consumption in these patients to be clinically relevant. ${ }^{25,79}$ Patients undergoing 
OPCAB surgery did not display significant changes in plasma NO-consuming capacity, which was in line with the absence of hemolysis in this patient group. Plasma NOconsumption was not analyzed in patients subject to OR-TAA(A) surgery. Nevertheless, as plasma $\mathrm{fHb}$ concentrations in these patients corresponded to $\mathrm{fHb}$ levels measured in $C A B G+V a l v e$ surgery patients, we expect the level of NO-consumption to be similar.

The impact of increased plasma fHb levels, and the subsequent increase in plasma NOconsuming capacity, on NO-mediated vasodilation was studied in Chapter 5. Using fore-arm venous occlusion plethysmography (a technique widely used to noninvasively study (arterial) vascular function in vivo ${ }^{80}$ ) blood flow responses to intraarterial infusion of the NO-donor sodium nitroprusside (SNP) were studied. Infusion of acetylcholine (Ach, a partly NO-independent but endothelium-dependent vasodilator) was performed to control for impaired endothelial vasodilatory capacity. We hypothesized that presence of $\mathrm{fHb}$ in the blood compartment would compete for the NO moiety released from SNP, preventing its vasodilatory effect. Interestingly, blood flow responses to SNP during peak $\mathrm{fHb}$ levels were significantly reduced compared to SNP-induced vasodilation on the first postoperative day when plasma $\mathrm{fHb}$ concentrations had normalized, indeed suggesting (although indirectly) scavenging of SNP-derived NO by fHb. Acetylcholine-induced vasodilation did not differ between the studied time points, indicating unchanged vasodilatory capacity of the brachial artery. In conclusion, acute hemolysis during cardiovascular surgery correlates to enhanced plasma NO-consumption capacity and reduces NO-dependent vasodilation of the (forearm) vasculature. These results support, but do not prove, a causal relation between increased plasma fHb levels, enhanced NO-scavenging and impaired blood flow in patients subjected to on-pump cardiovascular surgery.

Derangements in (microcirculatory) tissue perfusion play a central role in tissue injury development, especially when coinciding with a pro-inflammatory state as is often the case during (on-pump) cardiovascular surgery. ${ }^{41,81-83}$ Considering the data discussed above, the third aim of this thesis was to investigate whether acute hemolysis is associated with the development of visceral injury during cardiovascular surgery. As presented in Chapter 7, total release of $\mathrm{fHb}$ was significantly correlated with intestinal mucosal injury and renal tubular injury during on-pump cardiac surgery (CABG and CABG+Valve surgery). Similarly, a significant correlation between hemolysis and tubular injury was found in patients undergoing OR-TAA(A) surgery (Chapter 6). The correlation between $\mathrm{fHb}$ and intestinal damage was not assessed in these patients. The correlation between plasma NO-consumption, plasma IFABP concentrations, and urinary NAG values, was comparable to the correlation between $\mathrm{fHb}$, IFABP, and NAG substantiating a potential mechanistic role of $\mathrm{fHb}$-induced $\mathrm{NO}$-scavenging in the 
development of visceral tissue injury in this setting. In addition to a positive correlation between hemolysis and subclinical renal tubular damage (indicated by increased urinary NAG values), it was found that patients with postoperative AKI (after OR$\operatorname{TAA}(\mathrm{A})$ or cardiac surgery) displayed significantly higher plasma fHb levels during surgery compared to non-AKI patients, indicating that substantial hemolysis may be a direct risk factor for postoperative AKI as well. Considering the fact that hemolysis correlated with tissue damage of two independent organ systems, it is tempting to speculate that $\mathrm{fHb}$ can also induce tissue injury in other organs, for instance in the heart, liver, lungs. ${ }^{68,84}$

Historically, hemolysis has been principally contributed to the CPB. ${ }^{24,76,85-87}$ In line, we were able to indicate the $\mathrm{CPB}$ as the principal source of $\mathrm{fHb}$ during cardiovascular surgery (Chapter 5), with CPB-duration being significantly correlated to both peak $\mathrm{fHb}$ levels and total release of $\mathrm{fHb}$ during the study period (Chapter 7). Nevertheless, the results presented in Chapter 5 also suggest that cell-saver and transfusion of stored red blood cells (RBC) contribute to increased plasma $\mathrm{fHb}$ and arginase-1 levels, albeit to a lesser extent. The observation that transfusion of stored RBC may significantly contribute to increased plasma $\mathrm{fHb}$ concentrations and arginase-1 levels was interesting in light of the increasing number of papers reporting on the adverse relation between blood transfusion and adverse patient outcome. ${ }^{74,88-93}$ The fourth aim of this thesis was therefore to study the contribution of stored RBC transfusion on circulating $\mathrm{fHb}$ levels and plasma NO-consumption in patients (Chapter 8). To that end, we studied a group of patients undergoing isolated transfusion of stored RBC ( 1 or 2 units), that way preventing the confounding influence of the CPB and cell-saver. Indeed, transfusion of 2 stored RBC units significantly increased circulating $\mathrm{fHb}$ levels and plasma NO-consumption as soon as 15 minutes after transfusion. Transfusion of 1 stored RBC unit did not evoke a comparable increase of $\mathrm{fHb}$ or reduction in NObioavailability. The current debate concerning the relation between blood transfusion and adverse outcome mainly focuses on the effects of RBC storage duration. As RBC damage increases with prolonged storage, it has been suggested that transfusion of "old blood" is more harmful compared to "young blood". ${ }^{74}$ Interestingly, we found no correlation between storage duration of the transfused units, the increase in plasma $\mathrm{fHb}$, and NO-consumption. However, an inverse association between pre-transfusion plasma $\mathrm{Hp}$ levels and post-transfusion plasma $\mathrm{fHb}$ concentrations was found. This may suggest that patients with high $\mathrm{Hp}$ levels may be better protected against the adverse effects of increased $\mathrm{fHb}$ levels, potentially through enhanced $\mathrm{fHb}$ clearance by $\mathrm{Hp}$, compared to individuals with low baseline $\mathrm{Hp}$ concentrations. These results may be of particular importance for patients that receive multiple $\mathrm{RBC}$ transfusion, as is particularly seen during OR-TAA(A) and to a lesser extent during CABG+Valve or CABG 
surgery. The contributory effect of packed RBC transfusion on circulating $\mathrm{fHb}$ levels as demonstrated in Chapter 8 may even be an underestimation. It has been recently shown that a reduction of the membrane of stored red blood cells results in release of $\mathrm{fHb}$-containing microvescicles which possess an equally potent NO-scavenging property compared to $\mathrm{fHb}$ molecules. ${ }^{94}$ Formation and transfusion of these microvesicles were not evaluated in our study.

These results indicate that transfusion of stored RBC units may increase circulating plasma fHb levels and plasma NO-consumption during cardiovascular surgery, thereby contributing to the development of visceral injury. Furthermore, patients with low (pre-operative) plasma $\mathrm{Hp}$ concentrations and/or requiring massive blood transfusion, may be at particularly high risk.

Cardiovascular surgery is associated with a significant reduction of circulating $\mathrm{Hp}$ levels (Chapter 7) during surgery, potentially through increased clearance of $\mathrm{Hp}-\mathrm{fHb}$ complexes due to intravascular hemolysis. Extrapolating our previous discussed results, we hypothesize that patients with low preoperative $\mathrm{Hp}$ levels, preoperative impaired kidney function, undergoing complex cardiovascular surgery associated with long perfusion times and frequent RBC transfusion, are at higher risk for the adverse effects of circulating $\mathrm{fHb}$ compared with patients with normal to high preoperative $\mathrm{Hp}$, normal renal function, that undergo CABG or OPCAB surgery, for instance. (Routine) Evaluation of preoperative $\mathrm{Hp}$ status may therefore be a worthy addition to the current preoperative patient-risk assessment prior to (complex) cardiovascular surgery. Furthermore, as RBC units with a longer storage time generally contain higher $\mathrm{fHb}$ concentrations ${ }^{95,96}$, it could be speculated that "younger" RBC units should be reserved for patients with lowest preoperative plasma $\mathrm{Hp}$ levels, that way limiting the $\mathrm{fHb}$ load administered to these patients. Lastly, the administration of fresh frozen plasma during surgery, which contains haptoglobin, might also be worth considering.

The final and fifth aim of this thesis was to study the effect of enteral high fat feeding in a rodent model of acute hemolysis with the following rationale: 1) it has been suggested that the vascular reactivity to (partly) NO-independent vasodilatory compounds is (compensatory) increased during hemolysis, 2) acetylcholine (Ach), the principal neurotransmitter of the autonomic vagal nerve, is a much studied (largy) NOindependent vasodilator, 3) enteral lipid-rich nutrition has been shown to potently stimulate vagal activity and release of Ach, and 4) administration of a high fat diet reduced visceral organ injury and (systemic) inflammation in animal models ${ }^{97}$. In an established rodent model of acute hemolysis ${ }^{98}$ (in which similar $\mathrm{fHb}$ levels are achieved as measured during on-pump cardiovascular surgery) we found that high fat feeding indeed significantly reduced hemolysis-induced loss of intestinal integrity, renal tubular damage, hepatic cell damage, and systemic inflammation (Chapter 9). As lipid- 
rich nutrition promoted intestinal, renal and hepatic perfusion during hemolysis, the protective effect of high-fat feeding may indeed be a consequence of Ach-induced vasodilation, though we did not show this in the current study. Alternatively, enteral feeding has been shown to directly increase splanchnic perfusion (reactive postprandial hyperemia) to facilitate the increased oxygen demand. ${ }^{99}$ Either way, early enteral nutrition has been shown to be generally well-tolerated, beneficial for the preservation of intestinal integrity and stimulation of gastro-intestinal blood flow ${ }^{100}$, allowing a more rapid return of gastro-intestinal function and reduced morbidity and hospital stay following major gynecologic surgery ${ }^{101}$, a caesarian section $^{102}$, or gastrointestinal resection ${ }^{103}$.

Inferring from these results, it may be hypothesized that administration of high fat enteral nutrition could reduce the adverse effects of hemolysis during CPB-assisted cardiovascular surgery.

\section{CONCLUSION}

In the current thesis, we showed that hemolysis significantly decreased intravascular NO-bioavailability and impaired NO-mediated vasodilation during and after CPBassisted cardiovascular surgery. Furthermore, enhanced plasma $\mathrm{fHb}$ concentrations correlated with the development of intestinal mucosal injury, renal proximal tubular damage and clinical acute kidney injury in this setting. Low pre-operative haptoglobin levels, in addition to (massive) transfusion of stored RBC units during surgery, may further enhance the patients' susceptibility to the adverse effects of hemolysis. Considering these data, we consider that hemolysis significantly contributes to increased morbidity and mortality after cardiovascular surgery. As the adverse effects of $\mathrm{fHb}$ can be relatively easy counteracted in vivo, we consider that hemolysis is an attractive and promising (new) therapeutic target to improve patient outcome after cardiovascular surgery. 


\section{REFERENCES}

1. Fink MP. Thoracoabdominal aortic aneurysm repair: a human model of ischemia/reperfusion-induced cytokine-driven multiple organ dysfunction syndrome. Crit Care Med 2000; 28:3356-7.

2. Coselli JS, LeMaire SA, Conklin LD, Koksoy C, Schmittling ZC. Morbidity and mortality after extent II thoracoabdominal aortic aneurysm repair. Ann Thorac Surg 2002; 73:1107-15; discussion 1115-6.

3. Achouh PE, Madsen K, Miller CC, 3rd, Estrera AL, Azizzadeh A, Dhareshwar J, Porat E, Safi HJ. Gastrointestinal complications after descending thoracic and thoracoabdominal aortic repairs: a 14year experience. J Vasc Surg 2006; 44:442-6.

4. Bicknell CD, Cowan AR, Kerle MI, Mansfield AO, Cheshire NJ, Wolfe JH. Renal dysfunction and prolonged visceral ischaemia increase mortality rate after suprarenal aneurysm repair. Br J Surg 2003; 90:1142-6.

5. Huynh TT, van Eps RG, Miller CC, 3rd, Villa MA, Estrera AL, Azizzadeh A, Porat EE, Goodrick JS, Safi HJ. Glomerular filtration rate is superior to serum creatinine for prediction of mortality after thoracoabdominal aortic surgery. J Vasc Surg 2005; 42:206-12.

6. Walsh SR, Tang T, Sadat U, Varty K, Boyle JR, Gaunt ME. Preoperative glomerular filtration rate and outcome following open abdominal aortic aneurysm repair. Vasc Endovascular Surg 2007; 41:225-9.

7. Welborn MB, Oldenburg HS, Hess PJ, Huber TS, Martin TD, Rauwerda JA, Wesdorp RI, Espat NJ, Copeland EM, 3rd, Moldawer LL, Seeger JM. The relationship between visceral ischemia, proinflammatory cytokines, and organ injury in patients undergoing thoracoabdominal aortic aneurysm repair. Crit Care Med 2000; 28:3191-7.

8. Abu-Omar Y, Ratnatunga C. Cardiopulmonary bypass and renal injury. Perfusion 2006; 21:209-13.

9. Ariza M, Gothard JW, Macnaughton P, Hooper J, Morgan CJ, Evans TW. Blood lactate and mixed venous-arterial PCO2 gradient as indices of poor peripheral perfusion following cardiopulmonary bypass surgery. Intensive Care Med 1991; 17:320-4.

10. Ascione R, Talpahewa S, Rajakaruna C, Reeves BC, Lovell AT, Cohen A, Angelini GD. Splanchnic organ injury during coronary surgery with or without cardiopulmonary bypass: a randomized, controlled trial. Ann Thorac Surg 2006; 81:97-103.

11. Brudney CS, Gosling P, Manji M. Pulmonary and renal function following cardiopulmonary bypass is associated with systemic capillary leak. J Cardiothorac Vasc Anesth 2005; 19:188-92.

12. Huybregts RA, Morariu AM, Rakhorst G, Spiegelenberg SR, Romijn HW, de Vroege R, van Oeveren W. Attenuated renal and intestinal injury after use of a mini-cardiopulmonary bypass system. Ann Thorac Surg 2007; 83:1760-6.

13. Mangi AA, Christison-Lagay ER, Torchiana DF, Warshaw AL, Berger DL. Gastrointestinal complications in patients undergoing heart operation: an analysis of 8709 consecutive cardiac surgical patients. Ann Surg 2005; 241:895-901; discussion 901-4.

14. Ohri SK, Bjarnason I, Pathi V, Somasundaram S, Bowles CT, Keogh BE, Khaghani A, Menzies I, Yacoub $\mathrm{MH}$, Taylor KM. Cardiopulmonary bypass impairs small intestinal transport and increases gut permeability. Ann Thorac Surg 1993; 55:1080-6.

15. Rodriguez R, Robich MP, Plate JF, Trooskin SZ, Sellke FW. Gastrointestinal complications following cardiac surgery: a comprehensive review. J Card Surg; 25:188-97.

16. Tsunooka N, Maeyama K, Hamada Y, Imagawa H, Takano S, Watanabe Y, Kawachi K. Bacterial translocation secondary to small intestinal mucosal ischemia during cardiopulmonary bypass. Measurement by diamine oxidase and peptidoglycan. Eur J Cardiothorac Surg 2004; 25:275-80.

17. Ohri SK, Becket J, Brannan J, Keogh BE, Taylor KM. Effects of cardiopulmonary bypass on gut blood flow, oxygen utilization, and intramucosal pH. Ann Thorac Surg 1994; 57:1193-9.

18. Ohri SK, Bowles CW, Mathie RT, Lawrence DR, Keogh BE, Taylor KM. Effect of cardiopulmonary bypass perfusion protocols on gut tissue oxygenation and blood flow. Ann Thorac Surg 1997; 64:163-70.

19. Moat NE, Shore DF, Evans TW. Organ dysfunction and cardiopulmonary bypass: the role of complement and complement regulatory proteins. Eur J Cardiothorac Surg 1993; 7:563-73.

20. Gillinov AM, Redmond JM, Winkelstein JA, Zehr KJ, Herskowitz A, Baumgartner WA, Cameron DE. Complement and neutrophil activation during cardiopulmonary bypass: a study in the complementdeficient dog. Ann Thorac Surg 1994; 57:345-52.

21. Juneja R, Mehta Y. Inflammation and cardiopulmonary bypass. Ann Card Anaesth 1998; 1:1-4. 
22. Huybregts RA, de Vroege R, Jansen EK, van Schijndel AW, Christiaans HM, van Oeveren W. The association of hemodilution and transfusion of red blood cells with biochemical markers of splanchnic and renal injury during cardiopulmonary bypass. Anesth Analg 2009; 109:331-9.

23. Vermeer H, Teerenstra S, de Sevaux RG, van Swieten HA, Weerwind PW. The effect of hemodilution during normothermic cardiac surgery on renal physiology and function: a review. Perfusion 2008; 23:329-38.

24. Vercaemst L. Hemolysis in cardiac surgery patients undergoing cardiopulmonary bypass: a review in search of a treatment algorithm. J Extra Corpor Technol 2008; 40:257-67.

25. Reiter CD, Wang X, Tanus-Santos JE, Hogg N, Cannon RO, 3rd, Schechter AN, Gladwin MT. Cell-free hemoglobin limits nitric oxide bioavailability in sickle-cell disease. Nat Med 2002; 8:1383-9.

26. Rother RP, Bell L, Hillmen P, Gladwin MT. The clinical sequelae of intravascular hemolysis and extracellular plasma hemoglobin: a novel mechanism of human disease. Jama 2005; 293:1653-62.

27. Wang X, Tanus-Santos JE, Reiter CD, Dejam A, Shiva S, Smith RD, Hogg N, Gladwin MT. Biological activity of nitric oxide in the plasmatic compartment. Proc Natl Acad Sci U S A 2004; 101:11477-82.

28. Minneci PC, Deans KJ, Zhi H, Yuen PS, Star RA, Banks SM, Schechter AN, Natanson C, Gladwin MT, Solomon SB. Hemolysis-associated endothelial dysfunction mediated by accelerated NO inactivation by decompartmentalized oxyhemoglobin. J Clin Invest 2005; 115:3409-17.

29. Fink MP. Gastrointestinal mucosal injury in experimental models of shock, trauma, and sepsis. Crit Care Med 1991; 19:627-41.

30. Fink MP, Delude RL. Epithelial barrier dysfunction: a unifying theme to explain the pathogenesis of multiple organ dysfunction at the cellular level. Crit Care Clin 2005; 21:177-96.

31. Fiane AE, Videm V, Lingaas PS, Heggelund L, Nielsen EW, Geiran OR, Fung M, Mollnes TE. Mechanism of complement activation and its role in the inflammatory response after thoracoabdominal aortic aneurysm repair. Circulation 2003; 108:849-56.

32. Morariu AM, Loef BG, Aarts LP, Rietman GW, Rakhorst G, van Oeveren W, Epema AH. Dexamethasone: benefit and prejudice for patients undergoing on-pump coronary artery bypass grafting: a study on myocardial, pulmonary, renal, intestinal, and hepatic injury. Chest 2005; 128:2677-87.

33. Ytting H, Christensen IJ, Basse L, Lykke J, Thiel S, Jensenius JC, Nielsen HJ. Influence of major surgery on the mannan-binding lectin pathway of innate immunity. Clin Exp Immunol 2006; 144:239-46.

34. Fasano A, Shea-Donohue T. Mechanisms of disease: the role of intestinal barrier function in the pathogenesis of gastrointestinal autoimmune diseases. Nat Clin Pract Gastroenterol Hepatol 2005; 2:416-22.

35. Arrieta MC, Bistritz L, Meddings JB. Alterations in intestinal permeability. Gut 2006; 55:1512-20.

36. Mukherjee S, Vaishnava S, Hooper LV. Multi-layered regulation of intestinal antimicrobial defense. Cell Mol Life Sci 2008; 65:3019-27.

37. Chertow GM, Levy EM, Hammermeister KE, Grover F, Daley J. Independent association between acute renal failure and mortality following cardiac surgery. Am J Med 1998; 104:343-8.

38. Kelly KJ. Distant effects of experimental renal ischemia/reperfusion injury. J Am Soc Nephrol 2003; 14:1549-58.

39. Lassnigg A, Schmidlin D, Mouhieddine M, Bachmann LM, Druml W, Bauer P, Hiesmayr M. Minimal changes of serum creatinine predict prognosis in patients after cardiothoracic surgery: a prospective cohort study. J Am Soc Nephrol 2004; 15:1597-605.

40. Derikx JP, Matthijsen RA, de Bruine AP, van Bijnen AA, Heineman E, van Dam RM, Dejong $\mathrm{CH}$, Buurman WA. Rapid reversal of human intestinal ischemia-reperfusion induced damage by shedding of injured enterocytes and reepithelialisation. PLoS ONE 2008; 3:e3428.

41. Derikx JP, Poeze M, van Bijnen AA, Buurman WA, Heineman E. Evidence for intestinal and liver epithelial cell injury in the early phase of sepsis. Shock 2007; 28:544-8.

42. Derikx JP, van Waardenburg DA, Granzen B, van Bijnen AA, Heineman E, Buurman WA. Detection of chemotherapy-induced enterocyte toxicity with circulating intestinal fatty acid binding protein. J Pediatr Hematol Oncol 2006; 28:267-9.

43. Derikx JP, van Waardenburg DA, Thuijls G, Willigers HM, Koenraads M, van Bijnen AA, Heineman E, Poeze M, Ambergen T, van Ooij A, van Rhijn LW, Buurman WA. New Insight in Loss of Gut Barrier during Major Non-Abdominal Surgery. PLoS ONE 2008; 3:e3954. 
44. Derikx JP, Vreugdenhil AC, Van den Neucker AM, Grootjans J, van Bijnen AA, Damoiseaux JG, van Heurn LW, Heineman E, Buurman WA. A pilot study on the noninvasive evaluation of intestinal damage in celiac disease using I-FABP and L-FABP. J Clin Gastroenterol 2009; 43:727-33.

45. Grootjans J, Thuijls G, Verdam F, Derikx JP, Lenaerts K, Buurman WA. Non-invasive assessment of barrier integrity and function of the human gut. World J Gastrointest Surg; 2:61-9.

46. Thuijls G, de Haan JJ, Derikx JP, Daissormont I, Hadfoune M, Heineman E, Buurman WA. Intestinal cytoskeleton degradation precedes tight junction loss following hemorrhagic shock. Shock 2009; 31:164-9.

47. Thuijls G, Derikx JP, Prakken FJ, Huisman B, van Bijnen Ing AA, van Heurn EL, Buurman WA, Heineman E. A pilot study on potential new plasma markers for diagnosis of acute appendicitis. Am J Emerg Med; 29:256-60.

48. Thuijls G, Derikx JP, van Wijck K, Zimmermann $\sqcup$, Degraeuwe PL, Mulder TL, Van der Zee DC, Brouwers HA, Verhoeven BH, van Heurn LW, Kramer BW, Buurman WA, Heineman E. Non-invasive markers for early diagnosis and determination of the severity of necrotizing enterocolitis. Ann Surg; 251:1174-80.

49. Holmes JHt, Lieberman JM, Probert CB, Marks WH, Hill ME, Paull DL, Guyton SW, Sacchettini J, Hall RA. Elevated intestinal fatty acid binding protein and gastrointestinal complications following cardiopulmonary bypass: a preliminary analysis. J Surg Res 2001; 100:192-6.

50. Lieberman JM, Sacchettini J, Marks C, Marks WH. Human intestinal fatty acid binding protein: report of an assay with studies in normal volunteers and intestinal ischemia. Surgery 1997; 121:335-42.

51. Thuijls G, van Wijck K, Grootjans J, Derikx JP, van Bijnen AA, Heineman E, Dejong CH, Buurman WA, Poeze M. Early Diagnosis of Intestinal Ischemia Using Urinary and Plasma Fatty Acid Binding Protein. Ann Surg.

52. Dittrich S, Kurschat K, Dahnert I, Vogel M, Muller C, Alexi-Meskishvili V, Lange PE. Renal function after cardiopulmonary bypass surgery in cyanotic congenital heart disease. Int J Cardiol 2000; 73:173-9.

53. El-Assal ON, Radulescu A, Besner GE. Heparin-binding EGF-like growth factor preserves mesenteric microcirculatory blood flow and protects against intestinal injury in rats subjected to hemorrhagic shock and resuscitation. Surgery 2007; 142:234-42.

54. Zakaria el R, Garrison RN, Spain DA, Matheson PJ, Harris PD, Richardson JD. Intraperitoneal resuscitation improves intestinal blood flow following hemorrhagic shock. Ann Surg 2003; 237:704-11; discussion 711-3.

55. Fall PJ, Szerlip HM. Lactic acidosis: from sour milk to septic shock. J Intensive Care Med 2005; 20: 255-71.

56. Perry RJ, Martin MJ, Eckert MJ, Sohn VY, Steele SR. Colonic ischemia complicating open vs endovascular abdominal aortic aneurysm repair. J Vasc Surg 2008; 48:272-7.

57. Massoudy P, Wagner S, Thielmann M, Herold U, Kottenberg-Assenmacher E, Marggraf G, Kribben A, Philipp T, Jakob H, Herget-Rosenthal $\mathrm{S}$. Coronary artery bypass surgery and acute kidney injury--impact of the off-pump technique. Nephrol Dial Transplant 2008; 23:2853-60.

58. Nigwekar SU, Kandula P, Hix JK, Thakar CV. Off-pump coronary artery bypass surgery and acute kidney injury: a meta-analysis of randomized and observational studies. Am J Kidney Dis 2009; 54:413-23.

59. Bennett NJ, Bull AL, Dunt DR, Gurrin LC, Richards MJ, Russo PL, Spelman DW. A profile of smaller hospitals: planning for a novel, statewide surveillance program, Victoria, Australia. Am J Infect Control 2006; 34:170-5.

60. Al-Ruzzeh S, Nakamura K, Athanasiou T, Modine T, George S, Yacoub M, Ilsley C, Amrani M. Does offpump coronary artery bypass (OPCAB) surgery improve the outcome in high-risk patients?: a comparative study of 1398 high-risk patients. Eur J Cardiothorac Surg 2003; 23:50-5.

61. Brown LC, Brown EA, Greenhalgh RM, Powell JT, Thompson SG. Renal function and abdominal aortic aneurysm (AAA): the impact of different management strategies on long-term renal function in the UK EndoVascular Aneurysm Repair (EVAR) Trials. Ann Surg; 251:966-75.

62. Gladwin MT, Patel RP. The role of red blood cells and hemoglobin-nitric oxide interactions on blood flow. Am J Respir Cell Mol Biol 2008; 38:125-6.

63. Gladwin MT, Sachdev V, Jison ML, Shizukuda Y, Plehn JF, Minter K, Brown B, Coles WA, Nichols JS, Ernst I, Hunter LA, Blackwelder WC, Schechter AN, Rodgers GP, Castro O, Ognibene FP. Pulmonary hypertension as a risk factor for death in patients with sickle cell disease. N Engl J Med 2004; 350: 886-95. 
64. Hataishi R, Rodrigues AC, Neilan TG, Morgan JG, Buys E, Shiva S, Tambouret R, Jassal DS, Raher MJ, Furutani E, Ichinose F, Gladwin MT, Rosenzweig A, Zapol WM, Picard MH, Bloch KD, Scherrer-Crosbie $M$. Inhaled nitric oxide decreases infarction size and improves left ventricular function in a murine model of myocardial ischemia-reperfusion injury. Am J Physiol Heart Circ Physiol 2006; 291:H379-84.

65. Jeffers A, Gladwin MT, Kim-Shapiro DB. Computation of plasma hemoglobin nitric oxide scavenging in hemolytic anemias. Free Radic Biol Med 2006; 41:1557-65.

66. Kato GJ, Gladwin MT. Evolution of novel small-molecule therapeutics targeting sickle cell vasculopathy. Jama 2008; 300:2638-46.

67. Kato GJ, Hsieh M, Machado R, Taylor Jt, Little J, Butman JA, Lehky T, Tisdale J, Gladwin MT. Cerebrovascular disease associated with sickle cell pulmonary hypertension. Am J Hematol 2006; 81:503-10.

68. Morris CR, Gladwin MT, Kato GJ. Nitric oxide and arginine dysregulation: a novel pathway to pulmonary hypertension in hemolytic disorders. Curr Mol Med 2008; 8:620-32.

69. Morris CR, Kato GJ, Poljakovic M, Wang X, Blackwelder WC, Sachdev V, Hazen SL, Vichinsky EP, Morris SM, Jr., Gladwin MT. Dysregulated arginine metabolism, hemolysis-associated pulmonary hypertension, and mortality in sickle cell disease. Jama 2005; 294:81-90.

70. Rees DC, Williams TN, Gladwin MT. Sickle-cell disease. Lancet 2010; 376:2018-31.

71. Fransen EJ, Ganushchak YM, Vijay V, de Jong DS, Buurman WA, Maessen JG. Evaluation of a new condensed extra-corporeal circuit for cardiac surgery: a prospective randomized clinical pilot study. Perfusion 2005; 20:91-9.

72. Serrick CJ, Scholz M, Melo A, Singh O, Noel D. Quality of red blood cells using autotransfusion devices: a comparative analysis. J Extra Corpor Technol 2003; 35:28-34.

73. Karkouti K, Wijeysundera DN, Yau TM, Beattie WS, Abdelnaem E, McCluskey SA, Ghannam M, Yeo E, Djaiani G, Karski J. The independent association of massive blood loss with mortality in cardiac surgery. Transfusion 2004; 44:1453-62.

74. Koch CG, Li L, Sessler DI, Figueroa P, Hoeltge GA, Mihaljevic T, Blackstone EH. Duration of red-cell storage and complications after cardiac surgery. N Engl J Med 2008; 358:1229-39.

75. Haase M, Haase-Fielitz A, Bagshaw SM, Ronco C, Bellomo R. Cardiopulmonary bypass-associated acute kidney injury: a pigment nephropathy? Contrib Nephrol 2007; 156:340-53.

76. Cheung AT, Cruz-Shiavone GE, Meng QC, Pochettino A, Augoustides JA, Bavaria JE, Ochroch EA. Cardiopulmonary bypass, hemolysis, and nitroprusside-induced cyanide production. Anesth Analg 2007; 105:29-33.

77. van de Poll MC, Hanssen SJ, Berbee M, Deutz NE, Monbaliu D, Buurman WA, Dejong CH. Elevated plasma arginase-1 does not affect plasma arginine in patients undergoing liver resection. Clin Sci (Lond) 2008; 114:231-41.

78. Pohl U, Lamontagne D. Impaired tissue perfusion after inhibition of endothelium-derived nitric oxide. Basic Res Cardiol 1991; 86 Suppl 2:97-105.

79. Meyer C, Heiss C, Drexhage C, Kehmeier ES, Balzer J, Muhlfeld A, Merx MW, Lauer T, Kuhl H, Floege J, Kelm M, Rassaf T. Hemodialysis-induced release of hemoglobin limits nitric oxide bioavailability and impairs vascular function. J Am Coll Cardiol 2010; 55:454-9.

80. Wilkinson IB, Webb DJ. Venous occlusion plethysmography in cardiovascular research: methodology and clinical applications. Br J Clin Pharmacol 2001; 52:631-46.

81. Derikx JP, van Waardenburg DA, Thuijls $G$, Willigers HM, Koenraads $M$, van Bijnen AA, Heineman E, Poeze M, Ambergen T, van Ooij A, van Rhijn LW, Buurman WA. New Insight in Loss of Gut Barrier during Major Non-Abdominal Surgery. PLoS One 2008; 3:e3954.

82. Ohri SK, Somasundaram S, Koak Y, Macpherson A, Keogh BE, Taylor KM, Menzies IS, Bjarnason I. The effect of intestinal hypoperfusion on intestinal absorption and permeability during cardiopulmonary bypass. Gastroenterology 1994; 106:318-23.

83. Schrier RW, Wang W, Poole B, Mitra A. Acute renal failure: definitions, diagnosis, pathogenesis, and therapy. J Clin Invest 2004; 114:5-14.

84. Nemeto S, Aoki M, Dehua C, Imai Y. Free hemoglobin impairs cardiac function in neonatal rabbit hearts. Ann Thorac Surg 2000; 69:1484-9.

85. Gbadegesin R, Zhao S, Charpie J, Brophy PD, Smoyer WE, Lin JJ. Significance of hemolysis on extracorporeal life support after cardiac surgery in children. Pediatr Nephrol 2009; 24:589-95. 
86. Sakota D, Sakamoto R, Sobajima H, Yokoyama N, Waguri S, Ohuchi K, Takatani S. Mechanical damage of red blood cells by rotary blood pumps: selective destruction of aged red blood cells and subhemolytic trauma. Artif Organs 2008; 32:785-91.

87. Valeri CR, MacGregor H, Ragno G, Healey N, Fonger J, Khuri SF. Effects of centrifugal and roller pumps on survival of autologous red cells in cardiopulmonary bypass surgery. Perfusion 2006; 21:291-6.

88. Zallen G, Offner PJ, Moore EE, Blackwell J, Ciesla DJ, Gabriel J, Denny C, Silliman CC. Age of transfused blood is an independent risk factor for postinjury multiple organ failure. Am J Surg 1999; 178:570-2.

89. Marik PE, Sibbald WJ. Effect of stored-blood transfusion on oxygen delivery in patients with sepsis. Jama 1993; 269:3024-9.

90. Purdy FR, Tweeddale MG, Merrick PM. Association of mortality with age of blood transfused in septic ICU patients. Can J Anaesth 1997; 44:1256-61.

91. Offner PJ, Moore EE, BiffI WL, Johnson JL, Silliman CC. Increased rate of infection associated with transfusion of old blood after severe injury. Arch Surg 2002; 137:711-717.

92. Ranucci M, Carlucci C, Isgro G, Boncilli A, De Benedetti D, De la Torre T, Brozzi S, Frigiola A. Duration of red blood cell storage and outcomes in pediatric cardiac surgery: an association found for pump prime blood. Crit Care 2009; 13:R207.

93. Koch CG, Li L, Duncan Al, Mihaljevic T, Cosgrove DM, Loop FD, Starr NJ, Blackstone EH. Morbidity and mortality risk associated with red blood cell and blood-component transfusion in isolated coronary artery bypass grafting. Crit Care Med 2006; 34:1608-16.

94. Donadee C, Raat NJ, Kanias T, Tejero J, Lee JS, Kelley EE, Zhao X, Liu C, Reynolds H, Azarov I, Frizzell S, Meyer EM, Donnenberg AD, Qu L, Triulzi D, Kim-Shapiro DB, Gladwin MT. Nitric Oxide Scavenging by Red Blood Cell Microparticles and Cell-Free Hemoglobin as a Mechanism for the Red Cell Storage Lesion. Circulation 2011; 26:465-476.

95. Gladwin MT, Kim-Shapiro DB. Storage lesion in banked blood due to hemolysis-dependent disruption of nitric oxide homeostasis. Curr Opin Hematol 2009; 16:515-23.

96. Kim-Shapiro DB, Lee J, Gladwin MT. Storage lesion: role of red blood cell breakdown. Transfusion 2011; 51:844-51.

97. Luyer MD, Greve JW, Hadfoune M, Jacobs JA, Dejong $\mathrm{CH}$, Buurman WA. Nutritional stimulation of cholecystokinin receptors inhibits inflammation via the vagus nerve. J Exp Med 2005; 202:1023-9.

98. Hanssen SJ, Lubbers T, Hodin CM, Prinzen FW, Buurman WA, Jacobs MJ. Hemolysis results in impaired intestinal microcirculation and intestinal epithelial cell injury. World J Gastroenterol 2011; 17:213-8.

99. de Aguilar-Nascimento JE, Dock-Nascimento DB, Bragagnolo R. Role of enteral nutrition and pharmaconutrients in conditions of splanchnic hypoperfusion. Nutrition 2010; 26:354-8.

100. Inoue S, Lukes S, Alexander JW, Trocki O, Silberstein EB. Increased gut blood flow with early enteral feeding in burned guinea pigs. J Burn Care Rehabil 1989; 10:300-8.

101. MacMillan SL, Kammerer-Doak D, Rogers RG, Parker KM. Early feeding and the incidence of gastrointestinal symptoms after major gynecologic surgery. Obstet Gynecol 2000; 96:604-8.

102. Mangesi L, Hofmeyr GJ. Early compared with delayed oral fluids and food after caesarean section. Cochrane Database Syst Rev 2002:CD003516.

103. Carr CS, Ling KD, Boulos $P$, Singer M. Randomised trial of safety and efficacy of immediate postoperative enteral feeding in patients undergoing gastrointestinal resection. BMJ 1996; 312: 869-71. 


Nederlandse samenvatting 
Hart- en vaatziekten (cardiovasculaire ziekten) vormen nog steeds de primaire doodsoorzaak in Nederland. Voor een aantal hart- en vaataandoeningen is operatief ingrijpen de enige behandeling. Voorbeelden van dergelijke ziekten zijn het aorta aneurysma (een abnormale verwijding van de lichaamsslagader), coronair vaatlijden (meestal ten gevolge van vernauwingen van de kransslagaders van het hart) en hartklep afwijkingen. Tijdens dergelijke operaties moet vaak de functie van het hart en longen tijdelijk (buiten het lichaam) worden overgenomen. De ontwikkeling van de hart-longmachine (cardiopulmonale bypass of $\mathrm{CPB}$ ) in het begin van de jaren vijftig van de vorige eeuw heeft dan ook een grote vooruitgang betekend in de behandelingsmogelijkheden van deze patiënten.

Tot op de dag van vandaag wordt de CPB nog veelvuldig gebruikt bij hart operaties en enkele grote aorta operaties. De enorme technische ontwikkeling binnen de hart- en vaatchirurgie, met name op het gebied van de CPB, heeft gezorgd voor een flinke vermindering van het aantal postoperatieve complicaties en de sterftekans (mortaliteit). Desalniettemin komen, vooral na meer complexe aorta- en hartoperaties, nog relatief veel postoperatieve complicaties voor. Voorbeelden van dergelijk complexe operaties zijn het herstel van een thoracoabdominal aorta aneurysma (een uitgebreid aorta aneurysma waarbij zowel de aorta in de borstholte (de thorax) als in de buikholte (het abdomen) verwijd is), en hartoperaties waarbij zowel omleidingen (bypasses) rond zieke coronair arteriën worden aangelegd (een coronary artery bypass grafting of $C A B G$ ) en bovendien aan één of meerdere hartkleppen geopereerd moet worden. Vaak gerapporteerde postoperatieve complicaties na deze operaties zijn: stoornissen van de functie van de nier (tot dialyse aan toe), darmproblemen, longcomplicaties en hartproblemen. Ook wordt frequent een versterkte respons van het immuunsysteem waargenomen, wat zich klinisch uit in een verhoogde concentratie van ontstekingseiwitten in het bloed (een systemische inflammatoire respons). Deze ontstekingsrespons kan zich dusdanig uitbreiden dat dit leidt tot sepsis en het falen van meerdere organen. Eerder onderzoek in proefdieren en patiënten heeft aangetoond dat de mate van deze ontstekingsrespons gerelateerd is aan de mate van darmschade. Schade aan de darm barrière faciliteert namelijk (o.a.) de verplaatsing van bacteriën vanuit de darm naar de bloedbaan. De daaropvolgende reactie van het immuunsysteem is er op gericht deze ongewenste indringers zo snel mogelijk op te ruimen. Deze reactie van het immuunsysteem is om deze reden goed voor de patiënt. Een te sterke lokale ontstekingsreactie kan echter soms moeilijk onder controle gehouden worden door het immuunsysteem en uitbreiden tot een systemische inflammatoire respons en schade aan (andere) organen. 
Om de kans op het ontwikkelen van postoperatieve complicaties zo laag mogelijk te houden en, indien zich toch een complicatie ontwikkelt, de patiënt zo optimaal mogelijk te kunnen behandelen is het identificeren van beïnvloedbare risicofactoren (dus bijvoorbeeld de operatieduur) van belang. Immers, interventies gericht tegen dergelijke risicofactoren kunnen de uitkomst van de patiënt verbeteren. Risicofactoren zoals leeftijd en geslacht van de patiënt zijn niet beïnvloedbaar en kunnen om deze reden dan ook niet gebruikt worden voor therapeutische doeleinden.

De CPB is onvervangbaar en essentieel om sommige operaties uit te kunnen voeren. Desalniettemin heeft gebruik van een CPB ook ongewenste effecten. Eén van deze effecten is hemolyse dat, letterlijke vertaald, het 'uit elkaar vallen (lysis) van het bloed (hemo)' betekend. In de geneeskundige praktijk wordt deze term echter exclusief gebruikt voor het vroegtijdig kapot gaan van rode bloedcellen in de bloedbaan. Hemolyse ontstaat tijdens CPB vooral door mechanische stress in de slangen en pompen waaruit de CPB is opgebouwd. Tijdens hemolyse komen verschillende stoffen in het bloed terecht die normaal gesproken alleen in de rode bloedcel aanwezig zijn. Voorbeelden hiervan zijn het eiwit hemoglobine (dan vrij hemoglobine of $\mathrm{vHb}$ genoemd) en het enzym arginase-1. In 2002 is ontdekt dat zowel vHb als arginase- 1 de beschikbaarheid van het molecuul stikstof monoxide (nitric oxide, NO) in het bloed significant beperkt. Dit gebeurd op twee manieren: $\mathrm{vHb}$ reageert en inactiveert NO, en arginase-1 leidt tot afbraak van arginine, het aminozuur waaruit NO geproduceerd wordt. Omdat NO de belangrijkste vaatverwijder in ons lichaam is en essentieel is voor (het behoud van) een adequate weefseldoorbloeding, kan een verminderde beschikbaarheid van NO nadelige gevolgen hebben voor de orgaandoorbloeding en zo leiden tot orgaanschade. Bij patiënten met chronisch hemolytische aandoeningen (zoals malaria of sikkel cel anemie) is aangetoond dat hemolyse inderdaad gecorreleerd is met een slechtere doorbloeding van organen en weefselschade. Deze associatie kon verklaard worden door een verminderde beschikbaarheid van NO.

Hemolyse is ook tijdens chirurgie met CPB een bekend fenomeen, desalniettemin is de relatie tussen hemolyse en orgaanschade in deze setting nog beperkt bestudeerd. Wij hebben ons in dit proefschrift dan ook tot doel gesteld om te onderzoeken of hemolyse tijdens aorta- en hartchirurgie gecorreleerd is met schade aan darm- en nierweefsel (viscerale schade). Viscerale schade heeft een direct negatief effect op de prognose van de patiënt. Darmschade is, zoals boven beschreven, geassocieerd met een te sterke ontstekingsreactie van het lichaam. Nierschade, dat vrij vaak voorkomt, is gerelateerd aan het optreden van andere complicaties en een slechtere postoperatieve overleving. In dit proefschrift hebben wij vervolgens onderzocht of de eventuele relatie tussen hemolyse en viscerale schade verklaard kan worden door een verminderde beschikbaarheid van NO. 
Het eerste doel van dit proefschrift was het vaststellen van de mate van darm- en nierschade tijdens bepaalde typen aorta- en hartoperaties (Hoofdstukken 2, 3, 6, en 7). Dit werd onderzocht door bepaling van het eiwit intestinal fatty acid bindig protein (IFABP), een gevoelige marker voor schade aan darmcellen, in het bloed en door bepaling van het enzym $\mathrm{N}$-acetyl- $\beta$-D-glucosaminidase (NAG), een goede indicator voor niercelschade, in de urine. Verhoogde waardes van IFABP en NAG suggereren darm- en nierschade. Darm- en nierschade was het meest uitgesproken in patiënten die complexe operaties met een CPB ondergingen zoals open chirurgisch herstel van een thoracaal of thoracoabdominal aorta aneurysma (OR-TAA(A)), of gecombineerde bypass + hartklep operaties. In tegenstelling tot deze patiënten was darm- en nierschade zeer beperkt in patiënten die werden geopereerd aan een geïsoleerd aorta aneurysma in de buik (een abdominaal aorta aneurysma, hierbij wordt geen CPB gebruikt) en zelfs onmeetbaar bij patiënten die een hartoperatie zonder CPB of een aortaoperatie via de lies ondergingen.

Hoewel de patiënt deze mate van orgaanschade niet direct zelf hoeft te merken, heeft eerder onderzoek aangetoond dat deze zogenaamde subklinische schade (waarmee bedoeld wordt dat we de schade wel in het bloed of in urine kunnen aantonen) wel degelijk de kans op het ontwikkelen van complicaties vergroot en de overlevingskans van de patiënt verlaagt. In lijn met dit eerdere onderzoek bleek bij patiënten met (sterk) verhoogde NAG en $\mathrm{vHb}$ spiegels tijdens de operatie vaker postoperatieve nierfunctiestoornissen op te treden. Sommige patiënten werden zelfs tijdelijk dialyseafhankelijk (Hoofdstuk 6 en 7). De mate van darmschade bleek samen te hangen met de hoeveelheid ontstekingseiwitten (interleukine-6, en interleukine-8) in het bloed van de patiënt (Hoofdstuk 3). Bovendien voorspelde zeer hoge bloedspiegels van IFABP al vroegtijdig het optreden van darmischemie (het volledig afsterven van een stukje darm, Hoofdstuk 2). Deze laatste observatie was van uitgesproken klinisch belang omdat darmischemie een zeer lastig te diagnosticeren fenomeen is. Gezien de ernst van de aandoening, de meeste patiënten overleven darmischemie niet, is dit een groot probleem. Bepaling van IFABP aan het einde van de operatie maakte het mogelijk patiënten met darmischemie vroegtijdig, 1-2 dagen voordat zij ziek werden, te identificeren. Het zal in de toekomst moeten blijken of het gebruik van IFABP in het opsporen van patiënten met darmischemie zal leiden tot snellere behandeling van deze ziekte, en daarmee leidt tot een verbeterde overleving van deze patiënten.

Het tweede doel van dit proefschrift was het onderzoeken van de mate van hemolyse en de eventuele invloed van hemolyse op de NO-beschikbaarheid tijdens en na aortaen hartchirurgie (Hoofdstuk 4, 5, 6 en 7). Overeenkomend met de stijging van IFABP en NAG was de stijging van vHb het sterkst in de OR-TAA(A) patiënten en bij complexe hartoperaties. In deze patiënten bereikte de vHb concentraties in het bloed een niveau 
dat in eerder onderzoek geassocieerd was met een vermindering van de NObeschikbaarheid en een vermindering van weefseldoorbloeding. In tegenstelling tot de vHb waarden waren de arginase- 1 spiegels tijdens hemolyse in OR-TAA(A) patiënten niet hoog genoeg om een duidelijke afname van arginine te kunnen veroorzaken (Hoofdstuk 5). Om de beschikbaarheid van NO te onderzoeken hebben wij het verbruik van NO in het bloed onderzocht; de zogenaamde 'plasma NO-consumptie'. Hoe hoger de NO-consumptie van het plasma, hoe minder NO beschikbaar blijft voor, bijvoorbeeld, het induceren van vaatverwijding. De mate van hemolyse (gemeten door $\mathrm{vHb}$ ) bleek significant gecorreleerd te zijn aan de mate van NO-consumptie in het bloed, hetgeen overeen kwam met de theorie dat vHb NO wegvangt (Hoofdstuk 7). NO handhaaft de weefseldoorbloeding door vaatverwijding te veroorzaken. Als er door aanwezigheid van $\mathrm{vHb}$ veel $\mathrm{NO}$ wordt weggevangen is dus mogelijk de reactie van de vaatwand op toegediend NO ook verstoort. Om deze reden hebben wij vervolgens in een kleine groep OR-TAA(A) patiënten onderzocht of de vaatwand minder vaatverwijding vertoonde als reactie op het toedienen van de NO-donor sodiumnitroprusside op het moment dat er hoge concentraties $\mathrm{vHb}$ in het plasma meetbaar waren (Hoofdstuk 5). Dit bleek inderdaad het geval. Wij veronderstellen dat dit een gevolg is van het wegvangen van het, van sodiumnitroprusside afkomstige, NO door het $\mathrm{vHb}$. Controle experimenten een dag later, toen $\mathrm{vHb}$ spiegels genormaliseerd waren, liet een sterkere vaatverwijding zien na sodiumnitroprusside toediening. Deze resultaten suggereren dat er minder bloedvatverwijding optreedt in reactie op toegediend $\mathrm{NO}$ bij hoge $\mathrm{vHb}$ concentraties in het bloed in vergelijking met momenten waarop weinig $\mathrm{vHb}$ in het bloed aanwezig is. Deze data sluiten aan op het reeds bekende feit dat $\mathrm{vHb}$ zorgt voor inactivatie van $\mathrm{NO}$ in de bloedbaan.

Nadat we hadden aangetoond dat er tijdens (complexe) cardiovasculaire chirurgie met CPB zowel darmschade, nierschade, als hemolyse met een significante beperking van de intravasculaire NO-beschikbaarheid optreedt, stelden wij ons tot doel (derde doel) om te onderzoeken of deze fenomenen met elkaar verband houden. Hiervoor hebben wij de totale vrijgave van het IFABP, NAG, vHb en de totale mate van plasma NOconsumptie tijdens de studieperiode met elkaar gecorreleerd. In zowel OR-TAA(A) patiënten als hartchirurgie patiënten was hemolyse significant gecorreleerd aan nierschade (Hoofdstuk 6 en 7) en aan darmschade (Hoofdstuk 7). Ook was de mate van NO-consumptie significant gecorreleerd aan beide schademarkers (Hoofdstuk 7). Zelfs na statistische correctie voor andere beïnvloedende factoren bleef de significante relatie tussen hemolyse en viscerale schade bestaan. Piekwaarden van plasma vHb tijdens de operatie hadden tevens een voorspellende waarde voor postoperatieve nierfunctiestoornissen (Hoofdstuk 6). 
Deze data maken het aannemelijk dat hemolyse gerelateerd is aan de ernst van viscerale schade tijdens (complexe) cardiovasculaire chirurgie met CPB. Tevens is het waarschijnlijk dat een verminderde beschikbaarheid van NO, als gevolg van het wegvangen van $\mathrm{NO}$ door $\mathrm{vHb}$, belangrijk is in deze relatie.

Hemolyse tijdens cardiovasculaire chirurgie wordt met name toegeschreven aan de CPB. Echter, ook het transfunderen van rode bloedcellen zou kunnen bijdragen aan verhoogde $\mathrm{vHb}$ spiegels in deze setting. Opslag van rode bloedcellen leidt namelijk, zij het in beperkte mate, tot schade aan rode bloedcellen en zelfs tot hemolyse. Opslag van rode bloedcellen leidt om deze reden tot meetbaar verhoogde $\mathrm{vHb}$ concentraties in het opslagmedium. Tijdens de bloedtransfusie wordt gelijktijdig ook het vHbbevattende opslagmedium getransfundeerd, hetgeen theoretisch een toename van $\mathrm{vHb}$ spiegels in het bloed van de ontvanger kan veroorzaken. Om dit te onderzoeken hebben wij 30 patiënten met een vorm van bloedkanker onderzocht die werden getransfundeerd met 1 of 2 opgeslagen rode bloedcelproducten (packed cells, Hoofdstuk 8). Wij hebben gekozen voor het bestuderen van dergelijke patiënten omdat in deze setting het hemolyserende effect van de CPB (zoals bij hart- en vaatchirurgie patiënten) geen rol speelt. Transfusie van 2 packed cells resulteerde in een statistisch significante toename van het vHb en de NO-consumptie in het bloed. Hoewel het opslagmedium van langer opgeslagen bloedproducten meer vHb bevatte en meer NO kon consumeren, resulteerde de transfusie van oudere packed cells niet tot hogere $\mathrm{vHb}$ spiegels of sterkere NO-consumptie in het bloed van de ontvanger in vergelijking met transfusie van kort opgeslagen packed cells. Daarentegen bleken patiënten met lage haptoglobine spiegels (het eiwit dat onder fysiologische omstandigheden $\mathrm{vHb}$ wegvangt) vò̀r de transfusie, hogere $\mathrm{vHb}$ concentraties na de transfusie te vertonen. Omgekeerd lieten de patiënten met de hoogste pre-transfusie haptoglobine waarden geen stijging van het vHb zien, ongeacht of zij 1 of 2 packed cells ontvingen. Extrapolatie van deze resultaten naar de setting van (complexe) cardiovasculaire chirurgie zou kunnen betekenen dat transfusie van packed cells, vaak nodig om bijvoorbeeld bloedverlies tijdens de operatie te compenseren, de toename van $\mathrm{vHb}$ en NO-consumptie bij deze patiënten verder versterkt. Zeker indien uitgebreide transfusie noodzakelijk is, en patiënten lage haptoglobine spiegels hebben voor de operatie, kan de toename van $\mathrm{vHb}$ en NO-consumptie klinisch relevant worden; dat wil zeggen, potentieel bijdragen aan het ontstaan van darmschade, nierschade en postoperatieve nierfunctiestoornissen.

Gezien de bovenstaande resultaten achten wij het waarschijnlijk dat hemolyse een belangrijke, en beïnvloedbare, risicofactor is voor het ontstaan van viscerale schade tijdens en na (complexe) cardiovasculaire chirurgie. Het voorkomen of behandelen van 
hemolyse zou dus kunnen leiden tot minder complicaties en een betere overleving van de patiënt. Hoewel de oorzaak van hemolyse moeilijk aan te pakken is, zijn er wel diverse veelbelovende interventies die de schadelijke effecten van $\mathrm{vHb}$ kunnen verminderen. In Hoofdstuk 4 worden enkele voorbeelden van dergelijke interventies besproken die specifiek in deze setting van nut kunnen zijn. Een niet in dit hoofdstuk besproken therapeutische interventie hebben wij in Hoofdstuk 9 onderzocht. In een hemolyse proefdiermodel, waarbij aan ratten $\mathrm{vHb}$ werd toegediend totdat vergelijkbare concentraties als die in onze patiënten meetbaar waren, hebben wij onderzocht of het geven van vetrijke voeding beschermend werkt op het ontstaan van viscerale schade. Het aanbieden van voedsel in de darm leidt over het algemeen tot een verbeterde darm doorbloeding, onafhankelijk van NO. Bovendien heeft eerder onderzoek aangetoond dat vetrijke voeding in het bijzonder de lokale (in de darm) en systemische ontstekingsreacties vermindert. Vetrijke voeding stimuleert tevens de afgifte van het stofje acetylcholine door een belangrijke zenuw in ons lichaam; de nervus vagus. Acetylcholine kan, vergelijkbaar met NO, vaatverwijding veroorzaken. Het toedienen van vetrijke voeding voor de toediening van $\mathrm{vHb}$ resulteerde inderdaad in significant minder schade aan de darm, nier, en lever. Bovendien verbeterde de doorbloeding in deze organen significant vergeleken met dieren die geen vetrijke voeding gehad hadden. Hoewel we de rol van acetylcholine niet direct hebben kunnen aantonen was het beschermende effect afhankelijk van de nervus vagus.

Samenvattend laten de resultaten van dit proefschrift zien dat het optreden van hemolyse tijdens complexe cardiovasculaire chirurgie een klinisch relevant fenomeen is. Hemolyse leidt, via het wegvangen van $\mathrm{NO}$ door $\mathrm{vHb}$, tot duidelijk verminderde concentraties NO in het bloed. Hierdoor is er minder NO beschikbaar om vaatverwijding in stand te houden, dan wel te stimuleren, wat resulteert in een verminderde doorbloeding van weefsels en organen. De mate van hemolyse en plasma NO-consumptie is significant gecorreleerd aan darm- en nierschade, en patiënten met hoge $\mathrm{vHb}$ waarden tijdens de operatie hadden een groter risico op postoperatieve nierfunctieproblemen in vergelijking met patiënten met lagere $\mathrm{vHb}$ concentraties. Hoewel de CPB de voornaamste veroorzaker van hemolyse is, kan het geven van bloedtransfusies de concentratie $\mathrm{vHb}$ in het bloed, en daarmee de NO-consumptie, nog verder laten toenemen. Lage haptoglobine concentraties, waardoor vHb minder goed weggevangen kan worden, kunnen dit effect nog verder versterken. Patiënten met bijvoorbeeld een reeds preoperatief verminderde functie van de nier hebben, met lage preoperatieve haptoglobine spiegels, die grote operaties ondergaan en die vele bloedtransfusies nodig hebben zijn potentieel het meest gevoelig voor de schadelijke effecten van hemolyse in deze setting. 
Gezien deze resultaten beschouwen wij $\mathrm{vHb}$ als een potentieel waardevol therapeutisch doel om orgaanschade tijdens (complexe) cardiovasculaire operaties te verminderen. Het zal in de toekomst moeten blijken of dergelijke interventiestudies leiden tot een vermindering van postoperatieve complicaties en een verbeterde overleving van de patiënt. 

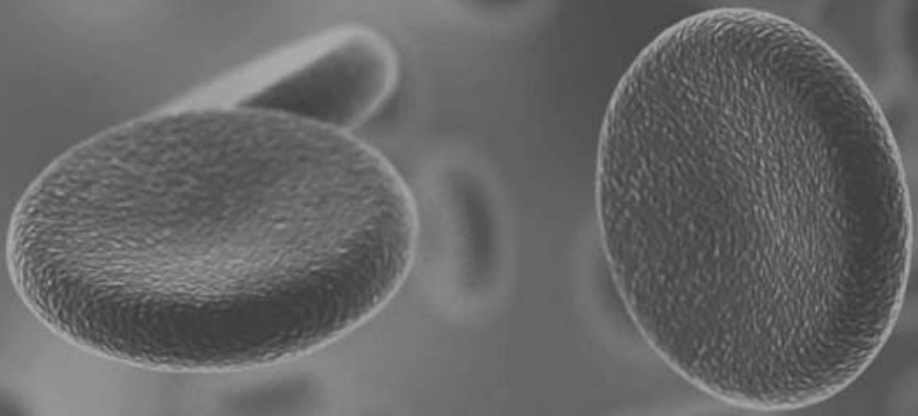
Dankwoord 


\section{DANKWOORD}

Als je denkt eindelijk het moeilijkste te hebben gehad; het schrijven van dit proefschrift, blijkt het moeilijkste nog te komen; het schrijven van het dankwoord. Promoveren doe je niet alleen. Dit proefschrift is het resultaat van jaren werk met helpende handen en meedenkende hersenen van inspirerende collegae, familie, vrienden en patiënten; dank daarvoor.

Enkele mensen hebben een buitengewone rol gespeeld in de totstandkoming van dit proefschrift. Allereerst mijn promotoren: Prof. Dr. WA Buurman en Prof. Dr. MJHM Jacobs. Beste Wim, bedankt voor je vertrouwen en het geduld dat je hebt gehad. Jij bleef in een goede afloop geloven terwijl je dat in het begin niet aan mijn eigenwijze verstand gepeuterd kreeg. Toen ik dat eindelijk besefte ontstond bij ons beiden een rust die onze samenwerking verder ten goede is gekomen. Ik bewonder je kritische, analytische en heldere blik waarmee je hoofd- en bijzaken scherp weet te onderscheiden. Ik heb van onze besprekingen veel over wetenschappelijk onderzoek, maar ook veel over mezelf geleerd. Beste Prof. Jacobs, $u$ bent vanaf het begin de schakel geweest tussen wetenschap en kliniek. Altijd concentrerend op de klinische relevantie zonder de basale wetenschap te schuwen. Uw kritische blik op de snelheid van de voortgang van het onderzoek stimuleerde altijd om nog even dat extra tandje bij te zetten. Bedankt daarvoor.

Graag wil ik de leden van de leescommissie bedanken voor de beoordeling, maar bovenal de goedkeuring, van mijn proefschrift: Prof. Dr. $\mathrm{H}$ ten Cate (voorzitter), Prof. Dr. PJEHM Kitslaar, Prof. Dr. KML Leunissen, Prof. Dr. G Marx, en Prof. Dr. CDA Stehouwer.

Mijn paranimfen: Dr. G Thuijls en Dr. B de Wit. Lieve Geertje, wat was het gezellig dat je naast me zat gedurende het grootste deel van mijn promotieonderzoek. We hebben gelachen tot de tranen over mijn wangen rolden, maar je was er ook voor me als ik het even moeilijk had. Ik vond het een eer jouw paranimf te mogen zijn. Ik ben blij dat we nog steeds vriendinnen zijn en dat je tijdens mijn verdediging ook letterlijk en figuurlijk achter mij zal staan. Beste Bart, nooit geweten dat een korte vraag aan jou tijdens een toevallig bezoek aan het hematologie lab zou resulteren in een mooie vriendschap. Ik ben je erg dankbaar dat je altijd bereid was om te sparren en dat je altijd zo enthousiast was over ons onderzoek (desnoods belde je nog even om dat te herhalen). Het heeft geresulteerd in twee mooie manuscripten waar je verdiend tweede auteur bent. Ik heb leuke herinneringen overgehouden aan onze dagelijkse reis tussen 
Eindhoven en Maastricht waarbij wij gelukkig altijd konden terugvallen op mijn nootjes en jouw mandarijntjes!

Ook buiten het directe promotieteam zijn er vele mensen die ik specifiek zou willen bedanken. Zonder hopelijk iemand tekort te doen wil ik deze personen hieronder in het bijzonder bedanken.

Ten eerste alle patiënten die vrijwel zonder uitzondering mee wilden doen aan mijn onderzoek terwijl dat voor hen geen direct voordeel had. Het feit dat zoveel mensen belangeloos bereid zijn om mee te werken aan onderzoek waar de resultaten enkel voor toekomstige patiënten van nut en belang kunnen zijn geeft vertrouwen voor de toekomst.

Dr. B Hanssen, beste Bas. Als studente nam ik deel aan het onderzoek dat jij en Maaike Berbee met veel effort hadden opgezet. Toen een promotieplek vrijkwam op datzelfde onderzoek kon ik op een rijdende trein stappen. Bedankt voor wat je me geleerd hebt en de lol die we samen hebben gehad om ons humane materiaal na uren sampelen in Aachen terug de grens over te 'smokkelen'. Ik ben de laatste van het TAAA-team die zal promoveren en eigenlijk blijft het jammer dat hierbij dit mooie maar ook lastige onderzoeksproject tot een einde is gekomen. Veel succes met het vervolg van je opleiding tot KNO-arts.

Mijn onderzoek heeft door zijn onderwerp raakvlakken gehad met diverse medische specialismen. Ik had mijn studies dan ook niet kunnen uitvoeren zonder de waardevolle input van vele stafleden en medewerkers van de afdelingen vaatchirurgie, cardiothoracale chirurgie, klinische chemie, hematologie, oncologie, nefrologie, anesthesie en extracorporele circulatie in zowel het Academisch Ziekenhuis Maastricht (later het Maastricht Universitair Medisch Centrum) en het Universitätsklinikum Aachen. Prof. Dr. Geert Willem Schurink, bedankt voor de praktische hulp tijdens het verzamelen van bloedmonsters op de ok (en het geduldig plaatsen van alle arteriële en veneuze lijnen) en de intellectuele input. Ik ben blij dat het Femke en mij toch gelukt is om het stuk betreffende darmischemie na aneurysma chirurgie in Annals of Surgery te publiceren. Van de afdeling Cardiothoracale Chirurgie zou ik in het bijzonder Prof. Dr. Jos Maessen en Prof. Dr. Bas Mochtar willen noemen. Sinds mijn keuze co-schap bij de Cardiothoracale chirurgie in 2004 ben ik met $u$ beiden in contact gebleven. Prof. Maessen, $u$ heeft altijd met interesse mijn onderzoeken gevolgd. $U$ was dan ook enthousiast toen ik mijn onderzoek naar de hartchirurgische patiënt wilde uitbreiden en $u$ heeft me met raad en daad bijgestaan. Prof. Mochtar, als we elkaar tegenkwamen, of het nu in de supermarkt of de operatiekamer was, waren we vaak 
snel in gesprek over het doen van onderzoek in het algemeen en de inzet die dat vergt. $U$ heeft me altijd op het hart gedrukt dat als je in de (verre) toekomst iets wil bereiken, je daar vandaag mee moet beginnen, bedankt daarvoor. Het voelde altijd een beetje als thuiskomen op OK 3 en 4 . Monique Miessen, bedankt voor je onophoudelijke inzet. Als spin in het web van de studies op de afdeling cardiothoracale chirurgie hield je iedereen (onderzoeker en patiënt) nauwlettend in de gaten en zorgde je ervoor dat ik aan mijn patiënten voor mijn onderzoek kwam. Ik had dat niet gekund zonder jou. Bovendien kon ik altijd even bij je terecht voor een praatje in dat kleine raamloze hokje, wat ik dan ook graag deed. Dr. John Heijmans, dank voor zowel het actief participeren in onze studies en de bijdrage aan diverse gepubliceerde manuscripten, alsmede voor de vele gezellige uren op en buiten de ok. Dr. Erik Beckers, bedankt voor de hulp bij het opzetten van de bloedtransfusie studie. Door jouw daadkracht waren meteen alle verpleegkundigen op afdeling A5 gemobiliseerd om te participeren in dit onderzoek waardoor we snel van start konden gaan en het onderzoek ook snel konden afronden. Dr. Yuri Ganushchak, we liepen elkaar altijd tegen het lijf op de operatiekamers en bespraken dan altijd even de voortgang van mijn onderzoek. Speciale dank voor de hulp in de experimentele setup voor de NOverzadigingsexperimenten waar ook $\mathrm{Dr}$. Antoine Simons met veel inzet bij betrokken was, ook jij bedankt Antoine. Dr. Jeroen Kooman, bedankt voor de interessante discussies en input op het gebied van de nefrologie. Dem ganzen Team der Gefäßchirurgie des Uniklinikums Aachen, insbesondere Prof. Dr. Thomas Koeppel (aktuell UK München) und Dr. Johannes Kalder in Aachen, Frau Heike Meier und Paula Keschenau. Vielen Dank für die nette und erfolgreiche Zusammenarbeit, Ihre Hilfe bei der patiënten Inklusion für die TAAA Studie in Aachen, und die viele netten Stunden im Versuchstier Labor. Prof. Tanus - Santos and Jonas Sertorio, thank you so much for our international collaboration and the analysis of NO-consumption in our samples. It was a (practical) fuss to send all the samples to Brazil, but it was worth it! If you would like additional stroopwafels in the future, just let me know. Dr. Martijn Poeze, je bent vrijwel altijd bereid om even laagdrempelig te overleggen, onderschat niet hoe prettig dat is. Dank je wel voor het lenen van je vriezerruimte op de ok! Dr. Otto Bekers, bedankt dat we altijd onze bloedbuisjes even mochten komen testen op hemoglobine fracties, het heeft ons erg geholpen. Dr. Frits Prinzen, het onderzoek met de microsferen hadden we niet kunnen doen zonder $u$, bedankt voor alle geduldige uitleg. Dr. Patrick Weerwind, bedankt voor de kritische vragen naar aanleiding van ons review; met opbouwende kritiek kom je uiteindelijk verder dan met alleen maar complimenten. Mijn bijzondere dank gaat ook uit naar Dr. Nicole Bouvy en Dr. Randolph van Eps. Jullie hebben mij geholpen bij de eerste stappen in de wetenschappelijke wereld. Ook al betrof het in eerste instantie alleen "simpel" statusonderzoek, het heeft de basis gelegd voor mijn latere wetenschappelijke 
carrière. Juist door simpel te beginnen blijf je je realiseren wat belangrijk is als het echt ingewikkeld wordt!

Jeanette, bij mijn bezoekjes aan jullie huis in Eijsden om in het weekend eens ongestoord de voortgang met Wim te kunnen bespreken, zorgde jij er altijd voor dat ook de innerlijke mens werd verzorgd, dank je wel daarvoor. Het bezoek aan Atlanta voor het Nitrite 2011 congres was erg plezierig!

Naast specifieke personen wil ik ook de verpleegkundige van enkele afdelingen van het ziekenhuis bedanken. Allereerst de afdeling A5, Hemato-Oncologie. Dank voor jullie belangeloze inzet om de bloedmonsters voor de bloedtransfusiestudie te verzamelen. Ik heb geloof ik nog nooit een studie zo snel kunnen starten en afronden! Tevens wil ik de verpleegkundigen van de Medium Care (D4) van de cardiochirurgie bedanken. Daar stond ik dan weer met mijn bloed- en urinebuisjes. Op een gegeven moment hoefde ik gelukkig niet meer uit te leggen wat ik kwam doen. In het geval dat in de vroege ochtenduren de arteriële lijn verwijderd werd waren jullie altijd bereid die laatste bloed- en urinemonsters af te nemen, bedankt daarvoor. Ook de verpleegkundigen van de cardiochirurgische Intensive Care F3 ben ik dank verschuldigd. Jullie hebben mij (op een gegeven moment omgedoopt tot Dr. Kaplaars) regelmatig zien langskomen met mijn piepschuimen dozen. Zelfs toen we urineverzamelingen wilden gaan doen en er grote flessen op de afdeling stonden hielpen jullie mee in het belang van de patiënt. Het feit dat ik op zoveel afdelingen werkzaam ben geweest heeft me in contact gebracht met veel leuke en inspirerende mensen. De lange tijd die ik op de operatiekamers heb doorgebracht werd zo steeds gemakkelijker (en leuker) om te doden. Van de afdeling perfusie wil ik in dit kader in het bijzonder Yvonne Bosch en Pieter Wortel bedanken. Pieter, als we samen op de ok stonden was het altijd lachen. Geen onderwerp was te gek, van wiskundige vraagstukken tot favoriete weekendbestedingen, alles kwam voorbij. Ook de anesthesiemedewerkers hebben wat geduld met me moeten hebben. In het begin stond ik ongetwijfeld alleen maar in de weg maar later wist ik redelijk goed wat jullie ook allemaal nodig hadden zodat we een en ander konden combineren. Zo kon ik nog wat terug doen. Leon, jij in het bijzonder bedankt. Jij was meteen vanaf het begin je vriendelijke zelf en vond het onnodig om 'nieuwelingen' op de operatiekamer aan een soort ontgroeningsritueel bloot te stellen. Bedankt voor je gezelligheid en je hulp.

De personen die het beste weten wat je moet doen (en laten) om een proefschrift te schrijven, zijn ongetwijfeld wel mijn collegae van het "lab Buurman" geweest. Het was een tijd met pieken en dalen, maar bovenal een tijd om nooit te vergeten. We waren op elkaar aangewezen; laboratorium technieken leerden we elkaar en kennis werd 
gedeeld in vele groepsbesprekingen en onderling overleg. Zonder jullie laagdrempeligheid en benaderbaarheid was het doen van wetenschappelijk onderzoek ongetwijfeld (nog) moeilijker geweest. De ongelofelijke grappen die uitgehaald zijn maken me nog steeds aan het lachen als ik er aan denk. Telefoontjes met de 'technische dienst', het verhuizen van bomen, natte stoelen, elektroshocks via balpennen, noem maar op. Annemarie en Sander, als kamergenootjes van het eerste uur moesten jullie altijd mijn geklets aanhoren. Jullie waren de eerste die deelden in een van mijn vele rare versprekingen, maar ook samen met Geertje, de eerste die mij bijstonden met (praktische) raad en daad. Bedankt voor jullie gezelligheid, luisterend oor en hulp, dit is heel waardevol geweest. Kim, jij bent inmiddels ook zelf bijna klaar met je proefschrift. Ik heb je enorme drive en passie, zowel in je werk als daar buiten altijd bewondert. Wat kan jij hard werken! Ik denk dat je dan ook een prima chirurg zal worden. Tim en Jacco/Sjaak, aka de high-fat task force. Wat was het leuk in Keulen en wat was het gezellig al die jaren op het lab en beneden in het proefdierlab, alleen de foto van het incident met de zwarte merkstift hoop ik niet terug te zien op mijn promotie. Femke en Joep (D), ik ben blij dat we hebben volgehouden met die IFABP's, bedankt voor jullie samenwerking en hulp. Maarten, bedankt voor al je input en hulp, specifiek bij het Kidney International paper. Ik ben blij dat ik van jou schrijftalent heb kunnen leren. Yanti, onze reis naar Madrid (en de weg ernaar toe) was ontzettend leuk. Ik vind het tot op de dag van vandaag knap hoe je naar je hart hebt geluisterd en na een studie geneeskunde en jaren onderzoek radicaal het stuur hebt omgegooid. Het feit dat je ontwerp-talent hebt is inmiddels nationaal erkend! Mo, jij bent het lab van de heelkunde. Door jouw onuitputtelijke inzet en ongeëvenaarde schaterlach kan jij iedereen een hart onder de riem steken, zowel op wetenschappelijk als op persoonlijk gebied. Samen met Tim W was en ben jij het episch centrum van de grappenmakerij. ${ }^{1}$ Onderschat jezelf en de waarde van je aanwezigheid niet. Ook dank aan alle andere (oud) collegae van het lab: Aron, Babs, Bas (B), Caroline, Charlotte, Dennis (J), Dennis (M), Dian, Dirk, Edgar, Eva, Evelien, Filip, Freek, Froukje, Givan, Guy, Hans, Henriette, Inca, Irma, Joep (G), Johanne, Kaatje, Kevin, Kim, Kirsten, Kostan, Liliane, Maartje, Mark (S), Mark (de W), Mechteld, Nicole, Nina, Paul, Pieter, Renske, Rob, Robert, Ruben, Sedigeh, Simon, Sofia, Tiara en Tine.

Naast alle collega onderzoekers en analisten ben ik ook dank verschuldigd aan de studenten die mij hebben geholpen tijdens mijn onderzoek: Ming, Niels, Ramon, Tom, Sarah, Sibel en Zainna. Naast jullie directe praktische hulp aan mij hebben jullie hopelijk ook zelf wat geleerd. Door jullie soms onverwachte vragen ging het leerproces beide kanten op!

\footnotetext{
${ }^{1} \mathrm{O}$ ja Tim, jij ook bedankt!
} 
Het blijft altijd moeilijk om een vertrouwde omgeving in te ruilen voor een nieuwe werkplek. Mijn collega's van de afdeling Cardiologie van het Catharina Ziekenhuis Eindhoven hebben dat gelukkig bijzonder gemakkelijk gemaakt, bedankt dat jullie mij in jullie midden hebben opgenomen. Prof. Dr. Nico Pijls en Dr. Jan-Melle van Dantzig, bedankt voor het in mij gestelde vertrouwen.

Hoewel een goede werkomgeving en fijne collega's het leven een stuk leuker maken, blijven je vrienden en familie het belangrijkst voor de rust, de afleiding, de lol, het ventileren, de broodnodige ontspanning en reflectie. Lieve Joke, sinds het moment dat we elkaar leerden kennen in het huis aan de Frankenstraat zijn we niet gestopt met praten en lachen. Bedankt dat je er altijd voor me bent en dat ik je midden in de nacht mag bellen, je bent een fantastische vriendin. Ik ben ervan overtuigd dat we later als twee oude besjes van 80 (met dat eeuwige enorme leeftijdsverschil) nog steeds aan het praten en lachten zijn. Jan en Jose Smit, nogmaals bedankt voor jullie aanwezigheid, als afgevaardigden van Joke, op de uitreiking van mijn doctoraal diploma. Ik voel me altijd erg thuis bij jullie. Lieve Janine en Marc, Mirjam en PeterPaul, onze weekendjes met zijn zessen zijn altijd gezellig en vorm(d)en altijd een heerlijke afleiding van het werk. Sorry als ik soms te veel over mijn werk praatte. Met de komst van Sem (plus nog meer kleintjes) is het nog gezelliger geworden! Lieve Lizelotte en Jeroen, Eline en Daniel, Paulien en Kees-Pieter, Lotje en Louis, bedankt voor jullie vriendschap door alle jaren, ups en downs. Ik heb me voorgenomen dat nu dit proefschrift klaar er meer tijd voor jullie moet zijn! Lizzy en Lientje, als full-time arts-onderzoeker bewonder ik jullie doorzettingsvermogen om een promotietraject te combineren met jullie opleiding tot respectievelijk dermatoloog en gynaecoloog. Jullie zijn fantastische en slimme meiden en ik heb er dan ook honderd procent vertrouwen in dat jullie die promotie tot een goed einde gaan brengen! Lieve dames van onafhankelijk damesdispuut Qui Vive: ook al is het contact verwaterd, heel erg bedankt voor de onvergetelijke studententijd die ik ook dankzij jullie heb gehad.

De laatste woorden van dank gaan uit naar mijn familie en (toekomstige) schoonfamilie. Lieve Krijntje en Gijs, Els en Fred, Marc en Inge. Die heerlijke dagen op de boot in Friesland had ik nodig, hard nodig. Bedankt voor jullie niet aflatende vertrouwen in een goede afloop en jullie luisterend oor. Familierelaties blijken soms moeizaam en ondoorgrondelijk, maar ik prijs me gelukkig met ooms en tantes zoals jullie. Lieve Opa, het is jammer dat je er niet bij bent als ook je tweede kleindochter promoveert. Ik weet zeker dat je trots op me zou zijn geweest. Lieve Luci, Leandro, Carola en Leon (boefje). Bedankt dat de deur in bella Roma altijd open stond. Lieve Dr. Hanna, Oscar, Tim en Vivienne, ook jullie bedankt voor de vele gezellige familie momenten waardoor ik mijn gedachten altijd even kon verzetten. Lieve Ronald en 
Margriet, Lenneke en David. Ik prijs me bijzonder gelukkig met jullie als toekomstige schoonfamilie. Vanaf het eerste moment voelde ik me thuis en vertrouwd bij jullie, bedankt voor alle mentale ondersteuning. Ik heb echt het gevoel alsof ik er een tweede familie bij heb gekregen.

Lieve Papa en Mama, jullie nooit aflatende steun en vertrouwen hebben mij geholpen te komen waar ik nu sta en te worden wie ik nu ben. Vanuit thuis kreeg ik altijd het voorbeeld om het beste uit mezelf te halen en niet zomaar tevreden te zijn met (een) "voldoende". Ik ben jullie bijzonder dankbaar voor deze kritische houding maar bovenal voor de onvoorwaardelijke liefde en trots die jullie altijd naar me hebben uitgesproken en waar jullie desnoods even voor uit Haarlem kwamen rijden. Ik voel me gesteund en gezegend met zo'n goede band met mijn ouders. Ik houd van jullie.

Lieve Xander en Annemieke. Grote broer, allereerst bedankt voor je prachtige ontwerp van de omslag van dit proefschrift! Het is precies geworden zoals ik had gehoopt, hoewel ik met een heel ander idee op de proppen kwam. Ik ben er ongelofelijk trots op dat je je eigen architectenbureau XVW Architectuur succesvol hebt opgestart in het huidige economische klimaat. Bovenal kan ik me geen betere broer wensen dan jij, ik ben heel gelukkig met de goede band die we hebben omdat ik weet dat dat alles behalve vanzelfsprekend is. Annemieke, mijn kersverse, slimme, gezellige en mooie schoonzusje, welkom in de familie van die rare Vermeulen Windsants, ook jij hebt nu een staartje gekregen. Ik kan me geen leuker schoonzusje voorstellen.

Liefste Jasper, voor jou de laatste woorden, hoewel je net zo goed de eerste verdiend. Nooit geweten dat het allemaal zo gemakkelijk kon zijn. Jouw onvoorwaardelijke liefde, blind vertrouwen, relativeringsvermogen, humor en rust zijn het beste medicijn voor deze dokter gebleken. Je hebt me geholpen dit proefschrift te maken zoals het nu is, letterlijk en figuurlijk. Het is ongelofelijk dat iedere nieuwe dag samen nog leuker lijkt dan de dag ervoor. De wereld is zo veel mooier samen met jou. Ik hou van je. 

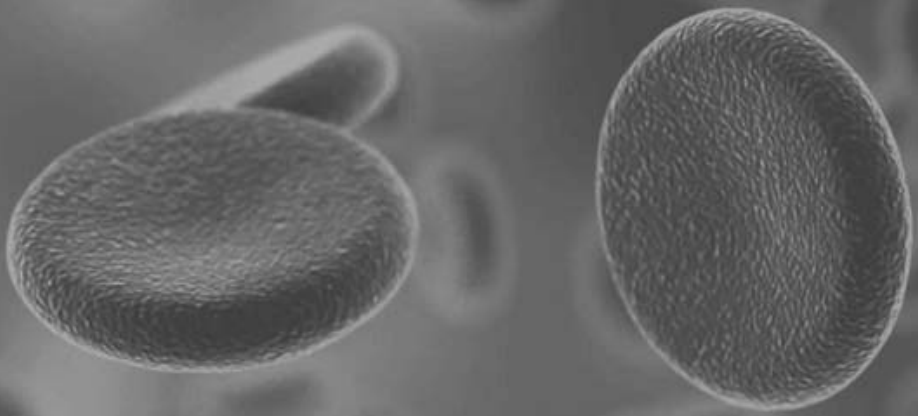
Curriculum vitae 


\section{CURRICULUM VITAE}

Iris Vermeulen Windsant werd op 19 november 1981 geboren in Haarlem, Nederland. Tussen 1994 en 2001 doorliep zij haar middelbare school aan de Rudolf Steiner School in Haarlem (1994-2000) en de Geert Groote School in Amsterdam (2001). Nadat zij haar VWO eindexamen (cum laude) behaalde begon zij in September 2001 met de studie Geneeskunde aan de Faculteit der Geneeskunde van de Universiteit Maastricht (later Faculty of Health Medicine and Life Sciences, Maastricht University). De eerste wetenschappelijke stappen werden in het derde studiejaar gezet door deelname aan onderzoek binnen de vakgroep Algemene Heelkunde (2003) bij Dr. Nicole Bouvy. Tijdens een keuze co-schap Cardiothoracale Chirurgie in 2004 verdiepte Iris zich verder in de wereld van het wetenschappelijk onderzoek onder begeleiding van Dr. Randolph van Eps. In het laatste jaar van haar studie (2006-2007) volgde tenslotte een keuze coschap Vaatchirurgie onder leiding van Prof. dr. Geert Willem Schurink, afgewisseld door de wetenschapsstage bij de onderzoeksafdeling van de Algemene Heelkunde onder leiding van Prof. dr. Wim Buurman. Tijdens dat jaar werd het fundament gelegd voor een verdere wetenschappelijke vorming en verdieping. Enkele maanden voor het behalen van haar artsenbul in september 2007 (cum laude), startte Iris op 1 maart 2007, onder leiding van Prof. dr. Wim Buurman en Prof. dr. Michael Jacobs met het promotietraject waarvan dit proefschrift het resultaat is.

Van 1 oktober 2011 tot en met 31 januari 2012 werkte Iris als Anios Cardiologie in het Catharina Ziekenhuis in Eindhoven waar zij vervolgens op 1 februari 2012 met veel enthousiasme gestart is met haar medische specialisatie tot cardioloog onder leiding van Dr. Jan Melle van Dantzig (opleider) en Prof. dr. Nico Pijls (plaatsvervangend opleider). 

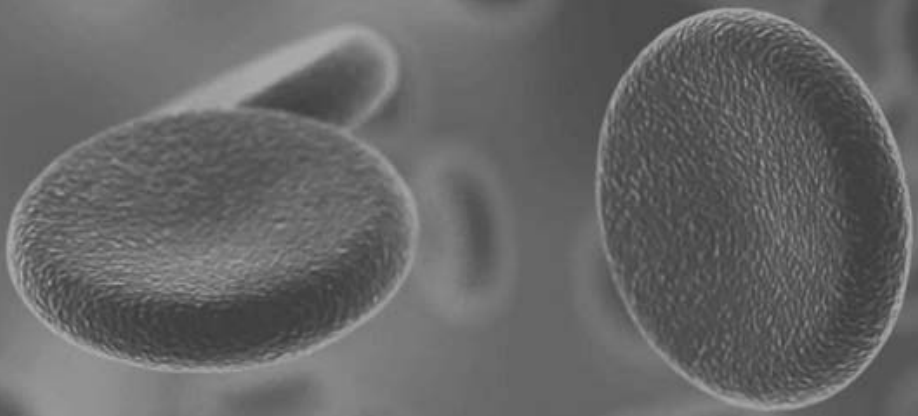
Publicatielijst 


\section{SCIENTIFIC OUTPUT}

\section{Published papers}

Vermeulen Windsant IC, de Wit NCJ, Sertorio JTC, Beckers EAM, Tanus-Santos JE, Jacobs MJ, Buurman WA. Blood transfusion increase circulating plasma free hemoglobin levels and plasma nitric oxide consumption; a prospective observational pilot study. Crit Care 2012;16:R95.

Kalder J, Keschenau P, Hanssen SJ, Greiner A, Vermeulen Windsant IC, Kennes LN, Tolba R, Prinzen FW, Buurman WA, Jacobs MJ, Koeppel TA. The impact of selective visceral perfusion on intestinal macrohemodynamics and microhemodynamics in a porcine model of thoracic aortic cross-clamping. J Vasc Surg 2012;56:149-58.

Hanssen SJ, van de Poll MC, Houben AJ, Vermeulen Windsant IC, Snoeijs MG, Bekers O, Buurman WA, Jacobs MJ. Hemolysis Compromises Nitric Oxide-Dependent Vasodilatory Responses in Patients Undergoing Major Cardiovascular Surgery. Thorac Cardiovasc Surg 2012;60:255-61.

Vermeulen Windsant IC and Hellenthal FA, Derikx JP, Prins MH, Buurman WA, Jacobs MJ and Schurink GWH. Circulating intestinal fatty acid-binding protein as an early marker of intestinal necrosis after aortic surgery: a prospective observational cohort study. Ann Surg 2012;255:796-803.

Vermeulen Windsant IC, Hanssen SJ, Buurman WA, Jacobs MJ. Cardiovascular surgery and organ injury; time to reconsider the role of hemolysis. J Thorac Cardiovasc Surg 2011;142:1-11.

Vermeulen Windsant IC, Snoeijs MG, Hanssen SJ, Altintas S, Heijmans JH, Koeppel TA, Schurink GWH, Buurman WA, Jacobs MJ. Hemolysis is associated with acute kidney injury during major aortic surgery. Kidney Int 2010;77:913-20.

Peppelenbosch AG, Vermeulen Windsant IC, Tordoir JHM, Schurink GWH. Open repair for ruptured abdominal aortic aneurysm and the risk of spinal cord ischemia. Review of the literature and risk-factor analysis. Eur J Vasc Endovasc 2010;40:589-95.

Vermeulen Windsant IC, Maessen JG. Invited commentary to Brown et al; Duration of Acute Kidney Injury Impacts Long-Term Survival Following Cardiac Surgery. Ann Thorac Surg 2010;90:1148-9.

Hanssen SJ, Derikx JP, Vermeulen Windsant IC, Heijmans JH, Koeppel TA, Schurink GW, Buurman WA, Jacobs MJ. Visceral injury and systemic inflammation in patients undergoing extracorporeal circulation during aortic surgery. Ann Surg 2008;248: 117-25.

\section{Submitted manuscripts or manuscripts in preparation}

Vermeulen Windsant IC, de Wit NCJ, Sertorio JTC, van Bijnen AM, Ganushchak YM, Heijmans JH, TanusSantos JE, Jacobs MJ, Maessen JG and Buurman WA. Hemolysis increases nitric oxide consumption and visceral tissue damage after cardiac surgery. Manuscript submitted.

Hellenthal FA, Schaefer SM, Pulinx B, Vermeulen Windsant IC, Wodzig WK, Heeneman S, Jacobs MJ, and Schurink GWH. Abdominal Aortic Aneurysm solitary or as part of thoracoabdominal aneurysm; two different entities? Manuscript submitted.

De Haan JJ, Vermeulen Windsant IC, Lubbers T, Hanssen SJ, Hadfoune M, Prinzen FW, Greve JWM, Buurman WA. Prevention of hemolysis-induced organ damage by nutrional activation of the vagal anti-inflammatory reflex. Manuscript in preparation. 


\section{PRESENTATIONS}

- Najaarsvergadering Nederlandse Vereniging voor Thoraxchirurgie, 25 november 2011, Utrecht, nederland. Hemolysis increases nitric oxide consumption and visceral tissue damage after cardiac surgery. Vermeulen Windsant IC, de Wit NCJ, Sertorio JTC, van Bijnen AM, Ganushchak YM, Heijmans JH, TanusSantos JE, Jacobs MJ, Maessen JG and Buurman WA.

- Nitrite 2011, 11-13 Mei 2011, Atlanta, United States of America. Prevention of hemolysis-induced organ damage by nutrional activation of the vagal anti-inflammatory reflex. De Haan JJ, Vermeulen Windsant IC, Lubbers T, Hanssen SJ, Hadfoune M, Prinzen FW, Greve JWM, Buurman WA.

- Chirurgendagen 2010, 20-21 mei 2010, Veldhoven, Nederland. Hemolysis is associated with acute kidney injury during major aortic surgery. Vermeulen Windsant IC, Snoeijs MG, Hanssen SJ, Altintas S, Heijmans JH, Koeppel TA, Schurink GWH, Buurman WA, Jacobs MJ.

- TSIS 2010 Congress on Trauma, Shock, Inflammation and Sepsis, 9-13 maart 2010, München, Duitsland. Hemolysis is associated with acute kidney injury during major aortic surgery. Vermeulen Windsant IC, Snoeijs MG, Hanssen SJ, Altintas S, Heijmans JH, Koeppel TA, Schurink GWH, Buurman WA, Jacobs MJ.

- Nitrite 2009, 16-20 juni 2009, Stockholm, Zweden. Hemolysis is associated with acute kidney injury during major aortic surgery. Vermeulen Windsant IC, Snoeijs MG, Hanssen SJ, Altintas S, Heijmans JH, Koeppel TA, Schurink GWH, Buurman WA, Jacobs MJ.

- Chirurgendagen 22 - 23 mei 2008, Veldhoven, Nederland. De rol van pulsatiele versus niet-pulsatiele perfusie bij het ontstaan van darmschade bij aortachirurgie. Vermeulen Windsant IC, Hanssen SJ, Hellenthal FAMVI, Schurink GW, Buurman WA, Jacobs MJ

- Vaatdagen 7-8 april 2008, Noordwijkerhout, Nederland. Vroegdiagnostiek van intestinale necrose bij aorta chirurgie. Vermeulen Windsant IC, Hellenthal FAMVI, Hanssen SJP, Derikx JPM, Buurman WA, Schurink GWH.

\section{GRANTS AND AWARDS}

"Annadal Stichting MUMC" grant of $€ 85000$,- for studying the effects of acute hemolysis during cardiovascular surgery, and 2) for studying the relation between blood transfusions and elevated markers of acute hemolysis.

"Najaarsvergadering Nederlandse Vereniging voor Thoraxchirurgie" (november 2011), prize for best oral presentation "Hemolysis increases nitric oxide consumption and visceral tissue damage after cardiac surgery". 

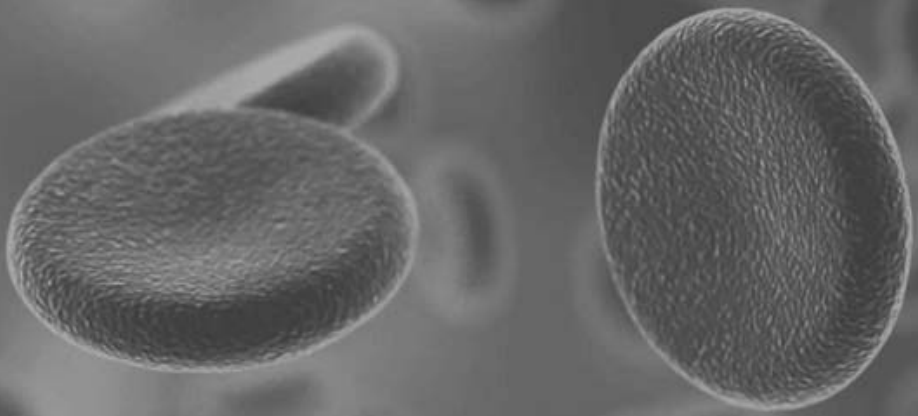
Abbreviations 


\section{ABBREVIATIONS}

\section{A}

AAA - abdominal aortic aneurysm

ACC - aortic cross clamp

ACE - angiotensin converting enzyme

Ach - acetylcholine

ALT - alanine transaminase

$A K I$ - acute kidney injury

AKIN - acute kidney injury network

ANOVA - analysis of variance

Arg - arginine

AST - aspartate aminotransferase

AUC - area under the curve

\section{B}

BT - blood transfusion

\section{C}

CABG - coronary artery bypass grafting

CABG + Valve - coronary artery bypass grafting + valve reconstruction (any type)

CCK-1R - cholecystokinine 1 receptor

$\mathrm{CO}$ - carbon monoxide

COPD - chronic obstructive pulmonary disease

CPB - cardiopulmonary bypass

\section{D}

DAP - distal aortic perfusion DeoxyfHb - deoxygenated fHb $\left[\mathrm{HbFe}^{2+}\right.$

\section{E}

ECC - extracorporeal circulation ECMO - extracorporeal membrane oxygenation ELISA - enzyme linked immunosorbent assay en\% - energy percent

ET - endothelin

EVAR - endovascular aortic repair

\section{$\mathbf{F}$}

$\mathrm{FHb}$ - free hemoglobin

FBF - forearm blood flow

\section{G}

GFR - glomerular filtration ratio

\section{H}

$\mathrm{HO}$ - heme oxygenase

$\mathrm{Hp}$ - haptoglobin

HRP - horseradish peroxidase

I

ICAM - intercellular adhesion molecule

ICU - intensive care unit

IFABP - intestinal fatty acid binding protein

IL - interleukin

IN - intestinal necrosis

IQR - inter quartile range
Iron-nitrosylHb - iron-nitrosylhemoglobin $\left[\mathrm{HbFe}^{2+} \mathrm{NO}\right]$

L

LFABP - liver fatty acid binding protein

M

MetHb - methemoglobin $\left[\mathrm{HbFe}^{3+}\right]$

MDRD - modification of diet in renal disease [formula]

MOF - multiple organ failure

N

nAChR - nicotinic acetylcholine receptor

NAG - N-acetyl- $\beta$-D-glucosaminidase

$\mathrm{NO}$ - nitric oxide

$\mathrm{NO}_{3}{ }^{-}$- nitrate

(e)NOS - (endothelial) nitric oxide synthase NS - non significant

0

Orn - ornithine

OPCAB - off-pump coronary artery bypass

[grafting]

OR-AAA - open repair of AAA

OR-TAA(A) - open repair of TAA(A)

OxyfHb - oxygenated $\mathrm{fHb}\left[\mathrm{HbFe}^{2+} \mathrm{O}_{2}\right]$

$\mathbf{P}$

PAOD - peripheral arterial occlusive disease

PEG - pegylated

PPM - parts per million

$\mathrm{pRBC}(\mathrm{s})$ - packed red blood cell(s)

$\mathbf{R}$

$\mathrm{RBC}(\mathrm{s})$ - red blood cell(s)

$\mathrm{Rh}$ - rhesus

ROC - receiver operating characteristic

$\mathrm{R}_{\mathrm{s}}$ - spearman correlation

$S$

S.E.M. - standard error of the mean

SIRS - systemic inflammatory response

syndrome

SM - storage medium

SNP - sodium nitroprusside

$\mathrm{SP}$ - selective organ perfusion

T

TAA - thoracic aortic aneurysm

TAAA - thoracoabdominal aortic aneurysm

V

VCAM - vascular cell adhesion molecule

W

wt\% - weight percent 